Florida International University FIU Digital Commons

\title{
Carmen de Burgos : la educación de la mujer y la literatura de viajes como género narrativo
}

Esther A. Daganzo-Cantens

Florida International University

DOI: $10.25148 /$ etd.FI14061584

Follow this and additional works at: https://digitalcommons.fiu.edu/etd

Part of the Spanish Literature Commons

\section{Recommended Citation}

Daganzo-Cantens, Esther A., "Carmen de Burgos : la educación de la mujer y la literatura de viajes como género narrativo" (2006). FIU Electronic Theses and Dissertations. 2650.

https://digitalcommons.fiu.edu/etd/2650 


\title{
FLORIDA INTERNATIONAL UNIVERSITY
}

Miami, Florida

\section{CARMEN DE BURGOS: LA EDUCACIÓN DE LA MUJER Y LA LITERATURA DE VIAJES COMO GÉNERO NARRATIVO}

\author{
A dissertation submitted in partial fulfillment of the \\ requirements for the degree of \\ DOCTOR OF PHILOSOPHY \\ in \\ SPANISH \\ by
}

Esther A. Daganzo-Cantens

2006 
To: Interim Dean Mark Szuchman

College of Arts and Sciences

This dissertation, written by Esther A. Daganzo-Cantens, and entitled Carmen de Burgos: La educación de la mujer y la literatura de viajes como género narrativo, having been approved in respect to style and intellectual content, is referred to you for judgment.

We have read this dissertation and recommend that it be approved.

Ricardo Castells

María Asunción Gómez

Aurora Morcillo

Joan Torres-Pou, Major Professor

Date of Defense: November 15, 2006

The dissertation of Esther A. Daganzo-Cantens is approved.

Interim Dean Mark Szuchman

College of Arts and Sciences

Dean George Walker

University Graduate School

Florida International University, 2006 
(C) Copyright 2006 by Esther A. Daganzo-Cantens

All rights reserved. 


\section{DEDICACIÓN}

Quiero dedicar esta tesis a la memoria de mi abuelo Ramón Daganzo Valriberas, quien hubiera disfrutado enormemente de este reconocimiento académico y a mi abuela Ángeles Castilla Padilla por su dulzura y cariño incondicional. También quiero agradecer a mis padres su apoyo en mi formación académica desde mi infancia y que, a pesar de la distancia, siempre están presentes en todo momento de mi vida. A mis suegros Gastón y Teresita Cantens por compartir mis logros en este arduo proceso educativo y profesional.

Muy especialmente, deseo agradecer a mi marido Bernie y a mis tres hijos Kristian, Kaila y Karina su apoyo, comprensión y paciencia, sin ellos esta tesis no hubiera sido posible. 


\section{RECONOCIMIENTOS}

Agradezco a los miembros de mi comité los doctores Ricardo Castells y Asunción Gómez su ayuda y sus comentarios para la estructuración de esta tesis y fundamentalmente, deseo dar las gracias al Dr. Joan Torres-Pou por su apoyo incondicional y su generosa guía en la elaboración de este trabajo. 


\section{ABSTRACT OF THE DISSERTATION \\ CARMEN DE BURGOS: LA EDUCACIÓN DE LA MUJER Y \\ LA LITERATURA DE VIAJES COMO GÉNERO NARRATIVO \\ by}

Esther A. Daganzo-Cantens

Florida Internacional University, 2006

Miami, Florida

Professor Joan Torres-Pou, Major Professor

This study analyzes Carmen de Burgos' European travel literature, and focuses on two themes: education and travel literature as a literary genre. An examination of her travel literature reveals two essential elements related to her view of education. The first is the influence that the European educational system had on her way of thinking, particularly with respect to the idea of tolerance, the practice of hygiene, and the important role of nature in education. The second is the development of her view of education as the foundation for the emancipation of women in Spain. Carmen de Burgos espoused the view that the reform of the Spanish educational system was the primary and foundational goal to further social, political and economic progress of women in Spain at the end of the $19^{\text {th }}$ and beginning of the $20^{\text {th }}$ Century.

In the second part of this dissertation I support the theory that her travel literature was her main source to convey to Spanish women the need for social change. I do this by analyzing four properties that are considered characteristic of women's travel literature: (1) the woman as a hero, (2) scientific authority of women, (3) feminine style, and (4) feminine content. I argue that Carmen de Burgos's travel literature uses these properties 
to facilitate her access to women audiences and to assure that this audience regarded her as an authoritative voice. 
ÍNDICE

CAPÍTULO

PÁGINA

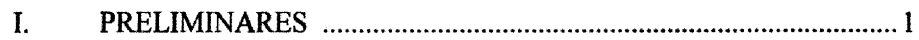

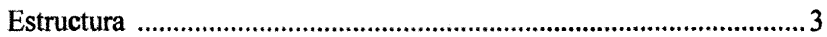

II. PARTE I. LA EDUCACIÓN EN LOS LIBROS DE

VIAJES DE CARMEN DE BURGOS. UN PASO HACIA EL FEMINISMO

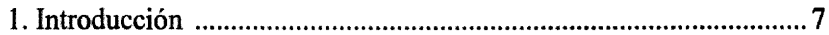

2. Primer viaje: Por Europa. Impresiones: Francia e Italia ....................21

3. Segundo viaje: Cartas sin destinatario .............................................56

4. Tercer viaje: Peregrinaciones: Suiza, Dinamarca, Suecia, Noruega, Alemania, Inglaterra y Portugal ó Mis viajes por Europa....................87

III. PARTE II. LA LITERATURA DE VIAJES DE CARMEN DE BURGOS COMO GÉNERO LITERARIO. REIVINDICACIÓN FEMENINA Y FEMINISTA.

1. Introducción 120

Enunciación de la literatura de viajes como género narrativo ............124

Características generales de la literatura de viajes ............................. 133

Diferencias entre literatura de viajes escrita por mujeres y por

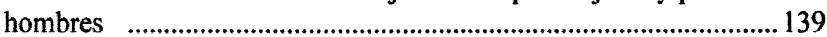

2. Carmen de Burgos héroe de sus viajes: una forma de apropiación del discurso masculino 160

3. Adquisición de poder y autoridad discursiva ....................................178

4. El "womanly weakness" o el discurso de la feminidad .....................206

5. Estilo y contenido como reivindicación femenina ............................229

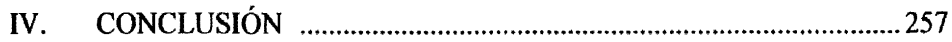

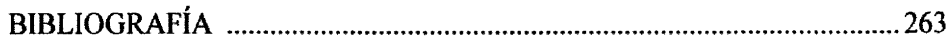

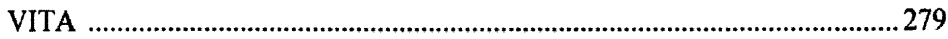




\section{PRELIMINARES}

Los cambios producidos en el mundo a finales del XIX y principios del XX suponen una revolución en la manera de pensar del individuo. Los avances tecnológicos, las ciencias, la educación, el cambio en la visión del mundo religioso y la nueva valoración de la mujer como componente integrante activo dentro de la sociedad, suponen un cuestionamiento de los valores de la sociedad que comienza a crearse. Europa es la cuna del pensamiento y la portadora de estas tendencias culturales. España no es ajena a esos cambios y, muy incipientemente, quiere participar en la evolución que impone el nuevo siglo. Mujeres como Concepción Arenal, Sofia Casanova y Margarita Nelken se cuestionan el papel de la mujer en la sociedad y reivindican los derechos del sexo femenino para que tenga una participación activa en la vida social, política y cultural del país. Carmen de Burgos y otras intelectuales como Emilia Pardo Bazán, María Lejárraga o Sofia Casanova realizan viajes al extranjero para impregnarse de los nuevos movimientos sociales y culturales que se están desarrollando en Europa. Mediante la escritura de viajes, se desarrolla la visión europea sobre temas fundamentales como la educación, el feminismo, la religión, las artes y la cultura.

En este estudio me propongo analizar la repercusión que las tendencias europeas con respecto al tema de la mujer y de la educación tuvieron en los libros de viajes de Carmen de Burgos. El enfoque que tiene este estudio es múltiple. Por un lado, estudia la influencia que los sistemas educativos europeos tuvieron en la manera de pensar de Carmen de Burgos en cuanto al tema de la educación. A su vez, me propongo analizar la influencia que dejó en la autora temas educativos tan importantes como la higiene, el papel de la naturaleza en la educación y, muy especialmente, la idea de la tolerancia. 
Estos preceptos suponían la máxima renovación de los sistemas europeos en el campo de la educación como el Krausismo o las teorías de Froëbel. Al mismo tiempo, presento el valor de la literatura de viajes como vehículo de transmisión del pensamiento europeo y demuestro la importancia que este tipo de literatura, apenas estudiado por la crítica hispánica, ${ }^{1}$ tiene para comprender la situación social y cultural del siglo XX.

Por otro lado, este estudio pretende fomentar el conocimiento de la obra de Carmen de Burgos, intelectual pionera de los movimientos en defensa de los derechos de la mujer y de la mejora del sistema educativo del primer tercio del siglo $\mathrm{XX}^{2}{ }^{2}$ Es importante un estudio de la obra de Carmen de Burgos puesto que ésta fue silenciada durante el sistema franquista debido a su adhesión al movimiento republicano. ${ }^{3}$ En las últimas décadas se ha comenzado a estudiar la relevancia de su obra como defensora del feminismo en España. Carmen de Burgos escribió nueve novelas largas, textos de

'La crítica francesa, inglesa e italiana ha estudiado extensamente la literatura de viajes tanto de hombres como de mujeres.

${ }^{2}$ Carmen de Burgos nació en Almería el 10 de diciembre de 1867 dentro del seno de una familia acomodada. Divorciada y con una hija, en 1901 decide trasladarse a Madrid y cursar estudios de maestra superior. A partir de ahí comienza a colaborar en periódicos de la época. En 1908 conoce a Ramón Gómez de la Serna con quien mantiene una relación amorosa durante muchos años y quien la influyó no sólo en su vida, sino en su obra. Escribió un sin fin de novelas y libros de todo tipo y participó activamente como redactora en numerosos periódicos de la época. Defensora de los derechos de la mujer, de la educación, del divorcio, de la causa judía, entre otras, dedicó gran parte de sus energías a luchar por sus ideales. Al final de su vida, se dedicó de forma más activa a la política, luchando por el socialismo republicano. El 9 de octubre de 1932 en un mitin que organizó el Círculo Radical Socialista sobre la Política escolar, le dio un ataque repentino y murió pronunciando las siguientes palabras: "Muero contenta, porque muero republicana. ¡Viva la república! Les ruego a Vdes. que sigan conmigo ¡Viva la república!" (El Heraldo de Madrid 10 de octubre de 1932).

${ }^{3}$ También por trabajar géneros dentro de la narrativa que eran parte de la cultura de masas. 
preocupación feminista y social, manuales de uso práctico para la mujer, biografias y un sinfin de cuentos, además de participar activamente como periodista en los periódicos más importantes de la época y de ser la primera corresponsal de guerra de España.

Las obras que se van a estudiar en este trabajo Por Europa (1906), Cartas sin destinatario (1912), Peregrinaciones (1916) y Mis viajes por Europa (1917), representan el conjunto de viajes que la autora hace por Europa. En dichas obras, pretende mostrar su visión particular de lo que ella percibe en los países a donde viaja: "Cuando el alma sirve de lente, se reflejan muchos de nuestros pensamientos, de nuestras ideas y de nuestros perjuicios sobre el fondo de los cuadros contemplados" (Por Europa 31-32).

Al mismo tiempo, puesto que no abundan los estudios críticos sobre la literatura de viajes, considero que es totalmente necesario llevar a cabo un estudio como el que propongo pues ampliará la visión global de la influencia que la literatura europea ha tenido en España en temas tan importantes como el feminismo y la educación. Asimismo, mi trabajo se propone subrayar la calidad literaria y documental de la poco conocida literatura femenina de viajes.

\section{ESTRUCTURA}

El trabajo está dividido en dos secciones independientes. La primera sección versa sobre el análisis de las innovaciones en la educación según la experiencia de Carmen de Burgos en Europa. Esta sección está dividida en cuatro capitulos fundamentales. En primer lugar, tiene un capitulo introductorio sitúa las diferentes corrientes educativas del momento y presenta el panorama de la educación en España. Siempre centrándome en las propuestas educativas, analizo en cada uno de los siguientes capítulos los acercamientos al tema de la educación que Carmen de Burgos presenta por 
medio de tres contextos sociogeográficos: Francia e Italia, Bélgica, Holanda y Luxemburgo, y Dinamarca, Suecia, Noruega, Alemania, Inglaterra, Portugal.

La segunda sección de este trabajo está dividida en cinco capítulos. En el primer capítulo se analiza la definición de lo que se entiende por literatura de viajes y sus diferencias con géneros similares, las particularidades de este tipo de producción y las características específicas de este género cuando está escrito por mujeres. A su vez, se comenta la importancia que la literatura de viajes ha tenido a través de los siglos y cómo esta forma de literatura escrita por mujeres es relevante para comprender un periodo histórico. Desde la perspectiva de los estudios sobre la mujer, se analizan las distintas tendencias críticas de aproximación a este tipo de literatura. Se presenta la crítica feminista propuesta por Sara Mills que establece la autoridad del sujeto femenino, la teoría de la resitencia de Foucault por la cual este tipo de narrativa establece un poder de resistencia que entra en conflicto con el poder tradicional establecido y la teoria sostenida por Mary Louise Pratt que expone la necesidad de un espacio privado personal para la mujer donde pueda realizarse. Por último, se analiza la repercusión que tiene el lector en este tipo de producciones ya que se pone de manifiesto la influencia que esta autora quería proyectar a sus lectores y cómo pretendía moldear la opinión de éstos.

El segundo capítulo, explora la posición de la narradora como "héroe." Esta característica, considerada típica del discurso masculino de viajes tradicional, presenta a de la mujer viajera como una mujer superior y modelo a seguir por otras mujeres. Así, esta mujer superior impone una autoridad discursiva al unir las formas del discurso masculino tradicional con el femenino, para influenciar al lector sobre la necesidad de proporcionar a la mujer una educación adecuada. 
El tercer capitulo analiza la autoridad narrativa que Carmen de Burgos presenta en sus libros de viajes en cuanto a la adopción de algunas características propias del discurso masculino como la visión de historiador o crítico de la sociedad. La autora une las particularidades de este discurso masculino con las propias del discurso femenino como la simpatía hacia el oprimido y los problemas relacionados directamente con las mujeres. Con esta unión realza el proceso dialéctico de empatía de la autora con el lector reafirmando la necesidad de reforma social para las personas marginadas y, muy especialmente para la mujer.

En el cuarto capítulo se analiza las características que el discurso tradicional masculino ha conferido a las mujeres respecto a su subordinación intelectual, cultural y social. Mediante una aproximación a los temas considerados "típicos" de mujeres, como la alimentación, la higiene, el hogar, la vestimenta o las profesiones propias de mujeres, Carmen de Burgos establece un vínculo de unión con sus lectoras. Este vínculo refuerza su discurso y le otorga un poder de divulgación, no sólo de los temas relativos a la mujer como "ángel del hogar," sino en temas reivindicativos de los derechos básicos de las mujeres.

El quinto capítulo trata de las peculiaridades estilísticas de este género literario cuando es escrito por mujeres y de los temas que éstas escogen para reivindicar la necesidad de evolucionar el papel de la mujer en la sociedad.

Finalmente, la conclusión establece que la literatura de viajes de Carmen de Burgos no se desvía de las características típicas de la narrativa de viajes de mujeres y que, además, muestra cómo el uso de esas estrategias facilita el acceso de la mujer a audiencias femeninas, asegurando que esta audiencia lee sus escritos asumiendo tras de 
ellos una voz autoritativa. Una vez, establecido el poder de producción de su discurso, Carmen de Burgos propone a su audiencia el objetivo primordial de sus libros: concienciar a las mujeres de la necesidad de reformar la instrucción femenina, para posteriormente, reivindicar los derechos civiles de las mujeres. 


\section{PARTE I}

\section{LA EDUCACIÓN EN LOS LIBROS DE VIAJES DE CARMEN DE BURGOS. UN PASO HACIA EL FEMINISMO.}

\section{CAPÍTULO I}

\section{INTRODUCCIÓN}

Para Carmen de Burgos viajar suponía no sólo una pasión, sino un ansia de adquirir experiencias y vivencias de otros países. La literatura de viajes era, a finales del siglo XIX y principios del XX, una práctica común entre los escritores de ambos sexos. $\mathrm{Al}$ igual que de Burgos, algunas escritoras vieron en este tipo de literatura una forma de desarrollar su imaginación y de expresar sus ideas sobre las sociedades de los países que visitaban. Mujeres de la talla de Emilia Serrano García, la Baronesa de Wilson, María Lejárraga ${ }^{4}$ Emilia Pardo Bazán o Sofia Casanova encuentran en este tipo de narraciones una manera de expresar inquietudes afines. Todas ellas ven la necesidad de mejorar las condiciones de la mujer española y buscan, en otros países, modelos que se ajusten al deseo reformista. Mediante el estudio de las costumbres de los pueblos que ellas consideran avanzados, intentan adoptar las mejoras conseguidas en estos países y tratan de implementarlas en España; o al menos, intentan concienciar al pueblo español de la necesidad de reformar al país en lo relativo a los derechos de la mujer. En este sentido, Carmen de Burgos se esfuerza por analizar algunas ciudades europeas bajo una perspectiva femenina y feminista.

\footnotetext{
${ }^{4}$ María Lejárraga viaja a Europa en las mismas fechas que lo hace Carmen de Burgos en su primer viaje. Ambas autoras comparten una vida profesional muy parecida. Las dos son maestras de la Escuela Normal. Aunque las separa la libertad que goza Carmen de Burgos y su independencia. Lejárraga siempre viajó con su marido y era éste el que firmaba los escritos de su mujer.
} 
Para ella, el viaje era algo más que un análisis de otro país, era una expresión de vida. Carmen de Burgos explica: "Si yo fuera rica no tendría casa. Una maleta grande, y viajar siempre, deteniéndome en donde me agradase, huyendo de lo molesto" (Utrera 14). A su vez, el viaje pretendía ser, para de Burgos, una forma de reflexionar sobre los problemas que tenía España. En particular, sobre los relacionados con la deficiencia de la educación de la mujer española. Por ello, pensaba que el incremento de la participación de la mujer en la educación era lo que le iba a proporcionar una mayor igualdad ante los hombres. Esta igualdad partia de lo educativo y pretendia repercutir en lo social y politico. De hecho, las primeras manifestaciones feministas surgieron por parte de los intelectuales, de ambos sexos, para pedir una mayor integración de la mujer en las instituciones educativas y para ampliar su instrucción a campos más científicos e intelectuales. Un ejemplo de esto lo encontramos en la obra de Fray Benito Jerónimo Feijoo y Montenegro (1676-1764) y Josefa Amar y Borbón (1749-1833). ${ }^{5}$

Para entender el proceso de integración de la mujer a los estamentos sociales, políticos y culturales de España, es preciso revisar las condiciones en las que éstas se encontraban a finales del siglo XIX. La condición esencial que necesita cualquier mujer

${ }^{5}$ Fray Benito Jerónimo Feijoo y Montenegro nació en 1676 en Orense. Fue maestro general de la orden Benedictina, catedrático de Oviedo y miembro del Consejo de Castilla. Entre sus obras más importantes destaca Teatro Crítico Universal de 1726 a 1749 en la que dedica el discurso número dieciséis a la Defensa de las mujeres. También publica Ilustración apologética en 1725, Cartas Eruditas en 1742-60. Se le considera el padre defensor de los derechos de la mujer y su obra supuso el eje de partida de los primeros movimientos a favor de la igualdad de las mujeres en España. Josefa Amar y Borbón nació en 1749 en Zaragoza. Fue socia de mérito de la Real Sociedad Aragonesa de los Amigos del País. En sus obras resaltaba el papel de la mujer en la sociedad y defendía su igualdad de talentos ante el hombre. En 1833 murió en Zaragoza. Entre sus obras más destacadas está su Discurso en defensa del talento de las mugeres de 1786, Oración gratulatoria... a la junta de Señoras de 1787 y Discurso sobre la educación fisica y moral de las mugeres de 1790. 
para tener un espíritu crítico que la lleve a darse cuenta de la necesidad de una intervención mayor y más igualitaria en la sociedad es el grado de participación que ésta tiene en las instituciones educativas. En España, en esa época, esa participación era considerablemente menor que en muchos países europeos. Para poder comprender y explicar este retraso en la participación de la mujer española en la educación, hay que tener en cuenta una serie de hechos, tanto históricos, culturales como sociales. En primer lugar, hay que resaltar que el papel de la mujer en la vida social y cultural en España estaba únicamente orientado hacia la familia, núcleo central de la organización social. Las primeras manifestaciones encaminadas a cambiar el discurso masculino de integración educativa de la mujer se produjeron a mediados del siglo XIX. Escritoras como Pilar Sinués de Marco y Faustina Sáez de Melgar comenzaron a poner en tela de juicio el discurso tradicional del papel exclusivo de la mujer como "ángel del hogar" y comenzaron a proponer la posibilidad de cambiar esta concepción y permitir a las mujeres el aprendizaje y la educación.

Sin dejar de lado las tres funciones tradicionales de la mujer: madre, hija y esposa, ambas escritoras intentan expandir el ámbito de la madre a la educadora de la hija. De esta forma, según Alda Blanco, la mujer comienza a formar parte de la esfera pública al incorporarse al sistema educativo gracias a su misión educadora del hijo y por extensión, paulatinamente, se va convirtiendo en educadora del discurso escrito o de la palabra escrita (22). Esta nueva propuesta de ama de casa que necesita educación por ser ella la que debe trasmitirla a sus hijos, irrumpe en el discurso masculino proponiendo un nuevo modelo de mujer que se seguirá utilizando a principios del siglo $\mathrm{XX}$, y al que Carmen de 
Burgos se referirá en sus textos mediante la constante valoración del papel educativo de la mujer en la sociedad española. ${ }^{6}$

El hecho de que algunas mujeres comenzaran a manifestarse en pro de una mejora en las condiciones sociales, laborales y, en general, culturales, de su género, no implica que en España la mujer gozara de una condición especial, su situación era precaria en relación con otros países. No obstante, es a partir de principios del siglo $\mathrm{XX}$ donde se comenzó, por primera vez en el país, a cuestionarse el problema de la mujer de una forma más organizada. Los debates en cuanto a la participación activa de la mitad del género humano en la sociedad eran comunes y suponían uno de los temas más problemáticos de la época. Organizaciones como la masonería, a modo de ejemplo, consideraban que la mujer debía tener más participación en la vida social y que, para mejorar la familia, la educación de la mujer era fundamental. Consideraban que la instrucción, mejoraría su capacidad para ser una buena compañera para su marido y que podría educar a sus hijos bajo un lema de progreso y libertad, que era la base del sistema krausista. Asimismo, había masones que defendían la participación y la igualdad de la mujer en todos los aspectos de la vida, ya fuera en lo político como en lo laboral.

A pesar de los movimientos de emancipación de la mujer, no hay que olvidar que a finales del siglo XIX y las primeras décadas del XX en España, no existió una conciencia colectiva propiamente emancipadora de la mujer. Se pretendía que la mujer se educara, pero no se tuvo, en ningún momento, la idea de una mujer liberada en los

\footnotetext{
${ }^{6}$ Para mayor información refiérase al libro de Iris Zavala. Breve historia feminista de la literatura española en lengua castellana. Volumen V. La literatura escrita por mujer (Del siglo XIX a la actualidad). Anthropos: Barcelona, 1998. Página 9-38.
} 
términos actuales. La gran mayoría de la sociedad finisecular pensaba que la posición de la mujer era la de agradar y servir al esposo de una forma sumisa. ${ }^{7}$ Del mismo modo, literatos como Vicente Blasco Ibáñez luchaban por una mujer librepensadora pero no una mujer completamente emancipada e integrada plenamente en el mundo laboral, político y cultural (Álvarez 307). Carmen de Brugos, a principios de siglo, pensaba que la educación de la mujer debía ser el instrumento básico para una buena madre y esposa. ${ }^{8}$ Una vez conseguida la instrucción de la esposa, se conseguiría mayor progreso en la sociedad. Para de Burgos, a principios de siglo, el fin principal de la mujer era:

Educar e instruir a las que más tarde han de llenar en el hogar doméstico las importantes misiones de esposa y madre, siendo por las que ejercen mayor influencia en la sociedad, porque ellas son las que educan al tierno corazón de sus hijos las que influyen con su ejemplo y sus consejos en las decisiones de su esposo, por lo que podemos decir que la mujer, desde su modesto hogar, es la que decide la suerte de las naciones. (Starcevic 42)

\footnotetext{
${ }^{7}$ Incluso en los discursos de entrada a las fraternidades masónicas femeninas que examina Pedro Álvarez Lázaro las mismas mujeres "muestran una dependencia determinante del varón" (308). Este es el caso de Cándida Baltar Bravo que dice: "he vencido a los secuaces del oscurantismo gracias a la honradez, fortaleza e hidalguia del que hoy es mi esposo ante la ley, y mucho ante mi conciencia" (11); o más radical aún las palabras de Mercedes Vargas Chambó, que dicen: "la educación de la mujer ha de estar basada en las más sana moral: todos los conocimientos que haya de adquirir han de ir encaminados a hacerla fiel esposa y una buena madre. A nuestro modo de ver, no es lo más conveniente dedicarla a ciertas carreras científicas que para nada necesita" (En Arco 106).

${ }^{8}$ La visión de Carmen de Burgos en cuanto a la educación de la mujer sufre unas modificaciones considerables, pasa de una posición más conservadora y acorde con la mentalidad tradicional, a una posición más liberal al final de sus días, abogando por la emancipación total de la mujer y la lucha por sus derechos.
} 
La situación en el campo de la educación de la mujer mejora considerablemente en el siglo XX y, un ejemplo de ello es que en 1909 se inauguró una escuela Superior de Magisterio que era totalmente mixta. ${ }^{9}$ Así pues, uno de los primeros organismos educativos que se crearon basados en la tolerancia y la coeducación fue el Instituto Internacional fundado por el matrimonio Gulik. ${ }^{10} \mathrm{~A}$ pesar de estos primeros intentos aislados, el primer acercamiento organizado y consciente que pretendía modificar la visión de la mujer en cuanto a su educación, fue el Ideal de Julián Sanz del Río. El ideal estaba basado en la filosofia krausista cuyo postulado fundamental era la tolerancia y de ésta partian los demás postulados. En el ideal se explicaba que el hombre debía cultivar su espíritu por medio de la combinación racional y equilibrada de la ciencia y el arte y que la mujer debía ser rescatada por el hombre de la degradación a la que se veía reducida. El Ideal quería:

\footnotetext{
${ }^{9}$ A pesar de los avances en la participación de la mujer en la educación y el incremento de los movimientos feministas, la participación real de la mujer en la vida social y cultural de España en el siglo XX siguió siendo mínima en comparación con otros países europeos.

${ }^{10}$ William Gulik y Alice Gordon Gulik fundaron en su casa de Santander en 1871 un internado internacional para chicas jóvenes. Este internado se inscribió en la Commonwealth e instruía a chicas siguiendo el modelo americano (Sánchez 1). Más tarde, esta asociación se convirtió en el Instituto Internacional con sede en San Sebastián donde permaneció hasta la guerra entre España y Los Estados Unidos en 1898, cuando se trasladó a Bayona. En 1903 regresó a España y se convirtió en el Instituto Internacional de Madrid. El programa de enseñanza que ofrecía estaba basado en la absoluta tolerancia. De este modo, se aceptaban y convivían en perfecta armonía niñas de cualquier orientación religiosa. Esta institución preparaba a las jóvenes para el examen de acceso a la Escuela Normal de Maestras y al Conservatorio de Música. Entre la plantilla de profesores del Instituto, destacaban Ramón Menéndez Pidal, Juan Ramón Jiménez, José Ortega y Gasset, Rafael Altamirano y, desde 1914, María de Maeztu.
} 
restablecer el santo derecho de la mujer al lado del varón, para mejorar su educación haciéndola más real, más elevada, más comprensiva, para despertar en todos el reconocimiento de la dignidad de la mujer y cultivar en ésta todos los sentimientos sociales, y sus facultades intelectuales en relación proporcionada a su carácter y destino. (106)

Esta ansia de elevar el nivel de educación de la mujer se canalizó mediante tres instituciones creadas por Fernando de Castro. En primer lugar, el Ateneo Artístico y Literario de Señoras de Madrid creado en febrero de 1869. Este organismo se definía como:

Una asociación de enseñanza universal, artística, literaria, científica, religiosa y recreativa, que se propone instruir a la mujer en todos los ramos de una educación esmerada y superior, para que por sí misma pueda instruir y educar a sus hijos, haciéndolos buenos ciudadanos y excelentes padres de familia. (3)

De esta forma, se establecía como primer postulado fundamental la formación de una buena madre. A pesar de no ser una institución revolucionaria en las materias que impartía, fue el primer paso organizado para promover una educación más efectiva para la mujer.

En segundo lugar, Castro organizó una serie de Conferencias Dominicales para la educación de la mujer desde febrero a mayo de 1869. A pesar de que el tema que las constituía era la educación de la mujer, estas conferencias supusieron un avance extraordinario para la sociedad universitaria española ya que permitieron, por primera 
vez, aunque sólo fuera en domingo, que la mujer accediera a la Universidad Central de Madrid, cosa que había estado prohibida anteriormente.

La tercera institución que creó el 11 de junio de 1871 Castro, fue la Asociación para la Enseñanza de la Mujer. Su objetivo fue "Contribuir al fomento de la educación e instrucción de la mujer en todas las esferas y condiciones de la vida social" (3). La Asociación surgió de la Escuela de Institutrices de Madrid. " Esta última pretendía ser:

un avance al ampliar la gama de conocimientos asequibles a la mujer $\mathbf{y}$, con ello, sus perspectivas profesionales; su labor no se limitó a sus propias escuelas, sino que ejerció una indiscutible influencia en instituciones públicas y privadas. La Escuela Normal Central de Maestras... fue reorganizada siguiendo su ejemplo. (62)

La nota más importante fue la implantación de la coeducación en La Institución Libre de Enseñanza. Tenía el propósito de cimentar el mutuo respeto entre los dos sexos y extendía la educación de la mujer hasta la universidad. Un ejemplo de la labor de la ILE fue la celebración del Congreso Nacional Pedagógico en la Universidad Central. En él se ofrecieron dos sesiones dirigidas a la educación de la mujer. ${ }^{12} \mathrm{Al}$ mismo tiempo, se celebró el Congreso Hispano-Portugués-Americano. En éste también se dedicó una sesión a los conceptos y límites en la educación de la mujer y su aptitud profesional. Este

\footnotetext{
${ }^{11}$ A su vez, la Asociación abrió nuevas escuelas de formación de maestras y, al mismo tiempo, abrió escuelas de tipo profesional como la Escuela de Comercio o la Escuela de Correos y Telégrafos. También publicó su propia revista quincenal Instrucción para la mujer.

${ }^{12}$ Una de estas conferencias versó sobre el tema de quién era más apto para enseñar las escuelas de párvulos y la otra, sobre la reforma de las Escuelas Normales.
} 
congreso es importante porque se debatió el tema de la instrucción de la educación fisica para las mujeres. Emilia Pardo Bazán expuso una ponencia con el título La educación de la mujer y la del hombre. Sus relaciones y diferencias. En ella argüía la discriminación que sufría la mujer frente al hombre ya que se le prohibía recibir clases de educación fisica por el simple hecho de ser mujer. Según Vázquez, Pardo Bazán:

resaltó el carácter subsidiario de la educación de la mujer, subordinada al bienestar del esposo y de los hijos; ese carácter subsidiario dicta que a las jóvenes se les prohíba el ejercicio físico tachándolo de indecente e impropio, que su formación moral ignore los grandes ideales y los valores nobles insuflados al varón, que su adiestramiento intelectual sea escaso y además inútil pues carece de perspectivas profesionales, que su educación estética caiga en el ridículo y que su instrucción cívica no exista, dejando campo para la más atroz mezquindad. (35)

Emilia Pardo Bazán termina este discurso diciendo: "No puede, en rigor, la educación actual de la mujer llamarse tal educación, sino doma, pues se propone por fin la obediencia, la pasividad y la sumisión" (92). Carmen de Burgos también participó en debates en pro de la educación física para las mujeres. Ballarín expresa que no se podía concebir una mujer completa si no se cuidaba la educación fisica al igual que la intelectual (69). Y para Carmen de Burgos: "los juegos, los ejercicios de fuerza, la carrera,... se prohibían a las niñas... error lamentable que ha influido en nuestro sexo" (De sport 32).

En definitiva, la educación suponía uno de los aspectos más importantes de la misión regeneracionista que se debía crear en el país ya que, según de Burgos: "[se debe] 
contribuir, en la medida que nos sea posible, a la gran obra de la regeneración social, cuya base es la educación de la mujer" (Ballarín 66) y para ello, el viaje suponia un vehículo excepcional para analizar la situación de la mujer en el extranjero ya que mediante las becas que ofrecía el gobierno español, las maestras e investigadoras podían viajar para aprender las nuevas formas de instrucción académica que existían en Europa. Estos avances en los sistemas educativos de algunos países europeos suponían un reto para la sociedad española y especialmente para la educación de la mujer ya que en este campo era donde se habían producido los mayores cambios. Así, Carmen de Burgos, además de describir las ciudades y países en los libros sobre sus viajes, se detuvo a observar y analizar la sociedad foránea desde el punto de vista de una mujer viajera comprometida con la mejora de la situación social de la mujer española. De esta forma, buscó en estas sociedades un modelo para la mejora de la condición de la mujer en cualquier campo de la vida social.

Es importante analizar el feminismo de Carmen de Burgos para entender la reivindicación que esta escritora hace sobre la mejora de los derechos de la mujer, ya que su feminismo sufre varias modificaciones a lo largo de su vida y de su producción literaria. En los primeros libros de Carmen de Burgos se aprecia una concepción del feminismo muy peculiar y la autora lo expresa en varias ocasiones, tanto en los libros de viajes como en sus demás escritos.

En primer lugar, se percibe su opinión sobre el feminismo en Por Europa en varias ocasiones. Propone a la mujer ante todo femenina y amante de su hogar. Esta visión estaba acorde con el discurso tradicional de la domesticidad y del "ángel del hogar" $\mathrm{y}$ en ningún momento suponía traspasar las barreras del discurso masculino 
tradicional. Lo expone diciendo: "es mejor ser mujer amada, que buscar triunfos y glorias masculinas" (262) o define la palabra feminismo de la siguiente manera:

Si se designa con la antipática palabra Feminismo el progreso de la mujer, en Italia hay mucho feminismo; pero si con ella se significa el desequilibrio de las que pretenden una igualdad a que se opone la naturaleza y hacen y dicen tantas extravagancias, en Italia no hay feministas... Las mujeres italianas son enemigas de las exhibiciones ruidosas, son amantes del hogar y poseen un juicio recto y equilibrado... no son frívolas...tratan de reivindicar todos sus derechos civiles hasta los políticos. (341)

Es evidente que en esta cita expone implícitamente su opinión sobre el feminismo no activista en contraposición con los movimientos feministas activistas que se estaban produciendo de manera asidua en Estados Unidos e Inglaterra. Ella pretende una mejora en las condiciones de la mujer y una revalorización de sus derechos tanto civiles como políticos, pero siempre desde una visión de la mujer tradicional: madre, esposa y núcleo fundamental de la familia. A su vez, en la conferencia que dio en Roma, dijo que el feminismo exagerado era el producto de una mala educación a la muchacha de clase media, a la que se la enseñaba solamente a tocar el piano y hablar en francés y que al no poder casarse, se convertía en esa feminista exaltada (30): "Pero la cuestión del feminismo no es más que uno de los muchos aspectos de la cuestión social; los funestos delirios de igualdad entre los dos sexos, la discusión antipática, las exageraciones, han venido a crear antagonismos y perjudicar la justa causa de las reivindicaciones femeninas. Afortunadamente el feminismo exagerado no arraiga en España" (30-1). No 
está de acuerdo con que se considere la mujer superior y víctima del hombre; sino que lucha por la igualdad y quiere resaltar la diferencia de lo que ella considera como feminismo, entendido como igualdad de derechos y feminidad o galantería hacia el hombre. Manifiesta también, la diferente misión social de las mujeres y se molesta con las feministas que irrumpen en la sociedad inspirando horror a los hombres con su conciencia de superioridad (31).

Esta posición poco clara sobre el feminismo, la sigue teniendo en 1911 cuando en una conferencia pronunciada en la Sociedad El Sitio de Madrid, expone: "no he logrado fijar aún la verdadera acepción de la palabra feminismo... Así que en realidad yo no sé si soy feminista" (Misión social 7). Aún en esta época, mantiene la misma idea en cuanto a la diferencia entre feminidad y feminismo. La autora lo expresa diciendo:

Me da miedo un feminismo que tiende a masculinizar a la mujer, que viene acompañado de los delirios y desequilibrios de las que no supieron entender su verdadero significado; y en cambio la idea de la libertad y dignificación de nuestro sexo tiene para mí un paladín apasionado (Misión 7).

Incluso en 1927, se sigue percibiendo esa posición que aboga por una hermandad entre la liberación de la mujer y su feminidad como contraposición a la masculinidad. En La mujer moderna y sus derechos, Carmen de Burgos indica que el feminismo es un: "Partido social que trabaja para lograr una justicia que no esclavice a la mitad del género humano, en perjuicio de todo él" (9). En este momento, ya se ve la evolución en cuanto a su visión de la diferencia entre feminidad y feminismo. Parecía que en sus primeros libros se vuelca más hacia la concepción de la mujer en cuanto a no alejarse nunca de su 
feminidad o su rol dentro de los cánones de la domesticidad y ahora, abogua más por el término feminismo; claro está, conciliando siempre al supuesto antagonismo entre la igualdad de derechos de la mujer y su "misión social" dentro del hogar. La autora expresa: "ser femenina como quieren las ilusas, es estar sometida sólo a los imperativos sexuales, sin aspirar más que a ser nodriza y gobernante. Ser feminista es ser mujer respetada, consciente, con personalidad, con responsabilidad, con derechos, que no se oponen al amor, al hogar y a la maternidad" (La mujer moderna 21 ).

El tema del feminismo en Carmen de Burgos es un tema recurrente en los estudios que se están realizando en la actualidad. Un ejemplo de ello, es el libro de Paloma Castañeda, Carmen de Burgos "Colombine," en el que muestra este antagonismo diciendo:

Su feminismo tiene dos vertientes diferentes y paralelas al mismo tiempo. De un lado es moderado, quiere cambios que mejoren la situación de la mujer, ve al hombre como un compañero con el que hay que compartir tanto penas como alegrías y responsabilidades. Por otro lado, reivindica el voto para las mujeres, postura que a principios del siglo $\mathrm{XX}$ implicaba defender ideas sumamente progresistas y hasta radicales en un país donde el hogar, el matrimonio y los hijos [es lo más importante]. (108-9)

$\mathrm{Su}$ visión del feminismo se modifica sustancialmente durante la España Republicana. Acepta las dos posibilidades de mujeres, las que se dedican al hogar y las que optan por el trabajo. Ambas deben cultivar y desarrollar su cultura. Pero su feminismo se ha extremado puesto que ya está completamente de acuerdo a que la mujer 
puede y debe de acceder a las mismas carreras y trabajos que el hombre; e incluso ir al servicio militar o pertenecer al ejército (Catañeda 1994, 139-30).

En definitiva, a la luz de esta evolución en su pensamiento en cuanto al feminismo, Carmen de Burgos mantiene en todo momento una separación de lo que es para ella la feminidad, entendida como las características específicas del sexo femenino y el feminismo como la lucha por reivindicar los derechos de igualdad de la mujer frente al hombre en la vida social, cultural y política del país. Este feminismo va desde una postura moderada de conciliación de la mujer educada, madre y compañera a una posición más radical en la que aboga por una mujer en absoluta igualdad de condiciones que el hombre. 


\section{CAPÍTULO II}

PRIMER VIAJE. POR EUROPA. IMPRESIONES: FRANCIA E ITALIA.

Los tres libros de viajes que escribió Carmen de Burgos comparten una serie de características comunes. En primer lugar, según Concepción Núñez Rey, todos ellos representan una amplia gama de información para conocer la biografia de la autora. A su vez, en estas obras de viajes es práctica frecuente intercalar, en medio de las descripciones de los lugares visitados, gran cantidad de información anecdótica, opiniones personales sobre los más diversos temas, juicios de valor ante problemas de interés internacional, así como sentimientos y estados de ánimo que la autora experimenta en el transcurso de sus viajes (148). Pero, sobre todo, se aprecia la evolución en el pensamiento de la autora en cuanto a su compromiso social y político.

Por Europa es el producto del viaje que realizó Carmen de Brugos para analizar los sistemas educativos europeos. Gracias a una beca de ampliación de estudios en el extranjero que le concedió el gobierno español, la autora viajó a Francia, Suiza e Italia. ${ }^{13}$ Este dato es curioso porque, a pesar de que el objetivo del viaje fue el estudio y la evaluación de las aportaciones del sistema educativo de los tres países a donde viaja, la autora no analiza explícitamente estas innovaciones en Por Europa. Sus valoraciones personales con respecto a la educación se muestran en esta narración de una forma indirecta y a modo opiniones personales. El análisis del sistema educativo suizo, italiano

${ }^{13}$ La beca era de tres mil pesetas al año que le permitía salir del país y recibir sus ingresos. Pidió que el claustro de profesores de la Escuela Normal de Guadalajara la propusieran para la beca y, de esta forma, la obtuvo. Para mayor información refiérase al libro de Paloma Castañeda, Carmen de Burgos "Colombine" publicado en 1994 en la página 68-9. 
y francés salió a la luz en forma de un informe que Carmen de Burgos hizo para la Administración de Instrucción Pública en el que expone, de forma detallada y con estadísticas, las novedades implementadas por estos países. Hay un dato curioso, la escritora no menciona su visita a Suiza, ni expresa el estudio que hizo sobre las instituciones educativas de ese país porque, según lo expresa en Por Europa, pretendía recogerlas en un libro que proyectaba publicar en el futuro: ${ }^{14}$

¡Un mes sin escribirle! He hecho una excursión por la libre y hermosa Suiza. De ella y de los abusos incalificables que se cometen en la Instrucción Pública y que me hacen apresurar mi vuelta, se enterará usted por el libro de sinceridad que preparo con el título de "Los Secretos de la Escuela." (Utrera 495)

Una vez conseguida la beca, Carmen de Burgos comenzó su viaje “en el expreso nocturno del día 4 de octubre de 1905" (Utrera 51); pero no sin antes recibir una despedida formal por parte del periódico El heraldo de Madrid, en el que colaboraba de forma asidua. ${ }^{15}$ De la misma manera, en La Memorias de Colombine de Federico Utrera, explica el ansia que la motiva a realizar este viaje: "Decidí poner tierra por medio para aclarar mis ideas y mi futuro: un viaje por Europa me ayudaría sin ninguna duda y aprovecharía para actualizar enseñanzas, realizar entrevistas y copiar lo mejor de los

\footnotetext{
${ }^{14}$ No existe ninguna referencia que indique que la autora publicara Los Secretos de la Escuela, libro mencionado en Por Europa.

${ }^{15}$ La reseña del periódico es la siguiente: "Colombine...después de lúcidas campañas en la prensa española, emprende ahora un viaje por el extranjero... tendrán conocimiento los lectores del Heraldo por los artículos con que nos honrará la notable escritora que en el expreso de anoche salió para París" (Jueves, 5 de octubre de 1905).
} 
sistemas educativos vecinos. El Ministerio daba unas becas y yo opté con éxito a una de ellas" (51).

En cuanto a las características formales del libro, éste está estructurado en forma epistolar, con lugar y fecha al final de cada uno de los 55 capitulos que lo componen y dirigidos al padre José Ferrándiz. ${ }^{16} \mathrm{La}$ autora divide el libro en tres partes. La primera, está compuesta por 22 capítulos que van desde su partida, titulada: De Madrid á la Francia hasta el capítulo llamado Monte Carlo; la segunda parte, que consta de 16 capítulos, va desde El puerto de Génova hasta La Erupción del Vesubio y la tercera de 16 capítulos que comienzan con El Coliseo y termina con Vuelta a España. ${ }^{17}$

El tono general del relato es de exaltación, a la vez que se percibe una gran emoción por explicar y analizar de forma subjetiva su visión personal de los hechos que suceden durante su viaje. No obstante, el libro mantiene la objetividad a la hora de hacer descripciones concretas de calles o de describir el paisaje natural. Núñez Rey explica que el tono del documento tiene cierta solemnidad y que registra fielmente los hechos e impresiones según se fueron produciendo (148). Esta solemnidad se percibe a la hora de retratar o describir aspectos concretos que a la autora le interesaban de forma especial

\footnotetext{
${ }^{16}$ Cuando Carmen de Burgos envió el documento original para que se publicara, envió, a su vez, una carta que iba dirigida al padre Ferrándiz en la cual explicaba quién era este señor. Esta carta aparece al principio del documento y nos muestra que, en primer lugar, mantiene una relación bastante estrecha, cordial y amistosa con el padre y, en segundo lugar, que este hombre era columnista del país. Hombre liberal que criticaba de forma regular y frecuente los abusos e injusticias sociales.

${ }^{17}$ En la edición analizada el capítulo XII está omitido. Pasa del XI al XIII. Esta omisión parece accidental ya que el capitulo XI termina el 20 de junio en Florencia y el XIII termina el 30 del mismo mes. El motivo de esta omisión no tiene ninguna relevancia temática, posiblemente haya sido un error a la hora de su publicación. No existe ningún documento en el que se haga referencia a esta anomalía en el texto.
} 
como por ejemplo los museos y las descripciones de las obras de arte, a las que les da un tratamiento casi sagrado y hace gala de un detallismo a veces exagerado. Por otro lado, su lenguaje se vuelve altamente subjetivo a la hora de hacer juicios sobre la sociedad que visita, sobre personajes especiales, a los que a veces aborda de forma directa y con una crítica fuerte y mordaz. Ejemplos claros de esa visión subjetiva y crítica son las numerosas referencias en contra del catolicismo.

La religión católica suponía uno de los aspectos más importantes que criticaba Carmen de Burgos. Dentro de la critica que hace a la religión católica, el tema de la corrupción y el favoritismo de clase lo abordaba con bastante frecuencia. En este sentido, la autora comenta su impresión en la primera visita al Papa diciendo:

un criado [del Papa] que recorre la fila de los que esperan [para visitarlo] y despide groseramente a todos los hombres y señoras que no van de traje de etiqueta. El padre común de los fieles no ve más que á los hijos bien vestidos; a los que llegan gozosos á sus pies, los desnudos, los tristes, los hambrientos... esos no tienen entrada cerca de él. (383)

Este ejemplo es de vital importancia porque suponía una forma de acercamiento con el lector. La autora utilizaba un lenguaje cargado de subjetividad, apasionado y lleno de juicios de valor para condicionar al lector de la necesidad de acabar con el catolicismo opresor. Así pues, este estilo sentimental, que se vuelve poético, llega hasta el límite de expresar su aversión contra esta institución en términos como: “!Oh! ¡Religión estúpida e inconsciente! ¡Que aún en el siglo XX sigas dando estos espectáculos! (255). Esta cita se refiere a los pescadores españoles que salen diariamente a faenar y de cómo estos 
hombres practican una religiosidad obsoleta que pretende mantenerles en un estado de ensimismamiento religioso.

Otro ejemplo en el que Carmen de Burgos despliega su aversión hacia la jerarquía eclesiástica es al enterarse de la destrucción que supuso la erupción del Vesubio. La autora explica a su interlocutor: “¿querrá usted creerlo? Los periódicos del Vaticano atribuyen la desgracia a castigo de los pecadores napolitanos. Pero eso son los clericales; ya los conoce usted. ¡Ni a Dios respetan! El que menos, se cree superior a todos los dioses habidos y por haber" (298).

La Iglesia católica, no sólo cometía discriminación estamental o de clase, sino que discriminaba a la mujer y suponía un freno para el progreso. La autora cree que uno de los problemas fundamentales del atraso de la mujer española era la marcada religiosidad de las mujeres, ello suponía una cerrazón a la modernidad y era la causa más obvia del retraso y de la subordinación de la mujer:

Nosotros no llegaremos nunca a este confort para hacer de Málaga, por ejemplo, otra Niza. Sería preciso descatolizarla primero; sanear su ambiente de la funesta influencia de Larios, Luises, Jesuitas, curas y demás aves negras que ahogan la libertad, minan como enemigo a todo el que no va a misa y ejercen su influencia en la sociedad femenina, supersticiosa y mojigata. (149)

Esta cita es clave porque propone un problema de fondo que afecta directamente a las mujeres. La Iglesia constituía una herramienta fundamental en el campo de la educación ya que dirigía la forma en la que se debían sentar las bases de la educación del individuo y la que implementaba las diferencias que se debían seguir en la educación de hombres y 
mujeres. Carmen de Burgos ataca al poder eclesiástico por ser los causantes de la mala educación de las mujeres que seguían a los clérigos de forma sumisa y eran los que las mantenían en un estado de vegetación y ensimismamiento. Es por ello, que el primer paso para la modernización de España, según de Burgos, era la eliminación del poder que la Iglesia ejercía en todos los aspectos de la sociedad y, concretamente en las instituciones educativas. Una vez eliminada esta influencia, la mujer podría comenzar a educarse de una forma más igualitaria $y$, de esta forma, podría emanciparse paulatinamente en todos los campos de la sociedad.

No se debe entender que para Carmen de Burgos la educación debía de prescindir de la religión. Todo lo contrario, de Burgos seguía la doctrina krausista, que proponía otra forma de entender la religiosidad. Esta filosofía exponía que se debía de implementar en los colegios una educación neutra. En otras palabras, se debía formar al maestro para alcanzar la paz en la escuela por medio de una religión que se basara en la tolerancia positiva. De esta forma, para los krausistas, la enseñanza de la Religión debía ser algo natural, sin limitaciones, una instrucción espiritual del individuo. ${ }^{18}$ La autora, en ningún

\footnotetext{
${ }^{18}$ A los krausistas se les tachó de anti-religiosos por predicar una libertad de cultos en sus enseñanzas, pero para Giner y sus seguidores, la educación religiosa no era una educación escéptica e indiferente, sino que pretendían ser un acercamiento hacia todos los cultos y creencias; es decir, Giner sólo pretendía una neutralidad religiosa. Posada dice: "La Institución Libre de Enseñanza fue siempre pura y sencillamente una escuela respetuosa con todas las creencias por considerar la religión, en sí, un alto valor moral y social, y las religiones positivas elementos esenciales de la civilización y de la cultura" (98). En este sentido, Giner expone que únicamente la enseñanza laica es la que puede formar un espíritu de tolerancia:

no sólo debe excluirse la enseñanza confesional o dogmática de las escuelas del Estado, sino aun de las privadas, con una diferencia muy natural, a saber: que de aquéllas ha de alejarlas la ley; de éstas, el buen sentido de sus fundadores y maestros. (Estudios 76)
} 
momento reniega de una formación religiosa, sus ataques están dirigidos únicamente al catolicismo institucionalizado. Ella propone el regreso a una religión primitiva fundada en los valores de igualdad de los individuos. Para Carmen de Burgos: "El cristianismo primitivo era al mismo tiempo una lucha política; peleaban por una nueva forma de la sociedad, encantados con la doctrina igualitaria que inventó San Pablo y que luego no se ha realizado bajo el cristianismo" (320). Esta visión de la religión igualitaria es completamente compatible con los principios krausistas ya que éstos tampoco reniegan de la religión, sino que para ellos la religión pura es un principio básico para implementar una buena formación moral. Esto es, en definitiva, lo que busca de Burgos para la mujer, una educación religiosa tolerante y "humanitaria [que aspire] a la fraternidad universal" (192) y no una religión que caiga en la mojigatería y se aleje de la cultura y sirva como instrumento de opresión.

Otro tema fundamental y recurrente que la autora inserta en el texto y que está íntimamente ligado a la instrucción de la mujer en una sociedad moderna es el tema del matrimonio y el divorcio. Hay que tener en cuenta que, un año antes, Carmen de Burgos había realizado y publicado la primera encuesta pública sobre el divorcio en España. La idea, que surgió como una noticia más para engrosar su columna en el periódico $E l$ Diario Universal, tuvo un gran impacto en la sociedad de su tiempo. ${ }^{19}$ En Por Europa, la

${ }^{19}$ Carmen de Burgos recopiló cartas que le habían mandado personajes importantes del mundo de las letras y las publicó de manera indiscriminada. La gran aceptación que tuvo la idea, la llevó a la publicación de su libro El divorcio en España (1904). Para ella, el implemento del divorcio en el país suponía un adelanto en la mejora social que no debía olvidarse. Burgos expresa: "El deseo de perpetuar en un libro los primeros pasos para el planteamiento de esta mejora social, me impulsó a recopilar en un volumen todo lo dicho en el plebiscito para que no se perdiera con la rapidez vertiginosa de la hoja periodística" 
escritora menciona la encuesta que hizo sobre este tema y la repercusión que ésta tuvo en la Iglesia. ${ }^{20}$

Carmen de Burgos muestra el problema del matrimonio y la necesidad de implementar el divorcio en España como una forma más de ayudar a la mujer. Para la escritora, es la mujer la que sufre las consecuencias de los problemas matrimoniales. ${ }^{21}$ Resalta el hecho de que ella no es la única que aboga por la aplicación de una nueva ley sobre el divorcio, sino que muchas personas más están a favor de esta reforma. Señala los adelantos conseguidos en Europa en el tema del divorcio. Por ejemplo, explica que las mujeres italianas también querian que se implementara el divorcio con una ley (342) e intercala conversaciones y entrevistas con personajes vinculados a las reformas respecto al divorcio como la realizada al intelectual francés Alfred Naquet (121), quien presentó la ley de divorcio en Francia o la escritora Matilde Serão, periodista que pretendía hacer en

(Utrera 38). En este libro incluyó las opiniones de personajes como Unamuno, Azorín, Vicente Blasco Ibáñez, Pío Baroja, Antonio Maura y Emilia Pardo Bazán, entre otros.

${ }^{20}$ En su texto, la autora lo expresa de la siguiente manera:

Cuando mi campaña a favor del divorcio me atrajo el anatema de Nocedal y sus ridículos fariseos, un cura, no tonto, con pretensiones de poeta y de escritor, ansioso de notoriedad, fingiendo el fervor que no posee (un pillo muy largo, en una palabra), enamoradizo y descreído, bastante cínico por añadidura fue uno de los que se mostraron más indignados de mi pecaminoso atrevimiento...vino a verme para conseguir de mi que le contestara en mi periódico, su objeto era dar ruido, que el Obispo agradeciera su defensa del matrimonio y le premiara con un destino. (299)

${ }^{21}$ Carmen de Burgos no dejará de participar activamente en pro de la ley del divorcio. En 1921 se pronuncia en contra del artículo 438 de la ley penal por el que se permitía al marido el tomarse la justicia por su mano, matando, si era preciso a su mujer y al amante de ésta si descubría la infidelidad. En ese año publica una novela corta con el nombre de El artículo 438 en el que se percibe perfectamente la injusticia que se produce ante la ley en el caso de una infidelidad por parte de la mujer. 
Italia una campaña a favor del divorcio al igual que lo había hecho Carmen de Burgos (242).

El pensamiento que Burgos expresa en Por Europa en cuanto al divorcio es la proposición de formar uniones entre parejas que se hagan de forma racional. Admira a los franceses que han llegado a convertir la institución del matrimonio en un símbolo de conveniencia económica para la pareja. Carmen de Burgos dice que para los parisinos "el matrimonio no tiene más que un fin económico" (51). Para de Burgos

El marido, lo mismo que el amante, no se inquietará por la procedencia del dinero que su mujer aporte; ella será más respetada, más querida que esas castas esposas españolas que pensando en la santidad del sacramento y el matrimonio se encierran en el hogar como en un templo, sin más objeto en su vida que el culto del amor único al esposo. (52)

Por un lado, la cita muestra una crítica hacia el "ángel del hogar" ya que derrumba los fundamentos que el discurso patriarcal proponía como los únicos posibles para las mujeres y, al mismo tiempo, derrumba el ideal tradicional de la misión social de la mujer. A su vez, esta cita presenta la finalidad económica del contrato matrimonial que llega hasta el punto de que el marido no se preocupa de dónde puede sacar el dinero su mujer con tal de que aporte al matrimonio su grano de arena. Este contrato civil y racional entre las parejas se percibe también en la descripción que la autora hace de la unión civil de dos obreros delante de la alcaldía, donde el alcalde les leía las obligaciones que han de tener los que se casan (51). El factor económico de la unión de una pareja es un ejemplo más de una unión matrimonial racional; pero lo que verdaderamente define una unión de pareja es el amor puro y sincero. Esta visión, que en principio parece absoluta, no se 
contradice con el matrimonio racional que proponían los franceses. El ataque que hace la autora es contra el matrimonio católico tradicional y las implicaciones de éste. La autora proponia el amor puro y sincero y una religión primitiva fundada en la igualdad entre los individuos. La visión de este amor puro y sincero en unión perfecta con la naturaleza lo expresa en Por Europa al ver a dos jóvenes besándose: "La Naturaleza realizaba la unión de la fuerza y de la juventud, por la atracción irresistible de una corriente de simpatia estallando en un apretón de manos y en un beso de fuego. ¿No es ésta la unión santa y legítima que no necesita sanción de leyes ni sacerdotes?" (308). El verdadero problema de las españolas es esa neblina en la cual la iglesia católica las ha envuelto con sus sermones de la santidad del hogar. Carmen de Burgos crítica nuevamente el papel tradicional de la mujer dentro del hogar y manifiesta el deseo de que las mujeres despierten de esa neblina y se den cuenta de los beneficios que suponen el verdadero amor y la necesidad del trabajo, no sólo para revalorizarlas, sino para ayudar al marido dentro de esa unión familiar que supone el matrimonio.

El énfasis fundamental que se aprecia en todo el libro es el carácter de denuncia sobre la situación de la mujer española. Desde el principio, la autora se aflige ante las necesidades que tienen las mujeres y se percibe la angustia y la pena con que describe la situación en la que se encuentran. El primer ejemplo en el que critica esa visión de la mujer desgarrada por su situación es cuando al alejarse de su tierra natal, la autora compara las mujeres burgalesas con las andaluzas a las que:

miserables y supersticiosas.... enflaquecidas, desgarradas, astrosas, dando a luz a un ejército de chicos de color terra cotta y pasando la vida envueltas en su atmósfera de fatalismo musulmán, sin deseos ni 
esperanzas, maltratadas por los maridos; esos mocetones robustos, inactivos, en la más estúpida de las resignaciones, (15)

Esta mujer española, desgarrada por la naturaleza feroz y la sociedad aplastante que ha generado unas costumbres bárbaras, es el punto de mira de la autora. Su crítica se centra en el anhelo de es destruir este tipo de mujer resignada y crear a una nueva mujer que, mediante una educación adecuada, sea capaz de salir de su estado de sumisión y ocupe el lugar que le corresponde en la sociedad. Es por ello que el tema de la educación ocupa un lugar primordial para la emancipación de la mujer; la educación es el primer paso para que la mujer se valore a sí misma y estime su capacidad y sus posibilidades de participación en la sociedad de una forma más igualitaria.

En cuanto a las menciones que se incluyen en el libro acerca de la educación propiamente dicha, la primera se muestra en el comentario inicial al comenzar su viaje que lo hace con un anhelo. La autora dice que viaja "en busca de horizontes amplios, de luz, de colores, de vida" (14) pero el recuerdo de las miserias y las injusticias que deja la historia en los hombres, la retrae: "Quizás si borrásemos todo el pasado, si no les enseñásemos a nuestros hijos tantas miserias, los hariamos mejores y más felices" (14). Esta primera inserción de su pensamiento en cuanto a las enseñanzas del niño, nos lleva a dilucidar el deseo de la autora de implementar una educación basada en el Ideal de Kraus que abogue por una educación positiva e instruya al niño en lo bello, en el Arte y en la Ciencia en lugar de acentuar las injusticias y miserias de la humanidad. De ahí que pase rápidamente a atacar a la Iglesia, educadora por excelencia, ya que implementa la oración y el castigo, el bien y el mal, el cielo y el infierno. Carmen de Brugos dice que lo único que puede satisfacer al espiritu no es la oración o el temor a Dios, sino la belleza, la 
ciencia y el arte (14). Como la autora indica en la Memoria que entregó a la Administración sobre el sistema educativo en el extranjero, su lema primordial es seguir las enseñanzas del sistema froëbeliano, ${ }^{22}$ a enseñar "todo lo que encamina a despertar el sentimiento artístico" (13). ${ }^{23}$

En este sentido, para Carmen de Burgos la educación que proporciona la Iglesia, a pesar de que admira el sistema educativo suizo por los avances que ha implementado, sigue menospreciando la influencia que ésta aún ejerce en la instrucción del niño en este país. Para la autora, uno de los avances más importantes que había implementado el sistema educativo suizo era la forma que éstos tenían de concebir la educación. Los suizos incitaban al niño desde temprana edad a preparase para el arte. Para la autora: "La educación en Suiza tiene como base la cultura del sentimiento. Ser artista es ser bueno" (16).

${ }^{22}$ Para mayor información dirijase a la tesis de Raquel Vázquez Ramil, "La Institución Libre de Enseñanza" y su aportación a la educación de la mujer española. En líneas generales, la Pedagogía Froëbeliana proponía un modelo de enseñanza intuitiva con un aprendizaje lúdico en donde se debía suprimir el libro de texto y las técnicas de memorización. Pretendía implementar la enseñanza oral y la vivencia activa del proceso de aprendizaje por parte del alumno, a través del contacto directo con la naturaleza, el arte y las tradiciones populares, entre otros. Establecía un sistema cíclico, en donde no había ruptura entre la enseñanza primaria y secundaria.

${ }^{23}$ Todas las referencias a la Memoria del viaje de ampliación de estudios a Suiza, Francia e Italia que Carmen de Burgos entregó a la Administración de Instrucción Pública, están paginadas de forma arbitraria. El texto original está dividido en pliegos de cuatro páginas cada uno. La paginación está hecha acorde con las páginas originales escritas a mano por la autora. He hecho esta división para tener una referencia precisa a la hora de localizar la información en el texto original. 
Carmen de Burgos, aunque explícitamente no lo indique en Por Europa, luchó por defender la coeducación de los niños y niñas. Como puede verse en sus frecuentes menciones al tema de la coeducación, la autora quiso:

una enseñanza distinta, dejar los castigos y dar una dignidad al niño, abandonar la memorización y despertar interés, mejorar los centros escolares, que éstos tengan un mínimo de higiene y comodidad para crear un ambiente agradable que fomente el estudio y el aprendizaje. (Castañeda 32)

Las innovaciones que quería proponer venían de su preparación. Hay que tener en cuenta que en esta época colaboraba asiduamente en las revistas pedagógicas La Tribuna Pedagógica y La Educación y leía los artículos sobre la nueva metodología de la educación de Soledad Villafranca que publicaba en la revista L'Humanité. El sistema metodológico de enseñanza que proponía el Instituto Internacional era el que más se ajustaba al conjunto de innovaciones que la autora quería implementar en España como por ejemplo las mejoras en la higiene, tolerancia religiosa y coeducación. A su vez, poseía una amplia biblioteca e impartía clases de idiomas, música, arte y gimnasia. ${ }^{24}$ También le influenció el pensamiento de Francisco Bernot y lo expresó en un artículo del 28 de junio de 1907 que publicó en el Heraldo de Madrid. En este artículo, intitulado El feminismo de Bernot, la autora valoraba el pensamiento de Bernot en cuanto a la educación de la mujer. Éste supuso una influencia decisiva en su doctrina puesto que veia a la mujer como:

${ }^{24} \mathrm{Al}$ Instituto Internacional asistió su hija, María Álvarez de Burgos. 
una persona educada, adornada de todas las perfecciones para dirigir el hogar; capaz de trabajar y de ser respetada, de vivir con su propio esfuerzo, pero libre de los deseos de ser "otra especie de hombre" y de luchar para lo que su propia naturaleza le impide y la buena organización de la sociedad le reclama. (Castañeda 1994, 108)

La segunda mención que hace la escritora en cuanto a la educación de los niños, es la referencia en relación a la crueldad del niño español que no ha sido instruido en el amor a la naturaleza. Carmen de Burgos señala: "con qué crueldad los niños [españoles] los despluman [a los pájaros] y les sacan los ojos. Está en los niños la verdadera esperanza de progreso de un pueblo, y en esto nos llevan ventaja casi todas las naciones de Europa" (42). La autora ve con lástima cómo el pueblo español no ha sabido criar a sus hijos en el respeto y la tolerancia. Estos niños que son el futuro de un país están condenados a seguir en las tinieblas de la intolerancia y la crueldad. Admira y envidia la corrección y respeto con que juegan los niños franceses en los jardines públicos. Y también, admira al gobierno francés, consciente del papel que los niños tienen en futuro de las sociedades, porque ha proporcionado los medios para activar las funciones motrices para su desarrollo. La autora expone que: "El municipio de París se preocupa por los niños; en todas partes hay sitios de recreo y gimnasios gratuitos" (43). Por un lado, indica que la creación de parques acerca a los niños a la naturaleza y les incentiva a que aprendan a amarla y a respetarla.

En segundo lugar, menciona la abundancia de gimnasios gratuitos en París. Este último tema es muy importante porque está intimamente ligado al tema de la educación de las mujeres. En esa época, el tema del ejercicio fisico de las mujeres era un tema muy 
candente y problemático. En España todavía se debatía la necesidad de incluir la educación fisica en el programa educativo femenino. La autora inserta aquí el hecho de que existan en París gimnasios gratuitos para niños, sin mencionar el sexo de éstos, porque piensa que de esta forma abre aún más el debate sobre el tema de la educación fisica de la niña y la mujer. No hay que olvidar que en 1892, Emilia Pardo Bazán expresaba su pensamiento sobre este tema en una ponencia en El congreso Pedagógico anteriormente mencionado. Para Bazán:

en ciertas materias a la mujer hemos retrocedido más bien que adelantado, y que respecto al punto del ejemplo, aún no se le permite a la mujer, o por lo menos no se ve con simpatía; a lo sumo, se toleran sin extrañeza, en las jóvenes, ciertos juegos no muy turbulentos...Esta capital diferencia entre la educación del hombre y de la mujer: el ejercicio físico, recomendado al hombre, se tolera a la mujer en la niñez y juventud y se reprueba después del matrimonio. (Schiavo 79)

Otro aspecto que menciona en Por Europa en cuanto a la educación del niño es la referencia que Carmen de Burgos hace al tipo de lectura que los pequeñines debían tener. En este sentido, propone que a los niños se les debe dar lecturas sencillas que formen su espíritu, engrandezcan su imaginación y les enseñen a apreciar la belleza (90). El arte para la autora supone el principal elemento que se debía implementar en la educación del individuo, arremete contra el mal artista que no antepone su misión de educar al pueblo. Se indigna cuando ve representaciones artísticas horrendas que no instruyen a nadie en lo bello y lo artístico y para la autora: "Es lastimoso que $<$ le hablen en necio al pueblo para darle gusto $>$ los que tienen la misión de educarlo. No debe ser el pueblo el que imponga 
su voluntad al escritor, sino éste el que enseñe el arte" (72). El arte está presente en todas las facetas del desarrollo educativo. Admira las universidades europeas que poseen unas condiciones higiénicas que no tenían las españolas y describe cómo estas universidades están rodeadas de arte. ${ }^{25}$

Asimismo, menciona la necesidad de crear un teatro que enseñe al pueblo y al niño la belleza: "El teatro es escuela, sí; pero escuela de arte y todo lo que es arte es bello y humano y llega al corazón del pueblo" (72). El buen teatro como espejo de la vida es un elemento educativo eficaz y Carmen de Burgos expresa ese anhelo de que en España pueda existir un teatro que eduque y forme. Para que este teatro sea viable, se necesitan intelectuales lo suficientemente preparados para que sean capaces de ejercer la misión a la que se deben encomendar. La escritora los expresa diciendo: “iCuándo habrá teatro para los niños y para el pueblo! Se han hecho muchas tentativas pero aun no se ha encontrado la forma verdadera; porque aun se les sigue creyendo incapaces de comprender el arte puro; o quizás porque existen pocos escritores capaces de saber expresarlo" (72). ${ }^{26}$

${ }^{25}$ Carmen de Burgos dice textualmente: "Al menos la juventud se educa rodeada de arte y en estancias grandes y sanas. He recordado con pena casi todas nuestras universidades, cuyo sólo aspecto incita a la huelga" (177).

${ }^{26} \mathrm{El}$ teatro escuela forma parte de un proyecto creado en el Museo Pedagógico Nacional. Fue una de las extensiones del doctrinario de la filosofia krausista de la Institución Libre de Enseñanza. Una de las funciones más importantes del Museo fue la creación del Patronato de Misiones Pedagógicas. Éste tenía como misión difundir la cultura general en todos los pueblos y villas del país pero con mayor atención a la población rural. Las Misiones Pedagógicas se centraban en el fomento de la cultura general mediante la creación de bibliotecas fijas y ambulantes y representaciones teatrales, que no necesitaban de un espacio físico determinado. Así pues, se creo en 1933 un teatro itinerante que se llamó el "Teatro del Pueblo," que estaba dirigido por Alejandro Casona. 
Pero la mención más evidente en Por Europa que hace referencia a la diferencia que existe entre la educación del niño español y el europeo es la alusión que hace la autora a las colonias de verano de los niños suizos. Ésta es la alusión más directa e importante que hace Burgos en su libro con respecto a su análisis de sistema educativo suizo. La autora ve en el Lido de Venecia una colonia de verano de niños suizos. En estas colonias de verano en el extranjero, el gobierno suizo trata de fortalecer a los niños mediante su contacto con la naturaleza, el mar, la montaña, o simplemente para enriquecer su visión del arte. Viajan al extranjero, visitan museos, catedrales, etc. Carmen de Burgos se refiere a las diferencias que existen entre la administración suiza y la española, diciendo que: "la libre Suiza necesita ciudadanos fuertes que conozcan y mantengan sus derechos... en la católica España conviene que no salga el pueblo de su inconsciencia" (449). De esta forma, pone de manifiesto la labor del gobierno suizo que ha hecho de la educación de sus niños el lema fundamental de su gobierno. Explica por qué era una necesidad fundamental en España la creación de las colonias de verano si se quería ciudadanos "fuertes de cuerpo y espíritu" (449). Mediante estas comparaciones, la autora demuestra su amargura al describir la situación de los niños españoles que estaban "embrutecidos" (449) y que el "Estado sólo se acuerda de ellos para llamarlos al servicio militar [y] los legisladores para exigirles responsabilidades" (449). La mala educación que se les da a los niños sólo tiene una consecuencia lógica: Estos niños, como dice

A su vez, Federico García Lorca funda junto a Eduardo Ugarte en 1931 la Compañía de Teatro Universitario ambulante "La Barraca." 
Burgos, se convertirán en el: "producto híbrido del alcohol y el vicio" (449) y su futuro sólo puede ser uno: "ser carne de presidio, confeti del arroyo" (449).

Por medio de estas palabras, Carmen de Burgos propone un cambio en varios puntos. En primer lugar, pide a la Administración que siga el modelo suizo para educar a los niños ya que, para ella, Suiza es el modelo de sociedad moderna. En la Memoria correspondiente al curso... define a este país como una sociedad perfecta gracias a la educación de sus ciudadanos, que ha permitido crear un país que no tiene criminales ni ejército porque los ciudadanos conviven en un ambiente de respeto. De Burgos indica: "La frase célebre de que <cada escuela que se abre cierra una prisión a los veinte años> es allí un hecho. Algunos cantones cerraron sus prisiones por falta de criminales" (6-7). Para la autora, no existen temperamentos distintos, la diferencia entre latinos y no latinos está basada simplemente en la educación que reciben los ciudadanos de un país. Así: "la educación lo modifica [el temperamento de los individuos] y es la que moldea generaciones sanas, puras, honradas; la que hace que una nación pueda vivir unida y federada dentro de una autonomía y una libertad tan grande como la República Helvética" (Memoria 7).

Como puede verse, el análisis y la descripción de las escuelas de verano implica una denuncia al sistema educativo español y propone unas reformas. En primer lugar, la autora deseaba pedir al gobierno español que se responsabilizara de la educación de los niños. A su vez, pone de manifiesto, nuevamente, la decadencia y la falta de progreso debido, en gran parte, al catolicismo. Frente a España, la católica, contrapone "la libre" Suiza y, de ese modo sugiere que para que España se convierta en un país libre como Suiza, debe liberarse de la opresión del catolicismo. 
Otro de los temas fundamentales en la educación es la inserción de los judíos en la sociedad, la revalorización de su cultura y la importancia que tuvieron en la historia de España. Carmen de Burgos simpatizaba con esta comunidad ya que pensaba que fue injusta su expulsión. Siente gran cariño por estas gentes que, a pesar de no vivir en el territorio español, siguen conservando el idioma y no muestran resentimiento por el país que los expulsó. En su visita a París, relata la reunión que mantuvo con Max Nordeau, al cual le comenta los resultados de las actividades pro-israelitas que estaba llevando a cabo su amigo Ángel Pulido, con el que la autora participaba activamente (Castañeda 2003, 147). A su vez, expone la nueva propuesta del ministro español de abrir escuelas para judíos (Por Europa 84). A diferencia de Emilia Pardo Bazán que muestra la comunidad judía de una forma negativa, reprochando su crueldad (Por la Europa católica 160-1), para Carmen de Burgos estas comunidades son también un ejemplo de minorías desfavorecidas socialmente. Mediante la empatía con ese pueblo, la autora pretendía resaltar, por un lado, la labor de los judíos en España y su evidente aportación cultural e histórica, una aportación que la historia oficial ha pretendido mantener en el olvido. Por otro lado, de Burgos pretendía equiparar la situación de discriminación cultural judía con la discriminación cultural de la mujer ya que la cultura patriarcal también pretendía mantener en el olvido las diferentes manifestaciones culturales de las mujeres. A su vez, las mujeres, para de Burgos, son, al igual que los judíos, un grupo heterogéneo que se encuentra en una situación de discriminación. ${ }^{27}$

\footnotetext{
${ }^{27}$ El hecho de afiliar la lucha feminista con la de otras minorías constituye una de las estrategias típicas de las escritoras.
} 
En cuanto al tema de la educación de la mujer propiamente dicho, éste está tratado de forma indirecta, pero con implicaciones profundas. La mención más directa es el efecto que produce en la autora la visión de las cuatro estudiantes americanas que van a ver y estudiar arte en Italia. Este encuentro sorprende y emociona a la narradora que ve en estas mujeres el ideal que se debiera implementar en España en la educación de la mujer. El problema para de Burgos es que: "no ha penetrado aún la civilización [en España], no se puede vivir en el siglo XX; estamos petrificados en plena Edad Media, y se comprende el constante ¡ $\mathrm{Ah}$ ¡ $\mathrm{Oh}$ ! que se escapa de los labios alemanes o ingleses" (196). Implícitamente estaba criticando al gobierno que no fimancia de forma efectiva el viaje de estudio al extranjero a muchachas para ampliar su formación. Se percibe con pena que tanto en Italia como en España no se haya alcanzado la modernidad. Las becas que existían eran precarias y los pensionados sufrían la penuria del mal pago y los retrasos. Carmen de Burgos lo expone en Por Europa diciendo: "Pensaba continuar a Nápoles, pero la falta de puntualidad en el pago de la pensión que como profesora me concede el Gobierno español, marca otro derrotero a mi viaje" (203). Al mismo tiempo, dice que solamente se puede viajar al extranjero por motivos de estudios, si el que viaja tiene una situación económica desahogada:

Estas pensiones no son para profesores ni alumnos modestos. En primer lugar, el pagar los meses vencidos hace preciso que el pensionado cuente con la cantidad necesaria para el viaje y el sostenimiento del primer mes... ¡Del primer mes!... Muy pronto lo he escrito; unas veces por fas y otras por nefas, transcurren a veces varios meses sin recibir un céntimo, y los pensionados se ven en el caso de mendigar. (203) 
Es evidente que esta cita autobiográfica tiene el propósito fundamental de informar directamente a la Administración de los problemas directos que encierra la ineficacia y la falta de subvención de los programas de investigación en el extranjero. A su vez, quería apelar abiertamente a que se valorara el trabajo que los pensionados realizaban en el extranjero; a pesar de que de Burgos muestra pocas esperanzas de que este trabajo fuera respetado por parte de los organismos competentes: "veo a muchos pensionados trabajar con celo e inteligencia; yo misma estudio a conciencia los problemas pedagógicos-sociales en lo que á la mujer se refiere; pero no me atrevo a esperar que mis observaciones pesen para nada en el ánimo de los que las lean... Si las leen" (204).

Para afirmar la ineficacia del gobierno español, de Burgos expone que no es la falta de mujeres intelectuales, sino de un gobierno que no quiere que éstas participen en la vida social, cultural y política del país. Es por ello que utiliza otra de las estrategias típicas de las teóricas feministas al hacer frecuentes referencias a mujeres intelectuales célebres. Menciona pintoras extranjeras como Rosa Bonheur, Elisa Connis, Sofía de Ribbring, Angélica Kauffman, Elisabeth Vigée Le Brun y entre ellas, la española María Luisa de la Riva Muñoz. Al mencionar a esta pintora española que pinta cuadros de naturaleza muerta con constantes referencias a España, expresa una nota de dolor al comentar que es famosa en el extranjero y no se la conoce en su país natal "apenas se sabe que existe" (82). Es una denuncia a la falta de aprecio por el artista que se tiene que ir al extranjero para poder ser famoso y sobre todo, a la mujer artista que trabaja y lucha en un país ajeno y que guarda siempre el amor a su patria aunque ésta no reconozca su 
talento. También menciona a mujeres españolas ilustres como Cecilia Madrazo de Fortuny y la influencia que esta mujer tuvo sobre la obra de su marido.

A pesar de que el gobierno español ignore las manifestaciones intelectuales de las españolas, la autora se enorgullece de que, a pesar del atraso que existe en España en el campo de la educación de la mujer, ésta va irrumpiendo en el campo intelectual mediante el acceso a carreras universitarias a las que antes no podía acceder. Un ejemplo de ello es la mención, en su conversación con la hija de Max Nordeau, de que en España también hay mujeres doctoras y alude a su amiga Concepción Aleixandre, ${ }^{28}$ una de las primeras doctoras de nuestro país. En definitiva, lo que quería decir es que el primer paso ya se había dado, la mujer española estaba accediendo a carreras universitarias tradicionalmente masculinas, pero no quería que la situación se quedase ahí; España debía seguir, según la autora, un programa en el que la participación de las mujeres fuese más constante y más extendida. Para ello se necesitaba implementar las reformas educativas que otros países ya habían realizado.

Producto de estos sistemas educativos, Carmen de Burgos propone un modelo de mujer, que mediante una instrucción más adecuada es a su vez, una mujer trabajadora educada. Para ello, pone como ejemplo a la mujer del cónsul de España en Florencia que escribe poemas en inglés y los publica en Londres y América (395). Con este ejemplo expone una doble realidad. Primero, presenta a una mujer educada, escritora y que es la mujer del cónsul español. Este hecho pretende acercar, no sólo geográficamente al lector;

\footnotetext{
${ }^{28}$ La primera mujer que empezó y terminó la carrera en la Universidad de Valencia se llamó Manuela Solís. Se matriculó en la Facultad de Medicina en el curso 1882-1883 a la edad de 20 años, aunque no le permitieron asistir a clase hasta 1889. Se doctoró en Medicina en Madrid en 1905. Al curso siguiente se le unió Concepción Aleixandre.
} 
sino étnicamente ya que se trataba de la esposa de un español. En segundo lugar, pone de relieve que la escritora utiliza la lengua inglesa para escribir y publicar sus poemas. $\mathrm{Si}$ bien es posible que esta escritora no supiera hablar ni escribir ni en italiano ni el español, lo que Carmen de Burgos quería resaltar era el hecho de que los países anglosajones iban a aceptar mejor la producción literaria de una mujer ya que de Burgos los consideraba más desarrollados y en donde los procesos de emancipación de las mujeres estaban más aventajados. También propone como modelo a mujeres de la talla de Matilde Serão, anteriormente mencionada, que no sólo es una mujer altamente instruida, sino que es una mujer que gracias a su educación puede desempeñar un trabajo respetado en el mundo intelectual. La nota fundamental, no está en estas mujeres que se podrían tener como la élite intelectual femenina, sino la mujer de clase media a la que de Burgos resalta constantemente. Son las cigarreras, las bordadoras, las maestras, etc a las que la autora dedica gran parte de su atención y son éstas las que mediante una educación más profesionalizada, pueden participar de forma más activa en la vida de cualquier país.

De esta forma, Carmen de Burgos une la idea de una mujer culta e instruida con la mujer trabajadora. Carmen de Burgos aboga por una mujer independiente, trabajadora, que se equipare con el marido en el campo laboral. Este tipo de mujer es la del ejemplo que se ha mencionado anteriormente de las trabajadoras parisinas que anteponen el trabajo al matrimonio y hacen de éste un contrato laboral. Mediante esta mujer trabajadora, la autora intentaba resaltar las posibilidades de poner en práctica en España una serie de actividades laborales autóctonas como las textiles, las agrarias o las educativas, pero esta vez con una formación más adecuada. La autora describe a las muchachas italianas que realizan trabajos en la industria del tabaco. A estas mujeres las 
compara físicamente con el tipo de la española. De esta forma, son presentadas como altivas, alegres y felices: "Son las mismas muchachas airosas de nuestro pueblo [las que trabajan en la fábrica de tabaco], con la falda corta, alto el tacón de la botina, descubierta la cabeza con rizos obscuros, y el cuerpo envuelto... jen el mantón de Manila!"(444). Con esta descripción lo que intenta hacer de Burgos es criticar la situación de miseria en que se encuentra la andaluza y por ello la compara físicamente con la italiana. En este sentido, la autora hace hincapié a lo que ya mencionó de la educación en Suiza. La falta de educación es lo que lleva a la miseria de un pueblo. Un pueblo solamente se redime de esa miseria con un mayor nivel de educación. La autora pretende resaltar la deficiencia de la instrucción y preparación de las andaluzas que no les ha sido posible integrarse a la vida laboral por falta de una instrucción especializada y una mentalidad retrógrada y esa misma falta de educación es la que las mantiene en un estado permanente de miseria.

También refiere la importancia que tenía el trabajo para el italiano y la forma en que éste estaba representado en la Exposición Universal, a la que España no asistió. Describe en detalle la labor de las cigarreras, de aspecto físico también igual a las españolas. Esta actividad se presenta en el texto de forma dulcificada: "Son unas italianitas preciosas, de ojos negros y caras aterciopeladas, enrollan con manos de niña las pardas hojas del tabaco para hacer los puros y cigarrillos" (491). La sensibilidad con la que describe este cuadro manifiesta, por un lado, que cualquier mujer podía hacer este tipo de trabajo ya que estas mujeres son casi niñas, o al menos, tienen manos de niña; y por otro, que mediante la descripción física de la cigarrera, la mujer no perdía la feminidad propia de su género al trabajar. Hay que tener en cuenta que el oficio de cigarrera, ya a finales del siglo XIX, junto con la industria textil, estaba constituido 
mayormente por mujeres. El caso específico de la cigarrera se convirtió en un objeto de inspiración para numerosas obras literarias como La Tribuna de Emilia Pardo Bazán de 1882, o el caso más famoso, Carmen de George Bizet de 1875, cuya heroína era una sevillana cigarrera; pasando por sainetes y zarzuelas y haciendo de esta trabajadora un objeto esteriotipado.

También describe otro caso de trabajadoras que se dedican a la industria del encaje, la otra industria básicamente femenina. De Burgos, mediante la explicación que hace de este tipo de industria en Venecia, propone una formación profesional para la mujer y la compara con un lugar específico en España, Almagro (443). Esta sugerencia de la autora tiene una contrapartida: la iglesia. De Burgos argumenta: "Pero renace un germen de decadencia y de ruina; las monjitas, con el pretexto de velar por la moralidad de las obreras, han empezado a entrometerse como maestras y acabarán por el acaparamiento de la lucrativa industria" (444). Es evidente que textualmente ataca de nuevo a la Iglesia que, con la intención de educar, lo único que quiere es el beneficio económico. Con esta cita pide un cambio y advierte de la existencia de un problema que para la autora es fundamental porque ha llevado a España al retraso que sufría. La Iglesia es, para de Burgos, la que ha influido más en ese retraso del país y es, además, una fuente de corrupción. La consecuencia categórica implícita en esta cita es el hecho de que si la Iglesia se hace con el dominio de esta industria, acabará con ella y con los avances que pudiera suponer para la mujer. Al mismo tiempo, plantea una solución. Si bien la Iglesia es un impedimento para el progreso, también puede haber otro estrato social que lo redima. En este caso propone que el estamento aristocrático femenino invierta su dinero, al igual que hacen las venecianas, para la financiación de escuelas de formación artesanal 
para las mujeres (174). ${ }^{29}$ De esta forma, se crearía, por un lado, una conciencia colectiva femenina para ayudar a mejorar la situación de género; y por otro lado, cambiaría de forma sustancial el panorama social español puesto que se desligaría considerablemente la relación de las aristócratas con el estamento eclesiástico. Hay que tener en cuenta que las donaciones de mujeres a la Iglesia eran bastante considerables, lo que permitía una relación estrecha de la jerarquía eclesiástica con este estamento social y repercutia en el dominio omnipotente de la Iglesia en la implantación de una moral mojigata en estas mujeres. Y esta moral mojigata es lo que impedía la aceptación de las nuevas corrientes que podía renovar la situación de la mujer

A su vez, se percibe una contrapartida en el texto en relación con esta mujer trabajadora. Carmen de Burgos pretende instruir a la mujer de clase media o baja para realizar unos trabajos que le sean propios; esta educación profesional le va a proporcionar una mayor independencia económica y una mejora en su calidad de vida. Pero, a su vez, Carmen de Burgos se da cuenta de las consecuencias que podría acarrear una posición demasiado radical y es por ello que, en algunas ocasiones intenta aminorar el efecto de sus pensamientos y utiliza la visión tradicionalmente aceptada por el poder patriarcal al proponer como misión fundamental de la mujer, el educarse para ser compañera, esposa

\footnotetext{
${ }^{29}$ No es esta la primera vez que Carmen de Burgos en el libro, alude a la financiación de las damas aristocráticas a algún aspecto de la vida cultural e intelectual de sus ciudades. En la página 176, la autora apunta a las donaciones que hacen estas mujeres para el embellecimiento de la ciudad, en lugar de dárselo a los religiosos que para nada lo necesitan y, al mismo tiempo, insta a las españolas ricas a que sigan su ejemplo. De Burgos dice: "La duquesa viuda, cuyo busto he visto en el municipio, no pensó en ganar el cielo por la donación de sus riquezas a los frailes, y prefirió el engrandecimiento de su ciudad y el alivio de los pobres. Es un ejemplo que sería digno de ser conocido por nuestras ricas devotas, si ellas fueran capaces de apreciarlo en lo que vale" (176).
} 
fiel y madre. Hay que tener en cuenta que en el momento de publicación de este libro todavía las mujeres tenían que expresar una serie de estrategias para no ser criticadas. De esta forma, la autora se valía de argumentos en los que proponía la educación de la mujer como instrumento de mejora de su posición dentro del círculo familiar tradicional. De Burgos era consciente que la única forma de convencer a la sociedad patriarcal de la necesidad de mejorar la educación de la mujer era mediante el convencimiento de que la educación femenina suponía la mejora de la familia. Esta estrategia se percibe claramente en el expediente que entregó de Burgos a la Administración Pública:

Para concluir me ocuparé de lo que yo creo el punto más importante de la educación de la mujer: la enseñanza del hogar. No debe entenderse por esto que para dueña del hogar la mujer necesita sólo la práctica de las labores caseras. No. La directora de la familia, compañera del hombre y educadora de la infancia; necesita conocer las arte, ciencias, las leyes, todo lo que necesita saber la maestra o la artista y además el modo de dirigir y administrar una casa, la economía doméstica, la higiene de los alimentos y de los individuos y la práctica de las labores caseras para saber disponerlas o ejecutarlas según la necesidad. (64-65)

En este sentido, en Por Europa, expresa con escándalo la situación de la parisina que preocupada en exceso de su toilette antepone esta práctica a su misión de madre y abandona a los hijos a que se eduquen lejos de ella. Carmen de Burgos dice que estas mujeres: "son esclavas de la toilette... incapaces de comprender que pudieran ser más felices vestidas de percal en un hogar modesto entre el amor y las sonrisas de sus hijos" (50). La civilización que percibe la escritora es una sociedad abrumadora donde no hay 
tiempo para la familia. Las mujeres ricas son vanidosas y envían a sus hijos a educarse al campo porque está de moda y, de igual manera, las mujeres de clase media se despreocupan del problema de los hijos para dedicarse únicamente al trabajo y a fortalecer su economía:

¡Los hijos! Se ven aquí pocos niños; tan pocos, que el Estado se alarma con la despoblación de Francia. Es consecuencia de la vida vertiginosa y de las costumbres. Las familias ricas los envían por moda a educarse al campo; la madre antepone el culto de su propia persona y los cuidados del tocador al deber para con sus hijos, creyendo que su fuerza reside en su hermosura. En la clase media la mujer trabaja en la oficina como su marido; no he visto en ninguna parte tantas mujeres empleadas como aquí; están en los comercios, en los cafés, en las oficinas, en todas partes; el matrimonio no tiene más que un fin económico. (50-1)

Si nos atenemos a un análisis meramente textual y no prestamos atención a la vida personal de la autora (divorciada, madre soltera y trabajadora que provee para su familia), nos encontramos nuevamente con la tensión que se percibe en el texto entre la imagen de la mujer tradicional "ángel del hogar" y la mujer trabajadora. Por un lado, Carmen de Burgos es defensora del divorcio, entendiendo éste como la ruptura del matrimonio y la afirmación del derecho de igualdad de la mujer frente al hombre y, por otro lado, protege el núcleo familiar y la misión subsidiaria de la mujer dentro del matrimonio. Esta visión que parecería a primera vista contradictoria responde a la visión que se tenía de la mujer a principios de siglo. La autora no es ajena a su tiempo y quiere resaltar el valor de la mujer trabajadora y educada como forma esencial de su incorporación a una sociedad más 
moderna e igualitaria; pero también, es consciente del efecto que produciria una visión muy radical dentro de una sociedad tan tradicional como la española y es por eso que son tan constantes esas técnicas para, como se ha mencionado anteriormente, aminorar las posibles críticas sobre sus ideas.

En esta cita, primero, se alarma de que no hay niños en Francia por la vida vertiginosa que llevan sus ciudadanos y por la despreocupación de las mujeres por sus hijos; y segundo, utiliza un lenguaje de admiración en cuanto a la diversidad de trabajos que ejercen las mujeres y en cuanto a la cantidad de participación de ésta en la vida laboral a la par que el hombre. El caso de la mujer rica es claro ya que, para Carmen de Burgos, es inexcusable que una mujer anteponga su misión de madre, al cuidado de su "tocador;" pero en el caso de la trabajadora de clase media, es diferente. No tiene hijos porque trabaja a la par del hombre, pero, a su vez, el trabajo la redime. Se asombra y se alegra de que tenga una situación laboral igualitaria al hombre e, incluso, muestra con cierto agrado ese contrato matrimonial lógico y económico que para la mentalidad tradicional española de principios de siglo XX sería una completa aberración. La tensión se acentúa si tenemos en cuenta las palabras que pronunció en la Conferencia que emitió a su paso por Roma:

Yo entiendo que la participación de la mujer en el trabajo no es un progreso de las sociedades, sino un retroceso. En una sociedad perfecta, donde exista la buena distribución del trabajo, á la mujer le estaría sólo encomendado el de la guarda del hogar, no el de las oficinas ni las fábricas. 
El trabajo de la mujer casada debería ser siempre sólo para ayudar á la familia, nunca con detrimento de sus deberes de madre. (La mujer 21)

Para Carmen de Burgos no existen sociedades perfectas en donde la distribución del trabajo sea también perfecta. En esta cita, la autora está hablando de una sociedad utópica en la que existe una distribución del trabajo perfecta. Producto de esta perfección laboral, la mujer casada debe dedicarse absolutamente a las labores del hogar. Al no existir esas sociedades utópicas, la autora muestra la tensión que produce una mala distribución laboral para la mujer. En otras palabras, si no existe una distribución perfecta del trabajo, la mujer no debería dedicarse exclusivamente al hogar, sino trabajar a la par del hombre.

Más adelante, nuevamente se aprecia otra tensión cuando admira la sencillez con la que se realiza el contrato matrimonial civil y la simpleza con que el juez explica los deberes y obligaciones de los nuevos cónyuges y la posibilidad de romper esos lazos civiles una vez haya concluido o haya sido este enlace desfavorable para una o ambas partes. Son frecuentes en Por Europa las alusiones adversas a la santidad y la indisolubilidad del matrimonio, ello permite afirmar que la autora aboga por una unión lógica y no sagrada. Carmen de Burgos lo comenta diciendo:

las que quieren enviudar, piden la muerte de su consorte arrojando piadosamente un alfiler negro. Tal vez coincidan muchas veces en la misma súplica los dos cónyuges. Esto es consecuencia lógica del sacramento que produce la gracia desunitiva y sólo la muerte puede romperlo. El día que yo miré por la rejilla había muchos alfileres negros. (222) 
La tensión entre el matrimonio y la mujer trabajadora se disipa aparentemente al final del texto cuando la autora expresa su ideal de unión matrimonial perfecta al describir la relación que mantienen sus amigos de Barcelona, Pelayo Vizuete y su mujer: "verdad que su amable y bella esposa no es la hembra sino la compañera, y su misión es la de dos intelectuales que trabajan juntos y tienen comunión de ideas y sentimientos. ¡Son tan raros estos ejemplos!" (497). La autora pretende acoplarse, aunque sea parcialmente, con el ideal de feminidad defendido por el sistema patriarcal español de principios del siglo $\mathrm{XX}$ y, por ello, propone a la mujer intelectual dentro del núcleo familiar. La mujer de Vizuete es la esposa perfecta que produce, a su vez, la unión perfecta entre compañeros intelectuales. De esta forma, no produce tensión en sus lectores al mostrar un moderantismo en la figura de la esposa educada y perfecta compañera del marido, ni produce una ruptura abierta al discurso patriarcal.

Nuevamente, volvemos al tema principal del este estudio: la educación. Ésta suponía la base fundamental sobre la que giran todos los aspectos relacionados con la mejora de las condiciones de las mujeres. Es por eso, que aunque implícitamente, la autora no inserte la forma en que se debía de ejecutar estas mejoras educativas en el libro, intrinsecamente sí lo hace mediante las referencias a las ocupaciones de las mujeres en los dos países que describe en este libro de viajes. Donde claramente sí expone cómo se debía de llevar a cabo estas mejoras educativas es en la conferencia que pronunció en la Asociación de Prensa de Roma y en las memorias que entregó a la Administración de Instrucción Pública ya que en estas dos ocasiones la autora destinaba sus interlocuciones a un público especializado. A su vez, en ambas ocasiones la función fundamental era la de informar especificamente de los temas relativos a la educación de la mujer. Por el 
contrario, los libros de viajes estaban destinados a un público general y las disertaciones concretas y específicas sobre la instrucción de las mujeres eran solamente un elemento más de la concienciación sobre la necesidad de reformar el sistema educativo para permitir una mayor igualdad de la mujer en la vida social, cultural y política del país.

De esta forma, en la conferencia de la Asociación de Prensa de Roma, la escritora solicita la necesidad de educar a las mujeres según su clase social y para ello pide "de un modo imperioso la necesidad de mejorar, educándola, la suerte de la campesina" (19). Esta educación seria mediante la creación en España de escuelas de agricultura como las ya existentes en Inglaterra. Pero sin olvidar que debe de existir una división clasista del trabajo de la mujer: "La hija del aldeano debe recibir una instrucción a la vez técnica e industrial; la del rico hacendado necesita cultura para dirigir su casa y ser compañera del padre, el hermano o el esposo en la vida comercial y rural" (20) y las mujeres de clase alta, para Carmen de Burgos: "Se educan con institutrices extranjeras o en el convento; tienen, pues, una educación más brillante que sólida" (33). En definitiva, su comunión entre la mujer y el trabajo es el ideal que tiene de "la Nicolasa" de Matrimonios Morganáticos de Max Nordeau. Éste propone que la mujer se debe educar en la escuela, pero también propone que se debe educar a la sociedad que la rodea. Carmen de Burgos lo explica diciendo:

Para mí el ideal de la educación de la mujer lo he encontrado en la Nicolasa... Es el tipo ideal de mujer moderna, dulce y fuerte, que ama y piensa, con conciencia perfecta de sus derechos y deberes. Pero este carácter no se forma en la escuela, es preciso que sea igual todo el medio 
ambiente, que la sociedad sea libre sin perjuicios ni preocupaciones. (La mujer 33)

Es evidente que esta aparente contradicción en su manera de pensar en cuanto a la mujer trabajadora y a la esposa que trabaja suponía un modelo conciliatorio entre el ideal del "ángel del hogar" y la mujer liberada y, a su vez, una forma de entrar en el discurso tradicional masculino imponiendo la visión de una nueva mujer que es a la vez buena madre y esposa y trabajadora independiente. De igual manera, esta forma de expresarse ante la Administración de Instrucción pública era una combinación de lo que ella pretendía cuando hablaba de su ideal de la Nicolasa. Esta nueva mujer que proponía Nordeau debía educar, por un lado, a la sociedad para que admitieran el nuevo modelo de mujer compañera, madre y educadora utilizando un acercamiento retórico en los mismos términos que el hombre (sociedad en términos generales de la época) entendía: compañera y madre sumisa. A su vez, esa sociedad debía de aceptar el rol de la mujermadre y esposa y adaptarlo a las necesidades educativas de ese momento para enfatizar la necesidad que ésta tiene de un aprendizaje más especializado. Este aprendizaje la llevaría a mejorar su misión de madre, esposa y compañera de una forma más efectiva. De esta forma, el lenguaje se convertía en una estrategia puesto que la autora sabía que debía aceptar un discurso masculino para adquirir la autoridad de que carecía como mujer. Así en sus escritos, utilizaba una retórica masculina para intentar implementar unas mejoras que la afectaban directamente. En segundo lugar, el modelo de la Nicolasa proponía la educación de la mujer en cuanto a la misión más activa que debía desarrollar dentro del matrimonio. 
Finalmente, Carmen de Burgos expresa una duda al no tener la certeza de que su trabajo como pensionada por la Administración fuera suficiente para producir un cambio en el sistema educativo del país. Esta duda la enuncia primero en su entrevista con Nordeau. Éste le pregunta: "Entonces, ¿espera usted que su viaje pueda servir para la reforma de la enseñanza femenina? Eludí la respuesta, sirviéndome de base sus palabras para hablar del admirable tipo ideal de la mujer moderna que ha sabido crear en la Nicolasa de Matrimonio Morganáticos” (84). Y más tarde lo afirma cuando expone: “... no me atrevo a esperar si mis observaciones pesen para nada en el ánimo de los que las lean... Si las leen" (204). Es por ello que hace público parte de sus viajes como forma de no quedar silenciada.

Esta duda implica una posición ante la sociedad de principios de siglo. Por un lado, es consciente de que los avances en la educación de la mujer requieren un proceso más lento y una concienciación extensiva en la sociedad española; pero por otro lado, a pesar de que no piense que sus esfuerzos vayan a tener una recompensa rápida, no quiere decir que su texto no sea un ejemplo de reivindicación de los derechos de la mujer; todo lo contrario, su texto se convierte en subversivo al intentar irrumpir en el discurso tradicional masculino con una voz pública que se afirma de forma femenina y feminista y que, no sólo critica de una forma directa al país, sino que propone soluciones concretas a problemas concretos. De esta forma, son evidentes sus últimas palabras al final del libro ya que hace una petición con la esperanza ferviente de que su trabajo suponga un grano de arena que pueda llevar al cambio. Se siente luchadora por lo que cree es justo y esa lucha es para ella, su vida. De Burgos argumenta: 
Dentro de pocos días estaré de nuevo en Madrid; ahí me espera el trabajo, la constante lucha... la eterna rebeldía que levanta mi pensamiento contra el terrible fardo de prejuicios, convencionalismos y miserias que nos oprimen. Luchar contra esa montaña, desquebrajarla, abrir en ella surcos para que germinen la Justicia y la Libertad, es un empeño semejante al que hizo salir a D. Quijote a los campos de Montiel. Lo sé. Sé que las fuerzas de una mujer no removerán la montaña, pero acaso le arranque un grano de arena y enseñe a otros el camino... La lucha es la vida y yo siento el ansia de vivir. (502-3)

Esta cita se convierte en la clave de sus aspiraciones reivindicativas de la mujer y supone, a su vez, una petición feminista en cuanto al hecho de pedir justicia y libertad para las mujeres. Por un lado, se muestra como una mujer trabajadora que lucha constantemente contra los perjuicios de la sociedad patriarcal estancada para liberar a la mujer de una sociedad que la oprime. A su vez, lucha por un sistema más libre e igualitario para la mujer. De esta forma, deshace definitivamente el ideal del "ángel del hogar" en el sentido de solamente con la mejora en la educación de la mujer, se puede confeccionar un hogar mejor, sino que propone una mujer que lucha constantemente por implementar una sociedad donde "germinen la Justicia y la Libertad". Su discurso se hace utópico como el de don Quijote y tiene como misión la búsqueda de adeptos ya que pretende enseñar "a otros el camino" para que sigan su lucha reivindicativa de los derechos de la mujer y protejan su ideal. 


\section{CAPÍTULO III}

\section{SEGUNDO VIAJE. CARTAS SIN DESTINATARIO (1911). ${ }^{30}$}

Carmen de Burgos en sus memorias explica la necesidad que tiene de viajar de nuevo ya que para ella el viaje suponía el mayor de los descansos. De esta forma, la autora explica que: "Van a llegar las vacaciones escolares de verano y necesito más que ningún otro año un descanso. $\mathrm{Y}$ como ya se intuye, el mejor sosiego lo alcanzo viajando. Bélgica, Holanda y Luxemburgo, pasando de nuevo por París, es mi nuevo itinerario" (Utrera 209).

A pesar de que Cartas sin destinatario no tiene fecha de publicación, sabemos, por las memorias que ha recogido Utrera, que viajó en el verano de 1911. Este año fue un año lleno de cambios para la autora. Primero, consiguió la plaza de maestra en la Escuela Normal de Madrid; siguió colaborando asiduamente en el diario El Liberal y participó en la revista Alhambra de Granada. El editor valenciano, Sempere, continuó encomendándole traducciones que le suponían una entrada más en su ajustado salario (Utrera 199); escribió dos libros, uno La voz de los muertos y Cartas sin destinatario y una novela corta, El honor de la familia, que habla sobre la intolerancia de los clérigos en una ciudad provinciana. A pesar de su actividad literaria y docente, Carmen de Burgos viajó en el verano de 1911 y después recogió sus experiencias personales de su viaje por Bélgica, Luxemburgo y Holanda y las hizo libro.

${ }^{30}$ El análisis que se ha hecho de este libro difiere un tanto del anterior. Éste se ha dividido en secciones que corresponden a los países que Carmen de Burgos visitó. 
La estructura de este libro difiere un tanto del anterior. A pesar de que mantiene la forma epistolar, ésta es más simplificada. El libro está dividido en 31 capitulos en números romanos y con título, que pretenden ser cartas dirigidas a un interlocutor desconocido, en apariencia, donde el lugar y la fecha de cada una de estas supuestas cartas han desaparecido. Cartas sin destinatario tiene una serie de rasgos estructurales específicos que lo diferencian de Por Europa.

En primer lugar, el título del libro nos hace pensar en el deseo de la autora de dirigir este libro a un público en general, desconocido y universal. Esta incógnita era sólo una técnica narrativa que utilizó la autora para desplazar la atención del verdadero destinatario de su libro: "Voy escribiendo mi diario del viaje, que servirá para mi próximo libro al que titularé Cartas sin destinatario. Un embuste más en mi vida, porque el destinatario existe, no puedo evitar pensar en él, y estoy muy cerca suya" (Utrera 209). La relación que mantiene la escritora con Ramón Gómez de la Serna es muy intensa en esa época y es un reflejo evidente en su obra. Pero si nos atenemos al análisis del discurso de superficie que propone Michel Foucault, que no existe ninguna realidad escondida dentro de un texto, sino diferentes interpretaciones y tampoco existe un sub-texto, sino lo que se ve superficialmente $(1992,119)$, debemos de interpretar el texto de Carmen de Burgos de la misma manera; es decir, según la realidad textual superficial del texto en sí. En este sentido, el anonimato del destinatario del texto se va desvelando según se analiza éste. De esta forma, a medida que nos adentramos en su lectura, nos damos cuenta, por las constantes referencias en el libro, de que sí tiene un destinatario muy concreto. De Burgos quiere esconder su interlocutor en una ola de misterio; Concepción Núñez Rey dice al respecto: "[aparece] un interlocutor invocado por la autora, pero esta vez lo 
envuelve el misterio, no es identificado" (167). Desde el primer capítulo, Carmen de Burgos nos muestra a un destinatario que pretende ser un ente o ser interior. La autora argumenta: "se le escribe al ser que va en nosotros y que no ha podido, porque está muy hondo, gozar las emociones que nos conmovieron" (6). A la vez, nos está diciendo que su destinatario es el "genio familiar" que "vive en nosotros y lejos de nosotros" (6). Este genio familiar conforma una trinidad mística que es descrita como "ese ser anónimo y amado, cuyo rostro no hemos visto, que tiene todos los rostros y crea una nueva Trinidad mística" (6). La utilización del "genio familiar," no es nueva; la autora utiliza ese mismo concepto en la novela que publicó ese mismo año, La voz de los muertos. En este libro, el "genio familiar" funciona como un ente imaginario que dialoga con el narrador y funciona como conciencia de la voz narrativa con la función de desvelar el pensamiento de la autora.

En el caso específico de Cartas sin destinatario, el uso de ese genio familiar es una tapadera inicial que deja paso rápidamente a la evidencia de un destinatario concreto. Este destinatario se va mostrando textualmente por la aparición de una serie de recursos narrativos que la autora va presentando. Primero, se va percibiendo un sentimiento de soledad en la nostalgia del país natal que nos lleva a dilucidar a esa persona a la que va dirigida el libro. Al final de este primer capítulo o carta, la autora siente la añoranza de España y por primera vez, su destinatario se hace concreto en la expresión de: "Me siento triste, y por eso te escribo mi primera carta" (9). Ya el destinatario no es desconocido y universal, se nos muestra a un ser concreto al que la autora le tiene un cariño especial al relacionar la tristeza que siente con el alivio de escribirle una primera carta. Esta referencia concreta se va especificando y en el segundo capitulo se hace más evidente 
cuando la escritora hace referencia a las bañistas que muestran su cuerpo medio desnudo y siente celos de que su amado pudiera ser uno de esos hombre que las devoran con los ojos. Carmen de Burgos expresa el sentimiento que siente por ese narratario concreto al mencionar: "Yo he sentido celos pensando en ti, en el bien amado; me ha parecido que la veías, que me eras infiel como todos esos hombres a sus amadas y he tenido miedo de no saber perdonar" (15). O más adelante, sigue buscando a su amado en la añoranza: "buscarte a ti en la ciudad silenciosa donde paseo sola mi tristeza" (20) e incluso intercala referencias biográficas concretas como: "Hoy he tenido carta de España" (69). Mediante la revelación paulatina de este interlocutor, le va dando al texto una autoridad narrativa ya que lo va acercando al lector al concederle un grado de sentimentalismo y subjetividad a su texto. A su vez, le está confiriendo a la narración una nota de realismo puesto que muestra datos supuestamente reales y concretos como el hecho de recibir una carta o sus sentimientos hacia ese interlocutor. De esta forma, crea un libro de viajes, que son además cartas de amor. La autora crea un doble género epistolar: el del viaje y el de amor El hecho de que en el libro se intercalen tres personas es muy curioso. En primer lugar, utiliza un yo que hace referencia al estado emocional de la autora y a la relación personal que mantiene con el narratario. Este yo está cargado de sentimentalismo y evocaciones románticas de la autora, así como de referencias a su soledad y a sus estados de ánimo. En otras palabras, muestra la relación que mantiene el yo narrativo con el enamorado. También, aparece un nosotras que se trata de un referente concreto a tres personas: la autora, su hija y la amiga que las acompaña: "Rafaela Sánchez Aroca saca sus pinceles y empieza a pintar" (196). Mediante el uso del "nosotras," la autora describe los lugares por los que está pasando y hace explicaciones específicas de museos, pinturas, 
edificios de interés o cualquier lugar concreto por el que pasean y, al mismo tiempo, hace referencia a la percepción que tienen las tres viajeras de estos lugares.

Existe otro "nosotros," más reflexivo, que hace referencia a una colectividad; en este caso, ese nosotros representa a los españoles bajo la perspectiva de Carmen de Burgos. Desde la primera página, la autora nos muestra esa colectividad diciendo: "Hay que decir todo esto que llevamos en el fondo de la conciencia con el dualismo de los sentimientos y la razón, en las mil sensaciones hijas de la pluralidad de nuestro espíritu" (5). Ese uso del nosotros muestra claras reflexiones sobre las diferencias que la autora encuentra entre los meridionales, es decir, los latinos y los europeos del norte. La autora menciona estas diferencias diciendo: "En estos temperamentos belgas la Historia hace poca impresión: se limita a saberla. En nosotros, los meridionales, marca una huella indeleble; nosotros no la sabemos sólo, nosotros la sentimos. Ellos aprenden la Historia con el cerebro, nosotros con el corazón" (20).

El texto no presenta referencias cronológicas concretas. Al contrario de Por Europa, aquí cada capítulo no termina con el lugar y la fecha, sino que se hace un recorrido más reflexivo en donde las circunstancias materiales y prácticas del viaje son menos frecuentes que en su libro anterior (Núñez 169). A pesar de que no se vea claramente el tiempo del libro, de Burgos hace alguna referencia aislada de un momento o tiempo especifico. Por ejemplo, cuando observa que: "Todo Julio es fiesta aquí, y hoy, noche de domingo, se engalana ante mí este lugar de duelo" (124). Por otra parte, el tema de la estética es bastante frecuente en el texto y es propio del periodo modernista y de la Generación del 98. La autora refleja su pasión por lo estético al hacer constantes 
referencias a sus preferencias artísticas, especialmente en pintura ya que las digresiones sobre cuadros y pintores ocupan una parte importante del mismo.

Este texto técnicamente difiere del anterior. Por un lado, según Núñez Rey, en su pretensión de objetividad informa sobre la realidad de las sociedades; incluye numerosos datos estadísticos y técnicos de la economía de los países. Por otro lado, emplea unas formas de lenguaje subjetivo, típicas del modernismo, para referir las emociones estéticas. La autora describe el paisaje belga como si se tratara de un cuadro impresionista y plasma estas impresiones de la siguiente manera:

El cielo está aquí más cerca del suelo, se aploma en fajas de nubes grises, por zonas, que sin ocultar el disco de luz lo amortiguan, lo enfrían, lo hacen pálido primero; amarillo rojizo después; sin rayos ni lumbre. Brilla con un claror lunar, como un objeto iluminado de lejos, y la Naturaleza toda se envuelve en una tonalidad melancólica, acuosa. (6)

Asimismo, utiliza un lenguaje pre-surrealista con expresiones formales y estéticas puramente vanguardistas como el párrafo siguiente:

Miro al cielo. Corren nubecillas ligeras; muy blancas y tenues...Son pedazos de estatuas rotas...Veo un campanario gótico; un rey sin rostro, con corona y vestiduras flotantes...dos trenzas largas...Deben de ser de mujer rubia...Un guerrero sin cabeza y con armadura... animales extraños; flores y plantas gigantescas. Un sepulcro con un figura yaciente; una mitra; las faldillas de gas de una bailarina sobre dos piernas de mármol... El sueño y la realidad se han confundido; el pasado y el presente se han 
mezclado. No veo ya los paisajes reales, sino los paisajes de las aguas y las nieblas. (210)

El libro tiene ciertos reflejos de la influencia de las greguerías de Ramón Gómez de la Serna. Carmen de Burgos las refleja de esta forma: "La vela latina es una joya en el prendido de gala del Océano" (11) o también cuando dice: "un interior que se sorprende tiene el encanto de un libro que no se ha leído" (239). Blanca Bravo Cela ha percibido esta tenue influencia de las greguerías de Ramón Gómez de la Serna y explica: " $<$ como las flores del almendro en la sonrisa de la primavera $>$. ¿No es ésta acaso una greguería? Indudablemente Carmen está pensando en Ramón cuando escribe y le hace un pequeño homenaje" (151).

Carmen de Burgos utiliza el perspectivismo al describir los espacios físicos. La escritora describe estos espacios intentando mostrarlos "sin contaminaciones" (Bravo 172). Se entremezclan los distintos puntos de vista al describir lugares y utiliza una técnica que se asimila a la cinematográfica al describir la catedral de Santa Gadula en Bruselas mostrándola desde fuera como si el objetivo la estuviera emplazando desde la periferia hasta su fachada; después, describe el interior para, finalmente volver al exterior e invitar al lector a visitarla. De Burgos hace participe directo al lector cuando le hace un llamamiento directo al indicarle: "Pero salgamos" (118). A su vez, presenta un punto de vista subjetivo en la descripción de esta catedral en la que se entremezclan las reflexiones personales de la autora acerca de la intolerancia religiosa y los crímenes en nombre de Dios:

Indigna ver en la cuarta ventana... la leyenda de aquellos judíos que robaban hostias para matar de nuevo en ellas á Jesús. Las formas dejan en 
pos de sus pasos un reguero de sangre al ser heridas por los puñales, $y$ descubierto el crimen por el milagro, los culpables son condenados a muerte. Se siente deseo de pasar una esponja húmeda y borrar los colores que perpetúan esa patraña a cuya sombra cometieron tantos crímenes.

A pesar de que el tono es mucho más moderado que en Por Europa, se percibe aún la denuncia sobre temas que le incumben de una forma intensa. La denuncia que Carmen de Burgos manifiesta en Cartas sin destinatario no es una denuncia directa como en el libro anterior, sino que, en este caso, intenta presentar los hechos sin enjuiciarlos abiertamente para mostrarlos en forma de digresiones personales. Los problemas a los que hace referencia siguen siendo los mismos: la religión, la mujer y su situación, las estructuras sociales y políticas y la educación.

La educación, en este viaje, no se presenta de la misma manera que en el anterior puesto que esta vez no viaja pensionada por el gobierno, sino por placer y por descanso. Para Carmen de Burgos, la originalidad de este viaje reside en reflexionar sobre Europa sin mediatizaciones: "Por fortuna, no viajo pensionada por el gobierno para tener que visitar escuelas pedantes y ver cómo nos preguntan candorosamente delante de un tablero contador: "-Usted no habrá visto estas cosas en España" (70).

A pesar de que el propósito de su viaje sea diferente, su pronunciamiento a favor de los ideales educativos del momento es mucho mayor que en el libro anterior ya que en el momento de redacción de este libro, la autora estaba libre de las cohibiciones gubernamentales que tenía cuando redactaba el anterior y, a su vez, el hecho de que escribiera el libro por placer, seleccionando los países que la autora quería visitar, hace 
que esta narración posea una mayor libertad narrativa para expresar sus opiniones. En este sentido, se pronuncia libremente a favor de la necesidad de la educación de la mujer y no se pone trabas para expresar su opinión sobre la mala instrucción gubernamental en el subdesarrollo intelectual de la mujer. En una conferencia que pronunció en Bilbao el 18 de febrero de 1911, Carmen de Burgos argumenta:

El problema de la libertad de la mujer queda demostrado que es sólo de educación...El arte de enseñar a enseñar apenas existe; pomposamente llamamos Pedagogía a los conocimientos rutinarios que poseemos...Lo escaso y mísero de las escuelas españolas lo sabéis todos. Lo único raro es que se sepa y se tolere. (Misión 12)

También reflexiona sobre la libertad que le da el hecho de viajar por placer y la libertad que tiene de poder criticar al gobierno que impone unos reglamentos específicos a los pensionado que buscan instruirse en las nuevas técnicas pedagógicas extranjeras: "Por fortuna, yo no traigo las terribles ocupaciones pedagógicas y puedo irme a pasear a los bosques" (129).

A pesar de que se percibe un cierto recelo hacia las escuelas europeas y la supuesta superioridad frente a las españolas, tema que se irá deshilando en el análisis de la obra, su interés por todo lo que supone la mejora en las condiciones educativas se refleja en sus obras de una forma bastante marcada. La primera mención que la autora hace sobre la educación de los niños es acerca de los hospicios. En este sentido, se percibe la influencia de los postulados educativos krausistas en cuanto a la educación del niño. Para Sanz del Río, se debía crear un ambiente familiar en todo centro educativo y, para ello, la escuela se convertía en una extensión del hogar. La educación debía ser una 
continuación de la vida familiar y era necesario que el niño volviera al seno familiar todos los días para "[que no] perturbe, ni mucho menos suprima, sino excepcionalmente, la insustituible vida familiar, sagrado e inviolable asilo de las intimidades personales" (Programa de la Institución Libre de Enseñanza 1934, 65). En este sentido, de Burgos reflexiona sobre la tristeza del niño sin hogar y la falta de sentimiento familiar que tienen los hospicios en general y concretamente el hospicio de niños de Roger de Grimbergher en la ciudad belga de Mariakerke. La autora expresa el alma de los hospicios en los que se ha de uniformar al niño por dentro y por fuera porque en ellos no hay cabida para la individualización:

¡Cómo apena el alma de un hospicio! Un edificio grande que hace añorar el calor del hogar de todas las casitas pequeñas. Se deben de sentir muy solos esos niños... Todos son iguales, se marca en todos los rostros una expresión común; oyen decir siempre las mismas cosas; se les uniforma el espíritu con el vestido... Es triste que la sociedad haya tenido que almacenar los hijos sin madre en un asilo grande y frío, cuando en todo hogar debe de haber un sitio para el hijo de todos. (12-13)

Esta cita, nos demuestra, por un lado, la tristeza que produce a la autora esos niños solitarios que ansían desesperadamente un hogar que les proporcione singularidad. A su vez, se convierte en un arma de crítica social porque arremete contra la sociedad en general, que no sabe canalizar un sentimiento que refuerce los vínculos familiares verdaderos y puros en el sentido de fortalecimiento de la personalidad del niño y la preparación para un futuro justo e igualitario. Además, canaliza esa crítica hacia sociedades concretas que no han sabido crear organismos en los que se integre a los niños 
huérfanos y se les proporcione una educación equilibrada basada en la unidad de la familia. Es importante mencionar que el fundamento primordial de la educación de las mujeres a finales del siglo XIX y principios de $\mathrm{XX}$ era, según Ballarín: "la transformación social a través de la educación y las mujeres, como madres y esposas, estaban en su base" (64). De esta forma, la autora propone la misión esencial de la mujer española de transformar la sociedad y para ello, es necesario que se eduque con las mismas bases de las mujeres de la Europa desarrollada y con sistemas de educación progresistas y, a su vez, que refuerce los lazos familiares para crear un nuevo individuo que será el futuro de la nación. La autora propone:

Educar e instruir a las que más tarde han de llenar en el hogar doméstico las importantes misiones de esposa y madre, siendo por tanto las que ejercen mayor influencia en la sociedad porque ellas son las que educan al tierno corazón de sus hijos y las que influyen con su ejemplo y sus consejos en las decisiones de su esposo, por lo que podemos decir que la mujer, desde su modesto hogar, es la que decide la suerte de las naciones. (En Starcevic 42)

Esta cita, a parte de exponer la necesidad de que la madre se eduque para "llenar el hogar doméstico," conlleva una intención subversiva a la hora de darle un valor a la misión de la mujer que antes no era siquiera imaginable. Ahora, según la autora, la mujer tiene el poder de transformar la sociedad hasta el punto de decidir "la suerte de las naciones." Así pues, se trata de una forma más de adoptar el discurso masculino desde el espacio simbólico femenino del patriarcado y subvertirlo hacia una primera llama de 
emancipación o de concienciación de la función de la mujer en un marco, ya no doméstico, sino cultural, social y, por qué no, político.

En cuanto a la percepción que tiene Carmen de Burgos de la sociedad flamenca, la nota más característica es la aversión hacia su gente. Para la autora el flamenco es un ser que influenciado por su herencia germánica es un pueblo sin alma. De Burgos explica que: "es este un país de brumas, en el que rara vez brillan las estrellas. Se apagan todos los tonos de color en este conjunto pálido, las mismas olas no tienen rumor ni espuma. Para ver el alma de un país basta ver su cielo" (16) o más adelante expone: "iVerdaderamente es hermosa Bruselas! Es lástima que le falte alma" (116). Su población es ruda, austera e intolerante. Define a los hombres como seres "sumergidos en un sueño estúpido... [que] dan la impresión de eternos durmientes... pero que sólo la vida animal les domina" (38). Pretende desmentir la idea que en España se tenía de los belgas flamencos como hombres creadores e imaginativos y con un gran sentido satírico. De Burgos los presenta como grotescos y fantoches:

Cuando no conocía Bélgica, creía ver un espíritu satírico en los cuadros de Terrier. Ahora veo sólo una admirable realidad. La sátira está en nosotros que no comprendemos este espíritu belga y pensamos que es falso lo grotesco, lo fantoche, lo forzado de los cuadros de Terrier. Es que aquí es la vida asi y son así las gentes. (102)

Lo único que redime al belga es su trabajo y su espiritu empresarial. Son numerosas las citas que la autora hace a lo largo del libro sobre el espíritu comercial y empresarial del belga y, en general, de todos los hombres de los países bajos: "Es curioso observar que hasta en los momentos más difíciles la política belga no pierde de vista el 
comercio" (52). También resalta el papel que el socialismo ha tenido en estas sociedades donde el obrero se ha convertido en un estamento primordial de la sociedad que se percibe en "las casas suntuosas pertenecientes á los gremios [que] demuestra la influencia del elemento obrero, preponderante desde muy antiguo en esta tierra de socialismo" (66). A pesar de esta notable redención por el trabajo, de Burgos intercala su rechazo a la cultura belga porque piensa que su pueblo carece de espíritu individual y de alma:

Su vida se desliza con la regularidad de una máquina...La individualidad poderosa de nuestro pueblo en que cada miserable lleva un señor dentro de sus harapos, se queda aquí anulada por el espíritu de asociación, de colectividad. Se hace todo en común; se obedece sin réplica y $\sin$ razonamiento. El trabajo siempre es mecánico, regular, perseverante. (634)

Esta aversión por el pueblo belga se incrementa por la falsedad de sus gentes y su falta de creatividad. Este pueblo busca solamente el negocio y el enriquecimiento a cualquier precio. Para la autora estas gentes: "toleran al extranjero porque les conviene, pero no llegan a amarle y si pueden le explotan cuando se les presenta la ocasión” (115).

Las descripciones que hace la autora de Bélgica son mecánicas, sin ilusión, da la sensación de que se fuerza a hacer las descripciones del país y se percibe en el texto ese deseo de salir de ellas lo más pronto posible. Aquí ya no hay, como en Por Europa, la admiración, el regocijo en lo visitado, la expectación. No existe ilusión, ni asombro, el país la aplasta, la aturde pero se ve obligada a seguir describiendo un país que ve vacío de espíritu, grotesco y falso. La autora tiene una pretensión interna a la hora de describir esa inferioridad espiritual, por así decirlo, de los belgas. Por un lado, la utiliza como crítica 
indirecta hacia el español que sumergido en una dilatada agonía producto del sentimiento de fracaso del 98, no sabe valorar las cualidades imaginativas y creativas que le son innatas y se deja llevar por unos condicionamientos externos que no deberian tener cabida para la superación de un pueblo. Por otro lado, hace una crítica al sistema político de Bélgica, cosa que otorga a su narración una autoridad empírica producto de la observación de la realidad belga. Esta autoridad empirica del que ve y escribe proporciona a la autora la herramienta para analizar el sistema de gobierno de ese país. Si bien, en su tercer libro, la adopción de los modelos políticos socialistas es mucho más marcada, en este relato, muestra las asociaciones de obreros y los gremios como algo positivo. Alaba la misión del gobierno que les proporciona la ayuda necesaria para constituirse en pos de una mejora económica del país, pero, a su vez, critica la deshumanización de estas asociaciones donde la individualidad ha perdido su razón de ser.

Otro de los temas constantes en los libros y ensayos de Carmen de Burgos es la higiene. Ésta es de vital importancia porque constituía una de las bases de la educación de la mujer. La escritora pretendía educar a la mujer española para que incrementara la higiene en todos los campos de su vida. En todo el libro, la autora hace constantes referencias a la higiene y la limpieza de las ciudades belgas con la intención de trasmitir una imagen saludable de lo que podría ser un país de progreso. Utiliza ejemplos específicos como la descripción de las calles de Amberes para exaltar la visión edénica de este pais:

Pocas poblaciones darán una sensación tan agradable á su entrada como Amberes... por todas partes se encuentran calles amplias y limpias, que 
casi todas llevan nombres de grandes pintores. En todas ellas he observado una nota simpatiquísima. La pasión por las flores, la limpieza y la ornamentación que hay en todas partes... Se piensa que en esas casas floridas por fuera debe de reinar dentro el amor, la tranquilidad, la paz patriarcal. (71-72)

Es curioso que estas descripciones recuerden los primeros textos del proceso de la conquista y colonización de América. Si bien, Cristóbal Colón tenía una doble pretensión a la hora de describir el nuevo mundo: vender el producto americano a los reyes de España para que siguieran financiando la colonización de Las Indias y proporcionarse un reconocimiento personal en el proceso del descubrimiento; Carmen de Burgos, utiliza la misma técnica, pero con pretensiones diferentes. La autora también quiere vender un producto: una nueva civilización donde reine la paz y el amor, donde ya que sus ciudadanos y su gobierno mantengan las ciudades limpias y se preocupen por el arte. A su vez, hace una crítica a la España tradicional. La autora describe la sociedad belga en los términos de un sistema de organización tradicional y patriarcal que son los que usualmente se proponían dentro del discurso dominante. Esta nueva Bélgica, tradicional y patriarcal, lo es porque ha impuesto una cultura basada en la limpieza y en el arte y España que aboga por mantenerse tradicional y patriarcal, no posee las condiciones higiénicas belgas, ni su gobierno se ocupa de ellas o del arte.

De esta forma, propone al poder patriarcal español un modelo social que da la estabilidad e impone las normas sociales de la división de género impuestas por el discurso masculino. La división de género que de Burgos describe en la sociedad belga otorga a la mujer los atributos tradicionales que la relegaban únicamente al entorno 
doméstico, el amor y la tranquilidad del hogar, y los hombres, por su parte, son los que: "administran la justicia y los negocios del pueblo rodeados de flores; por fuerza tienen que ser honrados y leales" (72). En definitiva, con esta táctica incita a la sociedad patriarcal española a que adopte unas normas que ella considera beneficiosas para el progreso implícito de la mujer, ya que para mejorar las condiciones higiénicas, éstas deben educarse mejor y a su vez, lo expone de forma que no irrumpa en el discurso patriarcal tradicional.

Al mismo tiempo que se percibe ese deseo por la limpieza, Carmen de Burgos introduce un matiz discordante en su descripción. Al decir que debe de reinar en las casas belgas la paz patriarcal, nos pone de manifiesto una autoridad omnipotente que vigila y controla el poder. Más adelante, la autora explica: "tengo que hacer un esfuerzo para que las flores no me oculten el verdadero espíritu de la ciudad... Aquí hay una nota pesante, alemana, sajona, en los suntuosos edificios nuevos, y sobre todo la torre de la catedral parece que aplasta á la ciudad entera bajo su peso" (72). Para ella, la limpieza de una ciudad no es, o no debe ser solamente superficial. Debe de ir unida a un espíritu armonioso que, en definitiva, no lo encuentra en el carácter del hombre germánico por su predominio y por su supuesta superioridad. Con respecto a este punto, Carmen de Burgos argumenta: "Me parece que nos ha mirado con cierto desprecio. Aquí una persona que no habla flamenco se considera como un ser inferior" (75). La idea de la superioridad propia que tienen los flamencos va unida a la intransigencia y a la intolerancia que tienen a lo foráneo y se convierte en una nota de alerta para cualquier sociedad que base su organización social, política o cultural en permitir enfrentamientos raciales inconsistentes y perjudiciales para una sociedad moderna basada en la igualdad del individuo. 
El tema de la tolerancia es también relevante para la educación y la autora lo expresa en un momento específico en la narración cuando expone los problemas que hay en este país a la hora de escoger un idioma para la nación. Este argumento que hoy en día sigue siendo un tema de actualidad, pone de manifiesto la necesidad de unificar la enseñanza, de no limitar la educación bajo lemas de intransigencia ya sean culturales, religiosos o lingüísticos. Para de Burgos, cada nación debería implantar el idioma que se considerase oficial del país; en el caso de naciones bilingües la enseñanza debía ser bilingüe también. Critica a la población flamenca por su intolerancia que llega hasta la injusticia y que está basada nuevamente en la supuesta superioridad petulante del flamenco:

En la enseñanza de las lenguas germánicas y en las de la historia, geografia y ciencias naturales se emplea siempre la lengua de la nación. Sin embargo, los flamencos no están contentos. Desean que su idioma se declare único oficial... En la escuela primaria la enseñanza es libre de adoptar la lengua que quiera; pero los flamingants piden que ningún discípulo sea admitido á los estudios universitarios, y que no se conceda voto a ningún ciudadano sin un certificado de haber estudiado y sufrido un examen especial del flamenco. (79)

Este aspecto es curioso en un país donde la mitad de la población es de origen francés. La autora muestra los enfrentamientos obstinados de su pueblo por el idioma que incluso "a veces ha tenido lugar sangrientas colisiones hijas del apasionamiento por el idioma. Se conserva memoria en Amberes de un movimiento del pueblo contra el ejército por haber escuchado á un oficial dar sus órdenes en francés, estando establecido que se 
mande en flamenco" (79). El problema de la desunión entre flamencos y valones lo universaliza: "Admito siempre con pena la idea de dividir en razas á la humanidad" (59). Para la autora, en la unión está el progreso y la división trae consigo el enfrentamiento y la cerrazón. Este problema lo trasplanta a España de la siguiente manera:

En Bélgica no se fundirá jamás en una sola aspiración para llegar á formar el alma nacional, como no nos hemos fundido nunca en España las diferentes regiones. Las separan las costumbres, los ideales, las tendencias que han moldeado las diferentes razas. Valones y flamencos no se confundirán nunca. Existe entre ellos la cuestión del flamengantismo, semejante a la del catalanismo español. (58)

Esta cita no implica que Carmen de Burgos abogue por una unidad nacional per sé, sino que para ella la división de razas supone un enfrentamiento obstinado e ilógico y es un impedimento para el desarrollo de las naciones. Pero a su vez, hay que tener en cuenta que, al mismo tiempo que critica el enfrentamiento racial entre flamencos y valones, exalta su espíritu de colaboración en el trabajo y en la economía. A diferencia del pueblo español, el belga deja de lado la individualidad para unirse en asociaciones laborales que puedan enriquecer al país.

Otro aspecto que la autora analiza en toda su producción es el problema de la religión. En este libro habla del progreso que de la religión en Bélgica. En este pais la religión no es totalizadora y aplastante como en España, sino que es una forma más del espíritu comercial del belga. A diferencia de la religión intransigente de España, la de Bélgica se ha adaptado a las peculiaridades del país y se ha convertido en la aliada del liberalismo. De Burgos observa: 
El instinto comercial belga salva su catolicismo plegándose á lo que le conviene y haciendo los tratos necesarios para conservarse... El neocatolicismo trata de encarnar lo substancial de la religión en las formas nuevas, que las ideas modernas y la organización de nuestras sociedades reclaman, y en las cuales todas las religiones históricas agonizan. (103)

El problema de la religión es fundamental para la educación porque bajo él está la organización educativa tradicional española. Así, en España, las instituciones educativas estaban en su mayoría regidas por las órdenes religiosas. Una de las mayores innovaciones propuesta por los krausista era la desvinculación del sistema educativo de las órdenes religiosas. Para los krausistas era objetivo primordial para la formación del maestro, alcanzar la paz en la escuela por medio de una religión que se basara en la tolerancia positiva. La enseñanza de la religión debía ser algo natural, sin limitaciones, una instrucción espiritual del individuo. En este sentido, Giner expone que únicamente la enseñanza laica es la que puede formar un espíritu de tolerancia. ${ }^{31}$ Giner propone que "no sólo debe excluirse la enseñanza confesional o dogmática de las escuelas del Estado,

\footnotetext{
${ }^{31}$ Al mismo tiempo, se debía de tener mucho cuidado con no confundir lo que era la enseñanza laica o la atea de orientación republicana. Para explicar este punto, Giner expone:

mucha parte de los defensores de la llamada "escuela laica" [lo que quieren hacer es] fundar una supuesta educación, "educación anticlerical y republicana". Olvidando que exactamente el mismo derecho que tiene la nación a que no se perturbe con preocupaciones intolerantes la conciencia del niño lo puede invocar frente a frente del ultraísmo como del anticatolicismo; contra los partidos políticos, contra los religiosos. Unos y otros ponen en peligro la neutralidad de la escuela y convierten la educación en obra exclusiva y sectaria. (Estudios 78)
} 
sino aun de las privadas, con una diferencia muy natural, a saber: que de aquéllas ha de alejarlas la ley; de éstas, el buen sentido de sus fundadores y maestros" (Estudios 76).

Carmen de Burgos opinaba que la religión en Bélgica había evolucionado y había permitido un progreso que se extendía a todos los campos de la sociedad. En primer lugar, la Iglesia había comprendido la necesidad de la mejora en el sistema de vida terrenal y colaboraba con el gobierno en la creación de sindicatos de interés público. De Burgos dice que el catolicismo se había transformado en "sociedades de fines políticos y económicos" (109). A su vez, en el campo de la educación, los católicos habian creado leyes para reclamar la enseñanza obligatoria y con ello se incrementó el número de escuelas (108). Sin embargo, a pesar de que de Burgos ve en este estado neocatólico una posible salida para el progreso de algunas naciones, la idea que ella conservaba de la religión seguía siendo la misma. Para la autora, la religión no era mas que una forma de vida vegetativa en donde los feligreses "mano sobre mano, inmovilizados, dormidos, en un Nirvana estúpido, dejan correr hora tras hora" (109). El neocatolicismo suponía en sí la única posibilidad que tenía la religión de convivir con un sistema político y económico en un país en donde la economía y el trabajo es la única razón de ser. De esta forma, en una sociedad como ésa, según de Burgos se "desvirtúa la esencia del catolicismo para convertirse en sociedad de fines políticos y económicos. Pero es el sólo modo que tienen de vivir" (109). Es evidente la diferencia en las opiniones que tenían de Burgos y Emilia Pardo Bazán ante este tema. Mientras que de Burgos mantiene una posición de recelo ante el neocatolicismo ya que, a pesar de las buenas intenciones que pueda tener en la mejora de la educación siempre intenta sacar un provecho para sí. Pardo Bazán exalta la unión de la Iglesia y el pensamiento positivista que "nos lleva hacia el porvenir, y así <el 
respeto de la Iglesia hacia la razón humana>" (Por la Europa católica 71-72) ya que para Emilia Pardo Bazán el tema de la unión de la Iglesia y la modernidad era la gran constante de parte de su producción.

La discrepancia que encuentra Carmen de Burgos en este viaje a diferencia de los otros es el reconocimiento de las posibilidades objetivas que tiene el hecho de viajar por placer. La autora puede analizar los problemas de las sociedades a las que viaja sin mediatizaciones. En este libro se percibe en el encuentro que tiene la autora con los pensionados españoles en Bélgica. Este hecho le hace reflexionar sobre la educación en este país y establece una serie de comparaciones explícitas. En primer lugar, dice que su sistema educativo no es tan próspero como los españoles se piensan. De Burgos expone que "el estado de la enseñanza en Bélgica no es tan floreciente como por lo general se cree" (130); para ella, el problema principal recaía de nuevo en la educación religiosa. Explica que hubo una ley por la que se establecía la enseñanza laica en todas las escuelas del Estado, esta ley no duró mucho tiempo porque el poder de la iglesia hizo que se aboliera y que se despojara al Estado de su labor educadora, pasando nuevamente a manos eclesiásticas. De esta forma, la autora critica de forma sutil a los gobiernos católicos que se alejan del liberalismo e imponen un sistema desigual y sin responsabilidad social. Equipara Bélgica con España en el sentido de que en ambos países seguía habiendo niños que no iban nunca a la escuela. Al mismo tiempo, exalta los países con gobiernos liberales en donde la enseñanza se hace un derecho y una obligación para todo niño. Carmen de Burgos manifiesta que:

El primer cuidado de los católicos fue abolir la ley y despojar al Estado de su misión educadora, dejándolo todo á merced de los municipios y 
restableciendo la enseñanza religiosa... al destruir la obra de los liberales se ha dejado sin efecto la enseñanza obligatoria, que tienen establecida hoy las naciones más libres de Europa, como Inglaterra y Suiza. (131)

Ante este problema, establece nuevamente que la redención del sistema educativo belga se lleva a cabo por medio de su espíritu comercial. El belga siente la necesidad de remitir todo al terreno económico. Por un lado, de Burgos indica que este proceso de redención se lleva a cabo por la peculiaridad de la iglesia protestante a obligar a todos sus miembros a leer la Biblia. De esta forma, el índice de analfabetos se aminoraba. Por otro, se establecía un sistema de competencia entre las escuelas católicas y las protestantes y el belga utilizaba su instinto comercial para, como menciona de Burgos: "atraer a los alumnos, [haciendo] como las tiendas y los almacenes que dan primas al comprador y le ofrecen donativos en ropas y en cartillas de las cajas de ahorros" (132). Esta ansia de atraer a estudiantes llega hasta el punto de la creación de colonias de verano y de un organismo peculiar llamado La Sopa Escolar (132). La asociación que llevaba este nombre se comprometía a dar diariamente a los niños de 35 escuelas de cualquier tipo, sopa y pan. Esta organización que hubiera podido ser tratada de forma positiva, Carmen de Burgos la analiza como una forma de cubrir las deficiencias de un sistema de injusticia social y lo expresa de la siguiente forma: "Es la limosna de la caridad, triste virtud que demuestra la existencia de la injusticia cuyos males repara" (132-33). Para la autora los problemas de una sociedad no se atajan con la limosna temporal, sino con la implementación de un programa estatal que refuerce y se comprometa a mejorar la calidad de la educación e intente suprimir o, al menos, aminorar las injusticias sociales. 
Carmen de Burgos dedica solamente un capítulo a su viaje a Luxemburgo. En él, lo único de que deja constancia es que la población germánica conserva leyes francesas. La autora alega que es un lugar "donde nos aburrimos extraordinariamente...tiene un aspecto severo...un espíritu hostil y arisco del que hay que apoderarse a viva fuerza" (227). Tanto hombres como mujeres se muestran a los ojos de la autora como rudos y pesados en donde el paisaje pesa y cansa. Solamente salva al país la anécdota del sentimiento maternal de una mujer que ha dejado a su hijo al cuidado de la autora. Éste viaja a Holanda para buscar trabajo. Ese sentimiento maternal, que se hace universal, redime a un pueblo sin alma. La mujer en su condición de madre se aúna con la autora para experimentar el sentimiento común y universal del amor filial: "Pero esta mujer buena y sencilla ha venido a derramar una gota de bálsamo en mis labios. Su recuerdo poetizará para mí el recuerdo de Luxemburgo" (232). Para la autora, un país puede sernos más o menos austero, pero lo que realmente lo define son sus gentes $\mathbf{y}$, en este sentido, de Burgos expresa un sentimiento maternal universal como forma de redención del papel de la madre dentro de una sociedad y de la hermandad de las mujeres en el terreno doméstico y, aunque no lo exprese directamente en el texto, la autora desea alentar la posibilidad de una posterior hermandad en otros campos hasta el momento vedados para las mujeres, tema que desarrollará con mayor detenimiento en su tercer libro de viajes.

La autora finaliza su viaje a Luxemburgo expresando la subjetividad de lo visto según el sentimiento del que lo ve. De Burgos expone: "Me confio en la idea de que las ciudades y las naciones no son bonitas ni feas, simpáticas ni hostiles. Las vemos según el estado de nuestra alma. La vida es tan subjetiva, que todo lo que no está en nosotros, no está fuera de nosotros" (232). 
El estudio que hace la autora de Holanda está compuesto de siete capítulos, del veinticuatro al treinta y uno. Se nos muestra un paisaje majestuoso lleno de grandes cambios de colores que representa una totalidad sencilla sin brusquedades fisicas ni geográficas y que sólo interrumpe su sencillez los molinos de viento. A este paisaje, se le une rápidamente la idea que tienen los holandeses del aprovechamiento de la naturaleza para la industria. La autora habla de cómo los molinos son utilizados para generar electricidad y de cómo un país que está rodeado de agua se las ingenia para promover el comercio.

En cuanto a la educación, en Holanda y, en especial en la ciudad de Róterdam, el nivel de educación es alto. De Burgos apunta: "por fortuna todos saben leer. Existe un nivel medio de cultura muy grato. No abundan las grandes inteligencias, pero apenas hay analfabetos" (240). Esta primera referencia a la cultura del holandés, se muestra un tanto contradictoria. En un primer lugar, quiere destacar que es un país en donde su pueblo se interesa más por el tema cultural pero que, a su vez, existen unos condicionantes que le va a impedir que sean como los pueblos que ella considera superiores; a saber, Italia, Francia e Inglaterra. Estos impedimentos físicos se muestran de una forma concreta cuando la autora argumenta que la constitución corpulenta del holandés ha hecho que se ejerciten en el trabajo físico y que dejen de lado el intelectual: "Se ve la raza fuerte que sólo se ha ejercitado en el trabajo corporal durante muchos siglos, como autómatas continúan moviéndose en virtud de la ley de la inercia... Sus corpachones grandes y flácidos parece que están formados por yuxtaposición, á pegotazos" (244). En segundo lugar, enfatiza rápidamente que esa primera impresión de la cultura del holandés es sólo superficial puesto que "les falta por completo la fantasía creadora, descuellan sólo en la 
reproductiva" (244) y su única dedicación es lo externo y no lo espiritual. La autora muestra la falta de intelectualidad del holandés para el cual "el pensar es enemigo de la dicha" (244). De Burgos llega al extremo de sostener que incluso la figura más ilustre de Holanda, Erasmo de Rótterdam, era un genio, no por ser holandés sino por considerarlo latino: "En verdad no puede molestarnos este alarde de admiración como un alarde de vanidad. Gerrit Dirkiszoon, que es el verdadero nombre de Erasmo, no es realmente holandés. Es latino. Por su espíritu y por su educación" (245).

Estas afirmaciones de la autora proponen un análisis de contenido más profundo. Carmen de Burgos juega con la propuesta que caracterizaba a los componentes de la Generación del 98 en cuanto a la exaltación del españolismo. En este sentido, la autora advierte que no todo lo foráneo es mejor que lo nacional. Muestra los luxemburgueses como a un pueblo que ellos mismos se consideran estandarte de la cultura por medio de su representante Erasmo de Rótterdam; pero, a su vez, la autora presenta a estas gentes como ignorantes y apegadas a la naturaleza barbárica y de instintos primarios. Para describirlos utiliza expresiones como: "borrachos" (243), "descendientes de los teutones..., todas las razas primitivas que realizaron la epopeya de crear una tierra donde... los hombres tenían que andar colgados de las ramas de los árboles" (243), su mente no sobresale (244), son frios (244). Es evidente que estos condicionantes son la consecuencia de la aversión de la autora a todo lo que tenga relación con lo germánico. Para Carmen de Burgos lo germánico era sinónimo de barbarie y es una de las constantes que va a mantener a lo largo de todas sus obras. El hecho fundamental de que el único personaje histórico que sobresalga intelectualmente lo considere latino manifiesta, en cierto sentido, una reivindicación de los valores de las sociedades meridionales que no 
poseen estas sociedades de influencia alemana. En un sentido específico, exalta el espíritu creativo del latino y la posibilidad que éste tiene de utilizar su actividad intelectual creativa como arma que se puede manipular en la lucha social por un mejor futuro.

Frente a la antipatía que siente Carmen de Burgos por los flamencos, defiende el valor que le otorgan a la higiene. La limpieza de un pueblo, para la autora, es sinónimo de educación y de desarrollo; y ésta sí es una virtud que tienen los pueblos que visita en esta ocasión. Es por ello que la autora expresa el culto que tienen estas gentes a la limpieza como una virtud admirable que lleva al país al bienestar y a la prosperidad. De Burgos argumenta: "la limpieza es signo de una superioridad ética, que se comprueba comparando las estadísticas de todos los países, y observando que la criminalidad está en razón directa de la suciedad, más que de la ineducación y la miseria" (242). De esta forma, quiere resaltar la necesidad primordial de la limpieza como base primera de la formación de una sociedad moderna y desarrollada. Esta necesidad la antepone a la misma educación porque, para ella, la limpieza fue siempre una de las cuestiones que se debían reformar en España. En numerosos artículos de periódico, resalta constantemente la necesidad de educar a las mujeres en la limpieza tanto del hogar como de todos los aspectos de la sociedad. ${ }^{32}$

${ }^{32}$ Carmen de Burgos, no sólo escribe en distintos periódicos nacionales sobre el tema de la higiene, también escribió varios libros cuyo tema principal es la higiene en el hogar. Ejemplo de alguno de ellos son: Salud y belleza. Valencia, F. Sempere, [1918], El Arte de saber vivir. Valencia, F. Sempere, [192-?], El arte de ser mujer. Madrid, Sociedad Española de Librería, [1920?] Tesoro de la belleza: (arte de seducir). Valencia, Sempere, 1924, El tocador práctico. Valencia, F. Sempere, [191-?], Vademécum femenino. Valencia, Prometeo, [192-?], entre otros. 
Finalmente, el capítulo treinta y dos hay que tratarlo aparte pues tiene unas caracteristicas especiales. En primer lugar, este capítulo junto a El cementerio de Nerke están ambos recogidos en su libro La justicia del mar (1912). En este capítulo, titulado Las islas del Zuiderzee, se narra el relato utópico de unas islas en donde hay una sociedad primitiva en la que sus habitantes viven en armonía con la naturaleza. De Burgos expresa que esa armonía viene dada por la purificación del mar: "Hay una pureza admirable en la vida de estas gentes. Les hace buenos el mar" (298). En esta sociedad no se plantean problemas matrimoniales porque viven en "una inocencia primitiva [que] advierte la expresión de calma y de reposo en estas gentes" (299). No se percibe una diferencia física aparente entre los niños y las niñas ya que visten igual. Este aspecto es fundamental porque para la autora esta sociedad primitiva ha concebido un sistema de educación igualitaria para ambos sexos. A pesar de que esta educación sea religiosa, la autora la llama "reformada [en donde] el pastor es al mismo tiempo maestro nacido en la isla. Tiene a su cargo las almas de todos sus paisanos con este doble carácter, y ha implantado la coeducación de sexos sin ninguna dificultad" (298).

El sistema de coeducación que estaba en vigencia en estas islas, manifiesta una crítica por parte de la autora hacia las sociedades que aún veían con aversión la implantación del mismo. Por medio del análisis de esta sociedad de Zuiderzee, la autora propone que en los demás países se implementen los avances de esta micro-sociedad. Carmen de Burgos explica la organización educativa que tienen en donde se ha podido, de una forma satisfactoria, implantar una misma enseñanza para niños y niñas y deja entrever la posibilidad de poder establecerla en otras sociedades. A su vez, plantea la única solución posible de unión entre la religión y la educación. La autora propone la 
posibilidad de una religión reformada en la figura de este pastor que hace las veces de cura y de maestro y que ha sido capaz de implementar las mejoras que el sistema educativo estaba necesitando en otros países y en especial en España.

A pesar de los aspectos positivos que tenían los Países Bajos, en general, Carmen de Burgos ve que su sistema educativo dejaba mucho que desear. Critica, en primer lugar, al español que se maravilla por todo lo extranjero sin hacer un análisis profundo y objetivo de la realidad de esos países. En segundo lugar, critica la educación religiosa belga porque sufría de las mismas trabas que en España ya que seguía habiendo, al igual que en España, niños que no iban la escuela y que el nivel de analfabetos también era alto. En tercer lugar, critica el espíritu comercial de estos hombres que relegaban cualquier otro aspecto de la vida del individuo a un segundo plano. A su vez, critica a la sociedad que pretendía ser liberal y socialista y que lo único que hacía era encubrir las taras y trabas de un sistema defectuoso. Para ella, estas trabas eran iguales a las que poseían otros países a los que ellos consideran inferiores. Como consecuencia lógica, la crítica más profunda que hace la autora se centra, sobre todo, en el falso espíritu de superioridad del flamenco ya que es en él donde estriba el gran problema que afecta a la educación. Ellos creían que poseían el gran modelo a seguir y que los demás países debían imitar sus sistemas innovadores sin darse cuenta que acarreaban las mismas dificultades que los demás países a los que consideraban inferiores.

La autora ve a Bélgica, Holanda y Luxemburgo como unos países que no son superiores a España pero que poseen una cualidad que España no tiene, lo que ella llama "el eterno espectáculo" (142). Por ejemplo, Bélgica sabe presentarse mejor al extranjero y lleva una imagen de superioridad cuando en realidad no lo es. De Burgos argumenta: "No 
sé, no sé... Pero no creo que España tenga nada que envidiarles á los belgas en el fondo y que sólo nos son superiores en el modo de saber representar las cuestiones" (142).

A pesar de la crítica tan severa que la autora hace del holandés y sobre todo del belga, hay varios aspectos que intenta resaltar del sistema social, político y educativo de estos países. En primer lugar, resalta el sentimiento competitivo que tiene Bélgica ya que mediante la necesidad de adquirir más devotos, el belga se esmera en mejorar la calidad del producto que ofrece. En este sentido, en el campo de la educación, los belgas proporcionan un aspecto de mayor libertad, al igual que benefician la calidad de enseñanza que se podía ofrecer. En segundo lugar, la tolerancia religiosa suponía un aspecto fundamental en cuanto a la educación en ese periodo. Este aspecto es primordial puesto que se basaba en los nuevos sistemas metodológicos de la enseñanza. De esta forma, mediante el análisis de la existencia de la relación que existía entre las escuelas del Estado, las católicas y las protestantes, Carmen de Burgos, implícitamente, exponía la existencia de una tolerancia en cuanto a la posibilidad de convivencia entre diferentes tipos de escuelas dentro de un país, cosa que en España seguía siendo un tema tabú y sin posibilidad aparente de cambio. La autora arremete específicamente contra la religión católica a la que ve anquilosada y reaccionaria, pero se muestra más condescendiente con la religión protestante que ha sabido ajustarse a las necesidades políticas y sociales de estos países y concretamente, en el caso del último capítulo, propone la posibilidad armoniosa de una educación protestante igualitaria y liberal en el caso de Las islas de Zuiderzee.

En tercer lugar, resalta la influencia y admiración que existía en el extranjero por personajes españoles vinculados a la educación y al liberalismo. En este sentido, subraya 
la pasión que tenían los belgas por la figura de Francisco Ferrer. ${ }^{33}$ Esta pasión la expresa de Burgos de la siguiente manera: "El día que he visitado La Casa del Pueblo... he encontrado una nota conmovedora en el culto que aquí se consagra a Francisco Ferrer" (140) y más adelante observa:

El retrato de Ferrer se encuentra en cuadros y tarjetas; se lleva en pequeñas medallas sobre el corazón, y dentro de poco se construirá un monumento simpático á todos los españoles que no estamos salpicados de su sangre, porque no pudimos impedir el crimen con nuestro esfuerzo y dejamos realizarlo. ¡Somos tan pocos! (142)

Con esta cita que habla por sí sola, no sólo muestra la autora la manera en que en el extranjero se valora los personajes emblemáticos del liberalismo de la España de la época, sino que insta a los españoles a seguir el ejemplo belga y unirse a los que quieren cambiar el país en aras de la modernidad y de la libertad, sobre todo en la figura de Ferrer quien fue considerado padre de la escuela moderna y que perdió su vida por culpa de sus convicciones.

${ }^{33}$ La figura de Francisco Ferrer es de gran importancia en los primeros años del siglo XX y las repercusiones de su Escuela Moderna son grandísimas en toda Europa. La creación de la escuela Moderna le vino a Ferrer de su contacto con los postulados pedagógicos del anarquista francés Pablo Robin, quien proponía que la única forma de conseguir una revolución anarquista era mediante la formación de una educación integral, racional y mixta que impulsara y dignificara la formación y el trabajo del obrero creando talleres de jóvenes. Ferrer, de esta forma fundó su escuela cuya misión era educar al niño en un ambiente libre, igualitario entre niños y niñas y, sobre todo, la escuela debía ser laica. Se basaba en la adopción del sistema práctico, en lugar del teórico y promovía el desarrollo de una educación racionalista que enfatizara el desarrollo individual de la iniciativa del niño, la libertad de expresión, la cooperación en un ámbito igualitario e incentivara su sentido crítico. En definitiva: "una escuela como elemento de emancipación" (Herraiz 1). 
Finalmente, ensalza la posibilidad de un sistema de coeducación armónico en una sociedad, a su vez armónica, en donde no exista diferencia entre la educación que se le da a los niños y las niñas como lo expone en "Las islas de Zuirderzee." A su vez, resalta la importancia de la limpieza que no sólo enaltece una sociedad, sino que la libra de delincuencia como se ha indicado anteriormente con las repercusiones que para la mujer conlleva esta afirmación. Al mismo tiempo, analiza la repercusión del espíritu comercial de estas gentes que, si lo tuvieran con moderación y con un "alma artística latina," constituirían una verdadera sociedad perfecta para Carmen de Burgos. No obstante, a pesar de que se perciba, de forma general, un desagrado por las sociedades de los Países Bajos, es evidente que el análisis y las críticas a la sociedad y sus lacras permitía a sus lectores reflexionar sobre los problemas y la lacras de España, a su vez que les inducía a aceptar y ver sus soluciones como las únicas posibles para mejorar al país. 


\section{CAPÍTULO IV}

TERCER VIAJE: PEREGRINACIONES: SUIZA, DINAMARCA, SUECIA, NORUEGA, ALEMANIA, INGLATERRA Y PORTUGAL O MIS VIAJES POR EUROPA. ${ }^{34}$

Carmen de Burgos realizó este viaje gracias a otra beca de ampliación de estudios concedida por el Ministerio a principios de 1914: "Gracias a que el Ministerio finalmente atendió mi demanda para una beca de ampliación de estudios por Europa ya puedo contarle a mis lectores cómo una sábana blanca cubre toda Suiza y cómo se siente el vértigo de la nieve, la obsesión de blancura" (Utrera 253). Este viaje, tiene una repercusión en la autora ya que en la misma época también comenzó a escribir de forma asidua en un periódico de viajes llamado La Esfera. Este hecho le proporciona una autoridad especial porque se vanagloria de ser la primera mujer española en escribir artículos de viajes (Utrera 253).

El libro se publicó originalmente en un solo volumen con el nombre de Peregrinaciones. Este primer volumen está dividido en siete partes que corresponden a los siete países a los que viaja y un epilogo escrito por Ramón Gómez de la Serna. De éste, Carmen de Burgos expresa: "Ramón me ha escrito un prólogo para mi libro de viajes por Europa, una suerte de panegírico donde se mezcla el humor, el elogio ingenioso y la buena literatura. ¡Eres único, Ramón!” (Utrera 269). ${ }^{35}$ El libro comprende un total de setenta y ocho capitulos con los del epílogo incluidos. Rápidamente se agotó

\footnotetext{
${ }^{34}$ La paginación que se ha utilizado es la de la segunda edición Mis viajes por Europa.

${ }^{35}$ En la cita, la autora explica que Ramón Gómez de la Serna le escribió un prólogo, pero en realidad, lo que de la Serna escribió fue un epílogo.
} 
la edición de Peregrinaciones y la segunda edición se publicó en 1917 con el nombre de Mis viajes por Europa en dos volúmenes. El primero comprende Suiza, Dinamarca, Suecia y Noruega; y el segundo, Alemania, Inglaterra y Portugal. En estos dos volúmenes, la única diferencia que existe con respecto a Peregrinaciones es que no se publicó el epílogo de Ramón Gómez de la Serna y que en la primera edición aparece la reproducción del salvoconducto del pasaporte español que les hiciera el consulado inglés a Carmen de Burgos y a su hija.

Las diferencias más notables que se aprecian en este libro con los dos anteriores es, en primer lugar, que Peregrinaciones no tiene estructura epistolar; es decir, no hay un narratario, lo que, según Concepción Núñez Rey, "acentúa el distanciamiento de la autora, que intenta desarrollar la reflexión y reducir las implicaciones personales y biográficas" (180). En segundo lugar, no se trata de un viaje único y cronológicamente lineal, sino que son una superposición de tres viajes que hizo la autora en un intervalo de tiempo de dos años. Núñez asegura que el primer viaje es anterior a 1914 en el que recorrió Suiza y ciudades fronterizas con Alemania, ${ }^{36} \mathrm{el} \mathrm{segundo} \mathrm{viaje} \mathrm{lo} \mathrm{realizó} \mathrm{en} 1914$ comenzando por Dinamarca, Suecia y Noruega. Este viaje compone la parte más extensa

\footnotetext{
${ }^{36}$ En el libro se puede ver cómo la autora viajó varias veces a Suiza. El capítulo, El pueblo que canta, parece ser otro viaje de la autora puesto que comienza diciendo: "He vuelto a Suiza en verano" (30). Posiblemente sea un anacronismo de la autora que hace referencia a su primer viaje en 1906, puesto que viajó durante la última quincena del mes de agosto. A su vez, la forma de describir el entorno tiene una técnica que se asemeja más a la utilizada en su primer libro que la que emplea en todo el cuerpo de este tercero. Un ejemplo de ello es que la crítica se hace más directa, atrevida y fuerte. Al mismo tiempo, esa crítica tan fuerte se percibe en la descripción que hace de sus mujeres, ya que éstas "parecían caricaturas de las modas de hace diez años...Los turistas se creen dispensados de conceder nada a la estética, y pasean sus vestidos grotescos, sus mochilas, sus gorras, sus pantorrillas y sus velos. Yo creo que inyectan su mal gusto y su despreocupación en el pais" (35).
} 
del texto y se ve claramente truncada por el estallido de la Primera Guerra Mundial. El tercer viaje, lo realizó en 1915 a Portugal, esta vez acompañada, no de su hija, sino de Gómez de la Serna (180). ${ }^{37}$

Al igual que en Cartas sin destinatario, en Peregrinaciones hay cuatro usos distintos de la voz narrativa. Aparece una primera persona que hace referencia a la vivencia individual, un nosotras que se refiere al viaje de la autora con su hija, María y un nosotros que se refiere a la colectividad de españoles y otro "nosotros" que a alude a su acompañante Gómez de la Serna y al viaje que realizó con éste a Portugal.

Del mismo modo, se aprecia otra diferencia con los dos libros anteriores en lo referente a lo que Núñez llama "la mirada ética" (186). Tanto en Por Europa como en Cartas sin destinatario, Carmen de Burgos dedica gran cantidad de tiempo a la descripción de las obras de arte, especialmente en pintura. Sin embargo, en Peregrinaciones estas descripciones artísticas o "miradas éticas," dejan paso a una reflexión más profunda de la sociedad y, en especial, se tiene más en cuenta a escritores que a pintores. A su vez, se traspasa esa "mirada ética" del arte a la naturaleza que se describe como el gran espectáculo de la creación y se aproxima más a los aspectos marginales o más pequeños de la sociedad.

${ }^{37}$ Concepción Núñez dice que la estructura espacio-temporal del libro se ve alterada en numerosas ocasiones. Núñez explica que:

De las fuentes del Rhin salta a Dinamarca en la segunda parte, y continúa por Suecia y Noruega en las dos partes siguientes. En la quinta parte retrocede a Alemania, antes de iniciar su recorrido por los países escandinavos, y en el capítulo quinto de esa parte reanuda el relato del viaje de regreso desde el Cabo Norte noruego, que había abandonado al final de la parte cuarta. Desde ese punto el relato es lineal hasta la llega a España, ya con toda independencia, la experiencia de Portugal. (180-81). 
En cuanto a la técnica que utiliza, se percibe un acercamiento mayor a los movimientos vanguardistas. Se observa reflejos futuristas y descripciones impresionistas como la descripción que hace de las campanas: ${ }^{38}$

La campana se presta a la poesía... su voz, como hacha para sonar desde lo alto, se desgrana y vuela modulando cantos que las almas perciben... Cuando hemos perdido un ser amado hay un recuerdo de su acento en la vibración de la campana que viene de noche a turbar nuestro sueño...en esas noches, el marinero perdido en la soledad de los mares escucha el eco de las campanas de su pueblo; va a él como un consuelo, se escapan de la lengüeta de metal y cruzan piadosas a buscarlo. (75)

Igualmente, se encuentran datos geográficos y técnicos concretos, humanizaciones, como cuando habla del árbol en los campos daneses: "El árbol se ha hecho animal y el animal va a humanizarse. Es humana esa mirada tan inteligente y tan amorosa" (110). Hay comparaciones constantes con realidades conocidas de España y fragmentaciones dentro de capítulos. A su vez, se hace notable una influencia del modernismo, que aunque se percibe también en los otros libros, toma aquí ejemplos claros en cuanto al uso de los colores. Denomina a Suiza la Blanca, a Ginebra la azul, los libros de Rousseau son: "libros que están llenos del azul de este lago y este cielo" (22) o "Todo está iluminado de un reflejo azul" (22) y termina el capítulo diciendo: "las agujas de los montes lejanos y el azul de su cielo y de su luz... el azul... mucho azul" (25).

\footnotetext{
${ }^{38}$ Un ejemplo de descripciones futuristas es la descripción de artefactos o de medios de comunicación: Por ejemplo: "pasa un tren. No se concibe belleza mayor" (82).
} 
En cuanto al tiempo, a pesar de que no exprese implícitamente el lugar y el momento en el que escribe, como en su primer libro, las referencias temporales son mayores que en el segundo. Por ejemplo, en Suiza señala que está en el verano porque explica: "Pero la luz no es dorada como la nuestra, es blanca y tenue hasta en esta estación de más luz...Lo he comprobado en su fiesta del 14 de Junio" (34) o también hace referencia a los días de la semana: "Hoy es domingo" (39).

El primer contacto que tiene Carmen de Burgos con Suiza le proporciona una gran emoción ante el gran espectáculo de la naturaleza. Se admira de la blancura de su paisaje que lo cubre todo como una manta. Las descripciones de ese primer encuentro con la nieve son exaltadas y poéticas lo que hace que desde un principio se perciba el cambio en la técnica narrativa. Se poetiza el lenguaje y se alargan las descripciones; a la vez que intercala un sentimiento profundo de admiración por la naturaleza que la rodea.

Las primeras descripciones de Suiza manifiestan una contradicción. Por un lado, hace prever que este fue su primer encuentro con este país y así, hace suponer que éstas son la recopilación de las experiencias de la autora en su primer viaje a Suiza en 1906, o al menos, que se entremezclan varias experiencias en la República Helvética. ${ }^{39}$ En segundo lugar, se perciben características estilísticas de este tercer libro en cuanto a la exaltación de la naturaleza y la extensión y tratamiento poetizado que ésta tiene en el

\footnotetext{
${ }^{39}$ Es interesante el tiempo en este viaje a Suiza. Empieza el capítulo con la blancura de la nieve, es decir, con el invierno, pero más adelante, la autora nos habla de que ha visto la luz de la estación estival y ha estado en la fiesta del 14 de junio. En el capítulo 4 menciona: "he vuelto a Suiza en verano." Estas alteraciones ponen de manifiesto la intención de la autora de invertir el orden espacio temporal, ya que la primera vez que estuvo en Suiza fue en el verano y, el segundo viaje, Carmen de Burgos lo comenzó en invierno (a finales de octubre).
} 
libro. Posiblemente, entremezcla las dos experiencias en sus dos viajes conocidos a ese país pero está escrito, no en 1906, sino en 1916.

En cuanto al tema de la educación, éste no está tratado en ningún momento de manera extensiva, ni hace ninguna reseña concreta a sistemas educativos, ni a formas propias de instrucción de la mujer. Este aspecto es importante porque pone de manifiesto el cambio en la función del texto. En este sentido, las referencias a la educación las hace, la autora, de manera superficial y a modo de explicación de la organización de la sociedad. La autora omite las descripciones detalladas del sistema educativo de estos países por varias razones. En primer lugar, porque ha desarrollado una técnica literaria más elaborada y ha sabido discernir entre lo que es meramente trabajo y el placer que conlleva un viaje; también de Burgos ha evolucionado su pensamiento y, en esta época, ya las mujeres no tenían tanta dificultad para acceder a carreras universitarias como en los primeros años de la centuria y las reivindicaciones de la autora van hacia una emancipación más profunda y que implica unos niveles de libertad e igualdad para la mujer mucho más radicales. Al mismo tiempo, su adhesión a las tendencias políticas socialistas-republicanas son mucho más abiertas y es en ésto dónde pone la mira sus escritos.

A pesar de ello, la autora inserta de forma sutil, algunas referencias a la educación como la descripción de la ciudad de Laussanne. De Burgos observa esta ciudad que "es la Atenas de la nación; la ciudad sabia llena de escuelas, de instituciones de enseñanza, de Academias y Universidades" (27). Esta ciudad de la sabiduría contrasta con un paisaje adverso que hace de ella un paraje hostil, árido y poco propicio para el estudio: 
Le faltan árboles, es árida, seca, hosca... Tal vez es tan triste por esto. No sé por qué razón no han hecho compatibles la felicidad y la sabiduria; la ciencia se presenta aún triste y tenebrosa, huyendo de la alegría, de la frivolidad, de la vida. Tal vez entristece la ansiedad que despierta la ciencia, tal vez desalienta el darnos cuenta de la vida que para ser dichosos es preciso vivir ciegamente. (27-28)

Explica sus impresiones sobre la ciudad de Laussanne y elogia la cantidad de instituciones de enseñanza que posee, pero a su vez, su descripción está impregnada de un sentimiento de soledad y tristeza que impide hacer una crítica directa a la educación misma. Este sentimiento que le produce la lluvia, no la deja analizar el sistema social con imparcialidad. Es así, que durante todo el libro, los ataques directos a las instituciones públicas o políticas y a la misma sociedad quedan relegados a un segundo lugar y, por el contrario, afloran los sentimientos íntimos de la autora y la vertiente poética del texto se acentúa. Carmen de Burgos ha pasado, en este libro, a temas más universales. La fugacidad del tiempo y el Carpe diem proporcionan al libro un sentido de angustia, de ansiedad de la vida que pasa y hay que conseguir "vivir ciegamente" (28) si se quiere disfrutar de los años que nos quedan.

A su vez, la autora resalta la importancia de la naturaleza para la formación del ser humano $\mathrm{y}$, muy especialmente, del niño. Describe cómo a los niños suizos se les expone a la naturaleza y al aire, librándolos así de la desdicha. Carmen de Burgos manifiesta: "Son verdaderamente afortunados estos niños suizos. No ven entorno de ellos esa miseria aterradora de nuestros pueblos: se les educa y se les da aire" (40). Nuevamente, el tema de la educación está destinado, no a la reivindicación para la mejora 
de los sistemas educativos, sino que es un elemento necesario para alcanzar la felicidad. Este contacto con la naturaleza es lo que más envidia de estos pueblos y lo que desearía que se implementase en España. No propone soluciones concretas ni específicas, sino que plantea una solución universal y ontológica que ha definido al hombre desde sus origenes: la búsqueda de la felicidad. Para de Burgos la naturaleza es "una garantía de sanidad; tiene el valor de una escuela que enseña lo que ninguna otra escuela puede enseñar. La Naturaleza obliga a pensar, es sugeridora siempre, y siempre recta y honrada" (109). Pretende regresar a los origenes primitivos y ancestrales del hombre en su unión perfecta con la naturaleza, sin artificios ni retóricas; busca una educación basada en los principios naturales que son, según la autora, los principios básicos de la organización perfecta del mundo.

En este mundo de armonía con la naturaleza que describe la autora, la mujer juega un papel doble. El discurso de de Burgos posee la ambivalencia que explica Maryellen Bieder en la producción de Emilia Pardo Bazán. ${ }^{40} \mathrm{Al}$ igual que Pardo Bazán, Carmen de Burgos inserta un doble discurso. Por un lado, es feminista en cuanto a la defensa de los derechos de la mujer, pero por otro, intercala un discurso propio de mujeres que escriben para mujeres queriendo resaltar las cualidades típicas de buena madre, hija y esposa propias de la teoria de la domesticidad. Es por ello, que son constantes las referencias a la comida, al vestido, y en general, al aspecto físico de la mujer. Esta doble voz que se

${ }^{40}$ Maryellen Bieder, en su artículo Emilia Pardo Bazán y la emergencia del discurso feminista, desarrolla ampliamente de la diferenciación del discurso de mujeres en cuanto a la terminología. Asigna el vocablo "literatos" al discurso de escritoras que no está sujeto a ningún convencionalismo considerado tradicionalmente como femenino $\mathrm{y}$, de "literatas" a la producción escrita por mujeres que sí está sujeta a esos convencionalismos tradicionales del "ángel del hogar." 
percibe, de una forma más acentuada en los libros anteriores de Carmen de Burgos, pretende, por un lado, no alienar a su público femenino que sigue identificándose con el "ángel del hogar" y, por otro, no enfrentarse a la sociedad de su tiempo. En este tercer libro, aunque sigua percibiéndose esa doble voz, ésta está disipada en pos de una reivindicación más profunda y abierta hacia la mejora de los derechos de la mujer.

La contrapartida viene en el momento en el que resalta el prototipo de mujer moderna. Carmen de Burgos muestra este modelo de mujer en la joven italiana que lee absorta libros revolucionarios; la autora se maravilla de ese país suizo en el que cabe la más pura de las libertades y en donde el pueblo entero no teme a revoluciones ni a anarquismos porque reina la tolerancia absoluta (45). Esta referencia que es la continuación de la que hizo en su libro Por Europa al llamar a Suiza, la libre en contraposición de la católica España, no es más que otra muestra de la inserción de un discurso feminista que quiere revalorizar a la mujer en términos de absoluta igualdad de derechos. Al tomar como espejo a esta mujer, muestra una liberación política y una liberación femenina por medio de la lectura pública de un libro. El hecho de que una mujer leyera un libro públicamente era inaudito en la sociedad española, pero mucho más inaudito era que este libro fuera un libro de ideas políticas. De esta forma, con esta mención a la joven leyendo un libro de ideas revolucionarias, hace que la mujer se inscriba en el concepto socio-político-sexual en igualdad de derechos. La autora reclama un nuevo espacio para la mujer mediante un el discurso feminista de emancipación para provocar la reacción de un público de ambos sexos ante la necesidad de una reforma socio-sexual. 
A su vez, Carmen de Burgos percibe que en Suiza: "Se ve que existe un concepto de los derechos de todos, una práctica de verdadera libertad" (46). Este era un proyecto ilustrado que defendian las feministas. La libertad y el espíritu revolucionario de los suizos se extienden, según la autora, a la más pura e íntima interpretación de sus cuadros. Se detiene a analizar la muerte vista en los cuadros de los pintores suizos y expresa, mediante un discurso de crítica social, la denuncia que hace la autora de la desigualdad que existe en la sociedad entre hombres y mujeres, pero, a su vez resalta la igualdad que existe en ambos sexo ante la muerte. En definitiva, la autora propone que si existe igualdad ante la muerte, debería también existir igualdad en la vida y, por extensión en todos los aspectos de la vida de una sociedad. Al expresar la forma en que los pintores plasman la muerte sin distinción de sexto, la autora está haciendo una crítica social que, a su vez, va también dirigida a la Iglesia. Para de Burgos, la iglesia en su estado puro debería haber acompañado a los movimientos revolucionarios para adquirir la igualdad entre los individuos:

Cuando estas obras aparecen en lugares santos o con caracteres religiosos y vemos como la Iglesia misma lanza valientemente ese grito de protesta contra la desigualdad, pensamos que sin el puritanismo que le impusieron los cismas ella sola nos hubiera llevado sin detenerse por el camino de la revolución y el paganismo. (57)

Dinamarca es un país moderno para de Burgos, con un amplio sistema de comunicaciones y servicios públicos admirables, en donde el bienestar colectivo está asegurado por el gobierno. De Burgos explica la organización de sociedades cooperativas en la industria que han dado al país una prosperidad envidiable: "Se nota el bienestar 
colectivo, se ve cómo la nación prospera y se engrandece... Las sociedades cooperativas han desarrollado la industria de la lechería, y el comercio progresa gracias al crédito que su honradez alcanza en mercados extranjeros" (98). De esta forma, pone de manifiesto la necesidad de que el gobierno se involucre en la ayuda al comercio y a las empresas cooperativas: "el Gobierno se preocupa de proteger los intereses de los pequeños industriales, ahogados por el desarrollo de las grandes empresas. Los subvenciona, les proporciona herramientas y les hace los préstamos necesarios" (98-99). Es evidente que la crítica que hace a la sociedad española es mucho más tenue y menos abierta que en los dos libros anteriores, pero no por ello tanto o más efeciaz. Si bien, Carmen de Burgos expone una escritura meramente descriptiva en cuanto a los avances que ha hecho el gobierno danés sin dar juicio de valor, a su vez, a pesar de que no critique directamente el sistema español, proyecta en el lector una reacción en contra del gobierno de España puesto que no existían esas subvenciones en el país y el gobierno nunca se ocupaba del pequeño empresario.

También es interesante mencionar el avance en cuanto al pensamiento de la autora con respecto a su implicación socialista. Se percibe un acercamiento más radical y profundo respecto a los movimientos socialista y anarquista. La autora describe estas sociedades europeas que han alcanzado un bienestar económico, político y social por medio de su espíritu democrático, tolerante y por su organización socialista. Esta sociedad moderna y próspera llega al límite de que el gobierno subvencione la educación en todos los ámbitos profesionales y la autora lo expresa de la siguiente manera: "En ningún país del mundo se gasta más dinero que en Dinamarca en la enseñanza del obrero; escuelas, institutos, pensiones para viajar; los patronos están obligados a procurar que los 
obreros aprendan bien su oficio y les hacen asistir diariamente a las escuelas profesionales" (99).

A su vez, exalta la participación de la mujer en todos los aspectos de la vida del pais: "La mujer tiene ancho campo, abierto en todos los empleos y carreras, es electora y elegible y goza de un gran respeto y una gran libertad" (99). Esta cita es fundamental porque es la continuación de la petición que proponía con la joven lectora de libros revolucionarios y, a su vez, supone un avance más profundo en las demandas que proyecta Carmen de Burgos. En este caso, ya no sólo busca una mayor participación de la mujer en la educación; sino que la pone en plenitud de igualdad frente al hombre en todos los campos de la vida de un país. Nuevamente, no hay que olvidar que la participación de la mujer en instituciones educativas no estaba tan restringida como los primeros años de la centuria ya que la mujer podía, desde 1910 , acceder oficialmente a cualquier carrera universitaria en España. ${ }^{41}$ De esta forma su petición va más allá y su discurso se hace más radical, ya no se conforma con algo que es accesible a todas las españolas que lo deseen, sino que desea que se amplíe la participación de la mujer en el terreno político: con el derecho a votar y ser elegidas políticamente o que puedan acceder, no sólo de derecho, sino de hecho, a cualquier oficio que deseen. De esta forma, su discurso se ha convertido en un discurso reivindicativo feminista y completamente directo.

Una de las cosas que sorprende más de su viaje a Suecia es la descripción que hace de las mujeres. Se asombra de la gran libertad que gozan y de su aversión hacia el matrimonio. Expone una sociedad en la que la mujer, por su naturaleza versátil, no le da

${ }^{41}$ Para mayor información, refiérase a los libros de Carmen de Zulueta: Cien años de Educación de la mujer española, y a Ni convento ni collage. La Residencia de Señoritas. 
importancia al matrimonio porque se cansan rápidamente de relaciones prolongadas: "Libertad mucha. En cuestiones de moralidad la manga es ancha...son enemigas del matrimonio; se cansan pronto de una misma amistad y los maridos están obligados a ser tolerantes. Un marido celoso o despótico estaría en ridículo y se quedaría sin mujer" (162-63). También se asombra de la amplia participación que tienen en la vida laboral, pero también, resalta que su trabajo es dificil y mal pagado: "La mujer trabaja mucho aquí; el trabajo es duro y mal remunerado" (162). Es evidente que, aunque la crítica no sea directa, la autora está poniendo en el tapete una serie de reivindicaciones que eran insospechables en sus dos libros anteriores. En primer lugar, propone una libertad matrimonial e implícitamente un sistema de divorcio legal y real en la vida de sus ciudadanos. Por otro lado, reprocha la injusticia que sufre la mujer en el terreno laboral. A estas mujeres que trabajan a la par del hombre y duramente, se les paga mal. En este sentido incita al lector a percibir la necesidad de una justicia laboral y de una remuneración justa para cada trabajo especifico sin diferencias de sexo.

En cuanto a la educación en Suecia, la práctica absoluta de la igualdad entre el hombre y la mujer hace que tengan la misma educación sin limitaciones. Esta libertad e igualdad con el hombre hace que según, de Burgos, la mujer adopte un papel típicamente masculino, según la mentalidad tradicional, y que no le dé importancia a los tabúes y prejuicios de la mentalidad tradicional. En este sentido, Carmen de Burgos adopta la postura de Simone de Beauvoir, quien dice que no se nace mujer, sino que se hace 
mujer. ${ }^{42}$ Así pues, de Burgos está mostrando implícitamente, que las diferencias entre lo femenino y lo masculino son producto de la educación y no de la biología:

Pero hay que tener en cuenta que ellas y ellos tienen los mismos temperamentos y la misma educación; las mismas ventajas de ambiente... Ellos se entretienen con sus amigas mientras ellas hacen un viajecito con sus amigos. No se preocupan de estas pequeñeces a las que no les dan importancia, ni alteran la felicidad del hogar. (163)

Es innegable que el discurso de la autora es ahora totalmente feminista en la reivindicación de una postura socio-sexual de una implicación altamente moralista que se resume a una oración: "La infidelidad no altera la felicidad del hogar." Esta declaración absolutamente chocante y con repercusiones dramáticas irrumpe en forma de voz interior que aboga por unas libertades absolutas en el plano social para la mujer. Si bien inserta esta declaración, también, rápidamente evoca al escritor sueco que más ha criticado el carácter de la mujer: Augusto Strimberg. Carmen de Burgos intercala los dos tipos de discursos para, de una forma sutil, aminorar el efecto de la libertad absoluta expuesto unas líneas antes y para no alienar a su público. Utiliza el discurso feminista de reivindicación de los derechos absolutos de la mujer, pero inserta un discurso masculino tradicionalista para paliar el efecto dramático de sus palabras:

[el] gran escritor, novelista, historiador y dramaturgo de genio que ha retratado en sus obras todos los defectos, falacias y ruindades de nuestro sexo. El gran enemigo de la mujer conoce maravillosamente su corazón, y

${ }^{42}$ Para mayor información refiérase a su libro El segundo sexo. 
cuando combate el feminismo tan denodadamente, creyéndolo nocivo para su país, lo hace con una verdad y una honradez que quizás estemos más capacitadas para comprender nosotros, aferrados a los atavismos románticos de nuestra tierra y nuestra raza, que estas gentes moldeadas ya en ambiente tan distinto. (163)

Concluye con una duda: "¿Quién está en lo cierto? No me atrevería a afirmarlo" (163). En principio, se percibe una ironía en cuanto a que los españoles están más capacitados a denunciar el feminismo por sus condiciones geopoliticas y sociales y manifiesta, por medio de esa conclusión, una estrategia para causar la duda en sus lectores. A su vez, intenta mantener un discurso conciliador entre las dos posturas más radicales y extremistas de la sociedad: el feminismo puro y el conservadurismo puro. Esta exposición de los extremos proyecta una visión hacia un moderantismo y un determinismo natural.

Nuevamente, establece un discurso feminista al describir la independencia de las suecas que han hecho de ellas mismas, mujeres con talento. Es práctica habitual que de Burgos inserte casos específicos de mujeres notables como ejemplos modélicos a seguir. De esta forma, la autora expone que el número de mujeres ilustres es considerablemente mayor en Suecia que en otros países en relación con su población (164) para resaltar que la mujer sueca ha adquirido el poder del que carece la española.

La referencia más directa al sistema educativo, la hace Carmen de Burgos en la ciudad de Upsala, en la que la autora dice que se enseña en el aula de una forma dogmática y en la que el edificio más importante es la universidad. El conjunto de la universidad hace de la ciudad un entorno lleno de "edificios didácticos" (167). La 
escritora hace una crítica al estudiante sueco que no tiene el espíritu alegre del español. También critica la forma en la que viven los estudiantes ya que, en lugar de promover la unión del pais, suscitan la división del territorio. En este sentido, la autora relata la forma en que los estudiantes conviven en albergues llamados "naciones": "se entiende por naciones las casas de estudiantes, establecidas en trece edificios suntuosos, que corresponden a las diferentes regiones en que está dividida Suecia" (168). Lo que para los suecos es una forma pedagógica de enseñanza de educación cívica y administración autonómica, para de Burgos supone un divisionismo que sólo lleva a incrementar la intolerancia, a fomentar el regionalismo para resaltar los defectos de cada región (168). La autora expresa que: "Desde luego no me parece el medio más progresivo de educación cuando el ideal moderno ha de tender a borrar regiones y fronteras" (168). A pesar de esta nota discordante en el régimen de organización de las universidades, en definitiva, para Carmen de Burgos el pueblo sueco es un pueblo racional con una mentalidad positiva y dada al estudio y la investigación ya que:

la ciencia detenida entre nosotros por las hogueras de la Inquisición mostrase su verdades y realidad triunfantes... por la modalidad de su espiritu su religión había de ser protestante, para permitir la investigación minuciosa, el examen, la enunciación de verdades demostrables. Un acomodo de la religión y la razón. (169)

En ninguno de los tres libros se ha borrado, ni se ha atenuado el ataque directo que hace la autora a la Iglesia y a los errores cometidos en contra de la razón. Se sigue percibiendo que su crítica es mucho más tenue que en los dos libros anteriores en donde aparecía de forma extremadamente directa. Ahora, explica la unión de la Iglesia con la 
razón, exalta al protestantismo por haberse adaptado a la mentalidad sueca y haber respetado los ímpetus de la razón, pero sin dejar, por ello, de ser un pueblo religioso. La mentalidad sueca concibe que: "Su cristianismo se ha hecho más fogoso; son más observantes que los católicos" (169-70) y a su vez: "existe la libertad de cultos y se consiente el matrimonio civil para católicos y judíos... mas para desempeñar los altos cargos hay que ser luterano" (170).

En cuanto a Noruega, la autora dedica gran parte de la sección a analizar la literatura noruega, su influencia en la germánica y los escritores más representativos del país. Analiza detalladamente las producciones de éstos y las corrientes literarias a las que se aproximan, relacionándolas con referentes conocidos españoles. A pesar de que esta parte ocupa la mayor cantidad de capítulos del libro, el sentimiento que expresa la autora es un tanto bipolar. Admira la cultura noruega, la gran cantidad de artistas que han dejado huella tanto en el país como fuera de él; pero a su vez, le produce una gran melancolía y tristeza ese pueblo sin sol que la autora lo expresa al describir la "melancolía noruega de mar y de montaña que se siente siempre, hasta sin mar y sin montaña, melancolía de su cielo, de su luz, como un presentimiento o una amenaza de la falta de sol" (255). A pesar de ello, Carmen de Burgos define esta sociedad como: "muy pura y honrada" (196).

Al igual que en Suecia, lo que más resalta la autora es la libertad con la que cuentan las mujeres noruegas en la vida pública y política del país: "Tienen voto en los municipios y pueden ejercer cargos públicos... Recientemente, las mujeres han tenido asiento en el Parlamento, y su influencia bienhechora se deja sentir en las costumbres y sobre todo en su admirable Liga contra el alcoholismo" (215). Vuelve a percibirse un discurso feminista reivindicativo de los derechos sociopolíticos de la mujer en una 
sociedad moderna, libre y socialista y los aportes que la mujer ciudadana puede hacer a la sociedad.

En cuanto a la educación de la mujer en Noruega, la misma libertad de la que gozan en la vida pública, se extiende al terreno educativo. Burgos expone que: "La mujer tiene una gran libertad... Las leyes las protegen y ejercen todas las carreras: la Medicina, el Profesorado, la Abogacía. Tienen acceso a la Universidad y su <Unión Feministas>, fundada en 1884, les ha dado mucha fuerza; gozan de la libre disposición del producto de su trabajo" (214-5). Esta cita encierra el nuevo prototipo de mujer para Carmen de Burgos. Ya no es una mujer que tiene solamente acceso a la educación, sino que goza de plena libertad para participar en la vida social, económica y cultural de su país en igualdad de condiciones que el hombre. Para la autora, los países escandinavos suponen el modelo de sociedad libre y democrática que se debería de imponer en los demás países. El único problema que les separa de éstos es la diferencia en el espíritu de sus ciudadanos. Mientras que el escandinavo es tolerante y absolutamente democrático, el latino no lo es. Esta es la clave de su proyecto. Al igual que el caso de las mujeres, el latino en general, no es tolerante porque no tiene una educación basada en la tolerancia. No se trata pues, de una cuestión de la naturaleza del individuo, sino de su educación.

Otra cita de la autora con respecto a la educación y con implicaciones políticas es la siguiente: "La enseñanza es obligatoria; no hay analfabetos, y así se comprende el sufragio universal, extensivo a la mujer, que da tan buenos resultados" (217). Con esta cita, se expone explícitamente las implicaciones de la educación para el desarrollo de la mujer. A partir de ese momento, se define el feminismo de Carmen de Burgos que pone de manifiesto la importancia de la educación de las mujeres para conseguir el derecho de 
éstas a la igualdad en todos los campos de la vida un país. Mediante la educación, una sociedad se hace más libre y democrática, se acepta a la mujer como un individuo en igualdad de condiciones, se amplia el derecho al voto y ello lleva consigo un resultado óptimo.

Finalmente, vuelve al tema primordial del libro: la comunión con la naturaleza. Su viaje a Noruega es exaltación máxima del espectáculo de la naturaleza. Esta comunión natural se hace palpable al visitar las comunidades laponas y la Finix Térrea. En estos parajes se produce un despliegue de emociones y de unión con el medio que la rodea hasta el punto de que la autora lamenta el regreso brusco a la realidad cotidiana después de viajar a lo más profundo de la maravilla de la naturaleza:

Hay que seguir la ruta del destino; volver al mundo de siempre... tengo que hacer un esfuerzo para poder moverme, para poder cerrar los ojos, librarme de la sugestión de este tinte azul pálido que envuelve todas las cosas en su luz difusa, esa luz infinita de espacio en el que ya no hay un horizonte que nos oculte los astros, en el que nosotros también nos habiamos sentido ilimitados e infinitos. (301)

Su viaje por Alemania supone para la autora la culminación de la aversión hacia lo germánico, que ya se había estado gestando en los libros anteriores. Alemania pesa, repele (18), "el país está todo preocupado para no perder el tiempo y bastarse cada uno

${ }^{43}$ Carmen de Burgos inserta una referencia temporal en la que indica que el viaje que realizó a Alemania es anterior al que hizo a Dinamarca, Suecia y Noruega. De Burgos dice: "no se puede perder ni una hora si hemos de recorrer Dinamarca, Suecia y Noruega, para entrar luego en Rusia" (32). Parece ser que salió de Alemania en dirección a Noruega y allí le pilló el estallido de la Primera Guerra Mundial. Canceló su viaje a Rusia 
por sí mismo" (20). Su antipatía por el país se extiende a todos los aspecto de la sociedad, la gente es de aspecto feo, calculadores, racistas y con un espíritu bélico y militarista que oprime y asusta. La repulsión de la autora hacia el pueblo alemán se incrementa en el momento en el que estalla la Guerra. Los describe al cantar el himno nacional como gentes que: "Abren mucho la boca, gesticulan y gritan como demonios; sus caras grasas y rubicundas parece que van a reventar en la excitación sanguínea que les produce su entusiasmo' (42). Llega hasta el límite de describirlos como:

Los alemanes, son, en efecto, de una raza distinta, inferior si no miente la frenología. Esas frentes espesas, huesudas, cuadradas y todos esos rasgos macizos acusan animalidad, grosería, un pensamiento tardo, que se refleja en los ojos de cristal, sin mirada, con esa expresión vaga, incierta, desleal y $\sin$ fijeza. (59)

Es una raza, que según la autora, a pesar del aspecto superficial de civilización, revela rápidamente a un pueblo bárbaro. Lo expresa diciendo: "con poco que nos fijemos en sus predilecciones guerreras, sus crueldades, su soberbia y su afición a los goces materiales más groseros, se ve cómo bajo el baño de civilización late su verdadero temperamento" (59). Lo único que redime al país es ser la patria que vio nacer a Henri Heine y por la limpieza de sus ciudades y el cuidado que hay por su entorno.

A pesar de la aversión que siente por el pueblo alemán, no deja de reconocer que en el terreno educativo hay aspectos que merecen la pena como la forma en la que los alemanes proponen la educación unida a la naturaleza. Carmen de Burgos explica que a

y decidió regresar rápidamente a España, entrando de nuevo por Alemania; pero esta vez, el país estaba en los albores de la guerra (34). 
cada niño se le da una planta para que la cuide y la lleve después a sus exámenes. Pero este amor a la naturaleza, se queda rápidamente nublado por el sentimiento militarista que no deja que el pueblo engrandezca su cultura. De Burgos explica que le da "lástima que esta bondad que dan las flores la destruyan luego con esa exagerada educación militarista que inculca la escuela en el corazón de los niños y niñas y que es la sombra que no deja brillar su cultura" (22).

En definitiva, lo único que podría redimir al país de su espíritu bélico e "inferior" en términos de de Burgos es la unión con la naturaleza; pero esta unión queda relegada a un segundo plano por el extremado barbarismo de los germanos que no han sabido conceder a la pureza, la libertad y la paz el lugar que le corresponde para crear una sociedad verdaderamente pura.

Inglaterra para la autora revela el sentimiento de superioridad que se muestra desde el principio al titular el capítulo como: La superioridad inglesa. Y donde expone cómo se van notando las características que definen al país:

Sin saber cómo se va infiltrando en nosotros el concepto de la superioridad inglesa. Vemos la Inglaterra firme, inconmovible... Se siente la confianza, la serenidad, lo perdurable y recio de su poder... Esta raza firme y tranquila... vela por su poderío y su justicia de un modo digno, serio, fundamental. (84)

A esta superioridad inglesa, lo único que Carmen de Burgos no perdona es el puritanismo inglés que ha dejado en el olvido a grandes genios de las letras como Oscar Wilde y Lord Byron a causa de su equivocado sentido de la moralidad (116). 
Se percibe el constante contraste entre este país y Alemania. Sus gentes pacíficas y contemplativas (96) dan a la autora una sensación de paz, de silencio y de limpieza (9697) que anhelaba después de la gran exaltación producida por los acontecimientos bélicos que acababa de sufrir. Se inserta el discurso femenino de la domesticidad por medio de la descripción de las comidas típicas de los ingleses y el ideal de la familia que estas gentes poseen. Describe la ciudad de Londres como conservadora rígida y absorbente donde el mayor ideal romántico de su pueblo es el culto al hogar (100).

La parte más extensa del libro está dedicada a Portugal. En ella se percibe una diferencia con el resto del cuerpo del texto al incluir una dedicatoria al principio del capítulo ofrecida a la escritora Ana de Castro Osorio. ${ }^{44}$ La admiración por la feminista portuguesa la lleva a expresar: "A la admirable Dña. Ana de Castro Osorio, gran espíritu, que tanto ha influido en el engrandecimiento y la libertad de Portugal" (137). Al dedicarle esta sección a la figura más representativa del movimiento feminista en Portugal, la autora se inscribe dentro de una tradición de lucha feminista. Impone una forma nueva de acercamiento a una lectura en la que ya abiertamente apoya el feminismo que esbozó en Suecia al desmantelar la institución del matrimonio y desmantelar la visión tradicional de la mujer dentro de esta institución al alegar: "la infidelidad [para los suecos] no altera la felicidad del hogar" (163), anteriormente mencionada. Además, busca la igualdad de la mujer y desea implementar reformas que la ayuden a adquirir esa igualdad. En este sentido, pone de manifiesto los avances que las mujeres de todos los

\footnotetext{
${ }^{44}$ Con Ana de Castro Osorio mantuvo una relación durante muchos años. Carmen de Burgos fundó la Cruzada de las mujeres española a imagen de la que Ana de Castro fundó en Portugal. Asimismo, de Castro era la directora de una revista con la que colaboró Carmen de Burgos, Portugal Feminino.
} 
estratos de la sociedad portuguesa han conseguido para reivindicar todos sus derechos. De esta forma, para de Burgos, la mujer en Portugal ha conquistado fronteras que son impensables en España en ese momento. Carmen de Burgos indica que las mujeres portuguesas son más refinadas y sabias que las francesas o inglesas (207) e incluso dice la autora:

las mujeres del pueblo y de clase media han dado siempre en Portugal muestras de inteligencia y energía. Ellas han laborado de tal modo en la implantación de la República, que una gran escritora francesa que visitó Lisboa,... advirtió a la reina Amelia: $<$ Señora: es preciso atraer a las mujeres portuguesas, porque en ellas está el peligro>. (208)

Estas mujeres que han sabido participar de forma activa en los movimientos políticos de su pais "están más adelantadas y marchan a la conquista de todos sus derechos de un modo seguro y rápido" (208). Es por eso que a diferencia de España, han conseguido el voto para la mujer (208). La autora resalta los valores típicamente masculinos de las mujeres ilustres portuguesas. El ejemplo más claro es el de la escritora Ana de Castro Osorio de la que indica es: "figura interesante de esas mujeres de la Revolución que se han consagrado, quizás con más intensidad que los hombres, a la gran obra social" (209). Esta mujer simbólica, no pierde su feminidad ya que la autora aúna la concepción de la mujer liberal con los atributos femeninos ya que Castro Osorio: "es una de esas mujeres sencillas, afables, llenas de naturalidad; dulces y buenas, que parecen querer hacerse perdonar su superioridad con su modestia" (210). De Burgos resalta la figura de Castro Osorio como una mujer excepcional que ejerció las profesiones propias de los hombres al participar de forma activa en la vida política del país. Esta mujer realizó: 
obra sociológica admirable. Presidenta del gremio Carolina Angelo y de la Liga Republicana, luchó denodadamente para la implantación de la República...ha influido en la ley del divorcio, en la reforma de los códigos. En la actualidad ocupa uno de los puestos que se han dado a la mujer en el nuevo Ministerio del Trabajo. (210)

Carmen de Burgos, muestra a las mujeres portuguesas como modelos que "siendo tan hermanas nuestras son tan distintas, tan extraordinarias y tan insospechables" (211) para reivindicar nuevamente la misión de la mujer que lucha por reclamar los derechos que les son propios en la sociedad. Mediante la figura de Castro, la autora no sólo abate el discurso tradicional propuesto para las mujeres, sino que propone una liberación completa de la mujer en todos los ámbitos de la sociedad. A su vez, Carmen de Burgos, es consciente de la alienación que puede causar en sus lectoras esta visión tan radical de la mujer y aúna a este feminismo un tanto exaltado otro más moderado al no despojar a la figura de Ana de Castro Osorio de sus atributos femeninos tradicionales. En este sentido, la autora dice que: "Ana de Castro es viuda del eminente poeta Paulino Oliveira, que murió siendo cónsul en el Brasil, y se ha dedicado a la tarea de educar a sus dos hijos" $(210)$.

El discurso de Carmen de Burgos tiene una función específica. La autora se da cuenta de las implicaciones que puede tener su postura radical en la sociedad tradicional española en general, por ello, después de proponer estas afirmaciones tan controversiales para la época, aminora el efecto subversivo que pudieran tener redefiniendo su postura desde una perspectiva más moderada. Esta estrategia que utiliza Carmen de Burgos 
permite ampliar los márgenes de acción de la mujer ya que ya ha subvertido su discurso hacia unas demandas más específicas a favor de los derechos de la mujer.

Al mismo tiempo, también propone esa visión feminista más moderada al interpretar la institución del matrimonio desde el punto de vista etimológico: "[como] oficio de la madre [para] rendir un homenaje a los desvelos maternos y al respeto que en este país gozan las mujeres guardadoras del hogar y educadoras de los hijos" (157). De esta forma, presenta la teoría de la domesticidad y del "ángel del hogar" no de una forma sumisa y tradicional, sino como una institución digna que se dedica a la importante misión de la educación del hijo y por extensión, la forjadora del futuro de un país. Propone el Matrimonio, con mayúsculas, como un oficio de mujer, un oficio que la redime y la libera de los convencionalismos tradicionales, ya no es madre y esposa sumisa, sino educadora. De esta forma, la autora profesionaliza el trabajo de madre y esposa y adopta un vocabulario propio de la esfera pública masculina para redefinir la función de la mujer en la esfera privada. Con ello, consigue darle prestigio al trabajo tradicional de la mujer como madre educadora y esposa compañera. Este nuevo oficio, en Portugal es mucho más importante que en otro país porque le permite tener un papel de protagonismo frente al hombre. En Portugal, los hijos eligen el apellido que quieren llevar primero, pero preferentemente escogen el materno. Esto es significativo porque resalta ese papel fundamental de la mujer dentro de la sociedad que además de educar el futuro de la nación, es el estandarte de la continuidad socio-sexual.

El modelo de mujer esposa y compañera sólo se presenta bajo un ambiente de republicanismo. De Burgos lo muestra en la figura de Elzira Dantas, esposa de Bernardino Machado, presidente de la República portuguesa. Esta mujer aúna las virtudes 
de la mujer tradicional madre y compañera que lucha a la par de su marido por la causa de la libertad (187). De esta forma, mediante la descripción de Elzira Dantas, la autora traspasa los límites impuestos por la visión del modelo tradicional de la mujer y la muestra como madre educadora y esposa compañera pero con una doble proyección. Por un lado, respeta el discurso de la domesticidad y, por otro, proyecta el papel de la mujer a un espacio públicos al ser presidenta de La Cruzada de Mujeres Portuguesas. Con esta reconciliación de los dos ámbitos privados y públicos de las mujeres, la autora propone un proyecto de consolidación político y cultural de un estado liberal en el que la mujer participa de forma activa y sin perder los atributos tradicionales de su género.

En cuanto a la referencia concreta hacia la educación de la mujer, no se percibe explícitamente, solamente hay algunas alusiones al carácter regeneracionista del pensamiento de los dirigentes políticos portugueses y una referencia concreta a la Institución Libre de Enseñanza, a Giner de los Ríos y a Morote. Describe a los dos últimos presidentes de la República portuguesa, Machado y Teófilo Braga, que ambos fueron profesores catedráticos de la Universidad de Coimbra. Las descripciones que hace de ambos dirigentes tienen una doble vertiente. Son hombres íntegros y políticamente honrados y los dulcifica mediante la participación que tienen en la vida diaria en lo que se mostraría espacio propio de lo femenino ya que participan de la vida cotidiana y familiar. De Machado, la autora expone que: "Se necesita un esfuerzo de voluntad para unir la figura del gran revolucionario, del jefe de Estado, con este padre de familia bondadoso, tan enamorado de sus hijos, de un gesto tan sencillo y tan señoril" (191). Y de Bragas en cuanto a su sencillez como persona de a pie "que revela la modalidad simpática de este hombre que siendo presidente de la República seguía viajando en tercera clase y 
paseando a pie por la ciudad" (193) o cuando observa: "Yo no soy más que un profesor, un pobre hombre- me decía; y se veía bien la sinceridad de su palabra al afirmar su deseo de no ser más que profesor" (194). De esta forma, presenta el sistema político perfecto que existe en Portugal por la existencia de la unión del hombre político que es a su vez artista y hombre de ciencia (197).

Finalmente, Carmen de Burgos propone como figura reconciliadora de su visión feminista a la figura histórica de Carolina Coronado. En esta escritora española en Portugal, se representaba todas las aspiraciones de trasgresión de la mujer. Esta mujer, para de Burgos, fue un modelo para las mujeres. La define como: "cerebro privilegiado, construido definitivamente por la Naturaleza con toda la fatalidad de su astro poético" (265) y que es la escritora y poeta romántica que impuso el modelo de mujer que, como examina de Burgos: "legitimó la inclinación literaria de la mujer hasta el límite que hoy tiene" (264).

En conclusión, Carmen de Burgos en estos tres libros de viajes a Europa, además de describir los países que visita, pasa revista al sistema social, político y económico de éstos. En sus relatos de viajes, los temas que más interesan en este estudio son, en primer lugar, el análisis que hace Carmen de Burgos de los avances que hay en Europa en el campo de la educación de la mujer. Éstos tienen como finalidad el deseo de la escritora de concienciar a los españoles de la necesidad de mejorar el sistema educativo español conforme a los avances producidos en algunos paises europeos. A su vez, destaca el interés que muestra por temas como el divorcio y el matrimonio y el papel que la mujer juega dentro de ellos. 
En su primer libro, Por Europa, la autora describe una de esas mejoras en el sistema educativo que han conseguido los franceses e italianos en cuanto a la importancia que tiene la naturaleza en la enseñanza. Para la autora, la naturaleza conforma uno de los elementos básicos para el aprendizaje del niño. Éste se encuentra en unión con la naturaleza y con el medio que le rodea y de esta forma, aprende a respetar y tolerar su entorno. A su vez, propone una enseñanza que incluye el arte como forma integrante del espiritu del niño porque para de Burgos, el arte desarrolla lo más íntimo y espiritual del individuo. En tercer lugar, exalta las condiciones higiénicas de las instituciones educativas de algunos países europeos que motivan al alumno al estudio. Otro de los avances que la autora resalta es la atención del gobierno francés e italiano en promocionar y crear gimnasios gratuitos y de acceso abierto a todos los ciudadanos. Este tema era de especial importancia dado que a la mujer española se le había negado la práctica del deporte o la enseñanza del mismo por motivos morales obsoletos.

En Suiza, la autora resalta la preocupación que tiene el gobierno de ese país por la educación de sus niños y la generosa subvención que concede a las instituciones de enseñanza para crear colonias de verano. En estas colonias se pretendía que el niño se acercara a la naturaleza y se fortaleciera física e intelectualmente. Asimismo, menciona que en este país, en donde la atención a la educación es tan alta, los ciudadanos son más conscientes, respetables y tolerantes y hacen del país un lugar sin crimen ni peligro. Al mismo tiempo, discute el papel de la mujer trabajadora y la instrucción profesional que ésta recibe en esos países, que sin intervención de las instituciones religiosas, ha conseguido prepararse profesionalmente para trabajos en la industria textil y la cigarrera con beneficios óptimos. Estas mejoras que ha visto en su viaje en estos tres países 
repercuten en la crítica que hace a España. Responsabiliza al gobierno español por la mala educación que se le da al niño y a la mujer y resalta la decadencia y la falta de progreso en el país y la necesidad de incrementar las subvenciones al extranjero para la formación de pensionados.

En su segundo libro, Cartas sin destinatario, la autora destaca el instinto comercial belga que le ha llevado a mejorar la educación haciendo de ella un producto comercial. Este instinto comercial hace que estos pueblos vean las instituciones educativas como empresas gananciales cuya finalidad es atraer el mayor número posible de alumnos; y para ello, estas instituciones mejoran la calidad de enseñanza que ofrecen. Asimismo, exalta la educación tolerante que existe en los Países Bajos en el tema del bilingüismo. El Gobierno permite que cada institución educativa implemente la enseñanza en el idioma o idiomas oficiales del país o la región en concreto. Lo más destacado, a pesar de la descripción de estas mejoras en el sistema educativo, es la forma en que la autora resalta su españolismo. Carmen de Burgos se cuestiona esa supuesta superioridad europea que, en defmitiva, no lo es tanto ya que estos países sufren las mismas lacras que en España: una educación insuficiente y un alto grado de analfabetismo. La única diferencia es en la percepción de sus logros. Mientras que el español se critica duramente, el holandés, el belga y el luxemburgués solamente realzan sus cualidades.

Finalmente, su tercer libro, Peregrinaciones, supone el compendio de las aspiraciones educativas de la autora. Estas aspiraciones se resumen en dos: la educación en la naturaleza y en la tolerancia. Estos dos principios convierten al individuo en un ser pleno que reconoce los valores igualitarios del ser humano sin diferencia de sexo. Este 
libro supone también una afirmación en su ideario feminista, que propone una conciliación entre el radical y el feminismo de tipo moderado. Por el análisis que hace la autora de los países del norte de Europa, ve la necesidad de adoptar un sistema de igualdad para hombres y mujeres en la educación por medio de la enseñanza obligatoria (como el caso sueco). Además, Carmen de Burgos defiende un sistema de igualdad de la mujer en el terreno profesional y político que sólo es posible con la imposición definitiva del voto femenino. Su viaje a Portugal tiene una peculiaridad ya que masculiniza la esfera femenina al hacerla pública y feminiza a los hombres dirigentes del país. Si bien no se altera, sustancialmente, los papeles socio-sexuales, sí se hace al mostrar su esfera de comportamiento privado. Esta técnica tiene como misión mostrar una sociedad igualitaria en términos de género. También, reivindica la figura de la mujer que participa activamente en los procesos revolucionarios del país pero sin pretender derrumbar la figura de madre y educadora y sobre todo propone la labor de la madre como un oficio y no como una cualidad natural e inherente de la mujer. A su vez, se perfila un proyecto de consolidación política y cultural de un estado liberal para que la mujer participe de forma activa sin perder los atributos de su género.

En definitiva, el tema esencial de la producción de Carmen de Burgos es la mujer y entorno a ella giran todos los temas subsidiarios. La finalidad primordial de la autora es analizar el ideal de la mujer moderna en una vertiente moderada. Este ideal de mujer se modifica con el tiempo y se percibe esta modificación primero, en su primer libro Por Europa, en donde se muestra la unión entre el "ángel del hogar" y la mujer educada y educadora; por supuesto con las limitaciones propias que a su sexo le impone el discurso patriarcal en que se mueve. En este sentido, la autora subordina la preparación cultural de 
la mujer a su misión de madre. Esta primera postura tradicional cambia hacia una posición más avanzada en su último libro. En Peregrinaciones, la escritora propone una mujer que además de ser buena madre, se educa para educar a los hijos, quienes están destinados a ser los futuros dirigentes del país, pero tiene igualdad de derechos en el campo político, con lo cual, la acción educativa privada se amplía al espacio público. A la vista de la realidad europea, propone para España una mujer emancipada con pleno derecho a la elección de cualquier carrera u oficio que desee y con plenos derechos políticos, abogando por el sufragio universal y defendiendo la posibilidad de que la mujer sea elegida representante político de un país. El papel educativo ahora se extiende a espacios simbólicos de poder y en actos explícitos de adquisición de poder.

La aspiración de Carmen de Burgos es que las actividades que considera modélicas impregnen el texto con una intencionalidad preestablecida: influir al lector de la necesidad de que en España se produzca un cambio social, cultural y político, subrayando en éstos un carácter de género: la mujer. En este sentido, la literatura de viajes como género literario marca unas diferencias entre la producción escrita por hombre y por mujeres. Entre las diferencias más marcadas, en la producción de relatos de viajes de mujeres en general, destacan la visión de la narradora como un protagonista desprotegida que hace de su discurso una reivindicación y una forma de escape tanto de la sociedad que la oprime como de su interior o de su condición de mujer, en contraposición con las narraciones escritas por hombres en la que éste es el héroe magnánimo y valeroso. A su vez, el discurso femenino de los libros de viajes se hace personal y descriptivo mientras que el del hombre es categórico, autoritativo y se convierte en una forma de descubrir su masculinidad. Otra diferencia es la representación 
de la mujer en el texto. Mientras que las escritoras muestran a una protagonista activa y ejecutora de la acción, el escritor la representa como un personaje siempre secundario, pasivo y objeto de deseo o del destino final. Otra característica de los textos escritos por mujeres es el travestismo que aunque en estos textos no se presente per sé, sí se percibe una adopción por parte de la autora de estrategias autoritativas masculinas. También es importante destacar la forma en que la escritora plasma su visión interior del proceso del viaje, mientras que el hombre sólo presenta una visión exterior de éste.

A su vez, y ésta es una de las características más importantes, las narraciones de viajes de mujeres presentan el discurso de la feminidad en el que muestran lo que se ha denominado "womanly weakness." Este efecto muestra a la protagonista como el sexo débil que proyecta una serie de cualidades como el miedo ante situaciones extremas por medio de sentimientos de inseguridad, de impulsividad y de curiosidad. También habla de los elementos más característicos del papel doméstico de la mujer. Dentro de este discurso se privilegian los temas relacionados con la higiene y la comida. Con esta técnica lo que se intenta es mostrar una autoridad de género para producir el efecto contrario: no es la mujer débil, sino que la autoridad que las mujeres tienen en los temas tradicionales domésticos, también se extienden a los demás temas de la esfera pública del texto. Se transgrede asi, el espacio femenino propio de un sistema patriarcal. Mientras que los hombres, en este sentido, reiteran su discurso masculino. Finalmente, en cuanto al estilo y la forma, los hombres utilizan un estilo sencillo y sin adornos, autoritativo y científico y, normalmente menos subjetivo que el de las mujeres. Las mujeres, por su parte, utilizan mayor cantidad de adjetivos con connotaciones más coloridas, frases descriptivas, más explicaciones, sumarios detallados y su contenido es más sentimental, 
subjetivo y con una escritura fragmentada, privada y compuesta por experiencias personales.

Esta forma que tienen las mujeres de escribir narraciones de viajes establece unos patrones específicos de género y los tres libros de Carmen de Burgos participan de ello. De esta forma, la necesidad de analizar estos tres textos bajo cánones de género tiene una doble finalidad. Por un lado, ratifica esta producción dentro de un discurso de género, lo cual, indirectamente muestra la desigualdad existente y establece unas caracteristicas recurrentes de este tipo de producción y, por otro, los relatos de viajes de la autora muestran las circunstancias sociales, políticas, culturales y concretamente educativas que afectan a la mujer en los países europeos a los que viaja y propone un cambio para la situación de la mujer española. 
PARTE II

\section{LA LITERATURA DE VIAJES DE CARMEN DE BURGOS COMO GÉNERO LITERARIO. REIVINDICACIÓN FEMENINA Y FEMINISTA}

"En los libros de literatura de viajes de Carmen de Burgos no hay las mentiras de los viajes, ni esa ansiedad de < sacar partido $>$, ni ese deseo de humillar a los demás que abunda en los libros de este género"

Ramón Gómez de la Serna

(Peregrinaciones, epígrafe 442)

\section{CAPÍTULO 1}

\section{INTRODUCCIÓN}

A partir de 1898 se comenzó un debate entre las dos Españas, la tradicional y la moderna, que configuró el punto de partida de una nueva forma de interpretar la vida tanto social, política, cultural y, como no, literaria. Este periodo al que se ha denominado la Edad de Plata de la literatura peninsular, tuvo como elemento más innovador la incorporación "de la voz femenina a la corriente general de la literatura" (Hurtado 139). Durante el primer tercio del siglo $\mathrm{XX}$, las escritoras comparten una serie de características comunes, entre ellas: "la ruptura con la historia femenina convencional, [el] cuestionamiento del amor y del matrimonio como finalidad de la vida, [la] participación en la vida pública [y la] defensa de ambiciones e ideales" (Hurtado 139-40).

La mujer viajera no es un fenómeno de principios del siglo XX. A partir del siglo XVIII, las mujeres viajan por diversos motivos: por afán de aventura, por motivos de salud, por descanso o por razones profesionales. En este último caso la viajera se desplazaba para realizar un estudio, alguna investigación o algún informe. Ésta es la 
razón de los viajes de Carmen de Burgos. La autora sale a viajar para aprender de la cultura de los paises europeos y trasmitir lo aprendido mediante su relato. Tanto si sus viajes son subvencionados por el Gobierno, como es el caso del viaje que relata en el primer y el tercer libro, como si son por placer, son viajes en los que se combina el afán de aventura con el viaje profesional. De Burgos analiza el panorama cultural de los países que visita y examina sus estructuras sociales y políticas; pero, a su vez, expresa la exaltación que le produce algún acontecimiento específico por el mero placer de vivir una experiencia arriesgada. En Por Europa lo expresa claramente en su visita al Vesubio en erupción, en el momento en el que corre la lava por sus laderas, la autora expresa su emoción ante el episodio de ir a un volcán activo y la seducción que éste le produce: "No lo puedo mirar tranquila; ejerce sobre mí la atracción irresistible del peligro; parece decirme: "¡Ven! ¡Ven tú que amas todo lo grande, ven ya que tu temperamento desea vencer dificultades y dominar obstáculos!" (232). Ante tales palabras resulta evidente que la autora transforma su viaje en una aventura de la que ella es el héroe de una situación peligrosa.

En cuanto a las diferencias que se han observado en la narrativa de viajes de mujeres en los últimos siglos, la única diferencia que se percibe de forma recurrente entre los relatos de viajes anteriores al siglo XVIII y los de finales del XIX y principios del XX es que en los primeros, el "trayecto, lo que se dice el puro discurrir del itinerario no formaba parte de sus objetivos [puesto que] el viaje era una incomodidad" (Albiac 140). Sin embargo, a partir del siglo XIX, gracias a las mejoras de los medios de comunicación y transporte, se comenzó a disfrutar del paisaje. En Cartas sin destinatario la autora menciona en varias ocasiones la comodidad de estos medios de transporte: "Aquí se nota 
más que en ninguna parte la facilidad de los viajes... los trenes son baratos y cómodos" (39). Estas alusiones hacen referencia a la inserción del tema de la modernidad. A su vez, se aprecia considerablemente en los tres libros de viajes de Carmen de Burgos, la importancia que le da la autora al paisaje como exaltación de los sentidos, sobre todo en su tercer libro Mis viajes por Europa. ${ }^{45}$

Asimismo, hay que tener en cuenta que, según Fernando Aínsa, el viajero, al realizar su desplazamiento produce un proceso de extrañamiento ante el nuevo entorno visitado que, a su vez, desdobla al escritor en un alter ego que mira desde fuera. El viaje se convierte, de esta forma, en un recorrido desde lo familiar hasta una confrontación con el otro, lo distinto y, por extensión, se produce una conquista de la identidad conformando una visión más completa del mismo viajero y de la realidad circundante. La nota más característica es que esta relación que se produce, da como resultado una unión entre el viaje y la escritura ya que la escritura nace para facilitar una comunicación a distancia entre el espacio y el tiempo (57). La consecuencia de este proceso de alejamiento es que se produce una distancia entre la verdadera realidad y la realidad del viajero; esta distancia está acentuada por las diferentes peculiaridades que conforman los países visitados con el país de origen y se incrementa con las caracteristicas literarias y culturales que rodean al viajero y que le influyen de manera directa. En el caso específico de los relatos de viajes de Carmen de Burgos, estas diferentes visiones de la realidad que

${ }^{45}$ La mayoría de las españolas viajeras de principios del siglo XX no se quejan de las incomodidades del viaje, todo lo contrario, alaban los avances tecnológicos en los medios de comunicación. Emilia Pardo Bazán, por el contrario, se queja de la incomodidad de los trenes, pero su visión es diferente y está mediatizada por unos estándares aristocráticos y una visión de superioridad de clase. 
percibe la autora están condicionadas por sus estados de ánimo. Así, pasa de mostrar de forma exaltada e idealizada, países como Francia, Italia o Portugal, a criticar países como Alemania o los Paises Bajos.

Se debe partir de la base de que los críticos literarios no se han puesto todavía de acuerdo a la hora de establecer una definición exacta de lo que es el género de literatura de viajes, pero, a pesar de ello, todos los críticos sí están de acuerdo en considerar que un relato de viajes propiamente dicho, no es nunca una narración novelesca en la que el viaje es accidental y no forma parte del corpus del texto, sino todo lo contrario, un relato de viajes debe ser una narración en la que el motivo o la estructura principal del relato es el viaje, ${ }^{46}$ y a éste se le supeditan los demás temas. ${ }^{47}$ Esto es importante en el momento de

${ }^{46}$ En este sentido, Lorenzo Silva expone que los relatos de viajes son "todas aquellas obras literarias que de uno u otro modo tienen el viaje como motivo o estructura, sea o no el viaje en sentido estricto su asunto principal" (Peñate 34). Esta defmición tiene un problema de base porque aunque este tipo de género sí debe de tener una estructura específica y su motivo debe de ser también propio de la narrativa de viajes, el asunto principal tiene que estar íntimamente conectado con el viaje en sí, puesto que de otra forma, serian autobiografias, memorias, o simplemente, novelas de cualquier tipo, en las que hay un desplazamiento. Este es el caso de Viaje de novios de Emilia Pardo Bazán, que no por ello se considera un relato de viajes per sé.

${ }^{47}$ En este sentido, Julio Peñate Rivero, en Relato de viaje y literaturas hispánicas, comete el error de incluir dentro de lo que se considera género de viajes a todo tipo de narraciones en las que por cualquier motivo se ha producido un desplazamiento tanto físico como psíquico. Si el viaje se ha producido de forma accidental o no, constituye parte de la trama de la narración o corpus de texto y no debería ser considerado un libro de viajes. Creo que es necesario siempre mantener un distanciamiento a la hora de perfilar una definición de género puesto que de lo contrario todo tipo de narración, ya sea literaria o no, entraría en conflicto con varios tipos de géneros completamente opuestos y divergentes entre sí. La literatura de viajes, a pesar de que responde siempre a las necesidades específicas de cada autor, tiene como motivo o tema principal el viaje (ya sea real o ficticio). En el caso específico de Carmen de Burgos, sus relatos de viajes son, como ya se ha dicho anteriormente, unos documentos narrativos y descriptivos, que tienen como finalidad la búsqueda introspectiva y subjetiva del autor-viajero al país visitado, en donde se realiza un proceso de percepción y descripción cultural de la nueva 
establecer un marco teórico que explique las caracteristicas de este género literario y lo deslinde con otros géneros similares. Asimismo, en el caso específico de las narraciones escritas por mujeres, es importante establecer las características peculiares y diferentes que este tipo de narraciones presenta con respecto a las producidas por los hombres para establecer las características distintivas de ambas producciones y mostrar que la escritoras utilizan una forma peculiar de escribir relatos de viajes para establecer autoridad discursiva e intentar reivindicar la necesidad de cambios sociales para las mujeres de principios del siglo XX.

\section{Enunciación de la literatura de viajes como género narrativo}

La narrativa de viajes es un género que la crítica ha considerado tradicionalmente como de menor importancia. Sin embargo, al igual que otros géneros literarios, las narraciones de viajes componen un vasto cuerpo dentro de las letras internacionales cuya producción se ha mantenido ininterrumpidamente a través de los siglos, claro está, teniendo siempre en cuenta las transformaciones históricas que todo género tiene a lo largo de su existencia histórica. Ahora bien, ya desde su establecimiento como modalidad genérica no tiene características precisas $\mathrm{y}$, a fin de establecer los rasgos que le son propios, es necesario determinar las diferencias existentes entre la literatura de viajes propiamente dicha, la literatura de viajes de ficción y las crónicas, memorias y biografias de viajes. Al mismo tiempo, es preciso establecer también las diferencias que existen entre la literatura de viajes escrita por hombres y la escrita por mujeres, sin las cuales no es posible comprender la función concreta que cumple la literatura femenina de viajes.

sociedad y se plasma esta nueva percepción intercultural con el propósito esencial de reflejar la incidencia que la cultura extranjera tiene en el país natal de la autora. 
Varios críticos han intentado hacer una definición del género de viajes que va, por un lado, desde lo específico, como el caso de José Manuel Herrero Massari, quien define la literatura de viajes como: "las narraciones autobiográficas de viajes por tierra o por mar, escritas en el transcurso de los mismos o una vez finalizados éstos, con la intención de darlos a conocer a un destinatario individual o colectivo" (17). Con esta definición, Herrero Massari pretende marcar los límites de este género pero, deja fuera muchas variaciones como son el caso de los relatos de viajes que no tienen la intención de publicarse. ${ }^{48}$ Por otro lado, tenemos definiciones como la de Bárbara Korte que engloban en este tipo de producción literaria todos los escritos en los que encontramos "la interacción entre el sujeto y el mundo que le rodea" (5). Para esta investigadora, la interacción forma parte de un proceso de percepción intelectual y construcción cultural mediante la cual el viajero se impregna, no sólo del entorno cultural del país viajado, sino que establece unos procesos individuales de percepción y de conocimiento que hacen de esta literatura un producto híbrido y subjetivo (6). Por supuesto, al igual que en el caso de Herrero Massari, esta definición se ajusta a unos determinados tipos de relatos de viajes y no a su totalidad. Asimismo, la defmición de Sofia Carrizo que dice que un relato de viajes debe ser un estudio narrativo y descriptivo en el que debe dominar el aspecto descriptivo para mostrar el objetivo final del relato como un espectáculo imaginario (14),

${ }^{48} \mathrm{He}$ querido incluir la defmición de José M. Herrero Massari porque con su tesis doctoral consiguió el premio extraordinario de doctorado de la Universidad de Alcalá en 1999. A pesar de que su estudio se centra en los siglos XVI y XVII, deja de un lado la producción escrita por mujeres. Si las englobara, debería modificar su definición y hacerla un poco más universal. Creo que la intención de que los libros de viajes esté categóricamente destinados a darse a conocer, ya sea a un público múltiple o individual, no siempre funciona en la literatura de viajes escrita por mujeres ya que muchas escritoras no tenían la intención de publicar sus libros de viajes. 
también responde a unos textos específicos dentro de lo que se podría llamar literatura de viajes; pero, es evidente, que deja de lado los relatos de viajes en los que no necesariamente predomine la función descriptiva o que ésta no tenga como objetivo final el espectáculo imaginario al que hace referencia Carrizo.

En defmitiva, todas estas definiciones parecen válidas ya que cada una de ellas se ajusta a unos propósitos específicos. La postura que se podría considerar más acertada es la que propone Ottmar Ette, para quien la literatura de viajes es un género "tragagéneros" (109), ya que con esta afirmación Ette quiere decir que debido a la hibridez de los relatos de viajes, en ellos hay cabida para otros tipos de géneros, pero a su vez, esta postura es en sí demasiado generalizada y esa misma generalidad no permite una clara determinación de las bases de lo que se podría considerar como literatura de viajes.

Con todo, hay algunos rasgos específicos que pueden permitir cierta delimitación de este tipo de producción literaria. En primer lugar, toda literatura de viajes tiene que tener como elemento fundamental la representación de las circunstancias del viaje; es decir, como señala Miguel Ángel Pérez Priego, las descripciones, las noticias o los informes del viaje tienen que dominar claramente sobre la experiencia del propio viajero y, al mismo tiempo, deben componer el cuerpo fundamental del texto (en Carrizo 5). De igual manera, todo libro de viajes debe estar constituido por la unión de lo que Sofia M. Carrizo llama lo documental y lo literario.

Dentro del elemento documental, la descripción juega un papel de vital importancia porque es la descripción lo que marca las diferencias entre géneros parecidos. Cuando una producción se constituye de narraciones descriptivas, hay que diferenciar si estas narraciones pertenecen al mundo de lo real o al mundo de la ficción. 
Cuando la narración de un viaje se convierte en materia imaginaria desligada del mundo real, el libro de viajes se transforma en libro de viajes de ficción, como el caso de Julio Verne o Juan Valera. En las narraciones de viajes de ficción, el contenido informativo está relegado a un segundo plano dejando el contenido literario o de ficción como elemento fundamental al que se supedita cualquier otro contexto narrativo.

Los relatos de viajes literarios tienen una relación muy estrecha con los relatos de aventuras dentro de un libro de viajes ya que comparten unas características fundamentales, como son: el peligro, el riego y la aventura. Toda literatura de viajes tiene una serie de situaciones de "riesgo narrativo," como lo llama Carrizo, que componen un cuerpo relativamente extenso dentro de la narración. En primer lugar, cuando estas situaciones de riesgo narrativo son la parte primordial del texto al que se someten las demás, este texto tiene un grado mayor de ficción. Mientras que, por el contrario, cuando estas situaciones de riesgo son solamente una variación más dentro del cuerpo narrativo en las cuales el narrador no ensalza la peligrosidad, estas narraciones se convierten en literatura de viajes no ficticia. Antonio Regales Serna denomina el referente de peligro de los libros de viajes: "un componente más de la andadura [y] el narrador no les otorga más jerarquía que la descripción de una ciudad, de un animal exótico o de una lápida recordatoria" (80). En segundo lugar, como indica Carrizo, el riesgo en las narraciones de aventuras dentro de un viaje aumenta el interés del lector por el desenlace. Carrizo dice que estos textos:

avivan las expectativas sobre diversos desenlaces y que empujan al receptor hacia el punto final [mientras que en los libros de viajes] los propósitos descriptivos.... "frenan" la lectura para poder asimilar las 
informaciones, reflexionar sobre ellas y disfrutar del asombro o del placer que depara cada una de las "escenas" del enorme espectáculo que proponen. (13)

En cuanto a la diferencia que existe entre las crónicas de exploración y descubrimiento y los libros de viajes, la más evidente se encuentra en el propósito de estos textos. La crónica de exploración, en resumen, es un documento en el que el narrador no tiene ninguna intención explícita de producir un documento literario. La ficción que existe en toda crónica de exploración responde a una intencionalidad predeterminada de antemano. Al mismo tiempo, manifiesta un elemento político que le da razón de ser. De esta forma, las descripciones de una crónica de exploración representan un discurso narrativo que explica un hecho o acontecimiento que se quiere destacar. Es decir, que si en algún momento existe descripción, esta descripción asume una función secundaria como ejemplo del hecho que se quiere resaltar. Carrizo expone que la prioridad de las crónicas de exploración es narrar lo que ella llama "procesos de mejoramiento o de empeoramiento" (15).

Las crónicas de exploración tienen su momento álgido a partir de 1492 con el descubrimiento y colonización de América que supuso un nuevo acercamiento a la forma de aproximarse a este tipo de literatura ya que antes de 1492 sólo se atenía a las conquistas y no a las exploraciones. Por un lado, el descubrimiento replanteó un proceso de acercamiento a una nueva realidad que tenía que definirse bajo unos cánones específicos y subjetivos. Este género literario, según Jenny Mezciems: "serves a worldly reality in which kings as patrons are anxious enough to believe" (7). El nuevo mundo encontrado crea un género nuevo, las crónicas de la conquista y la colonización, en las 
que se describe o se inventa a América. Esta recreación de la realidad representa una distorsión, no de hecho, sino de presentación en donde el autor describe la tierra con unos planes predeterminados y una intención de convencer y asombrar al lector. Por otro lado, estas narraciones tenían el propósito de intentar resaltar la participación de algunos individuos en los procesos de conquista y colonización, al mismo tiempo que enfatizaban el enriquecimiento personal que podía suponer el viajar a estas tierras recién conquistadas. ${ }^{49}$ Por su parte, Carlos Monsiváis explica que el propósito de las Crónicas de Indias es observar, comparar, anotar e inventar. Se trataba de hacer del Nuevo Mundo, un mundo habitable por medio del coraje, la valentía, la fe y la destrucción de los falsos ídolos. Las pretensiones eran múltiples: los conquistadores ansiaban perpetuar su fama, los misioneros, implementar la fe católica y los indígenas, preservar la memoria de su pasado (Monsiváis, "Chronicle” 25). En definitiva, para Monsiváis, la crónica del siglo XVI era una forma de capturar la historia, de preservar el tiempo y de convertir al indigena al cristianismo:

These soldiers and holy men sought to write neither history nor literature. For them, to chronicle was to seize the sensations of the moment, to capture chronos, to defend themselves from the enemy's version of history, to implicitly and explicitly celebrate their own grandeur, to save

\footnotetext{
${ }^{49}$ Los cronistas del descubrimiento resaltan su papel protagónico en el proceso de la conquista y colonización, pongo como ejemplo el caso de Bernal Díaz del Castillo, que con su Historia verdadera de la conquista de la Nueva España ejemplifica uno de los casos más conocidos, en el cual resalta, de manera evidente, la ansiedad de valorar su intervención personal en el proceso de la conquista de México.
} 
others' souls against their will, and to announce the blessings of Heaven. ("On the Chronicle" 26)

Al mismo tiempo, estos documentos que han sido considerados materiales de historia nacional o eclesiástica, o de la victoria de la civilización hacia la barbarie, tienen un elemento que para Monsiváis es esencial: tienen una alta cualidad literaria, porque para este crítico, la historia es también literatura ("On the Chronicle" 26).

En el siglo XIX se hacen muy populares las crónicas periodísticas en las que tanto hombres como mujeres, viajan a otros lugares para informar sobre gran variedad de acontecimientos del momento. El término crónica en el sentido periodístico del siglo XIX, se comenzó a difundir en los periódicos franceses Le Figaro y la Chronique Parisiense por los años 1850. Aníbal González define este tipo de género como "brief newspaper article on virtually any subject written in a self-conscious life style" ("Modernismo" 158). Para González, la crónica periodística tiene que estar formada por la conjunción de lo que él denomina las tres instituciones textuales. La primera es el género periodístico, el cual tiene que tener noticias de actualidad y estar sujeto a las leyes de la oferta y la demanda ya que la crónica es simplemente una mercancía. En segundo lugar, como género literario, tiene que entretener y ser creativo y, en tercer lugar, como género filosófico que posea la naturaleza sólida y bien organizada de un trabajo escrito con la conciencia filosófica de la historicidad de la lengua ("Modernismo" 158).

A su vez, la crónica buscaba lectores que disfrutaran no sólo del reportaje simple y sin adorno, sino que quisieran ver el aspecto personal del hecho que se quería relatar. Es decir, lectores que quisieran ver lo que José Joaquín Blanco llama "authorial reflection of the accounts" (61). En definitiva, toda crónica necesita tener un aspecto de interés 
humano y, a su vez, el reportero debe de contar su versión personal del hecho. Según Vicente Leñero, su estilo depende del tema que se trate en cada situación individual y su objetivo principal debe ser el narrar un acontecimiento que puede ir desde lo más frívolo hasta lo más polémico y trascendental (63).

A partir de finales del siglo XX surge otras modalidades de crónicas. Una de las que tiene mayor trascendencia es la crónica urbana. En estas, existe un elemento fundamental ya que, según Mary K. Long, resalta la idiosincrasia de una nación y define la identidad nacional de un pueblo. Esta nueva modalidad de la crónica es, en definitiva, lo que Subirats denomina el "espejo del alma" (55).

Las crónicas periodísticas del siglo XIX y XX se diferencian de los artículos periodisticos per se, según Amb́bal González, en que estos últimos están construidos a base de recopilar y diseminar las noticias y el lenguaje que se utiliza es un lenguaje altamente formatizado y regulado, alejado del lenguaje literario ya que el lenguaje de éstos es un lenguaje utilitario subordinado a las leyes del mercado ("Journalism" 5).

El caso de las biografias es diferente. En este tipo de narraciones el propósito fundamental es describir acontecimientos específicos e importantes de la vida de una persona. En este tipo de literatura, no siempre se narra el viaje físico de la existencia, sino que, en ocasiones, se nos relata un viaje interior. Ahora bien, cuando en una biografia se relatan viajes físicos, éstos tienen una característica fundamental que diferencia a las biografias de cualquier literatura de viajes. Esta característica es el elemento descriptivo del mundo visitado. La descripción en la biografia no tiene ningún valor por sí misma, sino que está subordinada a los aspectos existenciales del personaje narrado. Es decir, en las biografias, el viaje narrado no es más que un elemento descriptivo de la historia 
general de la vida de la persona a la que se refiere y responde únicamente a la representación de una etapa de ese camino existencial. Asimismo, las biografias generalmente están escritas al final de la vida del autor o al final de una etapa importante dentro de la vida del personaje descrito, o incluso, después de la muerte de éste; mientras que en los libros de viajes existe, generalmente, una inmediatez narrativa posterior al viaje realizado. $^{50}$

Esta característica de alejamiento también las comparten las memorias. Estos libros se narran desde un presente lejano a los hechos a los que se refieren y por un narrador-autor que plasma sus vivencias íntimas y personales en un momento de reflexión sobre las experiencias vividas. Podrá afirmarse que las memorias tienen dos finalidades específicas: una finalidad personal y una finalidad pública. El aspecto personal de las memorias es el hecho de contar la vida del narrador-autor. El aspecto público es la búsqueda de un reconocimiento, que puede ser material o psicológico, ya que al contar o revelar la historia del autor desde el punto de vista personal, se incita al lector a revalorizar las vivencias que este autor-narrador quiere mostrar. El punto de vista de las memorias es siempre subjetivo y está sujeto a la lección del narrador-autor. ${ }^{51}$ Este

${ }^{50}$ La caracteristica de la inmediatez también es un elemento de vital importancia en los libros de viajes científicos. Éstos, algunas veces se escriben al final de la vida de los autores como una recopilación de los descubrimientos alcanzados por el viajero pero, generalmente, se escribían inmediatamente después del viaje para resaltar los descubrimientos personales que se habian alcanzado. Mary Luoise Pratt, de forma detallada, presenta las obras de Charles de la Condamine, Carl Linné, Mungo Park y Alexander von Humboldt, entre otros, como ejemplos evidentes de este tipo de narraciones con una inmediatez al hecho documentado.

${ }^{51}$ La obra de Vida, ascendencia, nacimiento, crianza y aventuras de Diego de Torres Villarroel es un ejemplo claro y evidente de un libro de memorias con sentido económico. Villarroel en su obra pretende, por un lado, desmentir y aclarar las críticas 
tipo de literatura se diferencia de los libros de viajes en que éstos últimos tienen el carácter de inmediatez, ya mencionado; es decir, se producen en un periodo de tiempo no muy lejano a los hechos narrados $\mathrm{y}$, al mismo tiempo, se diferencian en el carácter informativo de los mismos. Mientras que las memorias se centran en lo personal, los libros de viajes tienen un carácter exterior, informan de realidades de otros lugares y tienen, además, un elemento de actualidad de lo narrado.

\section{Características generales de la literatura de viajes}

La literatura de viajes tiene una serie de características que han prevalecido o se han ido modificando a través de los tiempos. En primer lugar, la literatura de viajes de la antigüedad tiene unas formas propias y diferentes de las que tiene este tipo de narrativa en la actualidad; pero, al mismo tiempo, comparte unas características que se observan a través de los siglos lo que lo constituye como género. Es posible afirmar que los relatos de viajes son tan antiguos como la literatura misma. Desde la Odisea de Homero hasta la propia Biblia pasando por los libros de peregrinaciones, como el viaje de Egeria a Tierra Santa, tenemos un corpus literario del que parten las bases de la narrativa de viajes tal y como se la conoce hoy en día.

Según Peter Hume y Tim Youngs, las primeras manifestaciones de los relatos de viajes son los escritos de viajes épicos. Para estos críticos, estos primeros textos tienen una serie de características esenciales. En primer lugar, son unos relatos de aventuras episódicas que proporcionan una serie de situaciones. Estas situaciones repetitivas son el

que se habían hecho hacia su persona $\mathrm{y}$, por otro lado, intenta revalorizar su estatus burgués al hacer de su obra un elemento de enriquecimiento personal que le proporcionará la venta de ésta. 
peligro que supone el viaje, las situaciones sentimentales o amorosas en las que se ven envueltos los personajes del relato y la alegría del regreso al país de origen (2).

Aparte de las características que apuntan Hume y Young, se perciben, en estos primeros documentos, una intención persuasiva. Esta característica se observa en el primer documento de viajes que se conoce, el Itinerarium Burdigalense, ${ }^{52}$ del año 333 después de Cristo, es el primer itinerario que informa de las descripciones del viaje de Burdeos a Tierra Santa de un peregrino europeo desconocido. La forma de redacción de este documento es simple, se describen una serie de localidades, las distancias entre ellas, sus pueblos y aldeas, pero en esas descripciones, el autor incluye comentarios personales con una doble intención. Por un lado, proporciona una amplia información descriptiva de los lugares por los que va pasando, y en segundo lugar, intercala comentarios personales sobre su pensamiento religioso-cristiano dirigidos a influenciar a su audiencia. Este segundo aspecto es importante porque nos muestra la literatura de viajes, no solamente como una revista o catálogo de países, sino como un utensilio cuyo propósito es el de persuadir al lector. El autor-narrador es quien expresa a través del texto sus ideas desde una perspectiva subjetiva y personal. Esta intención persuasiva del autor del libro de viajes implica una inserción del pensamiento del autor y la visión que éste tiene del entorno que le rodea. De esta forma, el autor-narrador se impregna de la forma de vida y las costumbres diferentes del país o países por los que viaja produciéndose en él un

52 Se puede encontrar amplia información sobre estos primeros textos en la obra del editor Aubrey Stewart. The Anonymous Pilgrim of Bordeaux (333 AC). Palestine Pilgrim's Text society, 1887 o en www.christurex.org/www.ofm/pilgr 
proceso de transculturación que posteriormente plasmará en sus escritos con la intención de influir a sus lectores de las nuevas costumbres adquiridas.

Otra característica de la literatura de viajes de peregrinos, que también se va a apreciar en los demás relatos de viajes de todos los tiempos, es la curiosidad por el país visitado y las comparaciones de entidades desconocidas con realidades conocidas para el mundo europeo. Estas características se pueden apreciar en el primer documento de viajes que se conserva escrito por una mujer: El Itinerarium Egeria o Peregrinatio Aetheriae, que debió escribirse entre el año 381 y el 384. Este documento hace referencia a la labor del personaje de Egeria como peregrino. ${ }^{53}$ El manuscrito del Peregrinatio Aetheriae está considerado el primer documento escrito por una mujer. No se conoce exactamente el origen de ésta, pero se sabe que era una religiosa que pertenecía a la clase social alta y que era una persona bastante educada de Galicia. Egeria no sólo se propuso explicar la liturgia cristiana que se practicaba en las diversas localidades donde pasaba, sino que también impregnó su texto con una serie de aportaciones personales y subjetivas de los lugares que visitó. Esta primera referencia nos muestra una forma personal de acercamiento a un mundo exterior completamente diferente al lugar de origen.

${ }^{53}$ Según el libro de Jonh Wilkinson Egeria's Travel to the Holy Land, existen dos referencias externas al viaje de Egeria y parte del texto original de la autora. Una de las referencias externas es la carta que ella escribió a las monjas de su convento en el siglo IV, de la cual queda una copia en Monte Cassino que el padre Peter the Deacon (como lo llama Wilkinson), abad y bibliotecario del monasterio, incluye en un libro que escribió de lugares santos en el siglo XII. Después pasó a la comunidad de Santa Flora en Arezzo en 1599, y más tarde a la biblioteca en donde en 1884 lo descubrió J. F. Gamurrini, quien lo publicó en 1887. A partir de ese momento no han cesado las múltiples ediciones y traducciones. La segunda referencia que existe del viaje de Egeria es del siglo XVII y se encuentra en el Monasterio del Bierzo. Se trata de una carta del padre Valerius animando a sus monjes a seguir el ejemplo de la labor litúrgica de Egeria en su peregrinación a Tierra Santa. 
Asimismo, las narraciones de los peregrinos proporcionaban otra característica fundamental para la literatura de viajes en general: la visión del viaje desde el punto de vista de un narrador que muestra sus experiencias de viaje como fuente directa y de primera mano. Esta característica es fundamental porque a partir del momento en que el escritor se conciencia de la posición privilegiada que tiene por haber observado lo que describe con sus propios ojos, se atribuye una autoridad que cuestiona la de cualquier crítica que pudiera suscitar su texto. Esta actitud ante lo descrito confiere a la literatura de viajes una perspectiva que se reafirma a partir de la producción literaria del siglo XVI, consecuencia de la expansión y explotación del nuevo continente americano.

A partir de la autoridad que confiere la visión del narrador observador y actuante, en el siglo XVII aparece una nueva modalidad de libro de viaje cuya finalidad es política y económica. Se comienzan a hacer expediciones a América con propósito científico o político, es decir, con la intención de recopilar aspectos estratégicos o económicos sobre la nueva tierra que se está conociendo para aportar información al país natal del viajero. De esta forma, estos viajes cumplían una doble función; por un lado, pretendían ser una expedición científica, y por otro, tenían como finalidad mandar a las distintas potencias europeas, informes, mapas o posibles fuentes de riqueza de las tierras exploradas. Ejemplos de viajes cientificos son los viajes de Alexander von Humboldt, Charles de la Condamine, Charles Darwin, etc. Estos viajes proporcionaban una serie de documentos informativos sobre distintos aspectos geográficos, antropográficos y etnográficos. Las instituciones cientificas europeas costeaban este tipo de expediciones para informar a sus 
lectores sobre las nuevas regiones de América y de África. ${ }^{54}$ En cuanto a la forma de narrar, ésta cambia y se hace simple, sin pretensiones literarias ni didácticas y sin sentimientos de superioridad sobre el lector. Mezciems define al viajero de esta época como un hombre moderno que observa un fenómeno natural con pretensiones económicas pero no literarias: "It begins to appear the modern common man as traveller, as unjudging observer of material phenomena, as writer without literary pretensions and with no other standards than those of the market, needed saving from himself' (16).

Estos textos, además, cubrían la demanda de información de un público que no podía costearse esos viajes de conocimiento. ${ }^{55}$ Mary Luise Pratt menciona el proceso que sufriría el viajero en su contacto con ese mundo que le era ajeno. Según Pratt, una vez que el viajero pasaba la etapa de curiosidad hacia el nuevo mundo, se configuraba un espacio de interrelación entre lo visto y el viajero. Éste último se impregnaba, de una forma consciente o inconsciente, de la cultura del país visitado de tal manera que esta interrelación entre el viajero y el nuevo mundo producía un acercamiento cultural bilateral al que Pratt denomina la contact zone. Un fenómeno que ella define como un "social space where disparate cultures meet, clash, and grapple with each other, often in highly asymmetrical relation of domination and subordination" (4). Estas relaciones de subordinación y dominación que menciona Pratt, no siempre son del viajero hacia la cultura a la que se viaja, sino que también se producían por parte de la cultura visitada

${ }^{54}$ Mary Luise Pratt informa ampliamente de los primeros libros de viajes científicos a América y a África en su libro Imperial Eyes. Travel Wrting and Transculturation.

${ }^{55}$ Normalmente los documentos de las expediciones científicas tenían un público específico. Generalmente, eran informes científicos que iban dirigidos a sociedades científicas y, en general, a un público restringido, a una élite intelectual y política. 
hacia el viajero que la visitaba. Es importante tener en cuenta que Pratt establece la relación de dominación y subordinación del viajero sobre la cultura observada puesto que el objetivo de su estudio es la relación imperialista de los escritores viajeros europeos a civilizaciones consideradas subdesarrolladas a los ojos del hombre occidental. En el caso de Carmen de Burgos o Emilia Pardo Bazán, la relación es la opuesta ya que ambas viajan para impregnarse de los avances de la Europa del norte. En este caso, estas autoras son las que se muestran como las dominadas por la cultura europea y las que ansían una europeización para su país. A su vez, en la contact zone, el viajero, no sólo se impregnaba de la cultura exterior, sino que iba cambiando su forma de percepción del mundo que descubrían y se iba perfilando en él un proceso de transculturación que le iba a cambiar para siempre.

En los libros de viajes se ve ese proceso de transculturación mediante la plasmación de la visión del país al que se viaja desde una perspectiva personal. La percepción individual que tiene el autor de los libros de viajes es una de las características fundamentales de este tipo de narrativa. Mediante esa percepción individual, el escritor inserta su pensamiento dentro de la obra y manifiesta su visión particular del entorno que le rodea. Normalmente se sirve de la mitificación del nuevo mundo para él, para avivar en el lector la curiosidad. Al mismo tiempo, el propósito descriptivo en este tipo de narraciones juega un papel de una importancia fundamental porque es, en sí, la base de toda narración de viajes a la cual se supeditan todas las demás características. Todo libro de viajes tiene como propósito fundamental describir la nueva sociedad a la que viaja desde diferentes aspectos; tanto culturales y económico como personales, sociales o políticos. 
A la luz de las características esenciales de la literatura de viajes y las diferencias con géneros parecidos, se podría definir el libro de viajes como un documento narrativo y descriptivo, según menciona Carrizo (14), pero que, al mismo tiempo, tiene como finalidad la búsqueda introspectiva y subjetiva del autor-viajero. Mediante esta búsqueda, el viajero realiza un proceso de percepción y descripción cultural de la nueva sociedad y de él mismo. Una vez absorbida esta nueva realidad cultural, el viajero la construye de forma subjetiva, pero también en él se ha producido un proceso de transculturación. Este proceso le lleva a la plasmación de su percepción intercultural del nuevo mundo con el propósito esencial de reflejar la incidencia que la cultura extranjera tiene en su país natal. $^{56}$

\section{Diferencias entre la literatura de viajes escrita por mujeres y por hombres}

Algunos criticos de literatura de viajes, han centrado sus trabajos en intentar identificar las diferencias que existen en este tipo de producción literaria con respecto al sexo de sus autores. Algunos de ellos se han basado en evaluar las diferencias de estas producciones, en términos literarios, mientras que otros han enfatizado los aspectos históricos, imperialistas o coloniales. En defmitiva, ninguna diferenciación que se pueda hacer de ningún tipo de literatura según el sexo de sus autores es una diferenciación contundente y rotunda, siempre se van a encontrar casos, aislados o no, en los que la diferenciación efectuada rompe el esquema. De esta forma, una vez aclarado que las diferencias entre literatura de viajes de hombres y mujeres no son leyes físicas o

\footnotetext{
${ }^{56}$ Las especificaciones y características que he implementado en esta definición, son las que se ajustan al posterior análisis de las producciones de viajes de Carmen de Brugos y Emilia Pardo Bazán.
} 
matemáticas, sino acercamientos y evaluaciones de unas características que se pueden considerar repetitivas en un tipo de producción hecha por un grupo sociosexualmente determinado, se pueden establecer esas diferencias que, en definitiva, se ajustan al fin que el crítico quiera resaltar en su estudio.

De esta manera, los rasgos diferenciadores más evidentes y específicos que tienen este tipo de narraciones escritas por hombres o mujeres son los siguientes. En primer lugar, hay que considerar las características históricas por las cuales a las mujeres se las ha mantenido en un encierro físico y simbólico debido al sistema patriarcal. Así pues, los primeros acercamientos a este tipo de literatura han sido mayormente llevados a cabo por hombres, ya que ellos se podían desplazar de un lugar a otro de una forma más libre que las mujeres y tenían un acceso más libre dentro de la esfera pública. La literatura de viajes masculina responde a un patrón específico que, al igual que en la femenina, corresponde a las características sociales y culturales del entorno del autor y de la época en las que se produce, pero, en los autores destacan elementos que no encontramos en las autoras, tales como la posición del escritor como héroe valeroso que comienza una aventura y las acciones de riesgo dentro de la narración.

De esta forma, la primera característica que se va analizar es la visión del narrador como héroe o anti-héroe de la narración. Mientras que en la literatura masculina, el hombre es el héroe explorador que desde una posición dominante describe el mundo viajado, la mujer es el antihéroe que, en la mayoría de los casos, plasma una visión satírica de ese narrador omnipotente, héroe magnánimo de una empresa conquistadora. Mary Louise Pratt explica esta visión colonizadora del hombre escritor viajero que, desde una posición de superioridad, describe un nuevo mundo como forma de exploración tanto 
exterior como interior. Esta exploración se hace para definirse como protagonista principal dentro de los parámetros del nuevo mundo. El viajero científico de los siglos XVIII y XIX se convierte en embajador imperial (27). Éste no sólo incorpora sistemas de clasificación de la naturaleza, sino que él mismo se transforma en una autoridad, en un héroe que ha dominado la naturaleza hostil para dirigirse a las clases sociales medias y altas como conciencia eurocéntrica planetaria (38). En este sentido, el viajero se convierte en una entidad totalizadora del entorno extraño definido por un sistema de orden europeo.

Por el contrario, la viajera se convierte en el antihéroe de la narración de viajes. Este rasgo es evidente en el caso de la literatura de ficción del siglo de oro ya que las protagonistas femeninas son antihéroes que han sido burladas y necesitan tomar la iniciativa para no ser excluidas de la sociedad. Su protagonismo se convierte en una necesidad y su empresa viajera es solamente el medio para conseguir esa empresa. En los siglos XVIII y, sobre todo XIX y principios del XX, las mujeres viajeras se muestran a sí mismas como antihéroes que utilizan esta visión anti-heroica como técnica política ante la sociedad represiva y, al mismo tiempo, desde esa posición aparentemente desprotegida, critican a esa sociedad patriarcal que las oprime. Su narración se convierte en una forma de reivindicación de su status discriminado.

En el siglo XVII la mujer no podía acceder a la educación superior en ninguna parte del mundo y, por consiguiente, estaban excluidas de lo que Elizabeth A. Bohls llama "real solemn history" (1). La exclusión del sistema de conocimiento institucionalizado y admitido como prestigioso no les dejaba otra salida de expresión que los géneros considerados más asequibles para la mujer como los relatos de viajes, 
memorias, autobiografias, literatura religiosa y poesía. ${ }^{57}$ Mediante esta literatura, la mujer podía, de una forma más sutil "engage with philosophical concept without directly trespassing on the more forbidding territory of the treatise" (Bohls 6), pero esta forma de acercamiento sólo era posible desde una posición de inferioridad frente al hombre; es decir, sin irrumpir en el discurso autoritario propio de la escritura masculina.

De esta forma, una de las consecuencias principales por las que las mujeres se muestran a sí mismas como los antihéroes de sus narraciones es por la necesidad que tienen de huir. Por un lado, es un escape de la sociedad que las oprime y, por otro, es un escape interior y psicológico o de su condición de mujer. Sara Mills explica que la sociedad colonial e imperialista británica de los siglos XIX y principios del XX establecía que a las mujeres les estaba permitido ser únicamente emblemas del hogar y de la pureza. Mills dice: "British women were only allowed to figure as symbols of home and purity; women as active participant can barely be conceived of" (3). De esta forma, el discurso de ambos sexos es completamente opuesto. El discurso de hombre escritor-viajero es categórico, poseedor de la verdad absoluta, observador y científico que, desde su palco de superioridad, convierte su forma de narrar en el descubrimiento de su propia masculinidad; mientras que el discurso femenino, como señala Pratt, tiende a alejarse de los cuestionamientos de las verdades absolutas y se centra más en lo personal, en las

${ }^{57}$ Entre las escritoras más destacadas del siglo XVII se puede citar a Leonor de la Cueva y Silva, a Joaquina Comella, Ana Francisca Abasca de Bolea, entre otras. Para mayor información sobre escritoras hispánicas es bastante valioso el libro de Bárbara Mujica Women Writers of Early Spain. Sophia's daughters y en las actas del segundo congreso del grupo GESTE de Toulose sobre La mujer en el teatro y en la novela del siglo XVII de 1978. También existe amplia información en la red: www.escritoras.com en la que muestra una pequeña biografia de las escritoras hispanas más representativas de todos los tiempos. 
descripciones de los paisajes y de los habitantes de una forma más individual y no se concentra en mostrar aspectos universales del género humano como lo hace el discurso masculino (88).

En segundo lugar, es importante establecer la visión y la representación que existe de las mujeres viajeras, tanto en los escritos hechos por hombres como en los realizados por mujeres. En los viajes escritos por hombres, la mujer representa, en la mayoría de los casos, una función pasiva. Por un lado, ella es el objeto del deseo o el punto de destino final del viajante. Laura Gorfkle muestra la visión que el hombre tiene de la mujer como una forma de deseo ya que para éste es simplemente un objeto de belleza que proporciona el deleite masculino. Gorfkle dice: "Women are portrayed as an object through whose possession the male suitor may ultimately come to contemplate and possess divine beauty" (25).

Este tipo de visiones se extiende a otras épocas, en el caso de la literatura de los siglos XVI y XVII, a pesar de que existan referencias a princesas guerreras dentro de la literatura que se desplazan de un lugar a otro, la visión generalizada de la mujer cuando viajaba, respondía a unas necesidades determinadas. En el caso específico de España, las mujeres viajan solas o acompañadas para enmendar una injusticia. De esta forma, las mujeres se convierten en vehículos del destino o propósito final de la obra. ${ }^{58}$

\footnotetext{
${ }^{58}$ Un ejemplo evidente se puede apreciar en la obra de Calderón de la Barca, La vida es sueño, donde nos muestra a una mujer, Rosaura, que emprende un viaje en busca del que ha machado su honra. La mujer, en este caso, y en general en la producción literaria del siglo de oro, viaja ante la imposibilidad de que un hombre limpie la mancha de su honra. Estas mujeres tienen que reestablecer el estatus social y cultural de la época, es decir: la situación deshonrosa en la que por alguna circunstancia se han visto envueltas; así, se embarcan en una cruzada para instaurar su honor perdido.
} 
La literatura escrita por hombres en el siglo de oro español, muestra a un narrador masculino que, desde una posición privilegiada, presenta una situación en la que la mujer es sólo un instrumento que éste utiliza para resaltar el propósito de reestablecimiento del orden y la jerarquía social. Las mujeres son objetos que presentan un problema y actúan de forma independiente ante la incapacidad del hombre de hacerlo. Asimismo, son vehículos de crítica social en contra del hombre que no actúa dentro de los parámetros establecidos por la sociedad. Las mujeres, en estas narraciones, son, en definitiva, el medio a través del cual el narrador, desde una posición superior, critica la incapacidad de los hombres en no actuar como "hombres" en una sociedad meramente masculina. ${ }^{59}$

Otro caso en la literatura española del siglo de oro en el que se muestra la visión de la mujer como destino final y objeto de deseo, en este caso del viajante, es el peregrinaje o viaje de Don Quijote de la Mancha. El protagonista realiza una cruzada en busca de justicia social. La necesidad de arreglar entuertos se hace en nombre de una dama. En este caso, el viajante realiza, según lo define Helen Carr, sus aventuras y exploraciones a lo desconocido, teniendo a una mujer como el objeto de deseo, un estandarte simbólico y pasivo dentro de la narración y no como una acompañante en el viaje (Hulme 225). ${ }^{60}$

${ }^{59}$ El personaje femenino de Lucrecia en Fuenteovejuna de Lope de Vega, representa, precisamente, esa visión de la actuación de la mujer actuando con el papel de hombre, para reivindicar su honor perdido.

${ }^{60}$ Dulcinea, en los ojos de don Quijote, no necesita ser real, es solamente un objeto o un símbolo que le dará al viajante la valentía necesaria para continuar su cruzada. Asimismo, la mujer, en este caso Dulcinea, es un punto esencial y referencial del objeto deseado, en lugar de ser ésta un componente activo de la narración. Don Quijote comienza su viaje en nombre de una mujer que representa el objeto del dominio del deseo por parte de Quijote y la recompensa final de su peregrinaje. 
Por otro lado, esta obra de Cervantes muestra mujeres viajeras por diferentes notivos. En primer lugar, el caso de Marcela que rechaza el amor como consecuencia de lo que Rosilisie Hernández-Pecoraro denomina "love as objectification" (19). De esta manera, se muestra a una mujer independiente que quiere llevar las riendas de su vida sin intervención masculina. En segundo lugar, Leandra, labradora rica que decide seguir sus institutos, toma la iniciativa y se escapa con Vicente de la Rosa; en tercer lugar, la figura de Zoraida, la mora que viaja por España, como representación de lo impredecible y lo radical (Hernández-Pecoraro 20). Este personaje que, según Erin Webster Garrett, representa la figura binaria de la mora por su aspecto físico y de la cristiana por su alma, emprende un viaje como símbolo de un exilio existencial de su propia cultura en busca de actualizar su parte europea (141). Es decir, Zoraida representa el viaje de la otredad. Esta característica hace de este personaje, un símbolo importante en la obra ya que muestra la ambigüedad de una persona entre dos culturas.

La tercera característica específica de las viajeras, especialmente del siglo de oro es el travestismo. ${ }^{61}$ El travestismo en la literatura, como indica Beatriz Cortez, irrumpe como consecuencia de la prohibición de la participación de la mujer en el teatro. ${ }^{62} \mathrm{Cortez}$

\footnotetext{
${ }^{61}$ También hay referencias al travestismo en las exploradoras del siglo XVIII y XIX. Ver Imperial Eyes de Mary Luoise Pratt.

${ }^{62}$ Esta prohibición provocó numerosos conflictos en los teatros que dieron como resultado la aprobación de la participación de la mujer en las obras de teatro bajo una serie de condiciones. Según Joseph Oehrlein algunas de ellas eran que la mujeres debían estar casadas y tener a sus maridos con ellas y que debían de llevar ropas femeninas (En Cortez 372). Según Oehrlein, esta prerrogativa no funcionó ya que, en un escrito del rey al vicecanciller de Aragón de 1653, se ordenó la prohibición de la práctica común de mujeres de vestirse de hombre en representaciones teatrales (En Cortez 372).
} 
mantiene que, a pesar de las prohibiciones, esta práctica fue muy popular en la literatura del siglo de oro por dos razones. En primer lugar, porque la dualidad que encarna el travestismo, representaba a las metáforas propias del barroco. En segundo lugar, por las posibilidades eróticas que esta dualidad establecia tanto en la escena como en el público (373).

Al mismo tiempo, las mujeres, para sentirse libres en una sociedad patriarcal solamente podian hacerlo, como se ha dicho anteriormente, acompañadas por un hombre o disfrazadas de hombre. Este travestismo, por así decirlo, permite a la mujer desplazarse libremente al adoptar un rol masculino dentro de una sociedad que las relega a un segundo plano. Este proceso no solamente es una herramienta habitual de las narraciones hechas por hombres, sino que también lo es de las mujeres escritoras. Dos ejemplos de escritoras del siglo de oro que se sirven del travestismo, tanto en su obra como en su vida personal, son Ana Caro y Catalina de Erauso "la Monja Alférez." Ana Caro muestra el travestismo en sus personajes femeninos como forma de desmantelar el papel de la mujer en la sociedad, que a pesar de no ser la primera en utilizar el travestismo con este fin, sí lo hace como vehículo de valoración de las mujeres en un periodo histórico en el que se las consideraba inferiores. ${ }^{63}$ Por otro lado, Catalina de Erauso representa el travestismo

${ }^{63}$ Ana Caro hace de su personaje principal, Leonor, el centro de su obra. Ésta disfrazada de hombre, pretende restaurar su honor. Valor, agravio y mujer, a pesar de que la trama se ajuste a los cánones de la sociedad de su tiempo, propone, mediante el travestismo de su personaje principal, una serie de aspectos fundamentales que conlleva ese travestismo. En primer lugar, propone el desmantelamiento del papel de la mujer en la sociedad del siglo XVII ya que según Cortez este travestismo lleva a Leonor al desenlace final; en segundo lugar, propone una mayor valoración de la mujer en las obras de este periodo al dotarlas de valor, fuerza y, sobre todo, inteligencia para confundir mediante su travestismo (376), y finalmente, como desmantelamiento de la relación amorosa que se plantea entre Leonor en su forma masculina y Estela (Cortez 381). Al mismo tiempo, el 
físico al extremo de mantener oculta, durante gran parte de su vida, su identidad femenina. ${ }^{64}$ A pesar de que ambos casos no son una producción de viajes propiamente dicha, ilustran el travestismo como vehículo, como medio u utensilio del que se sirve el personaje femenino en esas narraciones para su desplazamiento.

El travestismo, a su vez, a partir del siglo XVIII tiene una contrapartida en lo que Sara Mills explica como la feminidad de la exploradora que no abandonaba sus vestimentas en la empresa exploradora. $\mathrm{Al}$ igual que las mujeres viajeras se sirven del travestismo para poder mantener una mayor libertad en un mundo de cánones masculinos, en otros casos, las viajeras utilizan la ropa como exaltación de su feminidad

travestismo provoca una subversión creada mediante una forma ilusoria. Según Grofkle, los acontecimientos que llevan al protagonista a transgredir los cánones sociales se ajustan a las normas del neoplatonismo (Re-staging 25) creando una dialéctica de intercambio interno que subvierte la obra y configura la visión subversiva del papel de la mujer en la sociedad. Esta dialéctica para Gorfkle se produce en la interrelación entre: "script and performance, action and frame, text and context" (33). Por otro lado, el travestismo en esta obra provoca un elemento de hermandad entre las dos protagonistas femeninas. Según Mercedes Maroto Camino, al hermanarse las dos protagonistas femeninas, una vez revelado el género de Leonor, se enfatiza la solidaridad entre los personajes femeninos como apoyo necesario para la reinvención de los derechos de la mujer (4).

${ }^{64}$ Otro caso de travestismo literario en el siglo de oro de las letras hispánicas, es el caso del libro de memorias de la monja Catalina de Erauso, llamada "la monja alférez." Catalina, al final de su vida, nos cuenta las memorias de su viaje por América Latina. La monja, disfrazada de hombre, participó activamente en la conquista de América, especialmente en la guerra contra los araucanos. El caso específico de Catalina de Erauso es ambivalente. Por un lado, su producción literaria no se puede considerar totalmente como femenina ya que Catalina en el momento en el que escribió su relato, lo hizo bajo atributos masculinos y, al mismo tiempo, su identidad era ambivalente, en su obra entremezcla el yo masculino con el femenino. Por otro lado, es importante mencionar que por el hecho de adoptar una identidad masculina en una sociedad patriarcal, pudo acceder a un mundo privilegiado e inaccesible para la mujer. Así, su libro queda a medio camino entre lo que se considera literatura escrita por mujeres propiamente dicha y literatura escrita por hombres. 
y como vehículo de libertad. En este sentido Pratt examina lo que ella denomina la perspectiva feminocéntrica (166), por la cual algunas autoras presentan a la mujer en un mundo idealizado, en el cual se les proporciona una cierta autonomía, poder y libertad; por supuesto, bajo las restricciones sexuales de la sociedad del siglo XIX. De esta forma, Pratt analiza la visión de Flora Tristán y el examen que ella hace de las mujeres limeñas y la independencia que éstas tenían en la sociedad peruana del siglo XVIII y XIX en la cual las ropas de mujer les proporcionaban un estado de libertad social y sexual. La saya y el manto de las mujeres limeñas, que cubría casi todo su cuerpo, les permitía una libertad de movimientos y de acción al ser prácticamente irreconocibles (167). Pratt dice: "She (Tristan) becomes fascinated by the independence of the Lima women. "There is no place on earth," she exults, "where women are so free and exercise so much power as in Lima"(167). Pratt continua diciendo: "Tristan offers a detailed and thoroughly analysis of this dress code. Because it permits women to go about unrecognized, she argues, the saya $y$ manto is the instrument of their freedom" (167). La libertad que le da el encubrimiento físico del que habla Mills es sólo parcial ya que seguían siendo mujeres y como tal, discriminadas. La única libertad que podían tener era la del anonimato. ${ }^{65}$

La cuarta característica fundamental de la literatura de viajes escrita por mujeres es la visión de la mujer como protagonista principal, la ejecutora de la acción, el

\footnotetext{
${ }^{65}$ La tradición de la limeña de cubrir su cuerpo con el "manto y saya" provenía de la cultura árabe que pasó a la Península Ibérica y de ahí al Nuevo Mundo; tanto es que aún hoy en día en algunos pueblos de la provincia de Cádiz se sigue usando el mismo apero que describe Mills para las limeñas en las pueblerinas gaditanas como traje tradicional.
} 
personaje que mueve los hilos de la narración. ${ }^{66}$ Las escritoras protagonistas se sirven de la falsa modestia para justificar el ejercicio de su profesión que hasta ese momento era exclusivo del hombre. De esta forma, mencionan en sus escritos referencias a mujeres importantes de la historia, tanto clásica como contemporánea de la autora, para reivindicar su caso como un fenómeno múltiple y no aislado. ${ }^{67}$ Esta caracteristica, no es sólo exclusiva de la producción femenina del siglo de oro, sino que en el siglo XIX forma parte esencial de la literatura de viajes escrita por mujeres. Florence Gabaude diferencia la forma de narrar entre el hombre y la mujer al explicar la manera de representación de la mujer en las obras literarias diciendo que ésta expone de manera implícita su escasa preparación cultural e intelectual. Este utensilio le proporciona a la mujer una herramienta de libertad. De esta forma, mediante la técnica de la falsa modestia, la mujer podía entrar y ser aceptada en la sociedad patriarcal ya que esa pretendida ignorancia no irrumpía el discurso masculino y, consecuentemente, podía participar activamente en el proceso narrativo con mayor libertad que si pretendía equipararse al hombre.

\footnotetext{
${ }^{66} \mathrm{La}$ obra de Ana Caro, y en especial Valor, agravio y mujer, es relevante para el estudio de la producción de literatura escrita por mujeres porque se puede apreciar en ella una visión de defensa y revalorización de la mujer al dar a sus personajes femeninos una autoridad propia. Según mi análisis, su obra marca un proceso revolucionario en las letras femeninas por ser, junto con la obra de María de Zayas, no sólo unos casos aislados en el siglo de oro, sino por el papel protagónico y la autoridad de actuación que confieren las autoras a estos personajes femeninos que sobrepasan las manifestaciones que los escritores hombres otorgan a estos mismo tipos de personajes en las mismas circunstancias.

${ }^{67}$ Esta referencia hace alusión a mujeres importantes de la historia clásica, no es exclusiva de Ana Caro sino que ha sido un utensilio muy utilizado en toda producción escrita por mujeres y también por hombres. Uno de los casos más conocidos es la obra de sor Juana Inés de la Cruz en el México colonial y, como ejemplo específico, se puede observar en la Respuesta a la carta de sor Filotea.
} 
La visión protagónica de las escritoras decimonónicas irrumpía en el discurso masculino de una forma más abierta aunque con limitaciones. Se les permitia escribir textos considerados "femeninos" como las cartas, memorias y relatos de viajes, con la intención, según Shirley Foster, de sugerir en sus escritos una orientación privada y doméstica (19). En ellos, estas escritoras narraban y describian las tierras a las que iban. Estos documentos se convertían en vehículos excelentes para expresar, de forma subjetiva, los hechos no científicos. Así pues, las mujeres entraban en un espacio conocido y aceptado como femenino por la sociedad de su tiempo: el subjetivo y sentimental.

La quinta característica de los relatos de viajes de mujeres es la visión interior del proceso del viaje. Karin Veit explica que las mujeres asumen una posición interior, describen lo que ven de una forma apasionada o de "going native." Mediante el hecho de mostrarse al mismo nivel que los habitantes locales, las escritoras se integran completamente a la sociedad extranjera y, desde esa posición within, pueden acceder a información de aspectos políticos, históricos y culturales (134). A esta visión interior se contrapone la visión masculina exterior. Los hombres, en general, según Veit, asumen una posición de superioridad, del verdadero explorador y experto. ${ }^{68}$ Las descripciones que hacen son, en la mayoría de los casos, despectivas en cuanto al entorno, a los edificios y al paisaje (135).

\footnotetext{
${ }^{68}$ Esta característica de superioridad masculina es una característica muy recurrente para la mayoría de los criticos de la literatura de viajes en general y ejemplifica múltiples diferencias con las narraciones de viajes de mujeres; es por eso que se ha repetido varias veces en este estudio.
} 
La sexta característica es la que Sara Mills explica en el proceso de creación de un texto de viajes, en el cual, la mujer se sirve de lo que Veit denomina el "womanly weakness" (94). Mediante esta técnica, las escritoras resaltan las cualidades propias del sexo débil, para producir en el lector el efecto contrario. Se pretende, de esta forma, utilizar el discurso de la feminidad como vehículo de autoridad femenina. Esta autoridad les viene dada mediante la compilación de lo que se espera de ellas como mujeres escritoras (94). Karin Veit ratifica este aspecto señalado por Mills, al estudiar la obra de Ella Maillart. Maillart se sirve del discurso femenino mostrando características consideradas típicas de las mujeres como la inseguridad, la impulsividad, la curiosidad y el miedo mezcladas con aspectos de descripciones domésticas, higiene, cocina, entre otras, para mostrar su autoridad de género. Maillart, a su vez, contrasta estas características propias de las mujeres para hacer una comparación con su compañero de viaje, Peter Fleming, al que irónicamente ridiculiza. En este sentido, la forma en la que se ridiculizaba al hombre era simple: primero, se exaltan las cualidades domésticas y "maternales" de las mujeres, segundo, se muestra la carencia del hombre de estas cualidades, que se presentan como simples e inferiores $\mathrm{y}$, tercero, se ridiculiza irónicamente al hombre ya que, al sentirse superior, no es capaz de dominar y ejecutar esas características típicas de las mujeres que son consideradas por ellos como inferiores. De esta forma, se cuestiona quién es verdaderamente mejor o peor, inferior o superior.

En definitiva, con este discurso de la feminidad lo que se intenta es crear una especie de autoridad legítima de la mujer por la cual las escritoras enfatizan su capacidad de integración con la cultura y la comprensión de las gentes del país visitado, enfatizando asimismo, sus propias habilidades, su integridad moral y su experiencia (134). 
El estilo y el contenido de los libros de viajes conforman la séptima característica que diferencia a los escritos de ambos grupos. Estas características, a rasgos generales en todos los periodos, según Jonh M. Faragher, el hombre utiliza un estilo normalmente más plano, sin adornos innecesarios (130). En cuanto a las descripciones, la mujer usa, generalmente, adjetivos más coloridos, frases más descriptivas y pasajes con explicaciones y sumarios más detallados que los hombres ya que, según Faragher, atribuye estas diferencias a las relaciones sociales y culturales de las mujeres y al hecho de que considere que los hombres son menos habladores y menos preocupados por los sentimientos y las formas o costumbres de los otros; en otras palabras, de los habitantes del país viajado. A pesar de que esta afirmación resulte extremista y chocante desde la perspectiva feminista, lo que sí es cierto es que se aprecia un acercamiento más intimista en la visión que estas mujeres dan del otro, del país visitado.

En este sentido, la manera estructural del discurso se presenta de forma distinta, mientras que el masculino es autoritario y científico, el femenino es más sentimental e intimista. En las narraciones de viajes de mujeres se aprecia una intención explícita de querer incluir dentro de sus escritos aspectos sentimentales y subjetivos del paisaje, cosa totalmente aceptada para la mujer en una sociedad misógina. De esta forma, pretendían dar una visión general y global del país extranjero sin ningún tipo de incursión explícita en temas que se consideraban vedados para ellas o típicos del discurso masculino. La escritura se convierte en privada, fragmentada y compuesta a base de experiencias autobiográficas. De esta forma, Catherine Barnes Stevenson señala que la literatura escrita por mujeres se deja llevar por la experiencia. Barnes dice: "women lend to record, to surrender to experience" (9). 
Asimismo, Barnes Stevenson afirma que la mujer viajera se sirve, en muchas ocasiones, del formato epistolar para dar del mundo al que viaja una visión más intimista y desde una perspectiva más subjetiva, mientras que el hombre nunca, o en muy raras ocasiones, escribe cartas con este mismo fin. De esta manera, Stevenson mantiene que las narraciones de viajeras tienen un tono híbrido hondamente autobiográfico y subjetivo a las que sobreponen el relato de viajes (cit. en Torres-Pou, "Aproximaciones" 79). Stacy Lee Spencer mantiene que la producción de viajes escrita por mujeres tiene una característica estilística evidente. Para esta crítica, la mujer-narradora quiere resaltar la apariencia fisica y la sensación que produce su persona en los que la rodean y en ella misma. De esta forma, se percibe en sus escritos constantes referencias a su aspecto físico, sus ropas, y el efecto que causa su presencia en los demás. En este sentido, es evidente que en la mayoría de la narrativa de este tipo escrita por hombres, no se perciben descripciones físicas sobre la apariencia a su persona con la misma recurrencia e intención de agradar como se muestra en las narraciones escritas por mujeres.

En cuanto a la posición del narrador, se evidencia la diferencia contextual de ambos tipos de textos. El masculino refleja una posición de supremacía, de poder y, sobre todo, de conocimiento de lo que está realizando. Esta posición de supremacía responde al propósito difusivo de los relatos de viajes escritos por hombres, mientras que en el discurso femenino, las narraciones se hacen mucho más personalizadas e interiores ya que, en muchas ocasiones, no se pretenden aparentemente publicarlas. Los relatos de viajes escritos por hombres poseen un objetivo determinado de antemano y responden a ese objetivo mediante la intención de su posterior difusión. 
Por el contrario, las narraciones de viajes escritas por mujeres no tienen, necesariamente, el propósito de ser difundidas públicamente. Muchas de las producciones de viajes de escritoras se quedan como meras memorias personales de un viaje realizado. ${ }^{69}$ Por el contrario, Foster explica que la intención aparente de las escritoras de no publicar sus escritos, responde a la estrategia de elegir la forma de presentar sus narraciones como diarios, cartas a amigos, etc., para sugerir lo que ella denomina: "suitably private and domestic orientation" (19). Al mismo tiempo, Mills asegura que las escritoras utilizan la técnica del "sefl-deprecting prefactory material." Es decir, tienden a hacer una auto-desaprobación de sus textos para producir el efecto opuesto: probar su modestia al señalar que ellas nunca escribieron con la intención de que sus escritos estuvieran expuestos al público en general (83).

En defmitiva, esta auto-desaprobación era una simple táctica para librarse de las críticas de que pudieran ser objeto una vez publicados sus textos. Por el contrario, un caso a parte es obra de Carmen de Burgos y Emilia Pardo Bazán, que se estudiará más adelante, ambas autoras, al ejercer la profesión de periodistas, se ven obligadas a hacer que sus narraciones de viajes respondan a un discurso mucho más autoritario puesto que varias de sus obras son el resultado de una investigación pagada por el gobierno español. En el caso específico de estas autoras, su producción responde a lo que Monicat describe como la formulación de un discurso reivindicativo, al utilizar el viaje como un dominio en el que la mujer construye una historia convirtiéndola en un acto político y social (29).

${ }^{69}$ Joan torres-Pou en su libro Aproximaciones a la narrativa femenina del diecinueve en Latinoamérica muestra el caso de María Mercedes Santacruz condensa de Merlín, como literatura de viajes de mujeres con intención de su posterior publicación. 
En este sentido, el hecho de sentirse protagonistas, con una función específica dada por la sociedad masculina, permite que la mujer se convierta en dueña, por primera vez, de su responsabilidad social.

La novena característica de los relatos de viajes de mujeres es el acercamiento a las minorías. Los discursos de los hombres escritores en torno a las minorías se muestran de una forma distanciada, como relaciones interraciales que dejan de lado el sentimentalismo para transformarse en relaciones sexuales, en lugar de afectivas y de amor romántico, producto del siglo XIX. En las narraciones de hombres, las referencias a las minorías, en general, se realizan mostrando a los nativos, ya sean indígenas o negros, como posesión del colonizador y siempre sometido a éste. Este narrador héroe colonizador blanco hace de su discurso un emblema de poder. Es característico de la literatura de la contact zone encontrarse con formas de incursiones en el discurso eróticosexual interracial. Pero estas relaciones, en la mayoría de los casos, se quedan en el efecto que deja la relación amorosa de carácter erótico y exótico. Pratt explica que durante el período colonial existía una tendencia a la explotación humana desde una perspectiva sexual, en la cual el hombre europeo compraba a las mujeres locales para servirle de personal doméstico y, al mismo tiempo, de amantes durante su estancia en las colonias (95). En estas relaciones interraciales se percibe un cambio de la sumisión del colonizado por medio de la relación amorosa. Se pasa de la esclavitud real a la esclavitud por amor. Las relaciones interraciales, explica Pratt, tienen un final común: el hombre blanco 
regresa a Europa y la amante esclava muere joven $(97) .{ }^{70}$ De esta forma, se reestablece el orden racial tradicional.

Por el contrario, es más común en el discurso de las escritoras, tanto anglosajonas como hispanas, encontrarse con narraciones en las que se manifiesta un acercamiento a los estamentos de la sociedad más desfavorecidos. A pesar de que el discurso colonial de las escritoras muestre un status de superioridad frente al país o países colonizados, este acercamiento difiere, en muchos casos, del acercamiento de los hombres. ${ }^{71}$ Las mujeres escritoras, desde su espacio privado y personal, muestran un interés por resaltar la situación desfavorecida de grupos sociales oprimidos, como los esclavos, porque de esa manera, denuncian indirectamente la opresión de que ellas, como grupos social, son víctimas. Uno de los primeros casos de libros de viajes de mujeres antes de 1850 es Narratives of Two Voyages to the River Sierra Leone de Anna María Falconbridge, es un texto abolicionista desde una perspectiva interior. Falconbridge se siente esclava de su

${ }^{70}$ Pratt menciona uno de los casos más representativos de la literatura anglosajona, el libro de Jonh Stedman Narrative of a Five Year's Expedition against the Revolved Negroes of Surinam en el que describe la historia de amor entre la esclava Joanna y Jonh Stedman. Éste decide regresar a Inglaterra y llevarse consigo a Joanna, cosa a la que ella se niega prefiriendo terminar su vida sola, sin marido y esclava. Al mismo tiempo, también cuenta las historia de Inkle y Yarico para mostrar que no existe reciprocidad en las relaciones interraciales. En este último caso, el marinero Inkle decide regresar a Inglaterra y vender a su amante, ésta para tratar de convencerlo le dice que está embarazada, a lo que le contesta Inkle que subirá el precio de su venta. Pratt, con estos casos, ilustra el final de desamparo de la mujer esclava.

${ }^{71}$ En el caso específico de Carmen de Burgos, muestra una relación de superioridad imperial al describir a los marroquíes como seres sin educación y salvajes. En mi opinión, es una excusa para mostrar el salvajismo de los pueblos sin educación en términos europeos. 
marido y escribe este texto por el sentimiento de esclavitud que siente ella misma (Pratt 103).

Este aspecto es fácilmente observable en la técnica de las novelistas del siglo XIX al abordar el tema de la esclavitud. Según dice Pratt, las escritoras se apropian de elementos de la retórica para establecer una autoridad (162). Esta autoridad es la del escritor que, de primera mano, escribe sobre un hecho. Pero esta autoridad tiene una diferencia fundamental. Mientras que los hombres plasman su percepción de la realidad desde un punto de vista alejado a su experiencia personal. Es decir, no son partícipes directos del proceso discriminatorio $\mathrm{y}$, por consiguiente, no sufren ningún tipo de empatía con la situación presentada, las mujeres sí son participes directas del proceso discriminatorio y lo muestran de forma más exaltada y subjetiva porque ellas son, al igual que el contexto narrativo que presentan, víctimas, igualmente, del hecho narrado. El discurso femenino se convierte, de esta forma, en un discurso de crítica social, frente al discurso del escritor el cual no observa ese tono y es, en la mayoría de los casos, un discurso que reafirma la supremacía del hombre occidental.

Otra característica que diferencia la literatura de viajes de hombres y mujeres es la relación con los lectores que se establece en este tipo de narraciones. A partir del siglo XVIII, se percibe un cambio considerable en la producción de literatura de viajes escrita por hombres porque se pasa de tener un público mayoritariamente masculino a tener un público femenino que, no sólo participa de forma pasiva como lector, sino que empieza a realizar revisiones críticas profundas del discurso masculino. La importancia que tiene el receptor de este siglo es básica. En el caso de Francia, según Florence Gabaude, el viaje es un mero sueño irrealizable que se suple con los libros de viajes que ofrecen las 
emociones fuertes que el lector ansía. Los lectores de ambos sexos buscan sensaciones nuevas y viajes extraordinarios donde la imaginación y la curiosidad insaciable jueguen un papel importantísimo. Jean-Claude Berchet declara que estos relatos proponen una doble emancipación; por un lado, están escritos con una intención contraria a las pretensiones enciclopedistas de racionalización, y por otro, revindican el derecho del viajante amateur de expresar una sinceridad narrativa. Berchet propone que:

La littérature de voyage se fonde au XIXe siècle sur une double émancipation. Contre la prétention encyclopédique de "tableau raisonné" à la Volney, elle revendique le droit à un amateurisme que semble le gage de la sincérité du narrateur. On refuse du même coup, sur le plan formel, les contraintes de genre, pour emprunter au roman la diversité de ses techniques narratives: lettre, journal, description, portrait, méditation lyrique, dialogue, etc. (11)

En conclusión, toda literatura de viajes tiene que tener en cuenta las circunstancias del viaje. En estas circunstancias del viaje, la descripción del mismo, las noticias o los informes del viaje representan la parte más importante del texto y lo que más domina en él. A estas características genéricas hay que añadir la diferenciación que existe entre los relatos de viajes escritos por hombres y por mujeres ya que, las mujeres, al tener un papel subordinado en la historia, han tenido que aproximarse a todo tipo de creación literaria de una forma diferente que, sin embargo, les ofrezca una posición de autoridad y cierta capacidad de acción individual. Ahora bien, para poder mantener una autoridad textual debian emplear técnicas específicas como la falsa modestia o la representación del personaje femenino como antihéroe de la trama como forma de escape 
múltiple a la sociedad patriarcal. De esta forma, los escritos de viajes de mujeres en general, se hacen más personales, con más descripciones de los paisajes y de los habitantes de los lugares que visitan $\mathrm{y}$, sobre todo, estos textos expresan una visión interior del proceso del viaje. El estilo se hace más intimista, más sentimental, con una fragmentación más pronunciada y de una forma más autobiográfica ya que la narradora ocupaba una posición en la que su supuesta debilidad femenina no le permitía expresar abiertamente una posición de autoridad. A pesar de ello, en sus narraciones se aprecia un acercamiento mayor a las minorías ya que ellas también son minorías y una finalidad difusora, que en la mayoría de los casos, no pretende ser intencionada. 


\section{CAPÍTULO 2}

\section{CARMEN DE BURGOS, HÉROE DE SUS VIAJES: UNA FORMA DE}

\section{APROPIACIÓN DEL DISCURSO MASCULINO}

Como se explicó en la introducción, la primera de las características que diferencian los relatos de viajes escrítos por hombres y por mujeres es la visión del protagonista como héroe o como anti-héroe de la narración. Mientras que el hombre en la narración masculina mantiene en todo momento una posición de héroe valeroso que se embarca en una aventura en la que él es el protagonista airoso de situaciones de riesgo y es también un héroe que domina la naturaleza hostil como una entidad totalizadora del entorno visitado (Pratt 38), la escritora ridiculiza oblicuamente esta posición masculina creando un anti-héroe. La mujer es el anti-héroe, que mediante una posición de pretendida desprotección, critica la sociedad que la oprime. Esta narradora se presenta en los libros de viajes de una forma recurrente. ${ }^{72}$

La mujer, en estos casos, pretendía plasmar una visión satírica del narrador omnipotente y utilizaba esta auto-representación de mostrarse anti-héroe como una técnica narrativa ante la sociedad represiva. A su vez, se mostraba como figura desprotegida y víctima de la sociedad que la oprímía y la narración se convertía, de este modo, en una postura en contra de un estado de discriminación. Era frecuente que la

${ }^{72}$ Esta característica es habitual en la mayoría de los textos de viajeras europeas o americanas; pero la ausencia de esa característica denota también una peculiaridad en los relatos de viajes de algunas mujeres. Ejemplo de ello son los relatos de Emilia Pardo Bazán y Carmen de Burgos en donde en ningún momento la posición de la narradora es de anti-héroe, sino de héroe. Esta característica resalta el dualismo narrativo en la adopción de cánones literarios propios del discurso masculino que se verá posteriormente. 
narradora comentara, de forma sutil, su situación de opresión y discriminación social con la finalidad de convertir su discurso en un refugio en el que se podía expresar de una forma más libre. Así pues, el viaje se convertía en el primer refugio que le permitía escapar de la sociedad que la rodeaba y que la discriminaba en el campo profesional, político y, en defmitiva, en la vida social del pais.

Asimismo, el viaje se convierte en un refugio interior para la mujer, o lo que es lo mismo, la mujer se recluía en su mundo interior para escapar de la opresión y la discriminación que sufría en el mundo exterior por el simple hecho de ser mujer en una sociedad patriarcal. De esta forma, mediante la escritura y la representación de la narradora-protagonista como un anti-héroe, la escritora criticaba, no solamente los problemas que sufría como tal en la narración de su viaje, sino también los problemas reales a los que ella misma estaba sometida en la vida de su país. Este tipo de escritura le permitía un alivio interior por el hecho de expresar sus aspiraciones de integración social y sus críticas hacia la sociedad que la discriminaba.

Esta técnica no irrumpía directamente el discurso masculino ya que se centraba en aspectos personales y no se adentraba en problemas de ámbito público, propios del discurso masculino como aspectos de la política, la economía, la organización social y, por lo general, no trataba directamente el problema de la discriminación racial o sexual. Un caso aparte son los libros de viajes de María Lejárraga. En primer lugar, porque la autora firma con el nombre de su marido, lo cual le da una ambigüedad a sus textos y es un caso más de travestismo autorial. De esta forma, se demuestra una vez más que "femenino" y "masculino" no es "natural," sino convenciones impuestas. Además, en estos libros no se muestra a una anti-héroe, ni siquiera a una mujer viajera; sino que 
Lejárraga presenta a un héroe como protagonista del viaje. En este sentido, sus textos presentan unas caracteristicas peculiares. Por un lado, propone a un narrador hombre que realiza un viaje y, por otro, confiere a varias voces femeninas la capacidad de criticar a la sociedad. Estas protagonistas femeninas son las que discuten los problemas de ámbito social, político o cultural. En el caso específico de su libro El peregrino ilusionado, la autora presenta, en forma de un sueño, un diálogo entre el narrador y una mujer con la que se encuentra en su camino. Ésta mujer establece la tensión y pone de manifiesto los problemas de la sociedad española de su tiempo (15-20). Lejárraga utiliza la estrategia de dar voz a una mujer y por medio ella expresa sus ideas sin, por ello comprometerse, pues es otro y no ella quien presenta estas alegaciones.

Esta característica de la narradora anti-heroína, que era común en los libros de viajes del siglo de oro, no se muestra de forma tan habitual en la literatura de viajes escrita por mujeres en España a partir del siglo XIX y principios del XX. Las viajeras del siglo XIX "are consciously entering an essentially male literary arena and are therefore to some extent assuming a voice of masculine authenticity" (Foster 9). A pesar de que Shirley Foster se refiere a las viajeras americanas por Europa, también es posible trasladar esa visión a algunas viajeras españolas por Europa, las cuales por motivos profesionales o culturales se presentan con las mismas características que las viajeras americanas que describe Foster. ${ }^{73}$

${ }^{73}$ A pesar de que la tradición literaria de las producciones de viajes escritas por mujeres, releguen a éstas a un segundo plano y que, en la mayoría de los casos, las mujeres viajen acompañadas de sus maridos o de algún familiar, a partir de principios del siglo XX, las mujeres comienzan a viajar solas. En España, las escritoras viajeras más famosas que viajaban sin la protección de un hombre o un familiar son Carmen de Burgos, Sofia Casanova, Emilia Pardo Bazán, Blanca de los Ríos y Emilia Serrano García. 
El caso de los relatos de viajes de Carmen de Burgos es diferente. La narradoraprotagonista no es un anti-heroína de esa narración, como se ha analizado anteriormente, sino que es un héroe según los parámetros del discurso masculino. En otras palabras, la autora se apropia de unas formas características de la escritura de hombres y se muestra como un ser superior, con plena autoridad, no sólo de actuación, sino de palabra y desde una posición privilegiada se impone como modelo. La narradora héroe en el sentido masculino, posee un discurso de una mujer que se siente superior y que, desde esa posición de superioridad, analiza las sociedades que visita desde una doble perspectiva: héroe, en el sentido textual y formal, al adoptar un discurso propio de las narraciones escritas por hombres y femenina porque trata temas propios de la literatura de mujeres, como la preocupación por los problemas sociales, culturales y políticos propios del mundo femenino e intercala un lenguaje intimista. Por el contrario, la visión de la narradora heroína tiene unas características que la diferencian del héroe ya que, a pesar de que disfrute de un protagonismo, siempre mantiene una posición de subordinación narrativa. Son mujeres que por circunstancias especiales dentro de la narración en un momento determinado, se desenvuelven en una serie de situaciones de una forma protagónica y excepcional. Por el contrario, propio del modernismo y de las narraciones de mujeres.

Esta forma de entremezclar el discurso masculino y el femenino es una característica esencial que analiza Sara Mills. En este tipo de producción según Mills, se hacen referencias a profesiones típicas de mujeres, al carácter maternal de la narradora o la visión del ángel del hogar para reforzar la visión de feminidad en los textos en los que 
se representa a la mujer en la esfera pública (22). Carmen de Burgos utiliza esta técnica por dos razones. En primer lugar, irrumpe de una forma autoritaria en el discurso masculino imponiéndose como una voz narrativa de autoridad profesional, ya que en ocasiones hace referencia a su profesión de periodista e incluso al hecho de ser la pionera en algunos aspectos profesionales, como el caso de ser la primera reportera que hizo una encuesta sobre el divorcio. En segundo lugar, también expone un discurso femenino cuando hace referencia en el texto a su hija o cuando analiza los oficios que tradicionalmente han sido considerados de mujeres como el de las hilanderas o las cigarreras.

La autoridad que impone la autora en cuanto a la definición de sí misma como héroe femenina del viaje se percibe en el momento en el que expresa lo que supone para ella, el viaje. Para De Burgos, el viaje es una expresión de vida (“Autobiografia”, Mis mejores cuentos 24). Desde el primer momento en que refleja sus primeras vivencias en el extranjero, se nos muestra a una escritora con confianza en sí misma, con libertad de espíritu y con sentido cosmopolita de la vida. Así en su primer libro de viajes, Por Europa, percibe que:

Hoy las fronteras se conservan para la vida política de las naciones; pero el espíritu que nos anima es cosmopolita, las facilidades de los viajes, la difusión rápida de las noticias telegráficas por medio de la prensa y lo

donde nacimos. (9) 
La autora tiene la determinación de viajar y las vicisitudes del viaje no son, como en siglos anteriores, penosas y difíciles. La autora añora los viajes en diligencias por la nota romántica y poética que dejaban a su paso; pero se siente una mujer moderna que va con los cambios y la tecnología. Así lo explica en su primer libro donde se expresa diciendo: "se dice que los viajes han perdido en poesía lo que ganaron en comodidad; prefiero que sea asi" (10).

El proceso de desplazamiento a Europa, para de Burgos, no es una aventura amazónica, pero sí es una aventura de conocimiento. Esta nueva aventura se expresa en unos términos reivindicativos de una voz que quiere imponer sus condiciones. Su autoridad se ejerce desde el momento en el que se pone en contacto con la nueva realidad y nos muestra su opinión como observadora omnipresente de los hechos que presencia. La voz de la narradora se expresa en términos masculinos al mostrar sus intereses profesionales como las referencias a su viaje subvencionado por el gobierno (Cartas 70), o sus entrevistas a personajes públicos donde denota una doble faceta; por un lado, la de profesional periodista y la segunda, en relación a los temas que trata en esas entrevistas: política (Por Europa 84) o, más concretamente, la referencia a la conferencia que dio para la Sociedad de Prensa de Italia (Por Europa 342). En este sentido, los textos de Carmen de Burgos responden a la idea que tiene Lorcin, por la cual "the masculine tradition of travel writing was considered to reflect public and professional concerns" (2).

Carmen de Burgos, al autodefinirse como mujer privilegiada, escritora reconocida y periodista de élite, analiza, describe y crítica las sociedades por las que pasa y confiere a su discurso la autoridad del que ha visto con sus propios ojos y del que, por su condición superior, puede analizar temas que tradicionalmente habían sido vedados a las 
mujeres. En este sentido, de Burgos ejemplifica la idea de Sara Mills del protofeminismo visto en sus textos por el que la mujer se convierte en "a simple representation of a role model" (29) ya que se presentan a mujeres excepcionales que escapan de alguna manera a las estructuras patriarcales. En este sentido, la narradora de los relatos de viajes de de Burgos muestra a una mujer que viaja sola y aunque esté acompañada, su acompañante, en la mayoría de los casos, su hija, no es una figura autoritaria en términos de las relaciones de poder patriarcal, sino alguien que está por debajo de ella en la escala de poder tradicional. A su vez, se enfrenta a situaciones peligrosas, como el caso de su visita a Alemania en Mis viajes por Europa en medio del estallido de la Primera Guerra Mundial en las cuales, no necesita la compañía de un hombre que la proteja, sino que ella misma asume las características del discurso de viajes de hombres al auto-representarse como héroe, con una posición de sujeto independiente, en estas situaciones tan difíciles.

Es por ello, que el discurso de los relatos de viajes de Carmen de Burgos son un ejemplo de lo que Mills explica como "women travellers' writings as examples of strong, exceptional women who somehow managed to escape the structures of patriarchy" (29). La figura de anti-heroína concebida antaño, se ha convertido, en el caso de los tres libros de viajes de Carmen de Burgos, en la figura de esta héroe que narra imponiendo unos valores y una visión particular, los de una mujer que viaja sola y que es capaz de afrontar cualquier adversidad que le surja en el viaje.

Esta visión de la narradora héroe se muestra en este primer libro en varias ocasiones. La narradora se presenta como una mujer diferente. Su primera representación como héroe se produce en la frontera de Hendaya; a pesar de las dificultades que podía encontrar al viajar sola al extranjero y los problemas que suponía la facturación de 
equipaje, la autora-narradora no los tuvo; los gendarmes la creen, la dejan pasar e incluso, la autora reivindica su posición superior de intelectual al llevar la maleta cargada de libros españoles (19). Con la descripción de este episodio, la autora confiere a su discurso una autoridad narrativa de una mujer modélica que ha conseguido, mediante la educación, establecer una posición de superioridad frente a otras mujeres $y$, que este hecho provoca, no sólo admiración, sino extrañaza en los gendarmes que la inspeccionan. Con ello, está reivindicando la figura de la mujer como intelectual, es decir, reitera su posición como mujer superior y, a su vez, diferente a las demás mujeres. Adopta, desde el principio de su viaje, un papel completamente masculino sin despojarse de sus atributos de mujer con todo lo que ello implica en la época; por ello denomino a esta "persona" que de Burgos crea en sus libros de viajes, héroe masculino con características femeninas. En este sentido, se considera una mujer privilegiada, una mujer culta que ha leído a los grandes artistas españoles y extranjeros y que ahora puede conocerlos personalmente por el hecho de ser periodista.

El hecho de ser reportera se convierte en un aspecto más de su representación como héroe de la narración ya que en términos de Pratt, el discurso del héroe de un relato de viajes es categórico, poseedor de la verdad absoluta, observador y científico (88). Por extensión, esta mujer excepcional tiene acceso directo a los personajes más importantes de la vida cultural, social o política de cualquier país que visita y lo expresa de forma abierta y directa en su narración: "he podido llegar cerca de ellos [hombre ilustres] gracias á mi título de periodista" (29). A su vez, el reconocimiento público asienta las características masculinas de su discurso (categórico, observador y científico) y, también, 
universaliza su figura pública al hacer referencia a que los grandes de las letras europeas conocen su trabajo, la respetan y admiran.

Este es el caso de la entrevista que tuvo con Max Nordau. Éste le dice: "Ya la conozco a usted y hasta tengo su retrato inserto por mi buen amigo el Doctor Pulido en el libro <Españoles sin patria>" (84). Así, de Burgos se convierte en entrevistadora y entrevistada: "en vez de interrogar fui interrogada" (87). Esta mujer modelo, se ha convertido en el punto de mira de la narración y se equipara intelectualmente con los intelectuales europeos más reconocidos de su tiempo.

También reivindica su posición de mujer excepcional por ser la pionera en algún tipo de actividad. En este sentido, se vanagloria de ser la primera mujer que pone los pies en la capilla dedicada a San Juan Bautista en la catedral de San Lorenzo: "hace cuatrocientos años que no se ha posado una planta femenina en esta capilla, hasta que yo arrodillada cerca, logré colarme en un momento de descuido" (183). Además, presume de ser la primera periodista en hacer una encuesta sobre el divorcio y de que escritoras italianas como Matilde Serão la siga en este empeño (242). Incluso, se refiere, explícitamente, a conferencias que ha pronunciado a favor de los derechos de las mujeres o en las que ha dado su interpretación sobre la situación de la mujer española (343).

En cuanto a su segundo libro, Cartas sin destinatario, la representación de la narradora como héroe, no se muestra de una forma tan marcada como en el libro anterior, pero sí impone su posición de superioridad por que conoce de primera mano lo que expone y que, además, tiene un conocimiento científico superior a las demás mujeres. En el texto, la autora inserta numerosas explicaciones y comentarios personales sobre el sistema político, económico y social de los países que visita y, sobre todo, se considera 
crítica de arte por lo que las digresiones y comentarios sobre cuadros y museos se extienden de forma considerable en todo el texto. Asimismo, se autorepresenta como una mujer instruida que conoce mejor la cultura de los flamencos que ellos mismos, a pesar de la supuesta superioridad de las gentes de los Países Bajos. Al buscar la casa de Rubens, nadie sabe ni siquiera quien es y toman a de Burgos por una cantante de opera que busca Paganini. La autora comenta: "Si tal cosa sucediera en España, se nos apellidaría en seguida de ignorantes y salvajes" (75).

En dos ocasiones se muestra a sí misma como un héroe. En primer lugar, la autora visita las grutas de Han. En esta ocasión de Burgos mantiene al lector en un estado de excitación producto del viaje subterráneo. En él expone la situación de tensión que produce la experiencia en un lugar de peligro: "Miramos con cierto temor la entrada.... Las profundidades de la tierra nos asustan siempre como todo lo desconocido" (215). Sin embargo, en todo momento mantiene el tono de superioridad de la persona que analiza con objetividad y de forma científica la cueva, describe la exaltación que le produce el contacto directo con la naturaleza virgen y la comunión que experimenta con ella. La experiencia de la cueva se convierte en un simulacro de viaje de exploración propio de la narrativa masculina puesto que se apropia de un nuevo espacio real y simbólico. Pratt habla de la curiosidad femenina en el caso de Falconbriedge, como algo específico de su género que "is in need of control. Her professed reluctance to know seems the antithesis of possession, a refusal of mastery. It is another kind of anti-conquest" (104). En el caso de Carmen de Burgos, esa necesidad de ver es el resultado de la adopción de un punto de vista de superioridad propia del discurso masculino (Pratt 104). Su exploración a la gruta de Han está guiada por la curiosidad de un viajero con una autoridad que se legitima con 
cada movimiento que da la autora. A su vez, la narradora-autora se expresa con las características de los libros de viajes de hombres en los que el narrador es un héroe valeroso que sale airoso de situaciones de riesgo lo mismo que ella.

El segundo episodio en el que se muestra a la narradora como héroe es cuando la autora, acompañada por su hija y su amiga Rafaela, visitan el barrio de Marailles en Bruselas. Este barrio de "gentes [que] con cara de ebrios, han salido de las casas y nos han seguido gritando y gesticulando" (119-20), proporciona el marco fundamental de expresión de la héroe. La autora plantea una situación de riesgo en el peligro que corren ella y sus acompañantes. Este escenario muestra la superioridad de de Burgos al adentrarse "a pie y sola" (119) en un lugar peligroso y salir de él airosa. A su vez, muestra una superioridad en términos del discurso colonial inglés tradicional ya que se percibe una situación de superioridad racial en el momento en el que la autora describe a las gentes que las persiguen como "jaurías de perros" (119). Esta superioridad racial que Carmen de Burgos expone en sus libros en general, es una de las contradicciones más evidentes de toda su producción. Si bien intenta rescatar a la mujer de la discriminación que sufre en la sociedad, también ella misma discrimina a determinados grupos raciales, como los alemanes o los árabes, sin tener unos motivos reales y concretos.

A su vez, la autora señala dos sociedades formadas por mujeres. La primera es un convento que es la representación de una "ciudad de mujeres que se retiran del mundo para consagrarse a la religión con votos de virginidad" (25). La autora nos analiza esta asociación de mujeres, que viven una vida vegetativa al alejarse del mundo real, de forma negativa. Estas mujeres, según de Burgos, viven en un estado de semi-inconsciencia que hace que se vean desde fuera rodeadas de una sensualidad mística pero que, en definitiva, 
están alejadas de la realidad cotidiana. La descripción de esta congregación se analiza como una forma de crítica de género puesto que manifiesta la situación tradicional de la mujer a la que se la recluia en un convento por diversos motivos. Las constantes referencias que de Burgos hace en contra de la religión y del espíritu beato, nos pone de manifiesto una crítica hacia las mujeres que pasan su vida vegetando en un estado de mojigateria.

Por el contrario, la segunda es una congregación de mujeres que adquiere las características de la feminotopía, en los términos que describe Pratt. La autora describe una congregación idílica de mujeres, la "Beguinage de Gante" (183). Esta comunidad de mujeres que dedican su vida a la religión sin votos monásticos y sin dependencia a ninguna orden religiosa, se muestran en los libros de de Burgos de una forma positiva. Para la autora estas congregaciones son una forma diferente de entender un convento. La autora ve en esta comunidad una armonía y explica que "en un beguinage se puede soñar. Hay para la fantasía una historia en cada toca monjil. Una simpatía para las novicias blancas, blancas de espíritu en la inocencia y blancas en un dolor que las aparta del mundo" (183). Percibe una espiritualidad en ese mundo voluntario de encerramiento, pero siente melancolía por esas mujeres que se apartan del mundo. A su vez, explica que existen diferencias marcadas entre estas congregaciones de mujeres con las de hombres y que las de mujeres tiene una razón de ser que no poseen la de hombres: "No odio a las monjas. Los conventos de mujeres tienen una razón de ser que no existe en los de hombres" (183). Esta afirmación categórica propone que de Burgos sabe que la huida del mundo de la mujer es aceptable porque en él no hay espacio para la mujer. En este caso, la visión feminotópica supone una violación al discurso tradicional masculino puesto que 
manifiesta una sociedad que no es utópica sino real en la que la congregación de mujeres tiene un propósito humanitario que no tiene la de los hombres: Son "asociación y refugio de mujeres doloridas, de muchos detritus de la vida. No hay en ellas la picardía y el vicio de los hombres" (183-84). Su discurso es concluyente y de superioridad en el que hace un descubrimiento de la feminidad mediante la aprobación de un sistema social de mujeres superior al de los hombres. Se trata, pues, de una forma de expresar una comunidad de mujeres superiores en valores a las mismas comunidades de hombres, porque en esta comunidad de mujeres no existe "el vicio ni la picardía" (184) propia de los hombres y, por extensión, del discurso masculino. En este sentido, no se puede decir que la autora establezca que los conventos o comunidades de mujeres, en general, son lugares feminotópicos. Todo lo contrario, De Burgos muestra el Beguinage como una comunidad excepcional de mujeres que no necesitan de los hombres y que, por las características especiales que lo constituye, es superior a las comunidades religiosas de hombres. Así pues, no hay que olvidar que la autora mantiene siempre una visión negativa de la religión, sobre todo católica y, específicamente ataca a las religiosas o mojas que se mantienen en la gazmoñería y que no ayudan al progreso, en la mayoría de los casos educativo, de la mujer.

Finalmente, en su tercer libro de viajes, Mis viajes por Europa, la autora, al viajar sola parte de él, representa lo que Catherine Barrer Stevenson analiza como la manifestación más trascendente del espíritu de independencia de la mujer (3) y en particular el hecho que "travel enabled women to acquire experience unlike that available to them at home, experience that could be recorded, analyzed, and published" (Frawley 23). En el caso de Carmen de Burgos, la posibilidad de analizar y publicar su experiencia 
se convierte también en una forma de denuncia. Si bien, denuncia la situación de discriminación de la mujer en la sociedad, sobre todo en el terreno educativo, también denuncia la confrontación bélica que comenzaba en Europa. El episodio del comienzo de la Guerra en Alemania confiere a su discurso una nota diferente que la que encontramos en los demás libros de viajes. La autora experimenta la persecución por motivos raciales y esto hace que, por primera vez, analice el racismo, no el que experimentan los otros, sino el que ella misma vive. Su discurso es ambivalente en varios sentidos. En primer lugar, manifiesta en todo momento una posición de superioridad porque ella se enfrenta a una sociedad hostil y es capaz de salir airosa de la contienda. Al mismo tiempo, como héroe se convierte en el "otro" por ser el objeto de la persecución y la víctima de una confusión física. Otro aspecto problemático en el episodio de la guerra en Alemania, es la posición racista que la autora tiene hacia los alemanes. De Burgos utiliza una terminología totalmente racista para describir a los alemanes y ésta es la misma que los alemanes emplean para discriminar a los rusos. La exaltación del discurso de la autora es igual a la exaltación del discurso de los alemanes en contra de los rusos. De esta forma, se pone de relieve, una vez más el carácter contradictorio de Carmen de Burgos en cuanto al tema del racismo.

Carmen de Burgos se autorepresenta como una mujer modélica que muestra su individualidad al viajar sola en situaciones de peligro, se enorgullece de su país y lo defiende, pero también expresa un españolismo exaltado. Un ejemplo de ello se percibe cuando el militar alemán intenta averiguar si verdaderamente son españolas y no rusas y le pregunta: “- ¿Usted entiende el español?" (II, 53) y de Burgos contesta: "Me vuelvo como si me picase una víbora y en mis labios hay una interjección violenta y muy 
castellana antes de responderle indignada, con ímpetu: -... Mejor que usted" (II, 53-54). La superioridad que muestra la autora en estas situaciones de peligro está unida a la exaltación de su españolismo que llega hasta el punto de decir: "-Verdaderamente tiene usted un espíritu esforzado. Y yo tocada ya de sus bravatas, respondo con orgullo. -Soy española" (II, 54).

Asimismo, su discurso presenta una caracteristica peculiar. Al mismo tiempo que exalta su españolismo mostrándose desde una posición de superioridad ante los alemanes, también experimenta lo opuesto: la opresión y la discriminación racial. En este sentido, no sólo se la discrimina como mujer, sino racialmente por su apariencia física semejante a las rusas. De Burgos se ve situada en la posición del "otro," que es el que ella otorga a los países y ciudadanos objetos de su escritura. El discurso de la autora que trataba de imponer una supremacía femenina muestra en este episodio lo que sufre el oprimido. En este sentido, la héroe, que experimenta las consecuencias de la opresión bélica por su parecido físico con las rusas, responde a lo que analiza Lila Marz Harper sobre la narrativa de viajes en el periodo imperialista británico. En este tipo de producciones se construye heroínas que caen en el riesgo de que se deconstruyan (32). Lo mismo sucede con esta experiencia de Carmen de Burgos en los albores de la Primera Guerra Mundial. De Burgos experimenta esta situación cuando le gritan: "Una espía rusa. Entonces sucede una cosa que aún me parece una pesadilla. La multitud se agrupa en torno mío; se alzan bastones; una mano me arranca el velo, y otra se lleva mi sobrero; mi hija llora, tendiéndome los brazos desde el vagón; hago un esfuerzo supremo y consigo subir en el estribo" (II, 47). La autora para poder defenderse, utiliza la treta de la mujer indefensa, diciendo: “¿Qué podríamos hacer dos pobres mujeres solas y sin armas? ¿Seriamos más 
culpables si hubiéramos nacido en Rusia?" (II, 55). Con esta alegación, la autora subraya la inferioridad moral del alemán que comete atropellos injustificados y llega a utilizar la teoria de la frenología para determinar la inferioridad del alemán y destacar los valores de los españoles y de los rusos. ${ }^{74} \mathrm{Al}$ mismo tiempo, resalta su figura modélica y superior por considerarse más civilizada que los alemanes y esta superioridad es, no sólo racial, sino de género. Es una mujer que ha demostrado en el proceso de la contienda una supremacía en el saber estar y comportarse ante esa situación de peligro.

Las instancias de heroísmo que de Burgos registra son varias y forman un repertorio temático. En primer lugar, en cuanto a la representación del viaje como una experiencia de emociones violentas. En este sentido, en su viaje en barco por el Rin, imita el viaje de aventuras exaltadas tradicional, por el cual la autora se ve envuelta en una situación de extrema peligrosidad producto de la experiencia de la naturaleza salvaje (I, 85). A su vez, la ascensión al Cabo, produce en la autora, la ansiedad de conocer en carne propia emociones fuertes. Su premio por el riesgo es llegar al clímax de comunión con la naturaleza para luego bajar física y alegóricamente a los infiernos de la vida cotidiana, del mundo real. La autora hace un paralelismo con el éxtasis místico de santa Teresa para expresar la sensación que le ha producido la unión con una naturaleza pura y primitiva tras los riesgos que ha experimentado para llegar a esa "visión" (I, 298-301).

En segundo lugar, expone ejemplos de mujeres heroicas como las noruegas que han sido capaces de imponer restricciones legales en contra de la venta de alcohol (I,216)

\footnotetext{
${ }^{74}$ Gabriela Pozzi analiza el proceso que utiliza Carmen de Burgos al usar la frenología como un intento para confrontar las caracteristicas de la otredad bárbara y retrograda del alemán, frente al "yo" noble y civilizado que representan los españoles y los rusos (3034).
} 
o el análisis de la vida de Carolina Coronado, que se mencionó anteriormente, como un ejemplo de mujer modelo que ilustra el compendio de todas las cualidades que deberia tener cualquier mujer. Carolina Coronado ocupa el último capítulo de Mis viajes por Europa y representa, por un lado, a la literata española que "legitimó la inclinación literaria de la mujer hasta el límite que hoy tiene" (II, 264). Este libro de viajes concluye con el anhelo de De Burgos de redefinirse bajo los parámetros para la mujer que inició de Coronado. Así pues, según De Burgos, Carolina Coronado es: "una mujer en la más profunda acepción de la palabra, en sus amores y en sus empresas "(II, 266), "estuvo henchida de una pasión honesta, pero fervorosa por la vida. Fue como una heroína de novela" (II, 265). Esta mujer fue "el ideal de mujer de corazón sensible y alma fuerte" (II, 268) en el que sobresalen tanto sus virtudes intelectuales como sus virtudes femeninas con todos los atributos propios de la mujer. De Burgos propone a esta mujer como la iniciadora del proceso de concienciación de la mujer de la necesidad de cambio ya que poseía todas las características que, en su opinión, debía tener una mujer: intelectual y femenina.

En definitiva, esta visión de mujer héroe que quiere resaltar la autora tiene un propósito específico. Para Carmen de Burgos esa mujer héroe tiene como objetivo adoptar y apropiar el discurso masculino de los libros de viajes para mostrar a una mujer excepcional y esa excepcionalidad viene dada por la educación. Su discurso llega a ser feminocéntrico en los términos que defiende Mary Louse Pratt (166), puesto que llega a mostrar la igualdad que puede conseguir la mujer con el hombre con el simple hecho de educarse. De esta forma, la héroe femenina trasforma y se apropia del discurso patriarcal para imponer una reivindicación a la mejora de la mujer en el terreno educativo. Ella se 
propone como modelo de otras mujeres ya que ha accedido a la educación y la ha convertido en precursora de la lucha por los derechos de las mujeres, sobre todo en el campo de la educación de principios del siglo XX. 


\section{CAPÍTULO 3}

\section{ADQUISICIÓN DE PODER Y AUTORIDAD DISCURSIVA}

Para poder establecer una noción de autoridad discursiva en un texto, ya sea escrito por mujer o por hombre, se tiene que partir de la base de unas imposiciones previas en relación con una jerarquía de poder preestablecido. Sara Mills propone que para formular un marco teórico que represente la posición de la mujer como autoridad textual, la crítica literaria existente debe ser adaptada y modificada para que cumpla un papel efectivo en cuanto a la adopción de sus teorias (14). En este sentido, las teorías de Foucault pueden servir para analizar la importancia que este crítico da a la centralización del poder y especialmente, a su noción de resistencia. La teoría de resistencia es imprescindible como fundamento para el análisis de las relaciones de poder y de autoridad discursiva en los textos de viajes de mujeres. De esta forma, según Meaghan Morris y Paul Patton aseguran que Foucault establece que:

Power is conceived as a sort of grand, absolute Subject... who articulates what is forbidden. On the side of which power is suffered, there is an equal tendency to 'subjectivise' it, by determining the point at which the acceptance of the interdict occurs, the point at which one says 'yes' or 'no' to power. (4)

Por su parte, Sara Mills afirma que para Foucault "it is not simply a matter of changing consciousness on an individual basis, but resistance being a necessary part of power" (16). Asi pues, Mills establece que esta postura de resistencia se aplica mediante la identificación de una posición que se ha adjudicado a un individuo y el posterior rechazo de esa posición (16). 
En la literatura de viajes de mujeres existe esa posición de resistencia hacia el poder establecido por la sociedad ya que impone unas restricciones al "absolute Subjet" del que habla Foucault. En este sentido, Foucault se refiere al poder absoluto e institucionalizado, que es el que rige las normas a seguir por una sociedad. Estas restricciones se producen al rechazar alguna de las normas que el "sujeto absoluto" o poder absoluto impone. En este sentido, el primer rechazo o punto de resistencia que han impuesto las escritoras de libros de viaje es el mismo hecho de viajar. Las viajeras dicen no al "poder absoluto" y se aventuran a viajar solas a pesar de que éste viera mal que una mujer viajara sola a principios de siglo. Así pues, se produce la primera resistencia al poder patriarcal y esta resistencia propone, a su vez, una implantación de un poder absoluto. Este nuevo poder proporciona la primera muestra de autoridad de la mujer frente a las normas establecidas. Es por ello, que Foucault dice que la resistencia es una parte necesaria del poder, puesto que establece una dialéctica entre poder y resistencia al convertirse la resistencia en poder y el poder en resistencia.

En este sentido, Carmen de Burgos expone, en sus libros de viajes, ese nuevo poder producto de la resistencia en el hecho de viajar. Por un lado, al viajar sola, sin la compañia de un hombre, impone una autoridad propia; es la mujer que sola se aventura a una expedición a un pais extranjero. Además de representar una aventura, es también, como dice Frawley, una forma de expresar la independencia personal de la mujer (23) y representa una nueva forma de libertad adquirida (Barnes 3). El hecho de viajar sola es, a su vez, una resistencia al "Poder," y una adquisición de poder. En su último libro de viajes, de Burgos muestra esta forma de rebelión a las normas establecidas por el poder patriarcal de la sociedad española y lo hace patente mostrando su indignación ante el 
concepto que tienen las europeas al pensar que en España una mujer no puede viajar sola (Mis Viajes II, 38).

Por otro lado, la autoridad textual de la mujer que viaja sola, no es exclusiva de Carmen de Burgos; Emilia Pardo Bazán, también se inscribió como autoridad textual en sus libros de viajes. Así en Al pie de la Torre Eiffel dice: "Si yo no conociese a fondo, casi palmo a palmo, la capital de Francia, iqué emoción experimentaría en estos instantes al encontrarme, como quien dice, puesto el pie en el estribo para salir hacia ella, con objeto de escribir cuanto en mi opinión merezca ser referido..." (1). En primer lugar, establece la autoridad del que conoce "palmo a palmo" la ciudad y mantiene un referente del "Monarch of all I survey" de Pratt; y en segundo lugar, impone el objetivo de su viaje: escribir lo que le parezca importante contar. En Cuarenta dias en la Exposición, la adquisición de autoridad textual se consigue con la inscripción que de si misma hace Pardo Bazán como observador cultural que describe los acontecimientos. El caso de Maria Lejárraga es completamente diferente porque el yo narrativo no es fidedigno y está insertado en una narración en el caso de El peregrino ilusionado, o es un narrador masculino en el caso de Kodak romántico; pero en ambos casos describe el viaje de alguna mujer que viaja sola o acompañada de algún hijo, como es el caso de la catalana que va a visitar las montañas de Zuric donde estudia su hijo (Kodak 25).

Otra resistencia que de Burgos propone contra el poder absoluto, la expresa en Cartas sin destinatario. La autora asegura que "no podemos en un viaje de estudio darlo todo al sueño" (137). En este sentido, la autora niega la parte subjetiva y romántica del discurso, que tradicionalmente se ha asignado a las mujeres. El poder patriarcal consiente que si una mujer viaja y escribe sobre su viaje se atenga a los parámetros establecidos en 
relación con la escritura que podía producir: todo lo relacionado con el mundo interior, el sentimentalismo y, en general, lo superficial. De Burgos impone una autoridad textual propia del discurso masculino al exclamar que no se va a atener a los sueños, sino que su viaje es de estudio y, por consiguiente, esta afirmación implica unos niveles diferentes de autoridad textual que pertenecen a la esfera simbólica masculina, como son el análisis y el estudio. Con esta cita, impone su nivel de resistencia al poder patriarcal, no solamente ha impuesto su autoridad al viajar sola, sino que, una vez transgredido su poder por el hecho de viajar y escribir, transgrede también mediante la forma de su discurso ya que implica que sus descripciones de sus viajes no van a ser subjetivas o sentimentales, sino analíticas y racionales. Este mismo pensamiento lo ratifica en su tercer libro al expresar que el viaje que ella propone es un viaje de conocimiento. De esta forma, compara la experiencia en cada lugar o ciudad que visita con libros abiertos que hay que leer al pasar por ellos (210).

Otra forma de expresar la autoridad intelectual que propone de Burgos, la hace mediante el intento de derrumbar los ídolos que tradicionalmente han sido impuestos a las mujeres, como por ejemplo, Santa Teresa de Jesús, a la que llama "neurótica" (Por Europa 251). Para de Burgos, la figura de Santa Teresa de Jesús no es el emblema distintivo de la mujer intelectual y sabia que revolucionó su tiempo y organizó una congregación de mujeres nunca antes pensada, sino que es el símbolo que el poder patriarcal institucionalizado utiliza para revalorizar a la mujer beata, católica y tradicional cuyo mito, la autora desea derrumbar. ${ }^{75}$ El hecho de llamarla neurótica ejerce un efecto

\footnotetext{
${ }^{75}$ Jean Franco en su libro Plotting Women. Gender and Representation in Mexico, dice que el discurso místico es propio de la mujer y como tal, está fuera de lo analítico e
} 
de resistencia e impone un poder mediante el derrumbamiento de la visión tradicional paternalista impuesta a las mujeres. De Burgos mediante esta crítica, asigna nuevos modelos basados, no en la devoción y el catolicismo, sino la intelectualidad, la visión analítica y la cultura. De esta forma, son frecuentes los ejemplos que la autora propone de mujeres, que por alguna razón u otra, considera que son la representación del modelo que plantea. Desde su primer libro, Por Europa, en el que se siente orgullosa de que haya en España mujeres médicos como Concepción Aleixandre (88), que haya mujeres periodistas y de letras en Italia (338), llega a la conclusión de que la modelo, patrón a seguir, debe ser una mujer con las cualidades de Matilde Serão (242), una persona culta e instruida que ha luchado por reivindicar los derechos de las mujeres.

En su tercer libro, Mis Viajes por Europa, a su vez, propone a una mujer liberada en todos los aspectos sociales y con absoluta igualdad de derechos frente al hombre (99). De esta forma, da ejemplos concretos de mujeres que, o bien han combatido y luchado por defender el feminismo y legalizar los derechos de la mujer como Anna Carlota Leffer, o bien, mujeres que han establecido un poder de resistencia al poder tradicional masculino en el campo de la cultura. Este caso, se manifiesta en la figura de Ellen Key a la que la autora considera más apta que cualquier hombre para recibir un premio Nobel (164-5). De esta manera, su libro no es solamente una forma de resistencia al poder establecido, sino una critica hacia las decisiones tomadas por el poder patriarcal en el

intelectual. Frente al discurso místico, está el trabajo intelectual que propone sor Juana. De esta forma, propone dos vertientes en la figura de sor Juana. Mientras que la primera, la mística, es aceptada por la sociedad y no rompe la especificidad de lo femenino en la sociedad patriarcal que le tocó vivir, la segunda, la intelectual, es reprimida porque sí implica un resquebrajamiento del sistema patriarcal en cuanto a su representación de lo femenino. Carmen de Burgos solamente ataca lo que representa la primera sor Juana. 
campo de la cultura y una articulación de un discurso de poder, pues se otorga a sí misma la autoridad de juzgar y plantear el camino a seguir.

Además de las formas de resistencia al poder establecido que propone Foucault, por las que se parte de esta noción de resistencia y se establece una autoridad que lucha en contra del poder patriarcal establecido, en algunos libros de viajes se percibe otra característica que Sara Mills denomina: patriarcalismo. Según Mills, para poder luchar en contra de este poder, es importante establecer unas restricciones propias que se ajusten a la producción literaria de mujeres en relación con el poder patriarcal. De esta manera, Mills afirma que en la literatura de viajes de mujeres se ha adoptado un modelo de representación del patriarcalismo y utiliza la definición por la que Chris Weedon: "see partriarchy as a set of institucional structures and representational practices which $<$ rest... on the social meanings given to biological sexual difference>"(2). ${ }^{76}$

En este sentido, en los libros de viajes de mujeres, se percibe esa relación de poder que ejerce el sistema social patriarcal en la mujer de clase media o media-alta que viaja al extranjero y cómo ese poder patriarcal opresivo actúa en las escritoras y en su producción marcando una diferenciación de género. En Cartas sin destinatario, expone que el efecto del poder patriarcal en el hecho de viajar y escribir se plasma en: "decir todo lo que llevamos en el fondo de la conciencia con el dualismo de los sentimientos y la razón, en las mil sensaciones hijas de la pluralidad de nuestro espíritu" (6). Esta

\footnotetext{
${ }^{76}$ Lo que Sara Mills intenta expresar en su libro es que no es necesario crear una teoría en la que se haga una conspiración de lo masculino frente a lo femenino; sino establecer una teoria, como sugiere Weedon, en la que se pueda explicar cómo y por qué las personas se oprimen entre ellas. Al mismo tiempo, es necesario que esta teoría sea subjetiva y que incluya los pensamientos inconscientes y las emociones que pueden ocurrir en las relaciones de los individuos y la sociedad (Weedon 3).
} 
pluralidad de espiritu, de lo racional y lo sentimental es la simple oposición de lo masculino y lo femenino que Mills establece como la confrontación de género. La representación de la dualidad es una técnica muy recurrente en todo tipo de género literario escrito por mujeres durante finales del siglo XIX y principios del XX. Como ya se ha mencionado anteriormente en este trabajo, esta dualidad representa la afirmación de la autora en cuanto a su género, pero a su vez, representa una excusa narrativa por el hecho de irrumpir en el discurso masculino. De esta manera, se utiliza las formas propias de la escritura masculina para establecer una autoridad textual y las femeninas para resaltar las cualidades establecidas por el discurso patriarcal para las mujeres y paliar el efecto subversivo de su representación como sujeto activo de una narración.

Por el simple hecho de viajar y escribir, se disipa la confrontación de género y la autora impone una superioridad y una autoridad textual porque escribe de la persona que escribe con conocimiento los hechos que describe en sus libros. Por otro lado, de Burgos propone como elemento necesario para hacer un libro de viajes, alguna de las características que el discurso patriarcal considera propias de la escritura de mujeres como la ingenuidad. De esta forma, concluye diciendo: "el alma se reviste de una ingenuidad, sin la cual no podría escribirse un libro de viajes" (7). Es decir, una de las cualidades femeninas, es la única imprescindible para escribir un libro de viajes. De esta forma, no sólo impone una confrontación de género, sino que establece una superioridad textual. La autora autoafirma su texto al proponer unos parámetros textuales, que han sido considerados por el discurso patriarcal como propios de la mujer, como los únicos realmente necesarios para escribir un libro de viajes. 
En este sentido, Gabriela Pozzi señala que en los textos de viajes de Carmen de Burgos, la autora textual mantiene una dualidad discursiva "aun cuando desempeña las actividades masculinas (públicas) de viajar y escribir, en la intimidad sigue siendo $<$ femenina $>$ (doméstica); y aquí, en la esfera privada, reside al principio su subjetividad, ya que sólo en este entorno, y muy brevemente, nos habla la narradora de sí misma" (301). Para Pozzi la tensión producida por la mezcla de los dos discursos, se resuelve en el momento en el que la autora textual femenina protagoniza la narración y lleva "su vida íntima a la esfera pública" (301).

Carmen de Burgos, no sólo protagoniza su viaje, sino que incorpora su vida privada e íntima a la esfera pública. En este sentido, son frecuentes las alusiones que la autora revela sobre su lugar de origen. Andalucía está muy presente en la memoria de de Burgos y la muestra como el lugar primigenio y ancestral donde encuentra la paz de su alma. Su infancia en Rodalquilar (Cartas 300) está presente en las distintas formas en que la autora describe en sus viajes desde las playas de su hogar en Andalucía (Por Europa 134), hasta sus recuerdos de niñez en Almería (Por Europa 501). De esta forma, su vida se convierte en punto de referencia y esto constituye otra forma de adquisición de poder.

De Burgos presenta estos aspectos de su vida personal y los traslada al terreno público para presentar una voz subjetiva que se desplaza a territorios públicos como la política, en el caso de la ley del divorcio, o la cultura, en el caso del análisis de las obras de arte. A su vez, se apropia de discursos de poder patriarcal, teorías científicas o estadísticas, para apoyar sus propias ideas. Ejemplo de ello es la explicación que hace la autora de los avances en el estudio de la oceanografía para el avance técnico en la instalación de tendidos eléctricos y para la mejora en la pesca (Por Europa 157); o 
también, la exposición que hace la autora de los distintos idiomas que se hablan en Bélgica los cuales los muestra de forma científica, mediante estadísticas y cuadros de porcentajes de hablantes (Cartas 81). El hecho de expresar su pensamiento y sus creencias, ya sea en temas culturales, como políticos o religiosos es importante porque confiere a su texto un carácter científico y, por extensión, le confiere autoridad narrativa. María Fawley analiza esta autoridad cultural que representan los textos de viajes de mujeres inglesas en la época victoriana y explica que:

Travel conferred on many Victorian women a measure of cultural competence that derived not from education but from experience. And as a mode of experience through which they gained the authority to write about culture, travel was empowering. Travel enabled many Victorian women to gain the experience necessary to win a new find of recognition for themselves. (24)

En primer lugar, a pesar de que Carmen de Burgos e incluso, las viajeras victorianas posean una educación más o menos adecuada, muestran en sus escritos un conocimiento producto de la experiencia para paliar el efecto de incursión en el terreno propiamente masculino. Este hecho muestra una autoridad cultural que parte de una restricción discursiva. Como dice Frawley, la mujer viaja y plasma sus interpretaciones del mundo visitado, no como una representación de su nivel de formación intelectual o educativa; sino por la experiencia personal del viaje. Por su parte, Carmen de Burgos combina la autoridad del conocimiento directo; en otras palabras, del derivado de la experiencia del que habla Frawley con una educación formal. Ello le permite crear un 
discurso que es a la vez serio, en el momento en el que se apropia del discurso masculino y también ameno, puesto que estaba dirigido a un público femenino.

A su vez, según explica Frawley, también representaba una conexión con ese sector de la sociedad al que iban, indirectamente, dirigidos estos textos: Las mujeres que, como las escritoras viajeras, sufrian carencias educativas. Paulatinamente y por diversas razones, estos textos adquirieron popularidad y la sociedad comenzó a reconocer su importancia por medio de la creación de revistas especializadas en viajes. Este es el caso del tercer libro de viajes de Carmen de Burgos que su éxito fue tal que en un año se agotó la edición se tuvo que re-editar. En España, esta popularidad es palpable en cuanto a la proliferación de artículos de periódicos destinados a los viajes de mujeres intelectuales a otros países y la creación de secciones en los periódicos destinados a crónicas de viajes; como por ejemplo, las secciones de viajes de los periódicos Blanco y Negro, donde escribió asiduamente Emilia Pardo Bazán y Carmen de Burgos, el diario El Imperial, en el que todos los lunes había una sección de viajes donde Pardo Bazán publicaba sus viajes, al igual que lo hacía en La Ilustración Artística. También Sofia Casanova publicaba asiduamente en el $A B C$ sus crónicas de viajes y, finalmente, La Esfera o el Heraldo de Madrid que reservaba un lugar para que Carmen de Burgos publicara sus impresiones y artículos de viajes.

En segundo lugar, se manifiesta mediante la percepción de una voz científica que pretende ser objetiva, en cuanto a la exposición de aspectos de la vida económica, cultural y política de los países a los que se viaja. En este sentido, en el primer libro, Carmen de Burgos mantiene una posición de autoridad, en el sentido de que sus divagaciones en temas relacionados con el mundo científico o cultural, la llevan a decir, 
indirectamente, el camino que han de seguir los estudios científicos: "Tengo fe en que la ciencia cumplirá su misión de librar al hombre de la hasta ahora inevitable enfermedad, de la vejez, de la ruina del organismo, de la decrepitud y las influencias funestas de los microbios, verdadero mundo de invisibles diablillos, destructores del cuerpo que les da vida" (28).

En su segundo libro, su autoridad cultural está establecida. Así, analiza los procesos sociales y políticos de los países y mediatiza una organización política socialista republicana. Critica abiertamente la organización política belga y los problemas de sus obreros "que no tienen una situación tan ventajosa como á primera vista puede creerse; pero la soportan más fácilmente que los meridionales sufren la suya" (50) y aboga por un socialismo que está latente en la sociedad y que a pesar de que "las medidas legislativas pretenden implantarse [en contra del socialismo en Bélgica] abortan, como atentatorias a la libertad" (84), al igual que expresa su ideal socialista de progreso en la forma del partido socialista belga del que dice: "no comulga en su mayoria en las doctrinas de Carlos Marx. Ellos no quieren suprimir la propiedad, sino que el trabajador sea propietario... tienden a mejorar la condición de los obreros y trabajan activamente para conseguir la reglamentación del trabajo, la inspección en los talleres y todas las reivindicaciones necesarias" (137).

En Mis Viajes por Europa, la autoridad discursiva ha abarcado mayor cantidad de campos, incluido el de los proyectos de trasformación económica. Por ejemplo, en Dinamarca habla sobre el bienestar colectivo y la prosperidad que producen las sociedades colectivas que "han desarrollado la industria de la lecheria... El gobierno se preocupa por proteger los intereses de los pequeños industriales, ahogados por el 
desarrollo de las grandes empresas. Los subvenciona, les proporciona herramientas y les hace los préstanos necesarios" (98-9). Todas estas incursiones en el mundo político de los paises europeos tienen un claro fin: abogar por una sociedad republicana democrática de corte socialista. Es por ello, que no se puede considerar sus descripciones objetivas, sino con pretensión de objetividad. Lo mismo hace Emilia Pardo Bazán en Por la Europa católica, pero en sentido opuesto. Si bien Carmen de Burgos aboga por un sistema socialista, Pardo Bazán critica este sistema que quería "suprimir la propiedad privada, nacionalizando el suelo y los instrumentos del trabajo, y que no sabemos si todavía llegará a implantarlas, pues es poderosísimo allí- las humildes instituciones cristianas de mutualidad y cooperación agrícola vinieron a poner dique a la ola invasora-“(77). El objetivo de Pardo Bazán es exaltar el catolicismo belga y derrumbarlo de sus mitos ancestrales, mostrándolo como un sistema de gobierno moderno que trabaja por y para el pueblo y que defiende la mejora educativa de todos los estratos de la sociedad.

En segundo lugar, en los relatos de viajes de Carmen de Burgos se percibe la autoridad cultural histórica y artística. En este sentido, son innumerables las citas y referencias que la autora hace a los distintos estilos artísticos de la época y analiza con la autoridad del experto en arte, las diferentes tendencias y estilos, hasta el límite de analizar los detalles de un cuadro o una escultura. Al mismo tiempo, se percibe un cambio en la forma de representar el arte. Mientras que en el primer libro explica y describe las obras de arte o los edificios con una técnica más de observador externo, en su segundo libro, analiza cuadro a cuadro los detalles específicos de cada uno y de su estilo y en el tercer libro, analiza de forma más profunda su opinión del arte y el artista (132-33) y de los diferentes movimientos artísticos como el neoclasicismo o el romanticismo (120). 
Al mismo tiempo, comenta algunos hechos históricos ocurridos en los países que usa preámbulo. En el caso de Por Europa, desde el principio, comienza a divagar sobre su aversión hacia la monarquia. Esta situación, la lleva a exponer, la situación política española bajo las diferentes monarquías y, de una forma directa y subjetiva, impone su visión personal sobre el hecho de que la monarquía es la responsable de la ausencia de progreso en el país (13). En Cartas sin destinatario, el tono general del libro en cuanto a los procesos históricos es diferente. A pesar de que analiza el efecto que la política del Duque de Alba y el emperador Carlos $\mathrm{V}$ ha dejado en la imagen de España para los belgas, su análisis es más bien una alocución de la responsabilidad de los belgas para que asuman su culpabilidad en los hechos políticos, al igual que España. De Burgos propone que se mire la historia, no desde el pasado, sino del presente en adelante puesto que anquilosarse en un pasado poco fructífero, degenera la conciencia intelectual del hombre y no ayuda al progreso de la humanidad. Carmen de Burgos no necesita detenerse en un pasado estancado y sin esperanza porque: "El espíritu humano no se aviene á la inmovilidad. Necesitamos la innovación. Caminar, caminar siempre" (36). Para la autora, sólo se puede innovar un país y a sus gentes si se tiene una conciencia de avance a un futuro mejor.

En cuanto al su tercer libro, las implicaciones históricas son diferentes por varios motivos. En primer lugar, tiene una tendencia más marcada hacia la revolución social y se percibe en el texto de forma más directa. Un ejemplo de ello es la forma en la que propone la reforma económica de los paises a base de la confiscación de los bienes de la iglesia católica (172-73) y sus criticas en contra de la tiranía monárquica son muy directas (204); pero sobre todo, su situación ante el estallido de la Primera Guerra 
Mundial hace que su discurso se convierta automáticamente en un discurso de autoridad al ser ella testigo privilegiado. Su autoridad la marca con el simple hecho de convertir su experiencia personal privada en una experiencia pública. Tiene la autoridad del que participa y, a su vez, del que sufre las amenazas del proceso bélico al ser tomadas (ella y su hija) por rusas y, por ende, enemigas de Alemania. Todo este capitulo se convierte en un ejercicio diferente en el que se experimenta una explosión de sentimientos anti-bélicos y anti-germánicos y, a pesar de que se convierte en documento histórico de primera mano, que imprime a la historia rasgos propios del discurso femenino, es subjetivo y está lleno de emotividad.

Esta autoridad cultural, en algunas ocasiones se equipara con la teoría del poder colonial de Sara Mills. Esta crítica combina la teoría de la resistencia de Foucault y la teoría del patriarcalismo con el poder colonial. Su estudio se centra en los relatos de viajes de inglesas a algún país bajo el dominio colonial de Gran Bretaña. Si bien, las circunstancias históricas españolas no permiten que exista una literatura de viajes de tipo colonialista al estilo inglés y la época es distinta en la mayoría de los casos, ${ }^{77}$ en los libros de viajes a Europa de las españolas, sí se percibe una forma de presentar algunas de las sociedades europeas con un sentido patriótico que denota unas similitudes, a la hora de describir la sociedad a la que se viaja, con el discurso colonial británico. Hay que partir

${ }^{77}$ Joan Torres-Pou en su artículo El viaje a oriente en la literatura femenina española: Carmen de Burgos, Aurora Bertrana y Rosa Regás, establece que sí se percibe una posición colonialista en relación con el mundo Islámico. Para Torres-Pou esta visión colonial del Islam no es más que una forma de construcción de un discurso en el que se "ha configurado la imagen de una alteridad, unas veces rechazada y otras aceptada, pero siempre inventada" (48) de un pueblo. En este sentido, los relatos de viaje de españolas al mundo islámico sí presentan unas características comunes al discurso colonial de las escritoras inglesas. 
de la base de que en España no habia, en ese momento, un sistema de poder colonial que conllevara a una relación de superioridad permanente, uniforme y estable, como en el discurso de las escritoras anglosajonas, todo lo contrario, en esa época se vivía la desilusión producto de los acontecimientos de 1898. Sin embargo, en las narraciones de viajes de españolas, sí se percibe algunas manifestaciones similares a las producidas en los escritos de las inglesas en cuanto a la relación colonial y a las relaciones de superioridad e inferioridad.

Las caracteristicas principales que se manifestan en el sistema de poder colonial y que se perciben con más frecuencia en los libros de viajes de españolas son dos. En primer lugar, la posición de superioridad cultural y social de la escritora frente al nuevo entorno y, en segundo, la empatía con el oprimido o desfavorecido social. Esta última manifestación representa la posición del anti-conquest de la que habla Pratt. Es decir, la narradora se encuentra con una realidad opresora hacia algún sector de la sociedad y por encontrarse, ella misma, en una situación de opresión de género, simpatiza con los individuos a los que afecta la opresión. Su discurso, de esta forma, se convierte en un texto que apela contra las opresiones producidas, como explica Mills: "in the process of interaction of colonial textual constraints and constraints of gender" (40).

Esta empatía con el desfavorecido social proporciona un aspecto muy interesante dentro de la producción de Carmen de Burgos. Si bien la autora simpatiza con los deprimidos y discriminados de las sociedades europeas, no lo hace con los de las sociedades islámicas. Según Torres-Pou, en la novela, En la guerra, la autora no simpatiza con la mujer islámica, como lo hace con las mujeres europeas que se encuentran en situaciones de discriminación social. Todo lo contrario, presenta a las 
musulmanas como "salvajes sedientas de sangre que, llevadas de su odio religioso, gozan torturando a los soldados" (En la Guerra IX). De esta forma, Torres-Pou revela que su aversión a las musulmanas llega hasta el límite de "desmitificar la imagen tradicional con que le discurso orientalista ha descrito la belleza y sensualidad de la mujer musulmana" (42). Torres-Pou indica que este proceso es la consecuencia del proceso de aceptación y rechazo de esa realidad mora que lleva dentro el español (42). Ese proceso de aceptación y rechazo de esa realidad innata del español hace que el discurso se convierta en un discurso colonial, en el sentido pleno de la palabra, en el que se inventa una realidad social y se produce un alejamiento del narrador con la verdadera realidad existente.

Esta aversión al mundo islámico es patente en los libros de viajes de Carmen de Burgos en los que explícitamente hace responsable a la herencia árabe del retraso cultural que sufre la mujer en España. En este sentido, como se ha mencionado con anterioridad, describe a las mujeres andaluzas como víctimas de ese "fatalismo musulmán" (Por Europa 15), que sufren la tortura de la dependencia matrimonial absoluta y que aceptan, "sin deseos ni esperanzas, maltratadas por sus maridos... la más estúpida de las resignaciones" (Por Europa 15). De esta forma, es evidente que la poca simpatía que siente de Burgos por la mujer musulmana está estrechamente unida a su "resignación estúpida" a unos convencionalismos matrimoniales que la autora intenta desesperadamente borrar de la sociedad española.

A pesar de que de Burgos intenta rescatar aspectos favorables de la cultura árabe como la limpieza: "Pienso con deleite en los baños de los judios, en los blancos velos y 
en las abluciones de los árabes!" (Por Europa 13), ${ }^{78}$ es palpable el tono general de desprecio hacia la cultura árabe que se extiende, no sólo a la mujer, sino a otros marginados sociales como los niños. La autora los muestra de forma peyorativa al mencionar los desfiles de D. Carlos de Borbón en la ciudad de Lido: "Marcha delante un pequeño morito... feo como todos los de su raza, el chiquillo marcha contento, juega y salta con muestras de alegría grotesca. Es la imagen de los bufones de las antiguas cortes" (Cartas 450). En este sentido, la autora adopta una posición de superioridad cultural, en la que se percibe una superioridad en cuanto a la construcción del yo narrativo frente al otro. Así, Gabriela Pozzi identifica ese otro, según el discurso nacionalista y colonial, como ese ser o sociedad inferior, infantil o con características cercanas a la animalidad (302).

Por otro lado, De Burgos, en algunas ocasiones, mantiene una posición de superioridad cultural frente a sociedades europeas. A pesar de que su misión en sus viajes a Europa es encontrar y analizar las sociedades que pudieran ser modelos para España, la autora muestra un patriotismo exaltado que hace que su discurso tome una posición de superioridad cultural. En este sentido, en su primer libro, a pesar de que el tono general de éste es de admiración a las sociedades que visita, se percibe alguna de esas notas de

\footnotetext{
${ }^{78}$ El tema de la aversión racial de Carmen de Burgos es un tema muy peculiar y a la vez controvertido. Si bien, manifiesta un rechazo completo a la cultura árabe, muestra una admiración absoluta por la judía. Este es un aspecto insólito puesto que ambas culturas discriminan a la mujer en sus sociedades y muestra una subordinación al hombre en casi todos los aspectos de la sociedad (con la única diferencia de la poligamia musulmana). La autora intenta rescatar el pasado histórico judío y resaltar la herencia judía que pervive en España, sin tener en cuenta que la herencia musulmana es mucho más evidente y palpable que la judía y forma parte constitutiva del carácter del español y, especialmente del andaluz.
} 
superioridad española. Un ejemplo de ello es al describir la ciudad de París que, a pesar de ser la cuna del republicanismo y de la libertad, es considerada por la autora inferior a algunas ciudades de España en los medios de comunicación: "El movimiento y el ruido son aquí atronadores: los ómnibus y los tranvías, más caros y malos que los nuestros" (36). Esta crítica llega hasta el punto de reprochar una forma de explotación humana: "Entre tanta animación y lujo, pasan no pocos carros arrastrados por hombres, espectáculo desagradable y de desdichado contraste" (37). Para la autora Francia es equivalente a extravagancia, lo considera un país sin moral, ni formación espiritual que solamente se sustenta del dinero. Concluye diciendo: "Por mi parte cuanto más veo á Francia más amo á nuestra tierra; no se me ocultan sus defectos, pero al lado de la civilización francesa comprendo mejor sus virtudes" (60).

Esta forma de patriotismo que exalta una supuesta superioridad nacional, también se extiende a los museos de los que piensa que: "después de haberse extasiado días enteros en nuestro Museo de Prado, ninguna maravilla de pintura pude sorprendernos" (61). En Italia, a pesar de que para de Burgos representa la tierra de sus "ensueños" (167), destaca un aspecto curioso. La autora resalta: "Yo pienso á veces que Nápoles es tan hermosa porque guarda las huellas de la raza española" (218). Esta cita, marca un claro chovinismo hacia lo español del que piensa que en todo lo bueno hay una raíz española.

En su segundo libro de viajes, Cartas sin destinatario, muestra la inferioridad de las gentes de los Paises Bajos en todos los estratos de la sociedad, si el comerciante falsifica los ingredientes de la cerveza para enriquecerse (82), el obrero es comparado a una máquina con un instinto grosero y dominado únicamente por las necesidades básicas: "comer, beber y dormir todo lo que pueda" (139). Para de Burgos, el belga "tienen una 
mentalidad muy inferior a la de los españoles; no lee, no se interesa por nada artístico, el alcohol le domina demasiado" (136). En su visita a Holanda, también menciona la inferioridad de sus mujeres que parecen animales pensadas y lentas (256). En su último libro, las referencias se atenúan en Suiza o Dinamarca, ya no se percibe una posición ni de superioridad, ni de inferioridad; sino que la autora utiliza una técnica de asimilación con las realidades de España. La diferencia más marcada la da el paisaje y la diferencia de luz. Mientras que en los Países Bajos, todo se "tiñe de añil" (93), la autora añora los cálidos colores españoles y las diferentes tonalidades del verde de los campos (94).

La superioridad que se crea en los textos de viajes de mujeres, no es solamente una superioridad de tipo cultural; sino también de género. En el caso específico de Carmen de Burgos, esta superioridad de género está presente de forma marcada en su libro Mis viajes por Europa en el que la autora contrapone los atributos y características de las mujeres alemanas con las demás europeas y, especialmente con las suyas propias. A la alemana le otorga una serie de atributos masculinos y hace comentarios como: "Muchas jóvenes llevan solas sus barquillas, y las guian y las impulsan con un arrojo masculino" (II, 26) o también: "Tan fuertes son ellas y tan rubios y delicados ellos, que a veces, cuando los veo remar juntos en las barquillas, no sé distinguir bien el sexo" (II, 27). Su descripciones son sobre todo peyorativas; "Observo que son menos bellas que las inglesas" (26). Estas mujeres a los ojos de la autora son fanáticas, militaristas y sin sentimientos maternales puesto que no lloran a sus hijos cuando van a la guerra, sino que lo festejan; es decir, son mujeres carentes de feminidad y por ello, masculinas, primitivas, animales y brutales. A estas mujeres, que adoptan unos atributos meramente masculinos, 
se contrapone la visión del yo. La autora asume la doble posición masculina-femenina. La narradora-autora, se apropia de las características masculinas en el hecho de ser la viajera, protectora, escritora e intelectual, pero, a su vez, sus características femeninas sobresalen en el texto. En este caso específico de la Primera Guerra Mundial, su feminidad se hace mucho más presente en el momento mismo en el que no sólo se siente protectora de su hija, sino que siente miedo, se encuentra en una situación de peligro $\mathrm{y}$, lo que es más importante, siente la necesidad del hogar. Su naturaleza maternal se agudiza y, por extensión, sus atributos femeninos también. La autoridad textual, ahora no sólo es una apropiación de lo masculino, sino que inserta lo femenino y esto es realmente importante porque equipara al mismo nivel de poder las dos formas sexualizadas.

A su vez, se equipara lo masculino a la guerra, la muerte y la intolerancia y lo femenino a la inteligencia, la lucidez y la tolerancia. Ella es pacifista y tolerante con los oprimidos, en contraposición con los "salvajes" alemanes (50). Esta característica es evidente al tratar todos los aspectos de Alemania en relación con referentes masculinos, sus mujeres son masculinizadas, el paisaje se muestra con adjetivos de referente masculino "crecen los árboles corpulentos y la vegetación es lujuriante" (II, 9), los edificios como catedrales, que en otros paises se describen con exaltación, en Alemania la catedral de Colonia "es una joya cara y pesante... [de] línea severa, augusta, grandiosa, pero que tiene algo que agobia: dogma, religión positiva, inquisición, cárcel" (11-2), dominios propios del ámbito masculino. En defmitiva, la autora propone un cambio radical y subversivo al otorgar una superioridad de género a la mujer. De esta forma, relaciona los atributos masculinos a la animalidad y a la muerte y muestra la superioridad 
de lo femenino en relación con la vida, con la racionalidad y la tolerancia; por ejemplo, Inglaterra es plácida, melancólica (II, 86) y Portugal tiene las connotaciones más evidentes de esa feminización. De Burgos comenta que Coimbra "es la ciudad madre, la ciudad tradicional, la que sirve de cimiento y fundamento a la nacionalidad" (II, 149), ya que para la autora, Portugal era modelo de modernidad y lugar donde se habian conseguido un proceso de democratización más importante que en España.

En cuanto a la manifestación empatía con el oprimido, Bénedicte Monicat sugiere que la mujer en cualquier civilización estaba destinada a proteger el género humano debido a los atributos que el discurso patriarcal decía que eran propios de su género, como la ternura, la compasión y la delicadeza. Era, por ello, que a la mujer se le reservaba el papel de civilizadora del mundo y de otras mujeres (56). Si bien, era la civilizadora del mundo, debía, a su vez, ser la portavoz de esa civilización en los estratos sociales que más lo necesitaban: los más desfavorecidos. Por ello, las viajeras se convertían en lo que Pratt denomina "las exploradoras sociales" (160).

La viajera, en su misión de acercamiento a los estratos más bajos de la sociedad, se dedicaba a visitar cárceles, hospicios, orfanatos, campamentos, plantaciones de azúcar y lugares propios de congregaciones de mujeres como conventos, asilos o escuelas. A su vez, según Fedler, la mujer tendía a enfatizar los: "family and relational values; getting along with groups, friendship, especially other women, customs, domestic circumstances (14). Es por ello, que son frecuentes los comentarios, el análisis y las descripciones de estos sectores de la sociedad más marginados y discriminados.

A causa de la marginación social que sufre la mujer, encuentra en estas visitas una forma de criticar a la sociedad patriarcal que mantiene en una marginación opresora a 
ciertos sectores de la sociedad y que no hace nada porque salgan de esa situación de marginación. A su vez, esas visitas constituyen un alivio personal e individual, ya que, por medio de estas críticas, expresa una situación de discriminación y de olvido social a unas personas que, al igual que las mujeres, se encuentran marginadas dentro de la sociedad. Es por ello que las escritoras al prestar mayor atención a las sociedades de mujeres, extienden esa crítica a la situación particular de la discriminación de género.

La mujer al simpatizar con los marginados sociales, hace que su discurso se pueda analizar según la teoría que Pratt denomina "contact zone." Pratt la define como: "social spaces where disparate cultures meet, clash, and grapple with each other, often in highly asymmetrical relations of domination and subordination" (4). En este sentido, la autora de la narración de viaje funciona como un agente observador y crítico de una situación de diferencia social que se produce bajo unos parámetros de opresor-oprimido. El opresor sería la sociedad patriarcal que permite y no corrige esa situación de discriminación hacia el oprimido y el marginado social. La autora se acerca a esa sociedad rechazada y se produce el proceso de concienciación de la "contact zone."

Carmen de Burgos describe un pasaje en el que el acercamiento que tiene la autora a un barrio marginado de la sociedad es muy peculiar y posee una doble perspectiva. En su visita al barrio de Marailles en Bruselas, por un lado, mantiene una posición de empatía con estas gentes que es propio de los libros de viajes de mujeres: "es el barrio pobre de Bruselas, el barrio de la miseria, de la suciedad, de las gentes de malvivir. Ese barrio que no se sabe cómo y por qué subsiste en las ciudades modernas" (Cartas 119). Su empatía va hasta el punto de la crítica a las sociedades que permiten que exista esa marginación; pero por otro lado, mantiene una posición parecida al discurso 
colonial británico del que habla Pratt, puesto que se percibe un atisbo de superioridad en el que la autora critica esa situación de opresión con las características del discurso patriarcal colonial masculino. Pasa de la crítica a la sociedad, que se tiene por moderna y que permite que existan esos barrios marginales, a la visión peyorativa de esas gentes, propia del discurso colonial masculino, donde llega al extremo de compararlos con “jaurias de perros" (120). No se percibe esa empatía con esta gente que vive en los suburbios en condiciones infrahumanas, todo lo contrario, la autora muestra a una sociedad con rasgos feroces: "Una multitud de gentes, con caras de ebrios, han salido de las casas y nos han seguido gritando y gesticulando... corrían detrás del coche como si nos fuesen a acometer, con los puños amenazadores" (119-20). En este sentido se aprecia un miedo ante el peligro que supone el salvajismo de una comunidad. La autora muestra señas del terror que le produce estas gentes, que están descritas como salvajes. Este episodio se asemeja a la situación de peligro que siente Mary Kingsley cuando visita un poblado de canibales (248-9). ${ }^{79}$ Esta escritora en su viaje a África, muestra en esa ocasión a estos pueblos como salvajes y con atributos de animales, al igual que hace Carmen de Burgos. A su vez, en este episodio no se percibe acercamiento humanitario por parte de la autora, sino la necesidad de salir lo antes posible: "Por fortuna, la mala impresión se desvanece pronto. La Gran Plaza de Bruselas es una de las cosas más bellas que he contemplado" (120). A pesar de la duplicidad de este episodio, De Burgos mantiene, en

79 Esta visión de miedo ante lo salvaje de una comunidad en los libros de viajes de mujeres en el periodo colonial británico no es frecuente y Mills asegura que: "This is unusual, since only rarely in women's travel wititng is danger from "savagery" so clearly described." (163). Tanto Kingsley como Carmen de Burgos expresan un miedo al peligro de estas gentes y los describen con rasgos animalísticos y salvajes. 
su totalidad, esa nota de empatía del discurso femenino. Esta compasión es doble, por un lado, su acercamiento está directamente relacionado con la mujer en sí y su situación social, cultural o política en el país analizado; y por otro está relacionado con el oprimido o el desfavorecido social.

La miseria social constituye un tema recurrente en sus escritos. Por un lado, es el vehículo de crítica hacia la religión que beneficia a los ricos en detrimento de los pobres. El Papa: "El padre común de los fieles no ve más que á sus hijos bien vestidos; a los que llegan gozosos a sus pies, los desnudos, los tristes, los hambrientos... esos no tienen entrada cerca de él" (Cartas 383). A su vez, ese favoritismo hacia los ricos lo muestra la autora al decir: "en la religión de los soberanos se consienten divorcios, se anulan casamientos, se santifican déspotas, se permite todo; lo estrecho, lo inmutable, la punta del embudo es para el pueblo, ese debe respetar la santidad de los sacramentos mientras muere de hambre y de miseria" (Por Europa 101); y, finalmente, propone como solución, su pensamiento socialista de repartición de las riquezas de la Iglesia: "Todas las riquezas de los templos italianos, repartidas entre el pueblo, y todos los conventos e iglesias puestos a disposición, harían que nadie careciese de albergue y desapareciera en un día la miseria de la bella Italia" (Por Europa 254).

La pobreza constituye también una crítica directa a la sociedad que no sabe repartir bien sus riquezas. El ejemplo más evidente es la descripción que hace de Burgos de una ciudad tan rica como Nápoles en la cual: "la iglesias y museos guardan millones; la tierra florece sin esfuerzo; el subsuelo encierra maravillosas riquezas; el cielo está enamorado de la más bella ciudad que alumbra... y sus hijos padecen la más espantosa de las miserias... como en nuestra Andalucía..." (Por Europa 222). Pero la miseria y 
pobreza no es sólo de Andalucía, sino que al describir la afluencia de gente de los Montes de Piedad de Bruselas, se da cuenta que en países tan desarrollados económica y culturalmente como los Países Bajos, también hay marginación: "una larga fila de mujeres pálidas, con vientres abultados, vientres de miserable, espera todo el día turno para depositar paquetes de ropas, mantas, abrigos, todo eso que es más preciso que las alhajas y que no sale de las casas hasta que el fantasma del hambre crece y se agiganta" (Cartas 140).

Una vez descrita la miseria, en términos generales, pasa a describir la miseria de las mujeres. Critica al pueblo francés que compadece a la emperatriz Eugenia de Montijo por sus circunstancias especiales de viuda de Napoleón y vuelve la vista a la verdadera mujer que hay que compadecer: "a una pobre mujer prematuramente envejecida, que con un niño en brazos y otro cogido a las faldas me ha pedido varias veces limosna" (Cartas 460). Esta mujer que por circunstancias reales: su marido, pescador, ha muerto en el mar, y ella tiene que pedir limosna para dar de comer a sus hijos, es la verdadera desfavorecida social y es la que pretende defender. También dedica parte de su narración a comentar hospicios de niños desamparados y a la sociedad que no ha sabido integrarlos en un ambiente más familiar (Cartas 12). Este ataque se hace directo al describir los asilos y hospitales en Suiza, en los que De Burgos comenta: "representan la miseria de la sociedad, que crea la casa de todos porque cada uno no puede tener su casa" (Mis viajes I, $51-2)$.

Otro aspecto que lleva a la marginación son las enfermedades mortales de la época como la tuberculosis que tienen un papel fundamental en los libros de viajes por la relación directa que esta enfermedad tiene en los marginados sociales: los niños, jóvenes 
y mujeres. De Burgos comenta el Congreso sobre tuberculosos que se realizó en París a principios de siglo como la esperanza en la mejora de la medicina (Por Europa 29); también describe el Castillo del marqués da Bacalhoa en Portugal que ha servido de refugio a los niños tuberculosos: "¡Su único bien! Se ve que el castillo tiene al fin un destino regio al darse así a esas criaturas míseras" (Mis viajes II, 259). En este sentido, se trata de nuevo de la manera en la que las mujeres ratifican su autoridad al entrar en la esfera pública. La mujer tiene mayor conocimiento de los aspectos sociales y, por lo tanto, está más capacitad para crear e implementar soluciones y criticar a la sociedad que permite esas injusticias, de una forma más abierta.

Trata el tema de la situación del minero, que es mostrado de una forma inhumana, igual que una máquina que se la reemplaza cuando desaparece. De Burgos ataca a:

La humanidad [que] debiera avergonzarse de sus minas... para los que fue tan escasa parte de ese oro, en las familias hambrientas y ansiosas, en los hombres enfermos y muertos en este trabajo tan cruel, arañando la tierra, cargados como brutos, deshecho el organismo con los venenos del metal. Siento el dolor de todos. (Mis viajes, 181)

Esta cita ejemplifica perfectamente la empatía de la autora hacia un sector de la sociedad rechazada y manifiesta, de forma analitica y jerarquizada, una autoridad textual que actúa directamente en el lector por medio de la compasión con ese sector marginado. De esta forma, se manifiesta primero, criticando a la sociedad que permite esa situación, después describiendo las condiciones en las que trabaja el minero y, finalmente, se hermana con él en el dolor de su situación. Del mismo modo, se compadece de la situación del pescador y lo expone en los mismo términos, primero denuncia su situación económica real: "su 
jornal rara vez llega a dos coronas diarias, aunque la cifra de los rendimientos de la pesca del bacalao se elevan de seis a siente millones de coronas al años" (Mis viajes $I, 274-5)$ y después se compadece de su situación emocional: "queda en el alma como una pesadilla el espectáculo de su miseria" (Mis viajes I, 277).

En cuanto al acercamiento a los problemas relacionados directamente con las mujeres, Shirley Foster dice que el género era un factor muy importante en el punto de mira de la viajera: "As might be expected, the women pay close attention to domestic concerns and aspects of social or institucional life relevant to their sex" (6). Ahora bien, Foster indica que especialmente éstas se interesaban por los estratos de la sociedad en los que las mujeres se mantenían aún más marginadas: "there was a strong and sympathetic interest in the plight of prostitutes and their treatment by male-centered value system" (8). La prostitución constituye un elemento en el que de Burgos se detiene a describir en sus viajes como forma de renovar la sociedad y mostrar la realidad que se esconde detrás de la fachada que encierra esa profesión. La descripción que la autora hace de la vida de las prostitutas tiene un momento álgido en el pasaje del asesinato de una prostituta en París y la descripción de la morgue donde está su cadáver. Esta descripción que mantiene un tono naturalista, choca contra los sentidos y abre una ventana a la incomunicación y pasividad de la sociedad hacia estas mujeres producto de esa ineficacia y falta de cultura. Su descripción toma tonos de alegato como: “¡Nadie viene a reclamarla!... ¡Cuántas de estas infelices perecen del mismo modo! ¡Asusta pensar que no hay una persona que se preocupe de ellas! Un cadáver insignificante que nadie ama ni nadie busca y ante el cual pasamos con indiferencia o repugnancia..." (Por Europa 119); para la autora "la sociedad entera es la culpable" (Por Europa 119). 
Asimismo, habla de las mujeres andaluzas que viven maltratadas por sus maridos (Por Europa 15); pero sobre todo ataca a la mujer que no se educa y se mantiene aislada dentro de los cánones impuestos a su género por el sistema patriarcal. Habla de la mujer vulgar que "ahoga el genio y lo destruye... hay una casta de mujeres que con ser honradas, o sea no tener un amante, se creen con derecho a envenenar la vida de sus esposos con celos y exigencias; ser puercas, derrochadoras y mal educadas, como si no tuviesen más deber que la fidelidad muy discutible" (Por Europa 454). La autora lucha por conseguir los derechos de la mujer y, a su vez, por lograr una sociedad donde exista mayor igualdad sexual. Para Carmen de Burgos, esas condiciones sólo son posibles si se comienza por implantar una mejora en la educación de la mujer. Una vez que la mujer se eduque, puede conseguir que se la respete y valore como se merece. En definitiva, Carmen de Burgos consigue una autoridad discursiva al simpatizar con los sectores más marginados de la sociedad ya que produce una empatía en su público femenino y, a su vez, su discurso adquiere poder al tratar estos temas en los que las mujeres tienen mayor conocimiento. De esta forma, su discurso tiene autoridad al entrar en la esfera del dominio público. 


\section{CAPÍTULO 4}

\section{EL "WOMANLY WEAKNESS" O EL DISCURSO DE LA FEMINIDAD}

Con el término "womanly weakness," mencionado en la introducción, Karen Veit define la idea de utilizar el discurso de la feminidad de Sara Mills en el que se enfatizan las cualidades femeninas impuestas por el discurso masculino dominante, para ganar autoridad discursiva (Veit 117). A finales del siglo XIX y principios del siglo XX, a la mujer de clase media se la confinaba a una serie de actividades dentro de la esfera de lo privado, lo espiritual y de lo moral dentro del grupo familiar; en otras palabras, todo lo que tuviera que ver con el mundo interior (Mills 94). No hay que olvidar que a la mujer se la veía dentro del sistema patriarcal como un objeto en lugar de un sujeto. En este sentido, es muy curiosa la posición de Elizabeth Bohls porque opina que si la mujer debía representar el papel de objeto estético del discurso masculino, ésta se debía de autoadornar. Este auto-adorno no sólo era físico, en cuanto a los atributos externos de la mujer; sino que su adorno se extendía al terreno intelectual. Es decir, para Bohls, la mujer incluía un auto-adorno que denominaba el "beauty of mind." Esta belleza intelectual tenía la finalidad de producir un efecto en el receptor masculino (3). Este efecto era la concienciación de que la mujer, no sólo tenía que ser bella físicamente ante los ojos del hombre, sino que su belleza también se extendía a su intelectualidad. De esta forma, la representación que la mujer hace de sí misma en sus escritos es una manera de reivindicación de su posición como sujeto pensante. Así pues, las escritoras incluían en sus producciones narrativas el auto-adorno externo que tendía a enfatizar sus facultades intelectuales. 
El concepto de auto-adorno fisico que analiza Bohls, se percibe muy someramente en los libros de viajes de Carmen de Burgos y, cuando se observa, la autora lo hace para exaltar, de una forma patriótica, su españolismo. Un ejemplo de ello se percibe en su primer libro, cuando de Burgos se describe físicamente en su visita al Papa. La autora resalta: "Veo que muchas damas se fijan en mi mantilla... Yo he recordado que soy española, y sólo me faltan los claveles rojos para ir á la Plaza de Toros" (383). Lo que sí resalta, de forma habitual, es, por un lado, el "beauty of mind" o, en otras palabras, la belleza intelectual y el efecto que produce esa belleza intelectual de las mujeres a las que la autora describe y, por otro lado, el aspecto propiamente físico de algunas mujeres europeas. Uno de los casos más evidentes de las descripciones de las mujeres extranjeras, lo encontramos en su tercer libro. La autora describe a la mujer sueca y una vez descritos los cánones de belleza de los nórdicos, pasa rápidamente a evaluar "la belleza intelectual" de estas mujeres que tienen "una solidaridad extraña en las mujeres que unas y otras se disculpan, se salvan, se ayudan" (I, 195). En este caso específico, Carmen de Burgos pretende manifestar un anhelo de reivindicación de la mujer por medio de la unión entre mujeres.

A su vez, la autora formula una reivindicación social que aboga por una igualdad de la mujer con el hombre en temas tan candentes en la época como el derecho de las mujeres a practicar deportes:

Hay una vida muy pura y muy honrada; los hombres se avergüenzan, como las mujeres, de la falta de castidad, como debe suceder en un pudor real y una lógica perfecta. Unas y otros aman mucho los sports, la vida al aire libre, la pesca, la natación, las excursiones a las montañas y los juegos 
entre la nieve. Sus energías se gastan y se multiplican a un tiempo en estos ejercicios, y los hombres se envanecen de ser puros para crear una familia sana y dichosa. $(I, 196)$

Carmen De Burgos, no sólo aboga por la igualdad en la educación fisica de ambos sexos, sino que expone un problema básico en cuanto a los atributos que el discurso masculino dominante ha establecido como propios para el hombre. En este sentido, la autora propone que el hombre adopte las normas establecidas para el "ángel del hogar" para crear una igualdad en la que la norma sea una norma de ética femenina. En este sentido, el hombre ha de ser casto y puro puesto que ello, llevará a crear una familia "sana y dichosa." Las implicaciones de esa subversión son poco habituales en la narrativa de principios de siglo XX y confieren al discurso de Carmen de Burgos una autoridad clara y directa ya que la castidad, la pureza y la honra han sido desde los comienzos de la literatura en español y, sobre todo en el siglo de oro, los atributos a las mujeres a las mujeres y, ahora, mediante esta descripción de los noruegos, insta a que, si se quiere llevar a cabo ese anhelado perfeccionamiento de los vínculos familiares, corresponde al hombre, en las mismas condiciones que a la mujer, aportar los mismos valores que habían sido tradicionalmente asignados solamente a las mujeres.

En cuanto al papel de la mujer dentro de la sociedad noruega, la autora comienza ese capítulo con las descripciones físicas de las mujeres noruegas a las que gustan vestirse de colores vivos en verano $(I, 193)$ y tomar "baños de sol y de nieve, en los que se exponen desnudos a los rayos débiles de su sol" (I, 193). La autora pretende producir una nota discordante al discurso tradicional dominante en relación con las normas morales y sociales de la buena mujer y esposa. La desnudez es natural a los ojos del 
noruego y se extiende a una visión completamente igualitaria en términos femeninos. Es por ello que Carmen de Burgos en estos tres libros de viajes no recurre de forma habitual al recurso del auto-embellecimiento ya que no lo necesita.

En relación al tema de la domesticidad, en la literatura española de viajes hay un caso muy peculiar. María Lejárraga (G. Martínez Sierra) en uno de sus libros de viajes, $E l$ peregrino ilusionado propone una controversia en cuanto a este tema. El peregrino viajero a su llegada a Bruselas se encuentra con una joven con la que conversa y le manifiesta su amor. Esta conversación fluye dentro de los parámetros del discurso de la domesticidad desde el primer momento; al preguntarle el nombre de la dama, el peregrino establece los parámetros del discurso patriarcal en cuanto al objetivo de la mujer: "¿Cómo te llamas? -Marta. -Tienes un nombre que dice hogar y paz" (16). Pero el tema se complica al pasar a temas más espirituales o intelectuales. La autora propone una revisión interior de un problema social. Mediante una conversación sobre la poesía se llega a la definición del carácter del español y, con ello, a los problemas de base que existen en España.

-Tú debes ser poeta. - ¿Acaso no te gusta? -Me da miedo. -¡Miedo la poesía! -La poesía, precisamente, no; algunas noche leo versos en un libro que tengo en el cestillo de labor... lo que me da miedo es la inquietud; además tú eres español, y dicen que por aquella tierra sois excitables e intolerantes. ¿Has visto en el Museo el cuadro de La furia española?

El Peregrino torna a suspirar; la novia le mira más bien desconcertada; cambian algunas más palabras sin sentido; luego 
ella se aleja tranquilamente, y el Peregrino, viéndola alejarse... siente al mismo tiempo un alivio grande y una pena honda. Así despierta de su primer sueño. (20)

A la joven, no le da miedo la poesía, puesto que dice que al mismo tiempo que hace sus labores del hogar, lee poesías; pero lo que le da miedo es la inquietud del hombre español y más todavía la intolerancia de los españoles. Y éste es, en defimitiva, el temor que tiene el peregrino, y que se extiende a la sociedad española: la intolerancia y la excitabilidad del español. En el segundo encuentro con una mujer, el narrador entabla una conversación con Carlota, quien representa la sabiduría y la razón: "Eres sabia en palabras todas dulces, y sin embargo, hay en ellas un dejo que me suena a razón" (25). El discurso de Martínez Sierra (María Lejarraga) tiene la peculiaridad de conceder a sus personajes femeninos una autoridad de la que carece su personaje principal masculino, el peregrino. Esto lleva consigo una propuesta en términos femeninos de valoración de un discurso también femenino.

Los temas relacionados con el espacio doméstico son importantes en los libros de viajes de mujeres porque como dice Pratt:

domestic setting have much more prominent presence in the women's travel account than in the men's (where one is hard pressed indeed to find even an interior description of a house) is a matter not just of differing spheres of interest or expertise, then, but of modes of constructing knowledge and subjectivity. (157)

Dentro del discurso de la domesticidad el traje y la indumentaria de las mujeres, tanto de la narradora como de las mujeres a las que describe, son un lugar común en 
todos los textos de viajes escritos por mujeres y prentenden, según Pratt, ser un símbolo de liberación de la mujer para algunas mujeres (167). Así, al igual que el caso de las vestimentas de las mujeres peruanas que describe Flora Tristán, anteriormente mencionado y las descripciones que hace Lady Mary Montagu de los trajes de las mujeres turcas, los cuales las envuelven de tal manera que ni siquiera sus maridos las reconocerían en las calles. Esto sirve para protegerlas porque, de esta forma, ningún hombre se atreve a meterse con ellas porque podrían ser su esposa, su madre, hermana o cualquier familiar. Para Montagu "this perpetual masquerade gives them entire liberty of following their inclinations without fear of discovery" (111).

En el caso de los tres libros de viajes analizados de Carmen de Burgos, esta función es diferente puesto que la autora no viaja a un pais en el que por la construcción política, social o cultural se mantenga una subordinación acusada de la mujer. De Burgos viaja a países considerados más liberales en términos políticos-culturales $\mathrm{y}$, sobre todo, sociales, donde la mujer, en la mayoría de los casos, tiene más derechos que en España y participa de la vida pública con más libertad y asiduidad. Es por ello que la función que las vestimentas tienen en los relatos de viajes de españolas a Europa, no sirva como símbolo de liberación de la mujer en los términos que lo describían Tristán y Montagu, sino para resaltar una característica social. Así es el caso de Gregorio Martínez Sierra en su libro Kodak romántico. ${ }^{80}$ En él se destaca el papel de las vestiduras de la mujer para

${ }^{80}$ Gregorio Martínez Sierra era el marido de María de la O Lejárraga a la que se le atribuyen la mayoría de los libros publicados bajo el nombre de su marido; entre ellos constan varios libros de viajes como: La feria de Neuilly de 1901, El peregrino ilusionado de 1908, Granada de 1901, Kodak romántico de 1921 y España: Andalucía de 1930. La autora, no sólo firmaba con el nombre de su marido, sino que también utilizaba el nombre de María Martínez Sierra para muchas de sus publicaciones. 
confeccionar un referente que resalta los valores tradicionales españoles. De esta forma, al describir a las ancianas inglesas que viajan por Europa pretendiendo fingir una juventud pasada, la autora piensa que: "no hay espectáculo más doloroso que el de un rostro de mujer que acaso fue bonita, cuando en el otoño de su vida se obstina en fingir, con una mueca fatigada, la luminosa sonrisa de mayo" (22). Ese luto que llevan las viejas inglesas por dentro, a pesar de sus vivos colores en el vestir, los contrapone con el simbolismo del canon tradicional de la anciana española: “¡Oh, las viejas de España, esas quietas señoras, que apenas alcanzado el linde de su estío, asumen con tan admirable resignación en la austeridad del ropaje negro, y hacen a su feminidad el supremo homenaje de una abdicación casi orgullosa!" (22).

También es muy interesante el caso de Emilia Pardo Bazán para quien el tema de la vestimenta cumple múltiples funciones. Si bien en su libro Por la Europa católica describe la moda en los grandes almacenes belgas que "son- en humilde y baratoreproducciones de los grandes Almacenes de París" (84), utiliza la descripción detallada del ropaje como una excusa para exaltar el sistema socialista católico y el régimen de cooperativas, puesto que la primera cooperativa que se convirtió en "precursores del socialismo belga son tejedores ganteses" (85). A su vez, la nota principal en el tema de la vestimenta, la expresa en el libro Cuarenta dias en la Exposición de 1901, en el que dedica dos capitulos enteros a explicar las secciones de ropa antigua y moderna en los pabellones de la exposición de París de 1900. En este libro, Pardo Bazán confiere a su discurso sobre la historia de la moda femenina autoridad y prestigio: "Es el génesis y el análisis del objeto, que nos preparan a comprenderlo; sistema que considero acertado 
desde el punto de vista del estudio, y que, por medio de los innumerables Museitos salpicados aquí y alli, modifica el aspecto de la Exposición" (94). De esta forma, la moda, no es sólo interesante, sino que forma parte de un discurso femenino que merece un espacio propio dentro de la Exposición Universal como una "una manifestación social y artística" (104).

Por su parte, Carmen de Burgos no es ajena a los cánones propios del libro de viajes de mujeres a los que se tenía que ajustar e incluye frecuentemente alusiones a la indumentaria de las mujeres europeas con una doble intención. Si bien era consciente de que su público era mayormente femenino y quería acercarlo a temas que le pudieran interesar más, también era consciente de la irrupción que estaba haciendo dentro del discurso masculino por el simple hecho de escribir y por su posición de autoridad textual. Mediante las descripciones consideradas típicas de las narraciones de mujeres para mujeres, la autora pretendía un doble proyecto. Por un lado, intentaba validar su discurso mediante la autoridad que le proporciona su género y, por otro lado, ampliar el campo de esa autoridad por medio de la apropiación de territorios masculinos.

El efecto del "womanly weakness" valida su discurso en cuanto a la visión de la mujer en términos femeninos al describir las normas estéticas y los cánones de belleza establecidos para las mujeres. De Burgos se sirve de las descripciones físicas del traje y la indumentaria de éstas para ofrecer una visión de la mujer contemporánea, unas veces para resaltar su españolismo y otras para criticar la decadencia de España. En este sentido, las descripciones de la vestimenta le servían para asegurar su autoridad discursiva en temas meramente conectados con la mujer y, una vez conseguido ésta, otorgaba a su discurso 
una autoridad, en términos del discurso masculino, al discutir temas relacionados con los problemas sociales y políticos de España.

En Por Europa, las alusiones al modo de vestir son variadas. En primer lugar, exalta el papel de las costumbres folklóricas cuando describe a las mujeres italianas vestidas con sus trajes típicos y alude que "presta este traje algo tan puro, tan elegante, que cada una de estas muchachas reidoras y ligeras, con sus zagalejas de colores y sus collares de vidrio recuerda la enamorada Graciella de Lamartine, que va a entonar su melancólica romanza a la orilla del encantado golfo" (215-16) y a que "se necesitaría ser muy fea para no parecer hermosa con este traje" (215). Asimismo, se lamenta de que en España se haya perdido una tradición que apela a la belleza y al romanticismo y que solamente se usen los trajes típicos "para bailes de carnaval" (215); de este modo, la autora apela al rescate de las tradiciones nacionalista del país.

También describe el traje de las encajeras italianas ambulantes que visten con gracia y colorido y que llegan a convertirse en señora, esposa o amante del artista del taller y salvaguarda de éste en momentos difíciles (347). En este sentido, mediante la descripción de un traje, la autora alude a la mujer trabajadora y compañera del hombre. Así, el vestido es el marco enunciativo de una labor social: la industria encajera; y ésta a su vez, enmarca a la mujer como protagonista de la misma, en situaciones especiales ya que, una vez que ésta ocupa una posición de compañera en el trabajo del marido, dueño del taller, puede sustituirle si éste faltase puesto que habría conseguido la preparación necesaria para poder desempeñar el mismo papel que él. Este protagonismo es doble, por un lado, proporciona una actividad laboral aceptada para las mujeres de su tiempo, pero a su vez, reivindica un papel protagónico dentro de la escala social, al proporcionarle a la 
mujer el rol no sólo de ayudante y compañera del maestro artesano del taller, sino que, con el "carácter enérgico" (347) de estas mujeres, se convierten en cabeza de familia en los momentos dificiles.

En su segundo libro se percibe cierto escepticismo a la hora de describir la vestimenta de las mujeres europeas. Si bien no deja de lado su españolismo al mostrar que las mujeres de Brujas "debajo de ese abrigo llevan un traje semejante al de las mujeres del pueblo español: falda, armilla, delantal grande y pañuelo del talle cruzado sobre el pecho. Guardan un sello de las costumbres españolas que se enseñorearon un día en todo el mundo" (22), a su vez, hace una crítica en la que menosprecia el aspecto físico inmediato que proporcionan estas mujeres que visten por fuera un abrigo que es: "la representación de las brujas tal como las concebía el idolátrico y supersticioso catolicismo de la Edad Media" (21).

De los aspectos meramente indumentarios, ensalza la comodidad de algunas vestimentas, para hacer una crítica a las modas españolas que están sujetas a un estancamiento producto de una moral obsoleta. Las damas holandesas van a bañarse a las playas con unos "vestidos blancos muy largos, muy envolventes; nada de ceñidos ni semidesnudos" (259). Estos trajes que se diferencian de los de las noruegas, que exponen sus cuerpos desnudos al sol y los de las españolas, que tienen que sufrir la ridícula fama de elegante en las playas y se sacrifican dentro de ajustados corsés, sin poder sentarse en la arena y con zapatitos de raso (259), establecen unas normas de moda que la autora desea imponer. Para de Burgos las holandesas recurren a la sencillez y a la comodidad en el vestir sin perder, por ello, los atributos morales de la época, que sí pierden las noruegas, y sin ajustarse a unas normas ridículas de una moda convencional y absurda, 
como las españolas. De esta forma, el traje se convierte en una forma de liberación, como aludía Pratt, en el sentido que libera a las mujeres españolas de la mentalidad tradicional del casticismo a ultranza y de unas modas que no van de acuerdo con el ritmo de la sociedad.

Otra característica del discurso de la domesticidad es el tema alimenticio que forma una parte esencial de este discurso y que no se produce de forma recurrente y de la misma forma en las producciones literarias realizadas por hombres. La narrativa de viaje, por la concepción en si de este tipo de producción, apela a las descripciones de las costumbres de otros pueblos y el sistema alimenticio es una forma más de esa descripción. Mientras que las referencias a las comidas en la literatura de hombres se hace de forma superficial describiendo algún restaurante o reunión ocasional en algún lugar, las descripciones sobre comida, platos típicos, etc en los libros de viaje de las mujeres suelen ocupar una parte más relevante dentro del cuerpo del texto.

En el caso de Emilia Pardo Bazán, ésta hace constantes referencias a la degustación de algún manjar. En Cuarenta días en la Exposición alega: "Para gobierno de los viajeros recomiendo el chocolate de Astorga, y el de León también. Sólo en estos dos puntos se pude tomar algo que no sea teja molida ó almagre ahumado" (6). De esta forma, para realizar un viaje, según Pardo Bazán, se debe comenzar por un deleitoso tentempié y, por ello, cuando llega a San Sebastián va a: "las sesiones de pastelería francesa, donde se encuentra a la crema enterita" (13), al bizcocho y los chocolates (6465) e incluso dedica un capítulo entero al papel de la comida en la Exposición (55-61). En Por Europa católica el tono de las descripciones de la comida cambia, en este libro la autora intenta mostrar la decadencia de Europa en cuestiones alimenticias y resalta su 
españolismo; en Burdeos alega: “Anticuados están aquí en Burdeos los hoteles por otros muchos conceptos. La comida, reducida a veinticuatro platos que turnan, es de una monotonía insufrible... cuanto más retumbante sea el nombre en la lista ipeor! Huevos pasados y lomo asado; lo demás es farsa" (111).

Para Carmen de Burgos el tema de la comida no es tan importante como para Pardo Bazán. A diferencia de ésta, de Burgos se centra más en los aspectos sociales que llevan intrínsecos las costumbres alimenticias porque es más directa a la hora de expresar la labor social que quiere mostrar y, a su vez, su posición social, no tan privilegiada como la de Pardo Bazán, le impide saborear una serie de lujos o costumbres asociadas a la aristocracia. Es evidente que Emilia Pardo Bazán manifiesta claramente en su obra su posición privilegiada ya sea desde los trenes de primera, los restaurantes de lujo o los hoteles de la más alta calidad. Critica los servicios de primera clase, pero deja entrever que si ellos, los privilegiados, se quejan de la mala organización, peor deben estar los de "abajo." Sin embargo, en los libros de de Burgos no hay críticas a hospedajes, trenes o vicisitudes del trayecto per sé, todo lo contrario, alaba la puntualidad de los medios de comunicación, la comodidad de los hotelitos o albergues en los que se hospeda y, sobre todo, se centra más en el aspecto humano y en las relaciones sociales que establece en cada rincón por el que pasa. De esta forma, las alusiones a costumbres propias de la aristocracia como saborear un chocolate o las exquisiteces de las dulcerías, no entran dentro de su discurso.

Uno de los casos en los que habla de algún elemento relacionado con la comida es en Mis viajes por Europa, en el que de forma costumbrista relata la comida típica de los italianos: la pizza, y la forma en la que la comen los italianos, sin necesidad de cubiertos 
y sin un protocolo establecido. Esta descripción tiene un propósito fundamental: criticar la diferencia de clase. De Burgos termina su descripción diciendo: "en ese momento son ricos, son señores, no necesitan nada... un instante después vendrán a sacudir el polvo del abrigo de su excelencia pidiéndole un sueldo para la otra comida" (219-20). Es evidente que las descripciones y la crítica social que hace la autora son desde abajo, desde el más desfavorecido. La empatía que indirectamente proyecta de Burgos hacia las clases más pobres es uno de los aspectos más característicos de las narraciones de viaje de mujeres. La autora se pone al mismo nivel del menos privilegiado, para extender este acercamiento al problema de las mujeres que se encuentran en una situación desfavorecida socialmente por el hecho de ser mujeres en una sociedad patriarcal. ${ }^{81}$

Un caso aparte es el de Emilia Pardo Bazán. Debido a su clase social, aristócrata adinerada, su posición se asemeja más a la masculina. Pardo Bazán no analiza el problema de la discriminación social en sus libros de viajes de la misma forma que lo hacen algunas escritoras, que por su posición social tienen más en común con los desfavorecidos. Todo lo contrario, su crítica a este estrato de la sociedad en sus libros de viajes a Europa, la hace desde fuera, desde una posición de superioridad. A diferencia de Pardo Bazán, Carmen de Burgos sí se encuentra más cercana a los personajes que describe. De Burgos manifiesta la discriminación de género y también critica su situación

${ }^{81}$ Como se ha mencionado anteriormente, Carmen de Burgos solamente mantiene esa empatía con el desfavorecido en las sociedades europeas o con la comunidad judía, caso a parte es el tratamiento que da a los árabes y en especial a la mujer árabe. La aversión que siente la autora hacia los árabes se atribuye a la idea que tiene de que parte del estancamiento cultural y, sobre todo social del pueblo español, se debe a la herencia árabe. 
social en una sociedad tradicional como la española, en la que una mujer de clase media, que tiene que valerse por sí misma con su trabajo y esfuerzo, es mal mirada.

Nos obstante, la referencia a la alimentación, que está directamente conectada con la educación de la mujer, la hace de Burgos cuando describe la forma en la que se alimentaban los ciudadanos de la antigua Pompeya. La autora pretende educar sobre los aspectos fundamentales de la alimentación y la higiene, este último tema es una de las grandes constantes de sus primeros dos libros:

$\mathrm{Y}$ eran higienistas estos pompeyanos. Sus comidas presenta una fórmula de las más sanas: <de la ova a la mele $>$, en latín $<a d$ ovo, ad mala>, o sea: <desde el huevo á las manzanas>. Ya comprendían las propiedades alimenticias del huevo propias para asimilarse y preparar el estómago a recibir carnes y pescados; ya sabían favorecer al final la digestión con el ácido saludable de la manzana. (Mis viajes, 284)

La higiene, el cuidado de la casa y la maternidad conforman otro de los elementos del discurso de la domesticidad. Carmen de Burgos, si bien en su primer libro expresa unas nociones de la mujer superior en términos de una sencillez y ternura primitiva en la figura de Natalia Vallina, hermana de un preso político que dedica absoluto cuidado a éste, muestra esta sencillez hasta el límite de la racionalidad. Por un lado, es el prototipo de "excesiva sensibilidad femenina" (127), pero por otro, es el artífice del propio pensamiento de la autora en contra de la injusticia social. En este sentido, la autora aúna las dos esferas que el patriarcado divide y expresa: “¿Acaso es delito permitirse el lujo de tener ideas aqui donde hay tanto cerebro vacío?" (130), o más adelante, al expresarle la 
posibilidad de que condenen a su hermano, la autora concluye su pensamiento diciendo: "Veo brillar un rayo de odio en sus ojos dulces; es el germen de la protesta de toda alma noble contra la injusticia" (130). En este sentido, la alusión al servicio que esta mujer está prestando a su hermano se inscribe dentro de un discurso sentimental, con ecos de descripciones del ser indefenso que trata de modificar la pasividad, considerada propia de su sexo, por una actividad moral, en este caso, la concienciación de una injusticia social.

El tema de la maternidad y de las relaciones familiares es para de Burgos un poco más complicado. A pesar de que su discurso mantenga críticas profundas a la discriminación que sufren las mujeres y a la necesidad de proporcionarle a éstas una educación más digna y completa que se equipare con la del hombre y las prepare a defenderse en la sociedad, también se percibe en su discurso algunas características del discurso femenino tradicional en lo referente a la familia, los hijos y todo lo relacionado con la maternidad. Desde las alusiones constantes a obras de arte de Vírgenes amamantando a sus hijos en los que representa, por ejemplo, a una joven madre que juega con su hijo y le proporciona amorosamente el jugo de vida (Por Europa 409), pasando por el amor que siente por las madres (Cartas 13), hasta definir la maternidad en el vientre de Eva como: "Un vientre donde la carne se convierte en alma, un vientre donde por vez primera ven los cielos y la tierra estremecidos el misterio de la encarnación. Las entrañas de mujer que primero se han abierto al amor y al dolor tienen algo de sagrado" (Cartas 68).

Por otro lado, es interesante mencionar la actitud de la autora ante el tema de la añoranza del "ángel del hogar." En Cartas sin destinatario dice: "A veces mi libertad me apena. Esta libertad supone abandono, indiferencia, falta de afectos que me dominen y 
me retengan. Siento el atavismo femenino que añora la esclavitud voluntaria y nos impide alejarnos del lugar amado" (39). A estas palabras, la autora contrapone, más adelante una critica a esa gente que se han dejado vencer por la costumbre y han hecho de ella, una esclavitud más (30). Carmen de Burgos habla de una doble esclavitud; por un lado, la esclavitud pasiva del hogar, la espera del ser amado; y, por otro lado, habla de la esclavitud de la costumbre. Ambas esclavitudes son pasivas en el sentido de permanencia, de repetición y constancia, pero ella ha sabido salir de la pasividad, su lucha diaria por establecer una mejora para las mujeres la aleja de esa esclavitud. Al mismo tiempo, al decir que añora la esclavitud voluntaria del ángel del hogar, la autora propone la sencillez y la falta de problemas de una situación en la cual no se tiene que cuestionar nada, todo viene dado puesto que se tiene una relación de subordinación y donde no existe una lucha por la superación. La vida se hace simple y sencilla. No se tiene que pensar, sólo hay que dejarse "dominar," pero una vez, que se ha traspasado ese estado primigenio, en el que no se tiene que cuestionar la situación de subordinación de la mujer en el mundo, la autora siente esa pena que la aparta de la sencillez de la esclavitud doméstica porque, ella eligió la libertad y ésta le proporciona los sin sabores de la lucha diaria por la reivindicación de los derechos a la mejora de la situación de las mujeres.

En definitiva, esa añoranza que siente por lo doméstico, por la reclusión tradicional de la mujer en el ámbito del hogar, es una añoranza de la facilidad, del dejarse llevar sin mostrar resistencia, es, en defimitiva, la pasividad de la esclavitud de la mujer tradicional. La autora pasa del estereotipo de la pasividad de la mujer que representa el discurso de la feminidad, a la actividad de la heroína que ha cambiado las circunstancias sociales, puesto que critica la esclavitud de la costumbre y alega su movilidad en el hecho 
de viajar. Asi pues, de Burgos propone un discurso que, según Mills parte de las relaciones personales, familiares, morales y espirituales, pero que va entrando paulatinamente en la esfera pública por el simple hecho reaventurarse en la descripción del viaje (95).

Otro ejemplo más, lo muestra al describir un cuadro de la familia de Antonio Wiertz, en el que presenta a su madre de la siguiente manera: "tiene una cara simpática, inteligente y enérgica, en la que hay rasgos del hijo. Su vestido conserva el porte modesto de las obreras y está ocupada en la labor con su rueca y su telar. .. Es de esas mujeres muy protectoras, muy maternales y muy diligentes" (Cartas 159). La autora muestra la unión del "ángel del hogar" con la mujer trabajadora. Añora quizás, a las mujeres que en el porche de sus casas amasan pan y están entregadas a sus amados y al hogar (Cartas 159), pero la experiencia cambia al ser humano y ahora descubre, conoce, la instrucción le ha abierto las puestas del conocimiento y, por ello, de Burgos concluyen diciendo: “Podremos ya las que cambiamos una vez de casa y vimos las olas del mar, vivir siempre a la orilla de un río? Tal vez no, si hay ansia de nuevos horizontes, de nuevos museos; seguramente cuando la curiosidad satisfecha reconcentra todos sus ideales en el marco de unas pupilas" (209).

De Burgos establece una autoridad textual al crear un discurso híbrido que participa tanto de lo propio de la mujer, de lo femenino, como lo del hombre, lo masculino. La autora se reinventa en los términos propuestos por Pratt (168). Se ha autorrealizado en el sentido de que ha satisfecho su necesidad de curiosidad intelectual, ha configurado un discurso producto de la mezcla de lo político y lo personal al 
entremezclar sus anécdotas personales con disertaciones sobre la politica y la vida social de los países que visita y ha conferido una armonía a su discurso.

Otro de los elementos propios de las narraciones de viajes en referencia al "womanly weakness" que analiza Bolhs y Mills y que está relacionado con el discurso de la feminidad es la narración interior. Estas narraciones interiores pretendían mostrar el mundo interior que el discurso dominante consideraba propio de la mujer. No obstante, en los libros de viajes propiamente dichos, no son solamente las mujeres las que comienzan a plasmar esa visión "femenina" en sus viajes, sino que existe en la literatura inglesa unos indicios de mostrar un viaje interior que era lo que se propomá como modelo para las narraciones de viajes de mujeres. Mary Louise Pratt menciona el caso de William Paterson como inaugurador del viaje interior (50). A su vez, Pratt habla de Anders Sparrman quien, utilizaba la visión inocente y vulnerable en el proceso del primer contacto con la cultura exterior para acercarse al lector mediante la representación de un héroe natural impotente, infantil, sin atributos fálicos. Este narrador tenía las mismas características que las narradoras de los relatos de viajes de mujeres. En este sentido, a pesar de que nunca dejaba de representarse como una imagen de conquista y posesión, típica del discurso masculino, también utilizaba particularidades consideradas femeninas (56-57). De esta forma, el discurso de Sparrman es doble; por un lado, es inocente y desinteresado repleto de sentimentalismo, propio del discurso femenino pero, por otro lado, también es egocéntrico con muestras de deseo y lucro ya que buscaba una necesidad masculina de superioridad de género que debía ser satisfecha.

Para Pratt esta duplicidad en el discurso masculino respondía al sentimiento de culpabilidad por el hecho de la conquista y la dominación inglesa en los territorios 
africanos y asiáticos (57). Del mismo modo, esta duplicidad del los discursos en la narrativa de viajes no es solamente propia de los relatos de hombres, sino que son habituales en los de mujeres. Mills establece que esta duplicidad de discursos en las producciones de mujeres hace que estas dificultades conformen un tipo de escritura que muestra la naturaleza del discurso dominante y, a su vez, constituye una crítica desde fuera. Mills lo expresa diciendo: "constraints enable a form of writing whose contours both disclose the nature of the dominant discourses and constitute a critique from its margins" (23). De esta forma, la narradora adopta una doble posición, por un lado refuerza la visión de la feminidad y, por otro lado, representa la posición de poder que ejerce la narración en cuanto crítica hacia los métodos de represión, desigualdad e injusticia que sufre la mujer.

A pesar de que esta doble visión de la que habla Pratt se refiere a escritores y escritoras anglosajones que escribían sobre las tierras conquistadas por el Reino Unido, esta posición tiene una semejanza en muchas de las producciones de libros de viajes de mujeres en España. El caso de Emilia Pardo Bazán es el más radical puesto que para la autora, la experiencia en sí del viaje se realiza desde una posición de control y de superioridad del que nunca se aparta. En su libro Cuarenta dias en la Exposición mantiene el tono de superioridad propios del discurso masculino, del que ve con sus propios ojos y del que posee el conocimiento para explicar sus percepciones: "Vi fabricar los vidrios y me enteré del procedimiento" (8). Esta superioridad del discurso de Pardo Bazán no es solamente de género, sino de situación social. La autora mantiene constantemente una posición de superioridad de clase que llega hasta el extremo de mostrar, en tono despectivo, superficial y desinteresado, las descripciones de las mujeres 
campesinas como: "Comadres curiosas, agasajando al seno rollizos mamones, se inclinan para vernos y comentar nuestra presencia" (Por la Europa católica, 162). Con esta cita, se muestra como un ser diferente que produce curiosidad en esas campesinas, pero que no participa de su realidad. Por otro lado, manifiesta esa duplicidad de la que habla Pratt al insertar pasajes sobre la comida, la educación de la mujer y, sobre todo, de la religiosidad. A pesar del aparente alejamiento que produce su discurso de las formas típicas del discurso femenino, se presenta la crítica social a la que alude Pratt que en el caso de Por Europa católica. En este libro Pardo Bazán legitima la posibilidad de establecer un sistema político católico en España como el belga.

Por su parte, Carmen de Burgos mantiene un tono de superioridad en cuanto a la posición de sujeto digno de confianza que observa, describe y analiza los acontecimientos históricos que presencia. Su discurso se presenta de forma pretendidamente objetiva, para describir el entorno que la rodea. Asimismo, de Burgos, en sus libros de viajes, muestra esa necesidad egocéntrica, de la que habla Pratt, por medio de la reivindicación feminista. Además, la autora confiere a su discurso una dualidad masculina y femenina como lo hacía Sparrman. De este modo, se expresa en un discurso híbrido y éste se muestra expresamente en la siguiente cita: "Yo debía verlo todo con la insaciable curiosidad del publicista, y después de visitar escuelas y estudiar la vida moderna, he ido a soñar entre las ruinas y a curiosear al Vaticano" (Por Europa 380). Por un lado, propone un discurso masculino de autoridad; ella es la publicista objetiva que tiene una misión acreditada por una institución gubernamental de estudiar los sistemas educativos de los países extranjeros, pero a esa labor considerada tradicionalmente masculina, rápidamente le agrega un discurso femenino. Una vez concluido su estudio, se dedica a lo propio de su 
género y utiliza dos vocablos comúnmente aceptado para ese discurso: soñar y curiosear. A pesar de que esta cita explícitamente se ajuste a la dualidad de que habla Pratt, toda su obra de viajes responde a esa doble dualidad; si bien analiza, estudia y critica la situación española y extranjera, también inserta su discurso bajo unas normativas propias del discurso femenino, no sólo en el ámbito lingüistico, sino en el temático mediante el filantropismo y las alusiones a los cuidados propios de la buena madre.

Por último, es necesario destacar las numerosas alusiones referentes a su irrupción en el discurso dominante mediante la treta del débil o la falsa modestia: “QQué podrán hacer dos mujeres solas y sin armas?" (Mis viajes II, 55), o también:

y no podré corresponder a manera tan sincera, tan amable, tan cortés, como han recibido a la compañera lejana, que ha llegado hasta aquí sin más tarjeta de presentación que el eco perdido de millares de artículos, ligeros y efímeros, y unas docenas de libros publicados, cosas todas que sorprende que fuera de la Patria hayan podido hacer ambiente. (Mis Viajes II, 243)

Esta falsa modestia proyectada, sólo pretendía exaltar su posición de superioridad, no sólo a nivel nacional, sino internacional. Por el contrario, en el discurso de Emilia Pardo Bazán no existen alusión alguna a esa falsa modestia ya que su discurso es completamente masculino en cuanto a su posición de superioridad no necesita excusarse puesto que se siente superior y no se cuestiona su discurso en términos femeninos.

En definitiva, con el "womanly weakness" se pretendía ganar autoridad por medio del discurso de la feminidad mediante una serie de técnicas. El auto-adorno pretendía enfatizar la capacidad intelectual de la mujer, los temas relacionados directamente con el 
hogar como el traje, proponian temas de interés para la mujer como la moda y la elegancia. Una vez establecida la credibilidad textual en temas relacionados directamente con la mujer, se introducia la crítica social. En este caso, el tema del decadentismo de España o el de la necesidad de conservar las costumbres españolas. Este problema bilateral de la concepción de España constituía el lastre de la concepción noventaiochista del españolismo versus el europeismo. Además, una característica primordial de los libros de viajes de Carmen de Burgos en especial es el papel preponderante que la mujer tiene en estos textos, ya sea como obrera encajera o textil o como artífice de liberación de tapujos arcaicos que reducían a las mujeres a unos cánones de belleza obsoletos y poco convencionales. El tema de la comida también estaba mítimamente relacionado con el hogar y, no sólo mostraba, de forma costumbrista, la manera de vivir de los europeos, sino que introducía el problema social en relación con las diferencias de clase.

Con el tema de la familia, los hijos y la maternidad, Carmen de Burgos proponia un modelo de mujer que era la unión de la tendencia tradicional del "ángel del hogar" con una mujer moderna y educada que se instruyera en los principios básicos de la higiene y la economía familiar, para que, de esta forma, partiendo de la concepción tradicional de la mujer en la familia, pudiera encontrar, mediante la educación, una mejor salida a sus necesidades, primero familiares y después intelectuales para conseguir una plena igualdad.

Finalmente, el discurso de la feminidad, o el "womanly weakness," proponía una incursión más profunda en el mundo interior por parte de las escritoras. De esta forma, temas como el miedo, la curiosidad, la impulsividad, el romanticismo y los celos, otorgaban al texto una autoridad femenina que, a su vez, llevaba implícita una autoridad 
masculina en las búsqueda de superioridad de género, deseo de lucro personal que se percibe en las numerosas alusiones biográficas que las escritoras hacen como mujeres excepcionales y, sobre todo, el poder que otorgaban a su discurso como una forma de crítica a los problemas de los derechos de las mujeres y de la sociedad en general. 


\section{CAPÍTULO 5}

\section{ESTILO Y CONTENIDO COMO REIVINDICACIÓN FEMENINA}

A partir de finales del siglo XIX en España, se percibe un interés creciente entre los lectores en adquirir lo que Catherine Banes Stevenson llama "información útil" (6). Esta información útil se canalizaba mediante los libros de viajes ya que con ellos se podia obtener información rápida y general sobre geografia, arte, arquitectura, botánica, etnología, entre otros campos. Por otra parte, este tipo de producción literaria, mostraba aspectos propios del modernismo al aportar de una forma un poco más marcada que en las producciones de hombres, aspectos íntimos y personales en lo relacionado con el mundo de la mujer para proporcionar en el lector un interés progresivo en el texto. A su vez, en este tipo de producción se combinaba frecuentemente datos autobiográficos, con aspectos psicológicos del viaje.

El libro de viajes de escritoras obtiene un mercado específico gracias a la creciente participación de la mujer en esferas públicas. A partir de finales del siglo XIX, la audiencia de este tipo de producción literaria era predominantemente femenina, lo que hace que las autoras de libros de viajes ajusten el contenido de sus escritos a las preferencias de su audiencia. Tradicionalmente, se consideraba propio de la escritura de mujeres el escribir novelas en las que la imaginación y la creatividad debían de jugar un papel fundamental. A la mujer, a finales del diecinueve, sólo se le permitía escribir sobre aquello que era considerado por el discurso masculino como "popular." En este sentido, según Maria H. Frawley, cualquier tipo de producción literaria realizada por mujeres era considerada por los escritores como sinónimo de escritura de lo popular y, por extensión, 
de segunda categoria; este tipo de escritura se contraponía con la escritura de hombres considerada como alta literatura en el sentido de ser más analítica y racional (32).

Además de esta consideración, los relatos de viajes escritos por mujeres tienen una serie de diferencias respecto a los producidos por hombres en cuanto al contenido de éstos. En primer lugar, es importante mencionar la forma en se muestra el contenido de los relatos de viajes. Las escritoras suelen presentar sus trabajos en géneros propios de la tradición literaria femenina como la carta y el diario. El discurso tradicional masculino aceptaba que la mujer escribiera cartas, puesto que el discurso dominante consideraba que pertenecía al terreno sentimental, interior e íntimo, propio del mundo de la mujer. Ahora bien, el género epistolar de tradición femenina se subvierte cuando las escritoras introducian junto con descripciones meramente paisajísticas y temas relacionados con el hogar, juicios de valor, temas políticos y culturales del país que visitaban (Barnes 9). ${ }^{82}$

Carmen de Burgos utilizó la forma epistolar en dos de sus tres libros, Por Europa y Cartas sin destinatario. En estos libros de viajes, la autora intercala el análisis político, social y cultural con temas femeninos. De esta manera, su discurso no es tan directo como el de los hombres. Por el contrario, su incursión al mundo masculino es más consciente y elaborada porque lo entremezcla con el discurso femenino tradicional. Así, disfraza la intromisión y la adopción de los recursos conceptuales del discurso masculino.

\footnotetext{
${ }^{82} \mathrm{El}$ género epistolar para los libros de viajes no es exclusivo de la literatura de mujeres, pero es mucho más habitual que en las producciones de hombres. A pesar de que en España tengamos el caso de José Cadalso y su libro Cartas Marruecas, como un ejemplo de libro de viajes en forma epistolar, son mucho más frecuentes los escritos por mujeres. Igual pasa en el caso de la literatura anglosajona y la francesa o italiana, en donde este tipo de género se utiliza con mayor frecuencia por las mujeres. Para mayor información refiérase a Pratt, Mills y Foster.
} 
El resultado es un discurso híbrido que ejemplifica la capacidad intelectiva de la mujer, a la vez que lleva la tradición propia femenina a un ámbito de poder simbólico. Esta técnica no es exclusiva de de Burgos, Emilia Pardo Bazán también utiliza el género epistolar en uno de sus libros de viajes, Al pie de la torre Eiffel, en el que de forma menos encubierta, se acerca de forma más acusada a las formas discursivas masculino. Asimismo, entremezcla las características formales femeninas en descripciones propiamente relacionadas con el ámbito del hogar, las instituciones de mujeres y la educación. Incluso María Lejárraga, a pesar de la construcción particular de sus narraciones de viajes, infiltra un sentimiento femenino y feminista muy profundo en sus dos narraciones de viajes por Europa.

En Cartas sin destinatario, Carmen de Burgos impregna el texto de una subjetividad, que entremezcla con temas propios de ámbito masculino. La forma epistolar le permite combinar esa doble visión masculina y femenina. En este sentido, la autora explica, por ejemplo, la economía de la ciudad de Gante de la que comenta:

La primera impresión que recibo en Gante es la de la ciudad moderna, agradable; muy comercial, con sus grandes canales navegables para los buques de alto bordo, sus Doks y sus puentes, en los que... pasan de 1000 los vapores que entran todos los años... Aqui se tejen las más célebres telas de hilo y de algodón; existen importantes fundiciones de hierro y fábricas de maquinaria. El subsuelo es rico en fosfatos y petróleo y el suelo produce el hilo, el algodón y la madera en cantidades extraordinarias. Pero lo poético de su producción, lo que fija mi imaginación en extremo, es la riqueza de sus flores. (49) 
En primer lugar, la autora comenta que la ciudad posee un puerto imponente en el que pasan más de mil vapores al año, comenta la producción de hierro y de maquinaria, a la vez que explica la producción de madera y la composición del subsuelo del país. Por sí sola, esta disertación sería propia de las características de la narrativa de viajes masculina puesto que se está refiriendo a lo que Frawley mencionaba como propio del discurso de viajes de hombres en cuanto a su proyección analítica y racional (32); pero a su vez, consciente de la incursión que estaba haciendo dentro de estos parámetros masculinos, apela rápidamente a aspectos que concernirian más a las mujeres de su época, las cuales, posiblemente, no entendían de la industria naviera o del comercio exterior; pero sí del algodón, de la industria del tejido y de las flores. Finalmente, resume esa visión de Frawley en la última oración en la que específicamente recurre a dos palabras: poesía e imaginación. De esta forma, reinscribe su ideología como femenina al utilizar el canon tradicionalmente asignado para las mujeres en el campo de la poesía y de la imaginación pero habiendo ya adoptado un discurso típicamente masculino con su exposición sobre aspectos económicos del país.

Otro aspecto que normalmente es propio de las características de los escritores es la forma en la que la autora intercala su visión política y personal sobre los sindicatos obreros, la repartición del trabajo y el salario de éstos o la renta per cápita de los países (85). Estas divagaciones, propias del discurso masculino, hacen que de Burgos nos muestre constantemente la ambivalencia de su discurso al intercalar su visión femenina en casos específicos, como al comentar los cuadros de Rubens (95) o al hacer descripciones fisicas de hombres y mujeres de estos países y a la vez, hacer constantes referencias al terreno sentimental como, por ejemplo, su sentimiento de soledad. 
El título de los relatos de viajes es una forma más de representación de este tipo de producción literaria. En este sentido, Florence Gabaude alude al efecto minimizador que tiene el título de los libros de viajes escritos por mujeres. Gabaude hace referencia a títulos como utensilios que aminoran la importancia del contenido de la obra de las escritoras para disminuir el efecto que supone la incursión de la mujer en la literatura (20). En este sentido es evidente que Carmen de Burgos juega con los títulos de sus tres libros de viajes a Europa en los que se aprecia esa aportación minimizadora de la que habla Gabaude.

En su primer libro, Por Europa, tiene como subtitulo "Impresiones" entre paréntesis. Al igual que su segundo libro, Cartas sin destinatario, el subtítulo es Impresiones de viaje. El término "impresiones" indica un aspecto intimo y personal de una visión particular del mundo. La autora subtitula estas dos obras para evidenciar que lo que está mostrando al lector es su visión personal de los países a los que viaja. Si bien con este subtítulo, de Burgos se adentra en el terreno masculino, también el término "impresiones" es el término que utilizaban los modernistas en sus viajes. El contenido de ambos textos evidencia que el objeto de la impresión es distinto. En Carmen de Burgos y en general, en la mayoría de las escritoras se utiliza de forma diferente a los modernistas. Las escritoras lo utilizan para referirse al mundo femenino: la madre, el niño, la lucha de las mujeres por la igualdad, etc.

El caso de su tercer libro es un tanto peculiar porque además de cambiar el título de la primera edición, ya que pasa de llamarse Peregrinaciones, en la primera edición, a Mis viajes por Europa, en la segunda, de Burgos hace una referencia personal explicita en la segunda edición. Mis viajes por Europa aminora el efecto de adopción de las 
normas del discurso masculino dominante, al presentarse de una forma individualizada. Se trata de un viaje personal de de Burgos. Ese "mis," al igual que Impresiones, alude al espacio personal de la autora. Es del territorio de su elección y por consiguiente es un territorio femenino. Al mismo tiempo, Mis viajes por Europa sugiere un viaje interior de la autora y por extensión, aceptado dentro de los cánones de la tradición literaria patriarcal. La contrapartida de este tercer libro es la primera edición. En esta edición, de Burgos escogió como título: Peregrinaciones. Suiza, Dinamarca, Suecia, Noruega, Alemania, Inglaterra, Portugal. Bénédicte Monicat asegura que la frontera entre el relato de viaje y la peregrinación es muy estrecha pero asegura que con el término peregrinación se le confiere al relato un carácter de circuito obligatorio previsto de antemano y, al mismo tiempo, posee unas connotaciones con referencias a descripciones religiosas (11).

Monicat confiere estas características a los viajes a Italia de las escritoras francesas del siglo XIX, pero en el caso de de Burgos tiene unas particularidades específicas. Por un lado, su viaje es el resultado de un recorrido más extenso que los dos libros anteriores y, de esta forma, hace referencia al peregrinaje en términos religiosos puesto que éstos suponían una expedición normalmente a países lejanos donde el periodo de tiempo en el que se realizaba solía ser mucho más largo y en donde se pasaba por muchos más países. En segundo lugar, hace referencia a otro libro de viajes muy popular en su época con el mismo título: Peregrinaciones de una paria (1838) de Flora Tristán. Este libro suponía la culminación del viaje de una mujer a tierras lejanas con un doble objetivo, reclamar el reconocimiento del linaje paterno de la autora en Perú y reclamar la herencia que le correspondía por lazos familiares. A pesar de que el objetivo sea 
completamente diferente al de los libros de Carmen de Burgos, existe un sub-texto que los aúna; éste es el acto mismo del viaje como forma de reconocimiento de una realidad: el de una mujer que se autoafirma en un doble sentido, como mujer luchadora y emprendedora que se enfrenta a un medio hostil para recuperar un privilegio perdido y el de la mujer que irrumpe en un discurso masculino haciendo juicios de valor y críticas sobre los peruanos en el caso de Tristán y de los pueblos europeos en el caso de de Burgos.

Según Cristina Guiñazú, uno de los elementos más importantes de la retórica de Tristán en el prefacio de la obra es la defensa y el derecho de las mujeres a escribir su historia. En este sentido Guiñazú opina que para Tristán: "el grado de civilización de un pueblo se mide según el grado de independencia de sus mujeres" (3). El hecho de la peregrinación "evoca el recorrido jalonado de penitencias que sigue un peregrino en pos de una figura de la cual espera favores y retribuciones" (8), pero en el caso de Tristán y de de Burgos, la peregrinación que opera en ambos textos es una peregrinación de la palabra en busca de dominar y legitimar su propia identidad femenina dentro de una jerarquía de poder masculino preestablecida. En otras palabras, se trata de una legitimación del hecho de escribir por parte de una mujer y de las penalidades que ésta tiene que sufrir para poder expresar su discurso frente al masculino tradicional. Es por ello que Carmen de Burgos en éste, su último libro de viajes a Europa, queria mostrar mediante la metáfora de la peregrinación, la culminación, no sólo del poder de su palabra y de la ejecución de su discurso de reivindicación de la mujer escritora -y por ende con educación plena e igualitaria-, sino que era a la vez la culminación de su peregrinar para 
conseguir una posición de poder dentro del mundo real masculino y dotar a su palabra del lugar privilegiado que pensaba que debía de tener.

Otra característica de los relatos de viajes de mujeres es la proyección del sentimentalismo femenino como técnica para paliar también la incursión dentro del discurso masculino. En este sentido, Foster explica que algunas escritoras emplean una visión romántica e idealizada. Así pues, Foster dice que para: "re-constructs a preconceptualized environment in which scenery is mediated through the lens of an aesthetic idealism" (12). ${ }^{83}$ Como se mencionó anteriormente, en la literatura producida por mujeres, éstas debian utilizar una serie de técnicas establecidas por las que se les imponía que se centraran en aspectos relacionados con el terreno sentimental, poético o imaginativo. Un elemento esencial para llevar a cabo esta técnica era lo que Foster denomina el factor de búsqueda de lo pintoresco (12). Para ello, las mujeres recurrían a hacer descripciones, de una forma romántica y pintoresca de los lugares que visitaban o bien, elegían las descripciones de los enclaves góticos en lugar de los neoclásicos, más ligados al aspecto racional del discurso masculino. ${ }^{84}$

${ }^{83}$ En este sentido Foster se refiere al libro de viajes de Sofia Hawthorne Notes in England and Italy (1869), en el que la autora americana plasma sus impresiones de su viaje por Europa.

${ }^{84}$ Emilia Pardo Bazán en Por la Europa católica, al describir la ciudad de Segovia se detiene a comentar que una de las impresiones que más le ha agradado es la fachada gótica del palacio del marqués (161-62) o un poco más adelante dice: "Al lado de la preciosa casa del marqués de Alpuente, la tan ensalzada de los Picos me pareció de una pesadez y una tosquedad extraordinarias" (163). De esta manera, resalta los elementos a los que alude Foster sobre la preferencia de las escritoras a las descripciones del gótico frente a la racionalidad y sencillez de los edificios renacentistas. 
En su primer libro, de la autora expresa de forma poética, por ejemplo, la sensación que le produce la catedral de Burgos, joya del gótico español (14) o al describir el Batisterio se refiere a los relieves como a "encajes pétreos" (187). A su vez, se suceden las descripciones de aspectos pintorescos de cada ciudad por la que pasa; otro ejemplo de ello es la descripción del mercado de vendedoras y el atuendo de éstas (48) o referencias más concretas a un romanticismo exaltado que llega hasta el límite de poetizar un suicidio de dos enamorados al estilo romántico de siglos anteriores (52-54) o describir a una pareja de enamorados en las ruinas del Coliseo con palabras como: "hay una pareja silenciosa que se destaca envuelta en luz; parece venir con ella un soplo vivificante á las ruinas; el amor bate aquí sus alas y hace brotar rosas de sangre como lirios de pasión" (308).

En cuanto a reseñas concretas sobre arte, elige lo que tiene que ver con fisionomias femeninas, como las descripciones de Vírgenes, tanto en cuadros como en esculturas, ya que mediante la descripción de las Vírgenes, la autora muestra características concretas del papel protagónico de la mujer y esta figura de la Virgen es lo único que redime a la iglesia católica ya que es el único aspecto del catolicismo que es mostrado de una forma positiva. Otro caso en el que la autora resalta esa visión física de la mujer es cuando dice: "Es más hermosa esta Venus morena, que la Venus rubia de Rafael; las rodillas que son el escollo de las bellezas desnudas, en ésta son admirables, presentan un hoyuelo encantador" (361). En este caso, la autora prefiere destacar la belleza de una Venus con características fisonómicas de las mujeres mediterráneas, para acercar la divinidad a la mujer meridional. 
En su segundo libro, Cartas sin destinatario, comienza a manifestar una preferencia por el renacimiento. Es muy decisiva la mención que hace a la Virgen de Amiens. De Burgos comenta: "Es la humanidad que comienza a despojarse de terrores, es la madre que goza en su maternidad. La idea de Divinidad llega á lo Divino al hacerse completamente humana. Es la primera de esa serie de vírgenes-mujeres que nacen del espíritu pagano del Renacimiento" (8). Si en su primer libro quiere destacar el romanticismo que le proporciona el gótico, en este segundo, la idea está en la renovación, en el nuevo espíritu que cambia el status quo de la mujer para adaptarlo a los nuevos tiempos, para quitarle el anquilosamiento de una religión obsoleta y darle un sentido pagano de modernidad y de humanidad a la mujer. Este sentido de renovación no despoja a la Virgen del sentimiento maternal, sino que acentúa sus valores femeninos. Foster explica que es común en la literatura de viajes de mujeres el expresar los sentimientos propios de la autora sobre los objetos o paisajes delante de ella (14). En defmitiva, la autora lo que quiere resaltar el papel protagónico de la mujer a lo largo de todas sus narraciones de viajes como un elemento fundamental.

Carmen de Burgos cambia sus preferencias artísticas y su técnica de aproximarse a ellas. En su primer libro, la autora explica más que analiza las obras de arte de una forma objetiva, da la sensación de descripciones fotográficas. En su segundo libro, la descripción fotográfica da paso a un análisis más detenido, cuadro por cuadro; para finalizar en el tercer libro, con un análisis más profundo en donde da su opinión sobre el arte en general y sobre cada artista en particular. Critica los movimientos artísticos como el neoclasicismo (120) y define lo que es para ella el arte (132) y el artista (133). Esta evolución en la forma de expresar su acercamiento a un tema específico como es el arte, 
ratifica la paulatina adquisición de poder de la autora a lo largo de sus tres libros de viajes.

Una de las características que más acentúa la diferencia entre las descripciones hechas por hombres y por mujeres es la búsqueda de lo pintoresco. Las escritoras prefieren incluir en sus textos de viajes pasajes pintorescos que den una nota de cotidianeidad a sus narraciones. En Por Europa, Carmen de Burgos inserta esos pasajes pintorescos de forma regular; ejemplos específicos son las descripciones de los cafés de la ciudad de Brujas (33-39); también describe situaciones pintorescas como la descripción de la joven que mira embelesada al pintor en un callejón de la ciudad de Malinas (111). En Mis viajes por Europa, de Burgos comenta: "Cada pueblecito parece un nacimiento en Nochebuena. Son todos silenciosos, apacibles, pintorescos, acogedores" (11); algunos de los comentarios pintorescos tienen una gran carga intimista como cuando dice:

Llueve, llueve intensamente. Las burbujas de aire escondidas en las gotas de agua corren rápidas las cuestas. Eso alegra un poco la ciudad; son cantarinas, animadas, corren, danzan, dan movimiento y vida. Los ojos las siguen, las ven juguetear, romperse, desaparecer. (28)

También es recurrente en los relatos de viajes de mujeres el uso de metáforas de paraísos edénicos para reforzar la visión imaginativa de un mundo ancestral. Si bien Emilia Pardo Bazán expresa directamente el ambiente de paraíso edénieo en Portugal al decir: "Además, este clima es un clima edénico. Los días se bañan de oro, en terciopelo turquí se rebozan las noches" (Por Europa 133), Carmen de Burgos alude en varias 
ocasiones a las religiones primitivas anteriores al cristianismo para expresar un mundo de perfección. El componente edénico en algunas ocasiones se contrapone al infernal. De esta forma, se envuelve el texto de subjetivismo, al mismo tiempo, que se hace posible una crítica por parte de la autora, a la sociedad y sus lacras. En el caso de la visita de Carmen de Burgos a París es clara la doble faceta de la ciudad; por un lado, describe el París de ensueño, centro del progreso y de la modernidad; pero por otro, intercala el París infernal, por medio de la descripción de los suburbios, del mundo de las prostitutas y la desoladora visión de la morgue parisina (Por Europa 117-20). Otro caso de esta doble visión edénica-infernal es la descripción que hace de Burgos del Vesubio antes y después de la erupción (Por Europa 291-300).

El hecho de intercalar esta doble visión paradisíaca e infernal sirve como táctica para mostrar la misma ambivalencia de la situación social de la mujer. Si bien el mundo edénico está representado por el progreso y la modernidad en términos masculinos puesto que es lo que pertenece al discurso patriarcal, también representa el mundo infernal con lo relativo a los aspectos más degradados y deprimidos de la sociedad como son los cementerios, la morgue o el mundo de la prostituta. Este mundo infernal se dirige hacia una crítica a esas lacras de la sociedad. Por extensión, al incluir dentro de esas lacras el mundo de las prostitutas, vagabundas y mujeres desamparadas, subvierte su discurso al llevarlo al terreno femenino, propone a la mujer siempre como protagonista y provoca una condena a las injusticias sociales y muy especialmente, a las injusticias de género.

En el caso del Vesubio su crítica es también doble. Por un lado, es infernal, no sólo por la destrucción que lleva la erupción de un volcán; sino también, por su crítica a la religión que no se ha preocupado por el apoyo espiritual y, por otro lado, el paraíso 
edénico, no sólo es el de antes de la erupción, sino que también es edénico en cuanto al discurso de género puesto que ella, mujer por encima del hecho histórico, observa, analiza y critica ese mismo proceso histórico, apropiándoselo en sus propios términos.

Uno de los aspectos que han causado más polémica en cuanto al contenido de los relatos de viajes es mostrar las diferentes lecturas que se pueden encontrar en ellos. Florence Gabaude alude a que en los libros de viajes de mujeres se percibe una serie de lecturas superpuestas que le dan un sentido completo a la obra. Para esta investigadora, en los relatos de viajes de mujeres se pueden encontrar lecturas históricas, una visión documental sociológica, lecturas autobiográficas, descripciones geográficas y manifiestos políticos (11). La lectura histórica es evidente y se percibe en todos los relatos de viajes de hombres y mujeres. Mientras que los hombres se detienen en analizar los acontecimientos históricos de forma más imperialista, analizando los procesos históricos decisivos para la evolución política del país que visitan, las mujeres tienden a explicar los acontecimientos históricos desde una perspectiva más femenina. La mujer y, específicamente, Carmen de Burgos analiza la situación histórica en el momento de la visita con una doble finalidad. Por un lado, confiere a su discurso una veracidad de hechos al enmarcarlos en acontecimientos de actualidad para el lector y reales históricamente. Por otro lado, selecciona los acontecimientos históricos que quiere relatar prefiriendo escoger los hechos que tienen que ver directa o indirectamente con la mujer.

En el caso de Carmen de Burgos, la narración histórica queda supeditada a unos preceptos de interés personal. En primer lugar, la autora elige mostrar las historias de personajes femeninos que por una u otra causa han sido importantes históricamente, uno de los casos más recurrentes son las historias de las reinas de todos los países a las que 
dedica gran parte de su narración. Ejemplo de ello son las diversas entrevistas y visitas que mantuvo con reinas. El discurso de Carmen de Burgos en relación con las reinas es siempre de simpatía hacia la figura de la mujer que por circunstancias sociales debe cubrir un papel impuesto. Este sentimentalismo se expresa en ejemplos como cuando dice:

los castillos de Francia han sido funestos para las soberanas. Maria Estuardo, reina de un día de esta nación, murió en el cadalso, María Antonieta, fue la víctima expiatoria de todos los crimenes de las monarquías; Josefina, repudiada con ingratitud, lloró sus penas en la Malmaison; María Luisa, herida en su orgullo, sentimiento único de su alma innoble, sufrió penoso destierro; y Eugenia de Montijo pasea hoy sus merecidas tristezas por toda la tierra. (Por Europa 39-40)

También lo expresa al mencionar: "Desdicha fue nacer mujer y reina, pasar la infancia en un trono combatido por intrigas, envidias y ambiciones; y la juventud entre gentes que aprovecharon su temperamento para explotarla mejor [Isabel II]" (Por Europa 105). De María Cristina de Saboya dice que es una santa y de Juana I que era déspota (Por Europa 205) o de la reina Elena de la que dice que su vulgaridad la hace "buena esposa, excelente madre... reina, no" (Por Europa 331). Admira lo que las reinas tienen de madres y, por extensión de mujeres y rechaza la pena con la que los franceses miran a la emperatriz Eugenia por ser viuda. Por otro lado, de Burgos no es ajena a la realidad de la vida de las reinas y critica la opulencia de éstas y la simpatía, muchas veces ciega, que tiene el pueblo hacia ellas. En una de las descripciones de reinas, la autora habla de la emperatriz Eugenia de Montijo y de la forma en que el pueblo se lamenta de la desdicha de la 
emperatriz. De Burgos dice: “¡Qué lástima! ¡Qué lástima! -he escuchado decir con ese acento de conmiseración que el pueblo siente para las desdichas de los grandes. ¿Lástima de qué? ¿Por qué es esta anciana digna de lástima? Ella vive entre los esplendores de una posición opulenta, adulada y llena de cuidados" (Cartas 460). Para la autora, a pesar de que simpatice con las reinas por lo que éstas tienen de humano: "Yo sólo la compadezco como madre, que es en lo que nadie piensa; todos se conduelen de la emperatriz de Francia" (Cartas 460); pero el problema fundamental de las sociedades desarrolladas se centra, según Carmen de Burgos, en la falta de reconocimiento que la sociedad otorga a las secciones más marginadas de la sociedad. En definitiva, la autora admira a la reina por lo que ésta tiene de mujer en términos de los atributos propios de ángel del hogar; pero resalta siempre la figura de la mujer que, por circunstancias sociales, culturales, políticas o económicas, se ven discriminadas y aisladas de la sociedad.

A su vez, en Cartas sin destinatario, dedica un capítulo entero a la Emperatriz Carlota. Cabe destacar cómo en este libro la humanización de las reinas es más acusada. En este sentido, de la reina Isabel II y la princesa Luisa, dice que: “ $i$ Es grato para el pueblo ver que los semidioses á los que sueñan entre esplendores, con coronas de pedrería y collares de dientes, participan de sus pequeñeces y miserias!" (Cartas 170). Para la autora lo importante es que ambas: "la una con gesto de madre; la otra con pasiones y pecados de mujer" (Cartas 170) son iguales a cualquier mujer. En este libro, no sólo admira a las reinas por lo que tienen de mujer en los términos de la ideología patriarcal; sino que las equipara a cualquier mujer, pues para la autora, son iguales que las demás mujeres ya que sienten y actúan como las demás. Hay que tener en cuanta que la autora, por sus convicciones políticas republicanas es antimonárquica y para ella, la 
figura de la reina tiene una importancia en cuanto posibles modelos de mujer en el sentido doméstico o femenino y no por su posición como figuras monárquicas.

Finalmente, en su último libro vuelve a la imagen de la reina como una mujer excepcional. De María Pía dice: "es mujer, muy mujer; pero es ante todo reina... no deja ver su dolor; va escondida en el fondo de su carroza... nunca predominó el clero dentro de ella. Muy soberana ante el público, era muy mujer en su intimidad" (Mis viajes 18081), también destaca el caso de Luisa de Guzmán que prefirió ser reina un día e incitar a la rebelión y la independencia de Portugal antes de ser duquesa toda la vida (Mis viajes 238). Mediante las descripciones de las reinas se percibe el desarrollo del pensamiento de la autora; si bien en su primer libro ajustaba la condición de reina al papel doméstico de la mujer, modelo que consideraba debía implementarse para toda mujer, en el segundo, las humaniza y las trae a un terreno más cercano, ya no son entidades etéreas y lejanas, sino que son mujeres reales de carne y huesos. El último libro supone la culminación del pensamiento de la autora al dotar a las reinas de un valor como mujeres excepcionales que revolucionan la sociedad e incitan al cambio social sin perder los aspectos o atributos femeninos. En este sentido, la autora desea que estas reinas sean también ejemplos de mujeres excepcionales que inciten a las lectoras a una posible reforma social. En este sentido, la figura de las reinas le sirve de marco para mostrar su evolución en su proceso ideológico

A su vez, en todo libro de viajes de mujeres hay que tener en cuenta el análisis de su contenido como documento social, manifiesto político o de reivindicación feminista. El ejemplo de las reinas, junto con las numerosas menciones a mujeres célebres por motivos de sus actuaciones en defensa de los derechos de las mujeres, también son 
numerosos en los tres textos de Carmen de Burgos. La autora analiza la vida y los hechos de mujeres clave en la sociedad y la política europea; ejemplo de ello son las menciones en su primer libro a la duquesa de Acosta, a la que considera "más inteligente que su marido" (Por Europa 238), a Matilde Serão (Por Europa 242), a Cecilia Madrazo de Fortuny (Por Europa 452) o Lola Serra (Por Europa 498). Sin embargo, en Cartas sin destinatario, en lugar de mencionar a mujeres específicas, prefiere comentar el papel de la mujer sencilla que ha innovado con su trabajo y ha impuesto unas normas de conducta para la mujer española trabajadora. No obstante, la nota decisiva sobre las incursiones a favor de las reivindicaciones para las mujeres, las hace en su tercer libro Mis viajes por Europa.

Hay que tener en cuenta la época de publicación de los tres libros y las implicaciones políticas y feministas que se van produciendo en cada momento. Si bien, en su primer libro, publicado en 1906, la postura de la autora en cuanto al feminismo estaba marcada por una aceptación de las normas vigentes para la mujer; es decir, la autora consideraba que era necesario mejorar la educación y la condición de la mujer para su mayor integración dentro del núcleo familiar; en su tercer libro, de 1916 la primera edición y de 1917 la segunda, esta visión se modifica e intenta reivindicar un feminismo más a ultranza proponiendo la total integración de la mujer a la vida social y política del país. Ejemplos de esta visión feminista son las disertaciones sobre Camila Collet, iniciadora del feminismo en Noruega, quien produce una revolución social por medio de su novela Las hijas del gobernador (Mis viajes 216), Federica Bremen que legalizó el feminismo en ese país. Elzira Dantes, esposa del presidente de Portugal y fundadora de la cruzada de mujeres o la escritora Carolina Coronado, mujer modélica y prototipo de 
mujer libre y emancipada. A su vez, se percibe una implicación política de la autora ligada intimamente con el socialismo republicano. Describe las organizaciones sociales de los países que considera más desarrollados que España y explica los modelos socialistas con una mirada romántica e idealista (Cartas 84, 174). A su vez, destaca la forma en la que describe el partido socialista belga para darse cuenta de la implicación de esta tendencia política en su vida personal. De Burgos comenta:

El partido socialista belga no comulga en su mayoría en las doctrinas de Carlos Marx. Ellos no quieren suprimir la propiedad, sino que el trabajador sea propietario; ni son enemigos de las máquinas, a las que consideran como manifestación del progreso social y "futuras libertadoras". La tendencia de los socialistas belgas... tiende a mejorar la condición de los obreros y trabajan activamente para conseguir la reglamentación del trabajo, la inspección en los talleres y todas las reivindicaciones necesarias. (Cartas 137)

En definitiva, anhela una sociedad ideal que se fortifique mediante el dolor del desengaño y el fortalecimiento de una humanidad anhelante del cambio que producirá un futuro mejor. De Burgos lo expresa magistralmente al comentar desde lo más profundo de su alma ese deseo:

¡Cuánto falta aún para llegar a esa sociedad ideal con que soñamos! La realidad de la vida nos hace sentir en el corazón esa puñalada dolorosa que nos roba la ventura del engaño... Los cobardes ante el dolor presentido somos fuertes para el dolor real. Nos aflige la idea de esta pobre humanidad sufriente como una traición á nuestra confianza y a nuestros 
sentimientos más queridos; pero no nos falta la fuerza para trabajar en el mejoramiento con la vista en el mañana futuro. (Cartas 140)

Otro aspecto que es frecuente en los relatos de viajes de mujeres es la lectura autobiográfica. Este tipo de lectura ha planteado una polémica ampliamente discutida entre la crítica. Por un lado, Florence Gabaude alude al hecho de que los relatos de viajes proporcionan un elemento autobiográfico del que no se pueden evadir ya que funcionan como textos autobiográficos. De esta forma, para Gabaude: "Ce sont des textes que leurs auteurs présent comme tels, et dans lesquels la métaphore de la vie comme voyage est doublement pertinente. C'est justement leur caractère profondément personnel qui rend ces récits intéressants" (20). Además, todo relato de viaje implica una concepción personal de la experiencia de viajar, ya que se presentan las experiencias personales de la narradora, en un país extranjero. El propósito del libro de viaje no es un recuento autobiográfico del narrador, sino la visión particular que éste tiene del entorno cultural, social y político de un país determinado. En ningún momento el elemento autobiográfico fue concebido como parte esencial del relato de viaje, a pesar de que, indudablemente tiene un gran peso en el análisis de la narración al ser una visión como "metáfora de vida" de la que habla Gabaude, pero el foco no es su vida, sino lo que ve, aprende y experimenta.

Sara Mills, por su parte, analiza el hecho de que la producción escrita por mujeres ha sido considerada tradicionalmente como no literaria y explica que ha sido la consecuencia de una serie de presiones discursivas que han llevado a considerar la literatura de viajes de mujeres como autobiografias: "One of the major problems in the analysis of women's travel writing is that of assuming that the text are autobiographical, 
and they are straightforward transcription of their lives of the woman travelers" (36). Si bien Mills asegura que: "this labelling [estas obras como autobiográficas] should be seen as an attempt to deny women the status of creator of cultural artifacts" (12), plantea una serie de problemas que conlleva la concepción de considerar este tipo de narrativa como trascripción absoluta de la vida de la viajera. En primer lugar, esta investigadora cuestiona la definición que se tiene del yo. Para Mills el yo: "it is used as easy shorthand for something amorphous and untextualisable. The self is presumed to be the writer's self which is translated into the persona or narrative voice of the text" (36). Es decir, si se tiene en cuenta que ese yo no es una identidad coherente y que el escritor no siempre tiene control absoluto sobre él, entonces, debemos entender que lo que leemos en un texto no es la representación absoluta y real del escritor (Mills 36). En este sentido, en los tres libros de Carmen de Burgos, el yo narrativo es, al mismo tiempo, selectivo. Mediante la selección que hace la autora de lo que quiere contar, mediatiza el grado de verdad absoluta de los hechos. Esta selección unida al análisis de los problemas, acontecimientos o visiones particulares de un entorno hace que su voz narrativa sea fiable en tanto en cuanto se concentre en acontecimientos históricos o descripciones del medio que la rodee. A su vez, la fiabilidad de yo narrativo está intimamente ligada al grado de literalidad del texto narrativo.

En tercer lugar, Mills añade que no se puede asumir que ese Yo narrativo sea fidedigno puesto que nosotros no podemos tener el mismo referente que en el tiempo en el que se escribió el texto en cuestión (36). En este sentido, es importante destacar la función que tiene el significado de las palabras, ya que las palabras tienen connotaciones y referencias múltiples que las llevan a poseer diferentes interpretaciones. Esta 
multiplicidad las hace depender del contenido del texto y del marco referencial del escritor y del lector; es decir, Mills defiende que: "the text itself is not a stable field of meaning, but something which readers work on and interpret. Therefore the range of meanings which the instable self of the writer attempts to encode are never decoded in a predictable way by the instable self of the reader" (36).

La interpretación de Mills sobre la consideración de la narrativa de viajes como autobiografias está íntimamente ligada a las teorias de Michel Foucault. Para este crítico la idea de considerar este tipo de escritura como autobiográfica no es acertada ya que el autor de los textos debe de ser considerado no como un ser individual, sino como un author-function, es decir, una entidad textual. Además, Foucault piensa que no existe un texto puro, trascripción real y verdadera de algo, sino múltiples interpretaciones que dependen de factores exteriores, entre ellos, el propio autor (Mills 38).

Otro problema que se plantea con las lecturas autobiográficas es que no se puede explicar cómo se produjeron ya que están íntimamente conectadas con la anormalidad, la extrañeza o las circunstancias extraordinarias de las escritoras. En este sentido, Mills expone: "How can a woman write and give herself a strong narrative voice and describe events which for many seem implausible within the discourses circulating around women at that time?" (38). Es imprescindible tener claro que Foucault no rechaza la ruptura total y completa de la relación entre el autor y el texto que produce, porque, en definitiva, la definición de un texto tiene que, necesariamente, estar unida al autor individual que lo ha creado. Pero, para él, al dejar a un lado la visión autobiográfica de un texto, se analiza éste desde su contenido, más que de la visión individual del autor que lo produjo. Mediante la utilización de la teoría de Foucault de "dispersion of the self," se pueden 
analizar los textos simplemente por su contenido y no por las referencias personales del autor.

Si bien, Sara Mills, en su estudio crítico, ha utilizado la teoría de Foucault para exponer su opinión sobre la valoración de la literatura de viajes como documento que se debe analizar por su contenido y no por las referencias autobiográficas, ${ }^{85}$ en este estudio es necesario también tener en consideración que las aportaciones autobiográficas son importantes en estas narraciones escritas por mujeres. Para ello, es primordial adoptar la posición de Foucault, en cuanto a las implicaciones que cada texto aporta según su contenido, y también es importante establecer un marco referencial en cuanto a las implicaciones que las referencias autobiográficas tienen en el texto para expresar una posición consciente de autoridad narrativa.

Mediante las referencias autobiográficas del texto, las escritoras y, en concreto Carmen de Burgos, conscientemente proporcionan al texto una serie de nuevas valoraciones analíticas. En primer lugar, otorgan al texto una visión individual y subjetiva al proyectar algunas referencias a su vida personal; a su vez, hay un acercamiento mayor al público lector ya que estas notas autobiográficas provocan en él una nota de sentimentalismo y, por extensión, de acercamiento a la narradora y a lo narrado; y finalmente, porque proporcionan al texto un tono de fiabilidad sobre lo que se está comentando ya que supone un marco introductorio real y concreto de la vida de la autora-

${ }^{85}$ Para Foucault, todo texto es siempre subjetivo, es puramente hermenéutico porque siempre está sujeto a interpretaciones. La primera restricción que considera Foucault es la interpretación que hace el autor que escribe el texto. La segunda restricción es la de producción ya que está sujeta a los discursos históricos, sociales y culturales del entorno del escritos y la tercera es la relativa a la peculiar interpretación que el lector hace del texto que lee. En definitiva, para Foucault no existe un texto puro, en el sentido científico o anónimo puesto que siempre existen restricciones personales del que lo ha producido. 
narradora que da paso al análisis de un elemento concreto de la otredad, ya sea concreta, en el sentido del análisis de algún acontecimiento social y personal, si se trata de algún hecho relativo al individuo.

Las referencias autobiográficas que aparecen en Por Europa, manifiestan ese sentimentalismo ya que expresan de forma subjetiva y autobiográfica un yo personal e individualizado y muestran sus sentimientos bajo formas específicas de un "yo senti un deseo increíble de ir a la orilla del mar" (19) o "en ninguna parte siento esta plenitud de vida" (19), también al recordar su lugar de origen: "Yo he evocado aquí el recuerdo de una pequeña playa andaluza" (134) y "el corazón va a llorar cerca de mi hogar de Andalucía"(166). Por su parte, en su segundo libro, Cartas sin destinatario, de Burgos siente una tristeza y un sentimiento de soledad ante la ausencia del ser amado que hace que la narración esté repleta de alusiones autobiográficas. Así, hace una referencia concreta a su tierra natal, Rodalquilar, para evocar la tierra primitiva de añoranza y melancolía al compararla con las casas de los aldeanos de Zuiderzee. De Burgos dice: "Esta tierra primitiva me recuerda Rodalquilar, otro lugar apartado del mundo en la provincia de Almeria, y observo las analogías de las costumbres y la vida sencilla de los pueblos" (300) y a su relación con Ramón Gómez de la Serna.

Finalmente, en Mis viajes por Europa, las referencias individuales y concretas las hace como medio de expresar la alegría y la ansiedad del ser amado, concretamente al mencionar la tristeza de la carta que no llega o la alegría que produce en el individuo, la que se recibe $(I, 89)$ o las menciones concretas a Ramón Gómez de la Serna en referencia a sus tertulias en el Pombo (II, 165) y (II, 225). A su vez, nos presenta reminiscencias de su infancia al recordar los juegos y las canciones populares de su pueblo natal para 
expresar que el júbilo de los niños es igual en todos los lugares y, de este modo, acercar Europa a España (II, 97). Por otro lado, analiza temas como la educación y los ejemplifica con datos personales como cuándo aprendió a leer (II, 241). De esta forma, intenta poner de manifiesto la necesidad de la educación. También, analiza la figura de Latino Coelho, quien, además de ser considerarlo una figura tanto literaria como política que merece ser tenida en cuenta, sirve de base para el análisis del ideal político que de Burgos quiere discutir. La forma en que la autora describe en su texto la figura de Coelho es muy interesante. En primer lugar, produce una sensación de fiabilidad puesto que, no sólo es una figura reconocida en Portugal, sino que la autora hace referencia a que era amigo íntimo de su padre (183) y que por ser su padre cónsul de Portugal, la palabra de éste tiene, necesariamente, que ser fiable. A su vez, Coelho actúa como marco que introduce sus ideales liberales republicanos ya que, la autora exalta su figura política como "partidario de la unión Ibérica bajo el régimen de una federación republicana" (II, 184), ideal que Carmen de Burgos defendía para España.

En cuanto al estilo propiamente dicho, en los relatos de viajes de mujeres, según Catherine Barnes Stevenson se percibe una escritura personal y privada con comentarios personales de lo escrito (100). Es frecuente en algunas escritoras utilizar un lenguaje propiamente femenino. Emilia Pardo Bazán utiliza palabras que pertenecen al léxico femenino en la utilización de diminutivos, como por ejemplo al buscar el "pabelloncito mudéjar" (Cuarenta 65), "los trajes de las aldeanitas son pintorescos (Cuarenta 181); o léxico propiamente femenino como: "Uno de los trajes de esta casa Boué es un sueño" (Cuarenta 102) o cuando se refiere a la descripción de los edificios que se han construido para la exposición, Pardo Bazán dice: "El Ecuador se ha construido un palacete chiquito 
muy cuco" (Cuarenta 219). A su vez, María Lejárraga también utiliza un léxico femenino al describir los hoteles suizos. La autora dice: "andan impresos a tres tintas y en tres idiomas para reclamo de fondas y kurhauses, que es un primor" (kodak 11).

En cambio, Carmen de Burgos no utiliza ese tipo de palabras del léxico femenino, como lo hace Pardo Bazán o Lejárraga. Su estilo se muestra femenino porque se circunscribe a la experiencia. Según Stevenson hay una diferencia evidente a la hora de evaluar los textos de viajes de hombres y mujeres. Para este crítico, los escritos de los hombres tienden a evaluar objetivamente el significado total del viaje (9), mientras que los de las mujeres "tend to record, to surrender to experience" (10). En este sentido, para las escritoras y, especialmente para Carmen de Burgos, lo más importante es expresar el sentimiento más intenso e íntimo de una experiencia cualquiera, a la vez que se concentran más en la dimensión humana de los países viajados. Así, Carmen de Burgos se detiene a observar y plasmar la vida familiar y, por ello, los cuadros costumbristas son frecuentes en sus tres obras de viajes.

Por otro lado, Mills añade que este tipo de escritura de mujeres suele ser mucho más tentativa que la de los hombres (3), puesto que el hombre tiene como objetivo juzgar y esquematizar la experiencia viajera mediante una escritura formal y con pretensiones objetivas (Barnes 9) y la mujer, por su parte, no trata, en la mayoría de los casos, de cuestionarse la verdad absoluta de los hechos, sino que tiende a concentrarse más en descripciones de individuos, en lugar de pueblos, países o comunidades en general (Mills 3). Éste es el caso de los libros de viajes de María Lejárraga. Por un lado, en El peregrino ilusionado, la autora expone las descripciones del viaje no en cuanto a una colectividad, sino mediante la interlocución con diferentes mujeres de los diferentes países por los que 
el narrador pasa y, a su vez, mantiene una descripción individualizada y personal que analiza problemas de ámbito universal. Y, por otro lado, en Kodak romántico, a pesar de estar constituido formalmente como libro de viaje en cuanto a su estructura, la autora manifiesta un lenguaje intimista, extremadamente poético en el que pretende mostrar la plenitud del paisaje mediante la experiencia de todos los sentidos (8). De esta forma, compara la tierra con la mujer, madre protectora y mujer objeto del deseo (8-9).

El caso de Carmen de Burgos y Emilia Pardo Bazán es un tanto diferente de lo que Mills propone como característico de la narrativa de viajes de mujeres. Si bien ambas autoras no mantienen nunca una escritura tentativa en el sentido de inseguridad en el proceso de su escritura, sí muestran un intimismo que apela a una subjetividad que se manifiesta con descripciones poéticas o exaltaciones de algún hecho que, normalmente, está relacionado con el mundo de la mujer. En este sentido, Pardo Bazán apela a la falta de educación de las mujeres que malgastan sus fortunas jugando y dice: "menos se jugaría si se leyese y estudiase y pensase más" (Cuarenta 15) o los dos capítulos en los que analiza el tema de la educación y sus consecuencias directas para la mujer (capítulo dieciocho y diecinueve de Cuarenta días en la Exposición). Por su lado, de Burgos tampoco manifiesta una escritura tentativa, en este sentido, pero sí da un mayor énfasis a sus descripciones sobre temas relacionados con los judios, las reformas políticas y, sobre todo, con el divorcio y los derechos de las mujeres.

A su vez, ambas autoras hacen frecuentes descripciones de individuos; en el caso de Carmen de Burgos se percibe gran interés por parte de la autora, en desarrollar temas de interés personal en sus múltiples encuentros con personas anónimas, normalmente mujeres, con las que por una razón u otra la autora muestra una simpatía especial y con 
las que quiere resaltar algún aspecto de un tema que le interesa. Así pues, en su encuentro con una madre en Bélgica, en su libro Cartas sin destinatario, simpatiza con esta mujer que deja a su custodia a su hijo y su excitación llega al extremo de ser esta anécdota la única que redime al país que le parece horrendo. Este episodio es, como ya se ha mencionado anteriormente, una exaltación del valor de la maternidad y del vínculo que éste proporciona a las mujeres.

La posición de Mills propone un problema en los libros de viajes de Pardo Bazán y Carmen de Burgos. Si bien, las autoras comparten esa visión que Mills confiere para las producciones de viajes de mujeres en cuanto a la escritura sentimental y poética y a las descripciones de individuos en lugar de colectividades, también comparten las características que Mills propone como modelo para las narraciones de viajes de hombres. Así pues, en ambas autoras se percibe una escritura formal, objetiva y esquematizada. También, son frecuentes las descripciones de colectividades de forma universal, como es el caso de las descripciones que de Burgos presenta del pueblo alemán en su segundo libro o la organización católica de la sociedad belga que hace Pardo Bazán en Por la Europa católica. Tanto Pardo Bazán como de Burgos mantienen una escritura formal y objetiva en las descripciones de paisajes, sobre todo, urbanísticos; Pardo Bazán en la descripción de los edificios que componen la Exposición y de Burgos en los distintos monumentos o emplazamientos de cada ciudad que visita. A su vez, ambas autoras juzgan su viaje desde la perspectiva de una serie de postulados que desean resaltar: Carmen de Burgos analiza las sociedades que visita desde un punto de vista social, político y cultural mostrando las diferentes organizaciones e instituciones sociales, culturales y políticas de esos países, juzgando estas sociedades según su visión particular 
de lo que debía ser una sociedad perfecta: una república democrática e igualitaria. Emilia Pardo Bazán hace la misma cosa, pero defendiendo una sociedad basada en una confederación católica. De esta forma, la combinación de estos dos estilos de escritura, el femenino y el masculino, lo que hace es confirmar la visión dualística que proponía Foster para los relatos de viajes de mujeres de finales del siglo XIX y principios del XX. Esta hibridez era el producto de mujeres modernas que han logrado poder individual. 


\section{PARTE III}

\section{CONCLUSIÓN}

El objetivo fundamental de estos tres libros de viajes de Carmen de Brugos es manifestar una reivindicación en la que se muestre la necesidad de mejorar las condiciones de las mujeres en la España finisecular y los albores del siglo XX. Para ello, la autora se sirve de una serie de recursos en los cuales, directa o indirectamente, expone la necesidad que existe en el país de implementar estas mejoras. En este sentido, la educación de la mujer es la base y el fundamento esencial por los cuales, la mujer puede modificar su situación de ente relegado socialmente e integrarse a la vida cultural, social y profesional de una forma igualitaria.

El papel de la educación es primordial puesto que de Burgos lo convierte en un arma de acción para la reforma social de España. La autora, en su capacidad de educadora, maestra de la Escuela Normal, se da cuenta, de una forma directa, de los problemas que tienen las mujeres en el terreno educativo. De esta forma, en sus libros de viajes muestra los avances que otros países europeos han realizado en el terreno de la educación y con ello pretende concienciar al pueblo español de la necesidad de reformar el sistema educativo. Esta necesidad de reforma la plasma mediante el análisis de los avances en la enseñanza primaria y las diferencias entre las formas educativas de los niños europeos y los españoles. Concluye que no es sólo necesaria la coeducación, sino que el acceso a la educación primaria de las niñas debe ser obligatorio para obtener posteriormente una mayor igualdad en el terreno profesional. En este sentido, su último libro, Mis Viajes por Europa, se convierte en la máxima reivindicación, puesto que la autora establece que una vez conseguida una educación igualitaria para la mujer, ésta 
puede tener mayor participación en la vida profesional y politica del pais. A su vez, establece un feminismo por el que propone una superioridad femenina, la cual es para De Burgos consecuencia de la unión del modelo de "ángel del hogar" y el de la mujer profesional.

De Burgos, se da cuenta de que hay tres cosas de los sistemas educativos europeos que España debe adoptar para poder conseguir una mejora en la educación del país y, por consiguiente, facilitar la emancipación de la mujer: la educación en la naturaleza, la tolerancia y la higiene. La educación en la naturaleza establece un regreso a la armonía ancestral del mundo en donde los hechos se suceden de forma natural. En este sentido, la igualdad de la mujer está mostrada por la autora como una necesidad lógica y natural. La higiene es, por un lado, parte esencial del discurso femenino y, en este sentido, reivindica la actuación de la mujer como parte activa en ese terreno. Por otro lado, manifiesta unas necesidades reales del sistema de instrucción público español que, en su opinión, carecen de las mínimas condiciones higiénicas y por lo tanto, hacen de las instituciones educativas lugares incómodos para el aprendizaje. Finalmente, la tolerancia constituye la base de un sistema de entendimiento mutuo en el que la reivindicación de la igualdad de la mujer en el campo educativo no es solamente apropiada, sino necesaria para constituir un sistema armónico.

Este deseo de la autora de modificar el sistema de enseñanza español para mejorar las condiciones de la mujer y reivindicar una posición más igualitaria para éstas dentro de la sociedad española se nos muestra mediante un tipo de género literario que ratifica de una forma excepcional estas peticiones. En primer lugar, la literatura de viajes se convierte en el vehículo por el cual la autora expresa una experiencia personal directa en 
otros países. De esta forma, la crítica y las peticiones que la autora hace sobre las reivindicaciones de la mujer, entre ellas la educación, están basadas en una percepción de las reformas producidas en los países europeos que visita. El hecho de que la autora conscientemente pretenda mostrar las reformas en el campo de la igualdad de la mujer como meras observaciones de lo que se ha implementado en otros países puede considerarse como una estrategia literaria mediante la cual de Burgos intenta dotar a su discurso de un carácter autoritativo y de una aparente objetividad.

Como género narrativo, la literatura de viajes de mujeres proporciona unas características que les son propias y que las diferencian de las producciones escritas por hombres. Los relatos de viajes de mujeres en esa época, se constituyen como vehículos para valorar la identidad de género. Una vez que este tipo de discurso establece una serie de características de género que les son propias, las escritoras plasman su objetivo primordial: proporcionar una autoridad discursiva a sus producciones. Una vez establecida esa autoridad discursiva, estos relatos pretenden sentar las bases para la aceptación de su discurso, que en este caso es la reivindicación femenina y/o feminista por medio de la educación de la mujer.

La forma en la que la narrativa de viajes de mujeres adopta características típicas del discurso masculino tradicional es mediante la imposición de un héroe. La narradora escoge dónde quiere viajar y se muestra como una persona con una educación superior a la mayoría de las mujeres de su tiempo. Este proceso se hace para presentar a una mujer excepcional, modelo a seguir por las demás mujeres que, gracias a su educación, se libera de la opresión impuesta por el poder patriarcal. A su vez, la narradora impone unos modelos femeninos de mujeres ilustradas, liberales y liberadas que participan 
activamente en el campo social y político de sus paises, para reivindicar la situación de desigualdad social de la mujer.

También, manifiesta su autoridad discursiva al mostrase como una autoridad de conocimiento en cuanto a crítica de arte o historiadora de primera mano. Desde el principio, Carmen de Burgos muestra su viaje como un viaje de estudios y de conocimiento, donde el placer de viajar ocupa un lugar secundario. Este hecho es la consecuencia de la demanda que la autora hace al lector de la necesidad de progreso en un futuro donde la educación será un elemento esencial en la política de cualquier país.

A su vez, esta voz autoritativa femenina, que crea un discurso hibrido producto de la unión de algunas de las características del discurso masculino racional y el femenino sentimental y muestra la superioridad de la mujer para escribir un libro de viaje. A su vez, aumenta la autoridad textual al traspasar su vida íntima al terreno público. De esta forma, plasma gradualmente su experiencia personal, mediante una voz aparentemente objetiva que analiza y critica las sociedades que visita y también, introduce aspectos íntimos de su vida personal. Esta técnica de intromisión paulatina de su experiencia personal y de su vida privada tiene la intención de acercar al lector a su escritura al darle mayor subjetividad al texto. Una vez conseguida la adhesión del lector a su discurso, por extensión, éste percibe las críticas internas sobre política, desigualdad social y discriminación de la mujer como un hecho indiscutible al ser una realidad experimentada personalmente por la autora.

En tercer lugar, con el mismo propósito de acercamiento al lector, la autora simpatiza con los marginados, ya sean los huérfanos, los pobres o las prostitutas, para mostrar un mundo de desigualdad social en dónde las mujeres forman una parte esencial 
y constitutiva. Ellas, además de ser discriminadas por ser pobres o huérfanas, lo son simplemente por su condición de mujeres. Otro aspecto importante que la autora utiliza para acercar su discurso a la lectora es la visión del "womanly weakness." Mediante la descripción de una serie de características femeninas que el discurso masculino tradicional ha mostrado como propias de las mujeres, la autora pretende ganar autoridad de género, acercar aún más su discurso a su público y validarlo en términos femeninos. Al hacer comentarios y descripciones de trajes, comidas o vida familiar, la autora desea moldear una visión de la mujer contemporánea. Para ello, de Burgos resalta su españolismo o su anti-españolismo con la pretensión de analizar los problemas de la sociedad y de la política de España. Pero, sobre todo, analiza la visión de la mujer en términos tradicionales y propone una mujer sujeto pensante, actuante y en plena libertad. Si bien, no pierde sus atributos femeninos, la mujer que propone de Burgos, ha establecido unas reivindicaciones sociales e intelectuales para su sexo. Utilizan el discurso masculino por lo que tiene de racional y analítico, pero no deja de lado el discurso femenino de la domesticidad. En defmitiva, mediante la utilización de estas “debilidades femeninas," la autora otorga a su discurso poder como una forma de crítica general a la sociedad y, en particular, a los problemas de los derechos de las mujeres e impone como igual la expresión femenina que estaba menospreciada socialmente.

Finalmente, todo texto de viaje escrito por mujeres, manifiesta una serie de características estilísticas comunes. Entre las más frecuentes, la escritura intimista, personal y privada es la más importante y la más recurrente puesto que cumple la misión de acercamiento con un público femenino y reivindica la tradición propia de la escritura de mujer. De esta forma, mediante una escritura exaltada, sentimental y poética, la autora 
critica la falta de educación y los problemas de la desigualdad de las mujeres y la combina con el modelo de escritura típica masculina, en cuanto a su formalidad, objetividad y esquematización para conferirle una autoridad textual que valida sus postulados. En el contenido de un relato de viajes de mujer, se perciben varias lecturas; entre ellas, una lectura histórica selectiva y de actualidad que pretende enfocarse en personajes femeninos modélicos. También, la autora utiliza una lectura social, política, documental o de reivindicación en la que muestra su evolución en cuanto al papel de la mujer en la sociedad. Pasa de proponer un modelo de mujer en la unión del "ángel del hogar" y la mujer educadora y educada, a proponer una mujer liberada e integrada en igualdad de condiciones en el mundo social, cultural y político. En este sentido la intención principal de Carmen de Burgos es mostrar a la mujer como protagonista. A su vez, mediante la intromisión de aspectos autobiográficos, la autora pone el último eslabón para simpatizar con el lector $\mathrm{y}$, por consiguiente, su discurso es aceptado por un público femenino que, impregnado ya de los postulados reformistas que la autora propone, acepta esos postulados como propios y necesarios. 


\section{BIBLIOGRAFIA}

Adams, Percy G. Travel Literature and the Evolution of the Novel. Kentucky: Kentucky UP, 1983.

Adams, W. H. Davenport. Celebrated Women Travelers of the Nineteenth Century. Londres: W. Swan Sonnenschein, 1883.

AGA. Memoria Correspondiente al curso de ampliación de estudios en el extranjero realizados por la autora desde primero de octubre de 1905 a 30 de septiembre de 1906. $31 / 17477$

Albiac, María Dolores. "Correr cortes: Los viajes europeos de Viera y Clavijo." Relato de viaje y literaturas hispánicas (2004): 133-72.

Asociación para la Enseñanza de la Mujer. Bases de la misma y Reglamento de sus escuelas. Madrid: Imprenta de U. Gómez, 1882.

Ateneo Artístico y Literario de Señoras de Madrid. Estatutos y Reglamento interior. Madrid: Imprenta de los Sres. Rojas, 1869.

Arco, Juana. "Influencia de la mujer en la familia." La Humanidad (1883): 106.

Altamira, Rafael. La España del siglo XLX. París: Club del libro español, 1961.

Álvarez Lázaro, Pedro. La masonería, escuela de formación del ciudadano. La educación interna de los masones españoles en el último tercio del siglo XLX. Madrid: UPCO, 1996.

Bachelard, Gastón. The Poetics of Space. Trans. María Jolas. Boston: Beacon Press, 1969.

Baelen, Jean. La vie de Flora Tristan: Socialisme et Féminisme au $19^{e}$ siècle. París: Senil, 1972.

Ballarín Domingo, Pilar. "Carmen de Burgos y la educación de las mujeres." Carmen de Brugos: Aproximación a la obra de una escritora comprometida. Ed. Miguel Naveros y Ramón Navarrete-Galiano. Almeria: Diputación Provincial. Instituto de Estudios Almerienses, 1996.

Baltar Bravo, Cándida. "Discurso pronunciado por la Il. H. doña Cándida Baltar Bravo, en tenida extraordinaria del 3 del corriente mes, celebrada en la Resp. Logia Casto Xulia número 20 al Or. De Trujillo." BP (1890): 11. 
Barca, Calderón de la. La vida es sueño. Ed. Ciriaco Morón Arroyo. Madrid: Cátedra, 2001.

Barnes Stevenson, Catherine. Victorian Women Travel Writers in Africa. Boston: G. K. Hall and Company, 1982.

Barreda, Pedro. "Abolicionismo y feminismo en la Avellaneda: lo negro como artificio narrativo en Sab." Cuadernos Hispanoamericanos 342 (1978): 613-26.

Beauvoir, Simone de. El segundo sexo. 2 vols. Madrid: Siglo XX, 1972.

Bell, Amy Joanne. Carmen de Burgos's Subtextual Approch to women and homosexuals: A study of El Veneno del arte, Ellas y ellos ó Ellos y ellas, and Quiero vivir mi vida. Diss. U Alabama, 2002.

Berchet, Jean-Claude. "Le préface des récits de voyage au XIXème siècle." Écrire le voyage. París: Prenses de la Sorbonne Nouvelle, 1994.

Bieder, Maryellen. "Emilia Pardo Bazán y la emergencia del discurso feministas." Breve Historia feminista de la literatura española (en lengua castellana). V. La literatura escrita por mujer (del s. XIX a la actualidad) (1998): 75-110.

Blanco, Alda. "Escritora, feminidad y escritura en la España de medio siglo." Breve historia feminista de la literatura española (en lengua castellana). 5 (1998): 9-38.

Blanton, Casey. Travel Writing. The Self and the World. Nueva York: Twayne Publishers, 1997.

Bohls, Elizabeth A. Women Travel Writings and the Language of Aesthetics 1716-1818. Cambirgde: Cambidge UP, 1995.

Bordonada, Angela Ena. Novelas breves de escritoras españolas (1900-1936). Madrid: Editorial Castalia, 1989.

Bouvier, Nicolas. "Routes et Déroutes: Réflexions sur l'espace et l'écriture." Revue des sciences humaines 214 (1989): 177-86.

Burgos Segui, Carmen de "Colombine." En la Guerra. Madrid: Cuento semanal, año III, 148, 29-X-1909.

---. La mujer en España. Conferencia pronunciada en la Asociación de Prensa de Roma el 28 de abril de 1906 por Carmen de Burgos Segui. Valencia: F. Sempere y Compañía, 1906.

-.-. La mujer moderna y sus derechos. Valencia: Sempere, 1927. 
--.. La voz de los muertos. Valencia: Sempere, 1911.

---. Misión social de la mujer. Conferencia en la sociedad El Sitio de Bilbao el 18 de febrero de 1911. Bilbao: Imprenta José Rojas Núñez, 1911.

---. Mis mejores cuentos. Sevilla: Ediciones Andaluzas Unidas, S. A., 1986.

---. Mis viajes por Europa (Suiza, Dinamarca, Suecia, Noruega). Madrid: V.H. de Sanz Callejas Editores, [1916].

--.. Peregrinaciones. Suiza, Dinamarca, Noruega, Alemania, Inglaterra, Portugal. Epílogo Ramón Gómez de la Serna. Madrid: Imprenta de Alrededor del mundo, 1916.

Bravo Cela, Blanca. Carmen de Burgos (Colombine) contra el silencio. Madrid: Espasa, 2003.

Brun, Jean. Les Vagabonds de l'occident. L'Expérience du voyage et la prison du moi. París: Desclée, 1976.

Buttor, Michel. Où. Le genie du lieu. París: Gallimard, 1971.

---. "Le voyage et lécriture." Romantisme 4 (1972): 4-19.

Buzard, James. The Beaten Track: European Tourism, Literature, and the Ways to "Culture," 1800-1910. Nueva York: Oxford UP, 1993.

Cacho Viu, Vicente. La Institución Libre de Enseñanza. Madrid: Ediciones Rialp, 1962.

Calcines de Delás, Diana. La literatura de viajes. Madrid: Universidad Complutense de Madrid, 2001.

Caro, Ana. Valor, agravio y mujer. Ed. Lola Luna. Madrid: Castalia, 1993.

---. www.trinity.edu/org/comedia/caro/valagr.pdf.

Caro Baroja, Julio. Introducción a una historia contemporánea del anticlericalismo español. Madrid: Ediciones Istmo, 1980.

Carrizo Rueda, Sofia. Poética del relato de viajes. Kassel: Reichenberger, 1997.

-.-."Presuposición e intertexto y la cuestionada estructura de un relato de viajes." Studia Hispanica Medievalia II (1992): 112-17. 
Castañeda, Paloma. Carmen de Burgos "Colombine." Madrid: Dirección General de la Mujer. Horas y horas la editorial feminista, 1994.

-.-. "Carmen de Burgos, pionera de una época." Paisajes desde el tren 17 (1992): 28-31.

--.. "Carmen de Burgos." Poder y libertad 13 (1990): 48-51.

-.-. Viajeras. Madrid: Alderabán, 2003.

Cervantes Saavedra, Miguel de. Don Quijote de la Mancha. Ed. Martín Alonso, pról. Francisco Umbral. Madrid: Millenium, 1999.

Clemessy, Nelly. Emilia Pardo Bazán, abogada de Europa en España. Madrid: Fundación Universitaria Española, 1975.

Correa, Ignacio y Jorgensen, Beth E. ed. The Contemporary Mexican Chronicle. Theoretical Perspectives on the Liminal Genre. Nueva York: State of New York UP, 2002.

Cortez, Beatriz. "El travestismo de Rosaura en La vida es sueño y de Leornor en Valor, agravio y mujer: El surgimiento de la agencialidad femenina $y$ la desnaturalización del binarismo del género." Bulletin of the Comediantes 50.2 (1998): 371-85.

Davies, Catherine. Spanish Women's Writings 1849-1996. London: The Athlone P, 1998.

De Cementi, Andreina, Stella Maria. Viaggi di donne. Nápoles: Liguori Editore, 1995.

Diamond, Arlyn, and Lee R. Edwards, eds. The Authority of Experience: Essays in Feminist Criticism. Amherst: Massachusetts UP, 1977.

Dilke, Emilia Pattison, Dixie, Florence. "Lady Travelres." Quarterly Review 76 (1845): 98-136.

Elshtain, Jean Bethke. Public Man/Private Women: Women in Social and Political Thought. Priceton: Princeton UP, 1981.

Erauso, Catalina de. Historia de la monja alférez escrita por ella misma. Ed. Jesús Munárriz. Madrid: Hiperión, 1986.

Establier Pérez, Helena. Mujer y feminismo en la obra de Carmen de Burgos "Colombine." Almería: Diputación Provincial. Instituto de Estudios Almerienses, 2000. 
Ette, Ottmar. "Los caminos del deseo: coreografias en la literatura de viajes." Revista de Occidente 60 (2003): 103-15.

Faranger, Jonh M. Women and Men on the Overland Trail. New Haven: Yale UP, 1979.

Fernández, Jaime. "Honor y libertad: El perro del hortelano de Lope de Vega." Bulletin of the Comediantes 50.2 (1998): 307-16.

Fernández Fernández, José Luis. Jovellanos: Antropología y teoria de la sociedad. Madrid: UPCO, 1991.

Ferrer, Joaquín María ed. Historia de la Monja Alferez Doña Catalina de Erauso, escrita por ella misma. ilustraciones y notas de Joaquín Maria de Ferrer. Paris: Imprenta de Julio Didot, 1829.

Fick, Bárbara. El libro de viajes en la España medieval. Santiago de Chile: Editorial Universitaria, 1976.

Flightner, James. "The Spanish Travel Book: 1898-1936." Diss. State U of New York, 1976.

Foster, Shirley. "American Women Travellers to Europe in the Nineteenth and Early Twentieth Centuries." British Association for American Studies 27 (1994): 4-46.

---. Across New Worlds: Ninteenth Century Women Travellers and their Writings. Nueva York: Harvester Wheatsheaf, 1990.

Foucault, Michel. The Archaeology of Knowledge. Trans. A. Sheridan Smith. Nueva York: Harper Colophon, 1972.

-.-. El orden del discurso. Trans. Alberto González Troyano. Barcelona: Fábula Tusquets Ed., 1973.

---. The Order of Things: An Acheology of Human Sciences. Nueva York: Vintage, Random, 1973.

Franco, Jean. Plotting Women. Gender and Representation in Mexico. Nueva York: Columbia UP, 1989.

Frawley, Maria H. A Wider Range. Travel Writing by Women in Victorian England. Rutherford: Fairleigh Dickinson UP, 1994.

Fussell, Paul. Aboard: Literary Traveling Between the Wars. Nueva York: Oxford UP, 1980. 
Gabaude, Florence. Expérience de l'espace et expression de l'identité. Femmes en voyage: Mme de Stael, Flora Tristan et Simone de Beanvoir. Diss. U. Vanderbilt, 1997.

García-Romeral Pérez, Carlos. Bio-bibliografia de viajeros por España y Portugal (siglo XVIII). Madrid: Ollero y Ramos, 2000.

Garnier, Odile. La littérature de voyage. Paris: Ellipses, 2001.

Garrett, Erin Webster. "Recycling Zoraida: The Muslim Herione in Mary Shelley's Frankenstein." Cervantes: Bulletin of the Cervantes Society of America 20.1 (2000): 133-57.

Gil Casado, Pablo. La novela social española (1920-1971). Barcelona: Editorial SeixBarral, 1973.

Gil Cremades, Juan José. El reformismo español. Krausismo, escuela histórica, neotomismo. Barcelona: Ediciones Ariel, 1969.

---. Krausistas y liberales. Madrid: Seminarios y Ediciones, 1975.

Gil Pecharromán, Julio. La segunda República. Madrid: Historia 16, 1999.

Gilbert, Sandra. No Man's Land: the Place of the Women Writer in the Twentieth Century. Vol 1. The War of the Words. Nueva Haven: Yale UP, 1988.

Giner de los Ríos, Francisco. "Educación y Enseñanza." 1933. Obras Completas de Francisco Giner de los Ríos. Vol.12. Madrid: Espasa- Calpe, 1933.

---. Estudios sobre educación. Madrid: M. Minuesa, 1886.

--.. Pedagogía universitaria. Madrid: La lectura, 1924.

Giner de los Ríos, Hermenegildo. Teoria de la literatura y de las artes. Barcelona: Sucesores de Manuel Soler Editores, 1908.

Gómez de la Serna, Gaspar. Los viajeros de la llustración. Madrid: Alianza, 1974.

Gómez Molleda, María Dolores. Los reformadores de la España contemporánea. Pról. Vicente Palacio Atard. Madrid: CSIC, 1966.

González, Aníbal. La crónica modernista hispanoamericana. Madrid: Porrúa Turanzas, 1983.

---. La novela modernista hispanoamericana. Madrid: Gredos, 1987. 
-... "Modernism, Journalism, and the Ethics of Writing: Manuel Guitiérrez Nájera's 'La hija del aire'." The Contemporary Mexican Chronicle. Theoretical Perspectives on the Liminal Genre. Ed. Ignacio Corona y Beth E. Jorgensen. Nueva York: State of New York UP, 2002.

--. Journalism and the development of Spanish American narrative. Cambridge: Cambridge UP, 1993.

Gorfkle, Laura. "Re-staging feminity in Ana Caro's Valor, agravio y mujer." Bulletin of the Comediantes 48.1 (1996): 25-36.

Grewal, Inderpal. Home and Harem: Nation, Gender, Empire, and the Cultures of Travel. Londres: Leicester UP, 1996.

Gringas, George, trans. Egeria: diary of a pilgrimage. Trans. George Gringas. Nueva York: Newman, 1970.

Guiñazú, Cristina. En el nombre del padre: 'La peregrinaciones de una paria' de Flora Tristan. Ciberletras: Revista de Critica Literaria y de Cultura. 5 (2002).

Hamalian, Leo, ed. Ladies on the Loose: Women Travelers of the Eighteenth and Nineteenth Centuries. Nueva York: Dodd Mead, 1981.

Harper, Lila Marz. Solitary Travelers. Nineteenth-Century Women's Travel Narratives and the Scientific Vocation. Madison: Fairleigh Dickinson UP, 2001.

Hernandez-Pecoraro, Rosilie. "Don Quijote's Dorotea: Portrait of a female subject." Hispanófila 135 (2005): 19-39.

Herraiz, J.L. Francisco Ferrer. La educación emancipadora.

http://www.nodo50org/sobrera/publicaciones/solidario/nueve/ferrer.htm

Herrero Massari, José Manuel. Libros de viajes de los siglos XVI y XVII en España y Portugal: Lectura y lectores. Madrid: Fundación universitaria española, 1999.

Hilton, Ronald. "The Significance of Travel literature, with Special Reference to the Spanish-and Portuguese Speaking world." Hispania 49 (1966): 836-45.

Holland, Patrick,and Graham Huggan. Tourist with tyewriters. Critical Reflections on Contemporary Travel Writing. Ann Arbor: UMI, 1998.

Homans, Margaret. Bearing the Word: Language and Female Experience in Nineteenth Century Women's Writing. Chicago: Chicago UP, 1986. 
Hook-Demarle, Marie-Claire. "Le Langage Littéraire des femmes enquêtrice." Ed. Stéphane Michaud. Un fabuleux destin: Flora Tristan. Dijon: Edition Universitaires, 1985.

Hulme, Peter y Tim Young, ed. The Cambridge Companion to Travel Writing. Cambridge: Cambridge UP, 2002.

Hurtado, Amparo. "Biografia de una generación: Las escritoras del noventa y ocho." Breve historia feminista de la literatura española (en lengua castellana) 5 (1998): 139-84.

Ianes, Raúl. "La esferidad de papel: Gertrudis Gómez de Avellaneda, La condesa de Merlín, y la literatura de viajes." Revista Iberoamericana 63 (1997): 209-18.

Imboden, Rita Catrina. Carmen de Burgos "Colombine" y la novela corta. Zurich: Peter Lang, 2001.

Jameson, Frederic. The Political Unconscious: Narrative as a Socially Symbolic Act. Ithaca: Cornell UP, 1981.

Jiménez García, Antonio. El krausismo y la institución libre de enseñanza. Pról. José Luis Abellán. Madrid: Editorial Cincel, 1987.

Jiménez-Landi, Antonio. La Institución Libre de Enseñanza y su ambiente. Madrid: Taurus, 1973.

Jobit, Pierre. Les Éducateurs de l'Espagne contemporaine. Paris : E. de Boccard, 1936.

Kingsley, Mary. Travels in West Africa. Londres: Virago, 1965.

Kirpatrick, Susan. Las Románticas. Women Writers and Subjectivity in Spain (18351850). Berkeley: California UP, 1991.

Korte, Barbara. English Travel Writing from Pilgrimages to Postcolonial Explorations. Trans. Catherine Mattias. Nueva York: St. Martin's Press, Inc., 2000.

Krause, Karl Christian Friedrich, Sanz del Río, Julián. Ideal de la Humanidad para la vida. Con introducción y comentarios de Julián Sanz del Río. Madrid: Imprenta de F. Martínez García, 1871.

Kroller, Eva-Marie. Canadian Travelers in Europe: 1851-1900. Vancouver: British Columbia UP, 1987.

Lain Entralgo, Pedro y Carlos Seco Serrano, Ed. España en 1898. Las claves del desastre. Barcelona: Círculo de lectores. Galaxia Gutemberg, 1998. 
Lida, Clara E. La Revolución de 1868. Nueva York: Las Américas Publishing Company, 1970.

Laffitte, María. La mujer en España. Cien años de su historia. Madrid: Aguilar, 1964.

Lee, Vernon. “On Modern Traveling." Macmillan's Magazines 69 (1894): 306-11.

---. The Sentimental Traveler: Notes on Places. Londres: John Lane, 1908.

Litvak, Lily. Antología de la novela corta erótica española de entreguerras, 1918-1936. Madrid: Taurus, 1993.

---."Visita al paraiso: ciencia y mito en las crónicas de viajes españoles a América en el siglo XIX." Dactylus 12 (1993): 41-58.

Long, Mary K. "Writing the City: The Chronicles of Salvador Novo." The Contemporary Mexican Chronicle. Theoretical Perspectives on the Liminal Genre. Ed. Ignacio Corona y Beth E. Jorgensen. Nueva York: State of New York UP, 2002.

López-Cordón, María Victoria. La Revolución de 1868 y la I República. Madrid: Siglo XXI, 1976.

López-Morillas, Juan, ed. y pról. Francisco Giner de los Ríos: Ensayos. Madrid: Alianza Editorial, 1969.

---. El krausismo Español. Perfil de una aventura intelectual. México: Fondo de cultura económica, 1956.

---. Krausismo: Estética y literatura. Barcelona: Editorial Labor, 1973.

Lorcin, Patricia. "Teaching Women and Gender in France d'Outre-Mer: Problems and Strategies." French Historial Studies 27 (2004): 293-310.

---. Women, Gender and Nation in Colonial Novels of Inter-war Algeria Historical Reflections/Reflexions Historiques, 2002.

--.. Women's Travel Writings.

http://chnm.gmu.edu/worldhistorysources/d/146/whm.html

Louis, Anja. Women and the Law: Carmen de Burgos, and Early Feminist. Woodbridge: Tamesis, 2005.

---. "Inferior, Superior or Just Different? A Woman's Sense of Justice in Carmen de Burgos's El abogado." Hispanic Research Journal 6 (2005): 13-27. 
Lucena Giraldo, Manuel y Puig-Samper, Miguel Angel. "Caminar escribiendo: Expansión europea y literatura de viajes." Revista de Occidente 260 (2003): 5115.

Macdonell, Diane. Theories of Discourse. Oxford: Blackwell, 1986.

Maroto Camino, Mercedes. "María de Zayas and Ana Caro: The space of woman's solidarity in the Spanish Golden Age." Hispanic Review 67.1 (1999): 1-16.

Martín Buezas, Fernando. El Krausismo español desde el destierro. Pról. José Luís Abellán. Madrid: Editorial Tecnos, 1978.

Martineau, Harriet. Retrospect of Western Travel. Nueva York: Lohman, 1838.

Martín-Gamero, Amalia. Antología del feminismo. Introducción, comentarios, notas y bibliografia, por Amlia Martín-Gamero. Madrid: Alianza Editorial, 1975.

Martínez Sierra, Gregorio. El peregrino ilusionado. Madrid: Saturnino Calleja, 1921.

---. Kodak romántico. Madrid: Estrella, 1921.

Marz Harper, Lila. Solitary Travelers: Nineteenth-Century Women's Travel Narratives. Diss. U. Oregon, 1996.

Massey, Doreen. Space, Place and Gender. Minnesota: Minneapolis UP, 1994.

Matthews Trice, Patricia. Krausismo y Educación: La interpretación galdosiana del krausismo. B.A. Thesis U of Noth Carolina, 1980.

Méndez Rodenas, Adriana. “Género e historiografía en La Vida en México (1843). " Los discursos de la cultura hoy. Ed. Lilia Granillo Vázquez. México: Universidad Autónoma Metropolitana-Azcapotzalco, Centro de la Cultura Casa Lamm y U de Tennessee, 1996.

Menéndez Pelayo, Marcelino. Historia de los heterodoxos españoles. Regalismo y enciclopedia, los afrancesados y las cortes de Cádiz, reinados de Fernando VII e Isabel II, Krausismo y apologistas católicos. Pról. Arturo Farinelli. México: Editorial Porrúa, 1983.

Merrin, Stephanie. "Catalina de Erauso: From anomaly to Icon." Code of encounters: Writing, Gender, and Ethnicity in Colonial Latin America. Amrhest: Massachusetts UP, 1994. 
Mezciems, Jenny. "'Tis not to divert the Reader": Moral and Literary Determinants in some Early Travel Narratives." The Art of Travel. Essays on Travel Writing. Ed. Philip Dodd. Londres: Frank Cass, 1982.

Middleton, Dorothy. Victorian Lady Travelers. Nueva York: Chicago Academy, 1982.

Mills, Sara. Discourse. Londres: Routledge, 1997.

---. Discourse of Difference. An Analysis of Women's Travel Writing and Colonialism. New York: Routledge, 1991.

Monicat, Bémédicte. Itinéraires de l'écriture au féminin. Voyageuses du 19e siècle. Atlanta: Rodopi, 1996.

---. "Pour une bibliographie des récits de voyage au féminine du 19e siècle." Romantisme 77 (1992): 95-100.

Monsiváis, Carlos. A ustedes les consta. Antología de la crónica en México. México: Ediciones Era, 2000.

---. Entrada libre. Crónicas de la sociedad que se organiza. México: Ediciones Era, 1989.

--- Literatura y periodismo. Buenos Aires: Cántaro Editores, 1998.

-... "On the Chronicle in Mexico." The Contemporary Mexican Chronicle. Theoretical Perspectives on the Liminal Genre. Ed. Ignacio Corona y Beth E. Jorgensen. Nueva York: New York UP, 2002.

Montagu, Lady Mary. Embassy to Constantinopla: The Travels of Lady Mary Wortley Montagu. Ed. and Com. Christopher Pick. Londres: Century Hutchinson Ltd, 1988.

Morris, Meaghan, Patton, Paul. Eds. Foucault, Power Truth and Strategy. Sydney: Federal Publications, 1979.

Mújica, Bárbara. Women Writers of Early Spain. Sophia's daughters. New Haven: Yale UP, 2004.

Murray, Janet. Strong-Minded Women: And Other Lost Voices from Nineteenth Century. Nueva York: Panthenon Books, 1982.

Naveros, Miguel y Ramón Navarrete-Galiano, ed. Carmen de Burgos. Aproximación a la obra de una escritora comprometida. Almería: Instituto de estudios almeriense. Diputación de Almería, 1996. 
Núñez Rey, Concepción. Carmen de Burgos, Colombine (1867-1932) biografia y obra literaria. Diss. U Complutense Madrid, 1992.

--.. Carmen de Burgos Colombine en la Edad de Plata de la literatura española. Sevilla: Fundación José Manuel Lara, 2005.

Oria, Tomás G. Martí y el Krausismo. Boulder, Colorado: Society of Spanish and Spanish American Studies, 1987.

Pardo Bazán, Emilia. Al pie de la Torre Eiffel. Crónicas de la Exposición. Madrid: La España editorial, 1890?

---.Cuarenta dias en la Exposición. Obras Completas. Vol. 21. Madrid: Administración, 1901.

---. La mujer española y otros artículos feministas. Selección y pról. Leda Schiavo. Madrid: Editora Nacional, 1976.

--- La Tribuna. Ed. Benito Valera Jácome. Madrid: Cátedra, 1989.

--.. Por la Europa católica. Obras Completas. Vol 26. Madrid: Administración, 1900.

Peñate Rivero, Julio Ed. Relato de viaje y literaturas hispánicas. Madrid: Visor Libros, 2004.

Pérez Priego, Miguel Ángel. "Estudio literario de los libros de viajes medievales." Epos I (1984): 217-39.

Poovey, Mary. The Proper Lady and the Women Writer: Ideology as Style in the Work of Mary Wollstonecraft, Mary Shelley, and Jane Austen. Chicago: Chicago UP, 1984.

---. Uneven Developments: the Ideological Work of Gender in Mid-Victorian England. Chicago: Chicago UP, 1988.

Porras, Soledad. "Concepto y actualización de la literatura de viajes: Viajeros en España en el siglo XIX." Castilla: Estudios de literatura 20 (1995): 181-88.

Posadas, Adolfo. Breve historia del krausismo español. Pról. Luís G. de Valdeavellano. Oviedo: U Oviedo, Servicio de publicaciones, 1981.

Pozzi, Gabriela. "Viajando por Europa con Carmen de Burgos ("Colombine"): A través de la Gran Guerra hacia la autoridad femenina." Literatura de viajes. El viejo 
mundo y el nuevo. Ed. Salvador García Castañeda. Madrid: Castalia, 1999. 299307.

Pratt, Mary Louise. Imperial Eyes. Travel Writing and Transculturation. Londres: Routledge, 1992.

-.-. "Travel Narrative and Imperialist Vision." Understanding Narrative. Ed. James Phelan and Peter J. Rabinowitz. Columbus: Ohio State UP, 1994.

Rannaud, Gérald. "Le Journal de voyage: forme littéraire ou fait culturel." Le Journal de voyage et Stendhal Genève: Slatkine, 1986.

Regales Serna, Antonio. "Para una crítica de la categoría literatura de viajes." Castilla 5 (1983): 63-85.

Reichler, Claude. "Frontières du monde et territorialité du sujet." L'Humanisme en géographie. París: Anthropos, 1990.

Robinson, Jane. Wayward Women: A Guide to Women Travelers. Oxford: Oxford UP, 1990.

Rodrigo, Antonina. Mujeres de España: Las silenciadas. Barcelona: Plaza \& Janés Editores, 1979.

Romano, Vicente. "El libro de viajes en la literatura española contemporánea." Proceedings of the Pacific Northwest Conference on Foreign Languages 18 (1967): 194-201.

Romero Tobar, Leonardo, ed. El camino hacia el 98. Los escritores de la Restauración y la crisis de fin de siglo. Madrid: Fundación duques de Soria, Visor Libros. 1998.

Roudaut, Jean. "Quelques variables du récit de voyage." Nouvelle Revue Française 377 (1984): 58-70.

Russell, Mary. The Blessing of a Good Thick Skirt: Women Travellers and Their World. Londres: Collins, 1986.

Santi, Dominique de. Flora Tristan, la femme révoltée. París: Hachette, 1972.

Sanz del Río, Julián. Ideal de la Humanidad para la vida. Madrid: Imprenta de Manuel Galiano, 1860.

-.-. Textos escogidos. Intro. Eloy Terrón. Barcelona: Ediciones de Cultura Popular, 1968. 
--. Metafisica Analitica. Introducción. Barcelona: Ediciones de Cultura Popular, s.f. [1868].

Schlau, Stacy. "Stranger in a Strager Land: The discourse of Alienation in Gómez de Avellaneda's Abolitionist Novel Sab." Hispania 63.3 (1986): 495-503.

Scott, Lynn Thomson. Carmen de Burgos: Piecing a profession, rewriting women's roles. Diss. U of Florida, 1999.

Seco Serrano, Carlos. Sociedad, literatura y política en la España del siglo XIX. Madrid: Guadiana de publicaciones, 1973.

Silva, Lorenzo. "Vivir y viajar, hacerse uno y hacerse otro." Relato de viaje y literatura hispánica. Editor Julio Peñate Rivero (2004): 33-43.

Smith, Sidonie. A Poetics of Women's Autobiography, Marginality and the Fictions of Self-Representation. Indiana: Indiana U P, 1987.

Smith, Valerie. Hosts and Guests: The Anthropology of Tourism. Philadelphia:

Pennsylvania UP, 1977.

Starcevic, Elizabeth. Carmen de Burgos defensora de la mujer. Almería: LibreriaEditorial Cajal, 1976.

-.-. La mujer en la obra literaria de Carmen de Burgos. Diss. Citty U of New York, 1976.

Stout, Janis P. Through the window, out the door: Women's Narratives of Departure, from Austin and Cather to Tylor, Morrison, and Didion. Alabama: Alabama UP, 1998.

Stowe, William W. European Travel in Nineteenth-Century American Culture. Princeton: Princeston UP, 1994.

Taddeo, Sara. "Mentis, que no soy mujer/mientras empuño este acero: Verdad, Engaño y Valor in La monja alférez." Looking at the Comedia in the Year of the Quincentenial: Porceedings of the 1992 Symposium on Goleen Age Drama at the University of Texas. Ed. Barbara Mujica y Sharon D. Voros. Maryland: América UP, 1993.

Tinling, Marion. Women into the Unknown: A Sourcebook on Women Explorers and Travelers. Nueva York: Greenwood Press, 1989.

Torres-Pou, Joan. Aproximaciones a la narrativa femenina del diecinueve en Latinoamérica. Nueva York: The Edwin Mellen Press, 2002. 
--.. "La ambigüedad del mensaje feminista de Sab de Gertrudis Gómez de Avellaneda." Letras femeninas 19.1-2 (1993): 55-64.

-.-. "El viaje a oriente en la literatura femenina española: Carmen de Burgos, Aurora Bertraba y Rosa Regás." Neophilologus 90 (2006): 39-51.

Torres Villarroel, Diego de. Vida, ascendencia, nacimiento, crianza y aventuras. Madrid: Cátedra, 1998.

Tuñón de Lara, Manuel. La España del siglo XIX. Paris: Club del libro español, 1961.

Ureña, Enrique M. El "Ideal de la Humanidad" de Sanz del Río y su original alemán. Madrid: UPCO, 1992.

Ureña, Enrique M. y Pedro Álvarez Lázaro, ed. La actualidad del krausismo en su contexto europeo. Madrid: UPCO, 1999.

Utrera, Federico. Memorias de Colombine. La primera periodista. Madrid: Hijos de Muley-Rubio, 1998.

Van Den Abeele, George. Travel as Metaphor. From Montaigne to Rousseau. Minneapolis: Minneapolis UP, 1992.

Váquez Ramil, Raquel. La Institución Libre de Enseñanza y la Educación de la mujer en España: La Residencia de Señoritas (1915-1936). Diss. U de Santiago, 1989.

Vega, Lope de. Fuenteovejuna. Ed. Juan María Marín. Madrid: Ediciones Cátedra, 1981.

Veit, Karin. "Journey and Gender. Diversity in Travel Writing." Feminist Contributions to the Literary Cannon. Setting Standards of Taste. Editor Susanne Fendler. 15 (1997) : 109-38.

Vierne, Simone. "Le voyage initiatique." Romantisme 4 (1972): 37-44.

Vivies, Jean. Le récit de voyage en Angleterre au dix-huitième siècle. Toulouse : Presses Universitaires du Mirail, 1999.

Weedon, Chris. Feminist Practice and Post-Structuralist Thought. Oxford: Blackwell, 1984.

Weimer, Christopher B. “Ana Caro's El conde Partinuplés and Calderón La Vida es sueño: Portofeminism and heuristic imitation." Bulletin of the Comediantes 52.1 (2000): 123-45. 
Zulueta, Carmen de. Cien años de educación de la mujer española: historia del Instituto Internacional. Madrid: Castalia, 1992.

--. Ni convento ni college. La Residencia de Señoritas. Madrid: Publicaciones de la Residencia de Estudiantes. 1993. 
VITA

ESTHER A. DAGANZO-CANTENS

\section{EDUCATION}

2002 - 2006 FLORIDA INTERNATIONAL UNIVERSITY, Florida

Doctoral Candidate- Spanish

1998 - 2002 FLORIDA INTERNATIONAL UNIVERSITY, Florida

Masters in Spanish, December 2002

1994 - 1998 FLORIDA INTERNATIONAL UNIVERSITY, Florida Bachelors of Arts in Spanish 1998

1990 -1991 Florida International University: English for Foreigners

1986 - 1989 UNIVERSITY OF GRANADA, Spain

Graduated with a Diplomatura in Library and Information Science

\section{COMPENTENCY IN OTHER LANGUAGES}

Italian (Grammar and Speech)

French (Grammar and Speech)

\section{MAJOR HONORS AND AWARDS}

Fellowship at the Archives of Bordeaux, France 1989.

Scholarship at The Centre Nationelle de la Rechercher Scientifique (CNRS). Pays Ibériques. Bordeaux, France 1990.

TA Excellence in Teaching Award 2005, Florida International University

Empire Who's Who of Women in Education in the "Honor Edition,"

\section{OTHER HONORS AND AWARDS}

Graduate Assistantship at Florida International University (2002- Present)

Teacher Assistantship at Florida International University Magnum Cum Laude (1998)

Golden Key National Honor Society (1998-2002).

The Honor Society of Phi Kappa Phi (2000-2002).

Delta Epsilon Iota Academic Honor Society (2006). 


\section{SEMINARS}

Summer 2004 Professional Seminar for Teachers of Spanish for Business in Avila (Spain).

\section{ADMINISTRATIVE EXPERIENCE}

Summer 2005 Co-Director of the Barry University Study Abroad Program in Spain.

1/03 - Spring 2004 Assistant to Dean Casines: Organization of an Advanced

Placement Summer Institute for high school teachers.

\section{TEACHING EXPERIECE}

Fall 2005-Spring 2006 Visiting Professor at IES (Institute for the International

Education of Students) Abroad in Granada (Spain).

Introduction to Spanish Grammar and Culture.

Summer 2005 SPN 101 Spanish 1 Avila (Spain).

Spring 2005

Fall 2004

Spring 2004

SPN 2201 Intermediate Spanish for non-native Speakers.

Fall $2003 \quad \begin{aligned} & \text { SPN } 1120 \text { Spanish } 1 \text { for non-n } \\ & \text { (Partly-Web based course) }\end{aligned}$

SPN 2340 Intermediate Spanish for Native Speakers.

8/00 - 2002 Doral Academy Charter School

Spanish Teacher $2001-2002 \mathrm{k}-5^{\text {th }}$

Spanish Teacher 2000-2001 k $-8^{\text {th }}$

\section{SERVICE AND PROFESSIONAL ORGANIZATIONS:}

Member of ALDEEU Asociación de Licenciados y Doctores españoles en Estados

Unidos.

Editor of Cuadernos Journal of the ALDEEU Association.

Member of AEIHM Asociación Española de Investigación de Historia de las

Mujeres.

Co-Editor of the 2005 edition of Mosaicos. Spanish as a World Language.

Founder of the Modern Languages Student Association at FIU, 2003.

President of the Modern Languages Student Association at FIU, 2003-2004.

Modern Languages Association, Member. 